University of Rhode Island

DigitalCommons@URI

Open Access Dissertations

2017

\title{
Atlantic Mackerel (Scomber scombrus) Population and Habitat Trends in the Northwest Atlantic
}

Michael Conor McManus

University of Rhode Island, cmcmanus@gso.uri.edu

Follow this and additional works at: https://digitalcommons.uri.edu/oa_diss

\section{Recommended Citation}

McManus, Michael Conor, "Atlantic Mackerel (Scomber scombrus) Population and Habitat Trends in the Northwest Atlantic" (2017). Open Access Dissertations. Paper 664.

https://digitalcommons.uri.edu/oa_diss/664

This Dissertation is brought to you for free and open access by DigitalCommons@URI. It has been accepted for inclusion in Open Access Dissertations by an authorized administrator of DigitalCommons@URI. For more information, please contact digitalcommons-group@uri.edu. 
ATLANTIC MACKEREL (SCOMBER SCOMBRUS)

POPULATION AND HABITAT TRENDS IN THE

NORTHWEST ATLANTIC

BY

M. CONOR MCMANUS

A DISSERTATION SUBMITTED IN PARTIAL FULFILLMENT OF THE

REQUIREMENTS FOR THE DEGREE OF

DOCTOR OF PHILOSOPHY

IN

OCEANOGRAPHY

UNIVERSITY OF RHODE ISLAND 
DOCTOR OF PHILOSOPHY DISSERTATION

OF

M. CONOR MCMANUS

\title{
APPROVED:
}

Dissertation Committee:

\author{
Major Professor Jeremy S. Collie \\ Jonathan A. Hare \\ Candace A. Oviatt \\ Nasser H. Zawia \\ DEAN OF THE GRADUATE SCHOOL
}

UNIVERSITY OF RHODE ISLAND

2017 


\begin{abstract}
Atlantic mackerel (Scomber scombrus) has long been a significant marine resource in the northwest Atlantic, supporting commercial and recreational fisheries over two centuries. As a small pelagic fish feeding on planktonic organisms, mackerel serve a critical role in the marine food web as prey for higher trophic level species, including large predatory fish, marine mammals, and sea birds. Significant harvest pressure and recent low abundances and landings have led to questioning whether such removals have jeopardized the fishery and ecosystem's sustainability. Further complicating management, mackerel populations throughout the North Atlantic have been significantly influenced by climate change, represented principally through shifts in population distribution. With forage fish like Atlantic mackerel particularly sensitive to oceanographic and environmental conditions, shifts in the ecosystem's state may pose issues for the species' future growth, survival, and recruitment. This dissertation aims to provide tools for future northwest Atlantic mackerel stock assessments through better description of population trends, both contemporary and historical, and to quantify habitat changes for the stock to inform current knowledge on the stock's spatial structure.
\end{abstract}

The first chapter aimed to provide an additional abundance index for future northwest Atlantic mackerel benchmark stock assessments. Given conflicting information provided by currently used fishery-independent trawl survey data and commercial landings information, a larval abundance index using long-term federal ichthyoplankton data was constructed for the stock's southern contingent. The larval index captured peaks in years with believed strong recruitment, and significantly 
correlated to estimated annual egg production and spawning stock biomass. However, catchability corrections conducted likely still underestimate earlier years' larval abundances. Thus, when using the larval index in future assessments, we recommend the time series without catchability corrections be split and each have their own correction factor $q$ estimated within the overall stock assessment model.

The second chapter estimated how Atlantic mackerel larval habitat suitability has changed over the last four decades using species distribution models. Physical (temperature) and biological (zooplankton) variables that have been reported to influence larval survival were included to determine how such relations influence habitat suitability in the Northeast U.S. Shelf. Atlantic mackerel larval densities correlated with sea temperature and copepod abundances, suggesting that larval survival may be sensitive to specific temperatures and zooplankton prey. Since the 1970s, suitable habitat located in the Mid-Atlantic Bight has decreased, as southern New England and the western Gulf of Maine regions have become more suitable ecoregions, highlighting an overall northeast habitat shift. While total Northeast U.S. Shelf habitat suitability has decreased since the 1970s, the time series' declining trend was not statistically significant.

The third and final chapter uses stochastic stock reduction analysis (SSRA) to infer northwest Atlantic mackerel population trends over the last two centuries, using historical landings, data on mackerel biology, and descriptions of the fisheries' evolution. Population trends were estimated from 1804 through 2016. Population trajectories highlighted many of the major population decreases through time from harvest, with results suggesting the stock in 2016 could be as low as $11 \%$ of the 1804 , 
unfished stock size. The SSRA developed could benefit from additional model development, but should be considered for inclusion in future stock assessments as part of an ensemble approach.

The research in this dissertation aims to provide scientists and managers with a better understanding of Atlantic mackerel ecology, population dynamics, the fishery, and improve future management for one of the most historically significant marine species of the North Atlantic. The application of the tools transcends Atlantic mackerel, and can be applied to other fish stocks. This dissertation serves as an example of how fisheries science can be conducted to inform and improve fisheries management. 


\section{ACKNOWLEDGMENTS}

Holy mackerel! This has been quite a journey. I would first like to thank my major advisor, Jeremy Collie. Thank you for your willingness to take me on as a part-time doctoral student, and all that you have taught me over the course of my degree. Your expertise, insight, and encouragement throughout the program were vital in helping me reach my goals. I look forward to maintaining our collaborations on fisheries research beyond my degree, and of course, more croquet matches. I would also like to specifically thank Jon Hare for all he has done for me, both for my dissertation and career. I will always be grateful for your motivation and support of me pursing a Ph.D., your help in devising my research plans, the countless meetings reviewing my work, and all that I learned about fisheries oceanography and management from our many conversations. I hope to continue our collaborations in the future. I'm thankful for my other committee members, Candace Oviatt, Austin Humphries, and Gavino Puggioni, for providing helpful feedback on my dissertation.

This dissertation was funded by The Nature Conservancy Global Marine Initiative Student Research Award Program, to which I am grateful. Further, this dissertation could not have been completed without the many scientists and crew members who have and continue to dedicate their careers to collecting high-quality fisheries and oceanographic data. This research benefited from thoughtful reviews from the 2017 NOAA Atlantic Mackerel Stock Assessment Working Group.

This dissertation was made possible with the help of several colleagues not included within the dissertation committee. David Richardson and Kiersten Curti, thank you for the time you invested in me through many meetings, phone conversations, and 
reviews of my research. Your significant contributions are reflected throughout this work. I thank Matt McKenzie, David Secor, Chris Legault, and John Manderson for the many conversations regarding mackerel biology, fishing history, and statistical modeling that have strengthened this work. As a part-time student working full-time, completing this degree could not be done without the support of my employers over time. Debbie French-McCay, Jill Rowe, Jason McNamee, and Scott Olszewski: thank you for your understanding and encouragement throughout my degree. Collie Laboratory members through time (Jason McNamee, Chris Orphanides, Rich Bell, Adrien Tableau, Corrine Truesdale, Joe Langan, Anna Malek), thank you for the all the help, laughs, and commiserating over the years.

Fellow graduate-student, coworkers, and friends, have made my time in Rhode Island to date exceptionally enjoyable. These friendships have meant so much to me, many of which will undoubtedly be lifelong. To my family, thank you for the motivation and moral support through this entire journey. From times of happiness and confidence to others of discouragement and worry, you were always there for me. I'm eternally grateful for this support. Lastly, my wife. Shelley, I cannot thank you enough for your patience, encouragement, and support through my Ph.D. From the many late nights working and missing time at home, to writing and coding in the passenger seat while you drove on our road trips, and the countless warm, sunny weekends spent inside working, you were there for me through all of it. Your support most of all is what helped me succeed. Thank you so much for everything, and I can't wait to begin the next chapter of our lives together. 


\section{PREFACE}

This dissertation was formatted in accordance with the manuscript format guidelines established by the Graduate School of the University of Rhode Island. The first manuscript is formatted for the journal ICES Journal of Marine Science, with coauthors David Richardson, Kiersten Curti, and Jeremy Collie. The second manuscript is formatted and published in the journal Fisheries Oceanography, with coauthors Jonathan Hare, David Richardson, and Jeremy Collie. The third manuscript is formatted for the journal Canadian Journal of Fisheries and Aquatic Sciences, with coauthors Jeremy Collie, Kiersten Curti, and Matt McKenzie. 


\section{TABLE OF CONTENTS}

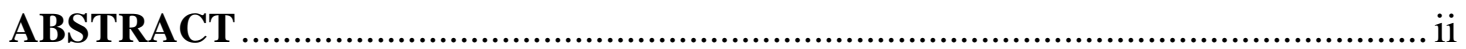

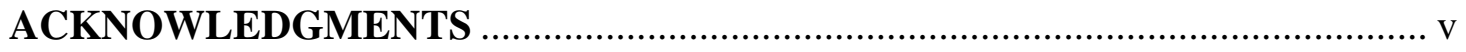

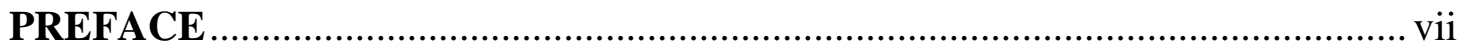

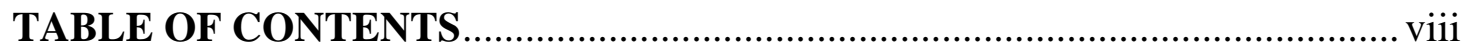

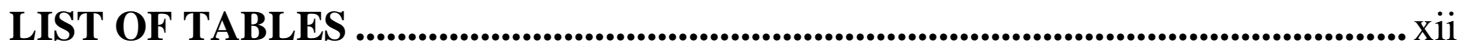

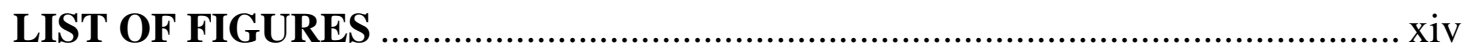

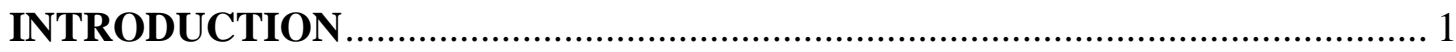

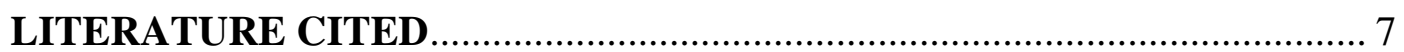

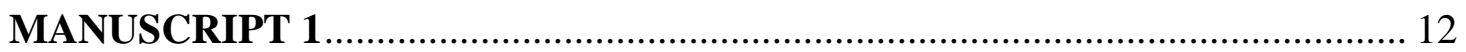

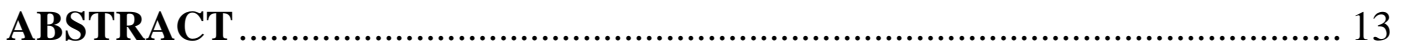

INTRODUCTION

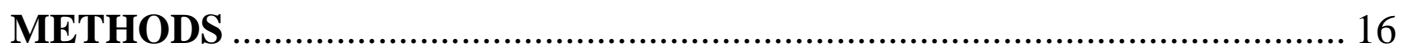

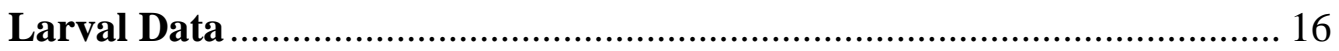

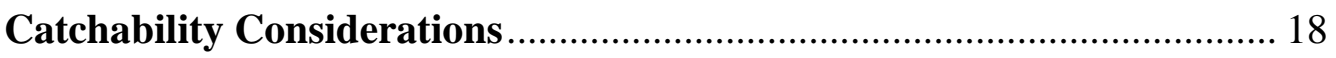

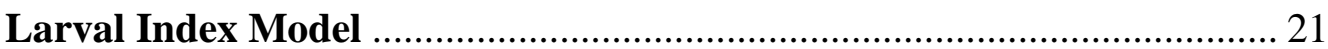

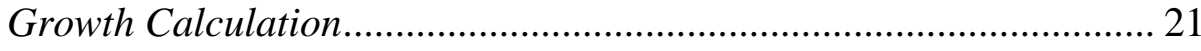

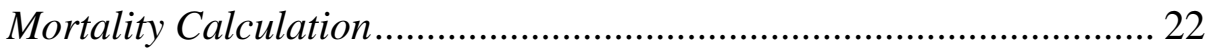

Hatching Seasonality ..................................................................... 22

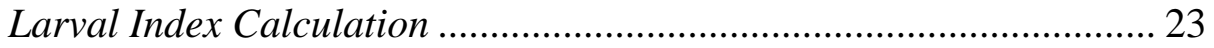

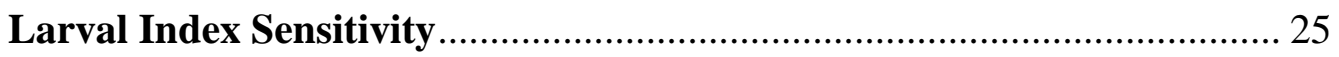

Observed vs. Catchability-Corrected Abundances .............................. 25

Model Variants: Cruise vs. Sample Level Analyses ............................ 25 
Variants in Residual Minimizations

Static Growth Assumptions: Bootstrapped Growth Curves ................ 27

Alternative Methods ................................................................ 28

Correspondence to Other Population Indices and the Environment ... 28

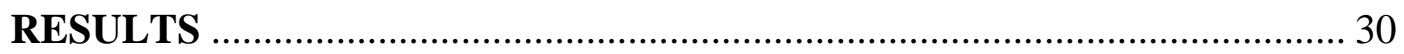

Estimated Life History of Atlantic Mackerel Larvae ................................ 30

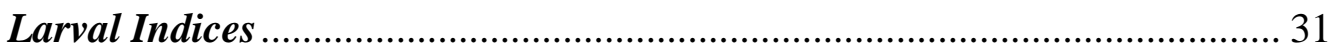

Bootstrapped Growth Curves ............................................................... 32

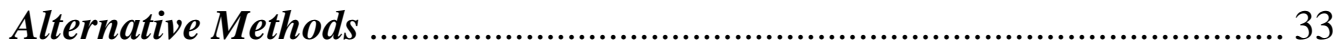

Correspondence to Alternate Abundance Indicators and the Environment 33

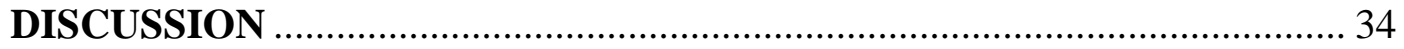

Larval Index Selection and Review of Sensitivity Analyses ....................... 34

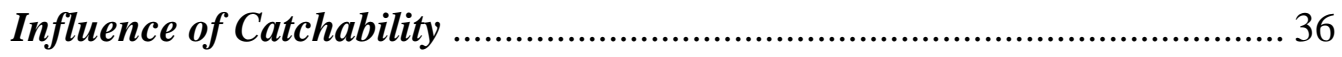

Estimating Life History Patterns ...................................................... 37

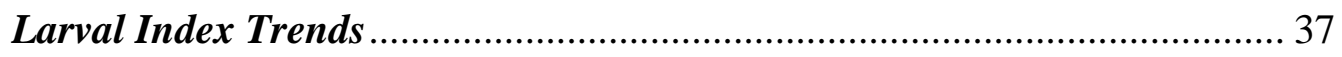

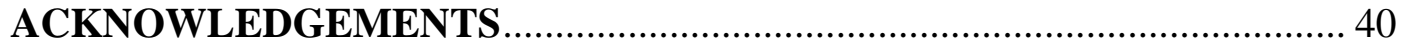

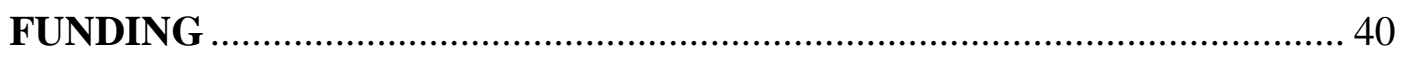

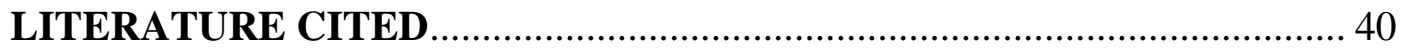

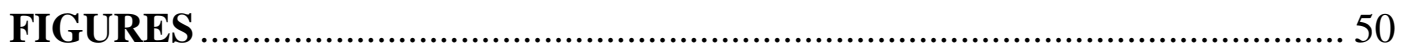

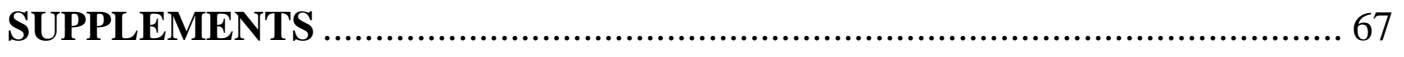

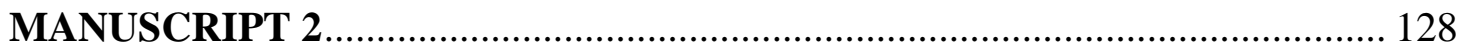

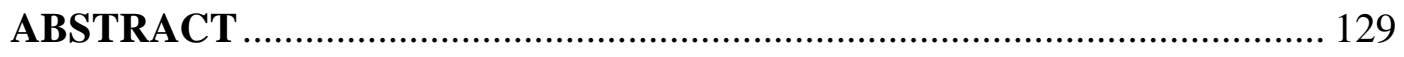

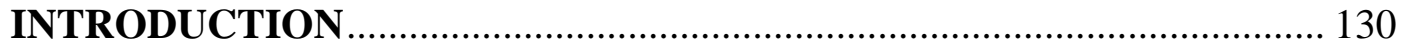


MATERIAL AND METHODS

Field Sampling .

Species Distribution Models ..................................................................... 136

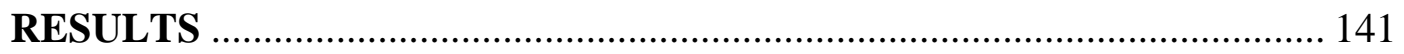

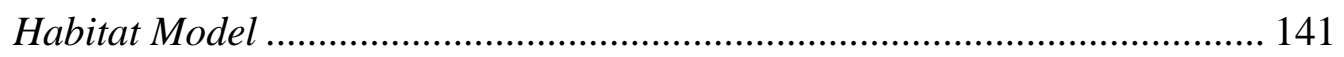

Temporal and Spatial Trends in Larval Habitat Suitability ...................... 157

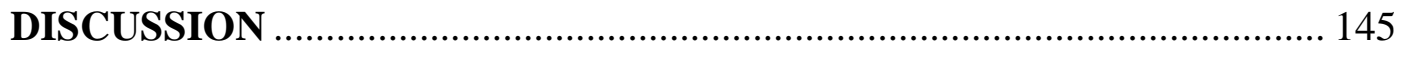

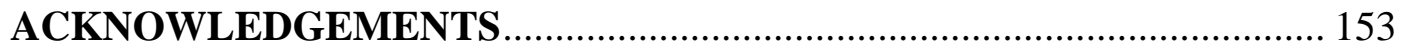

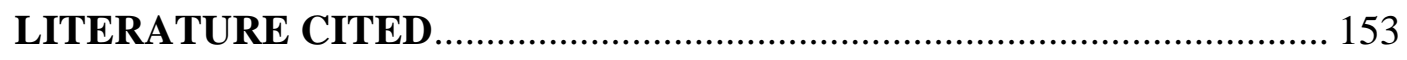

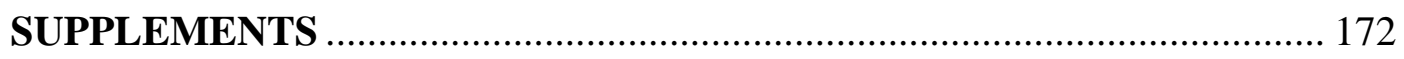

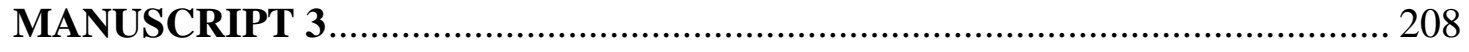

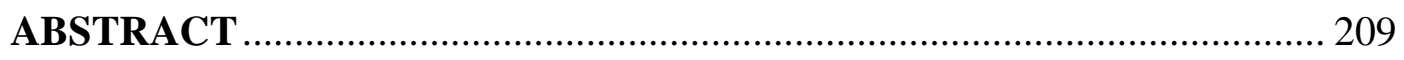

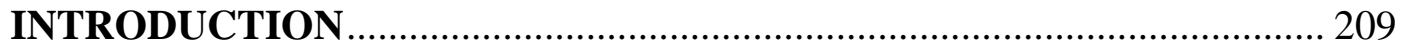

Evolution of the Northwest Atlantic Mackerel Fishery ............................... 212

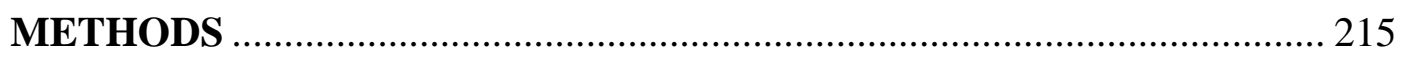

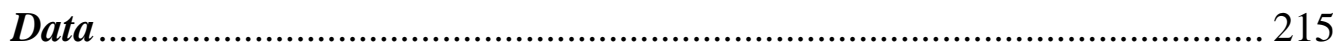

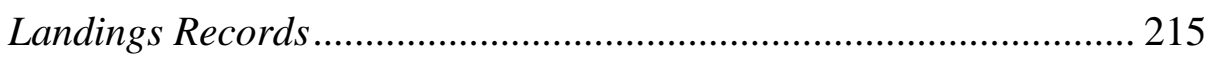

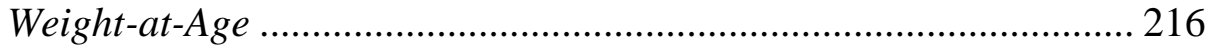

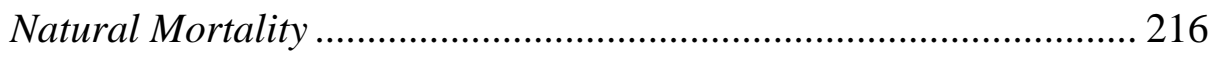

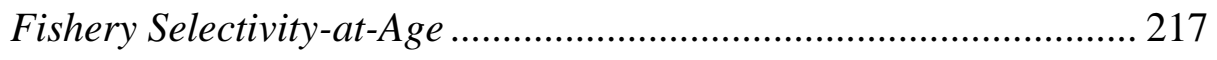

Stock Reduction Analysis Model ........................................................... 218

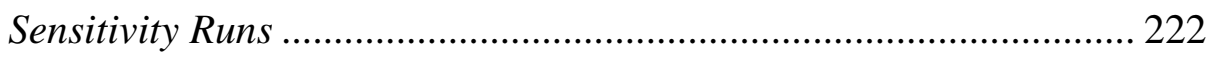

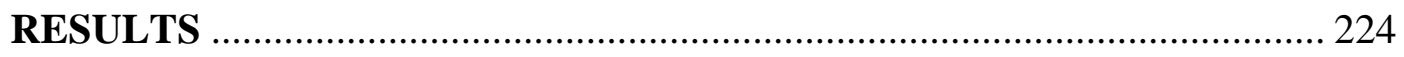


Population and Harvest Trends.

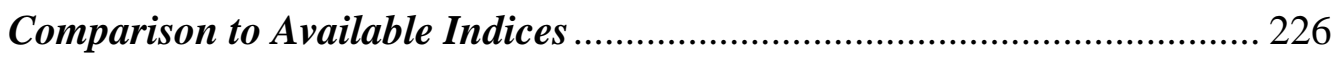

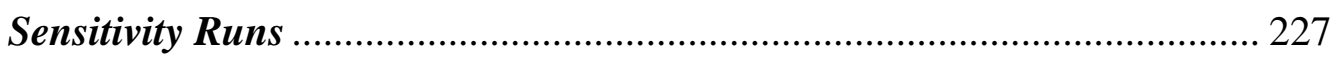

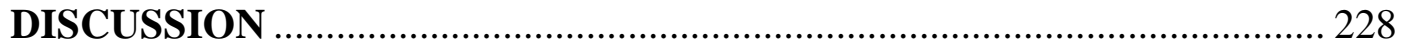

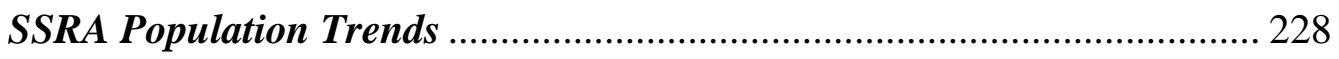

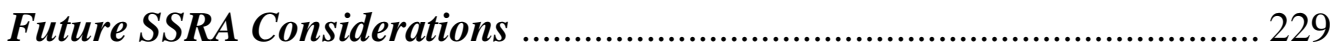

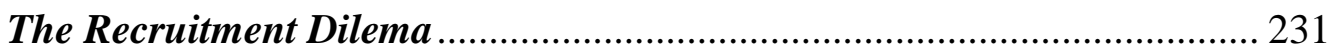

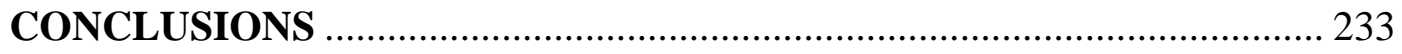

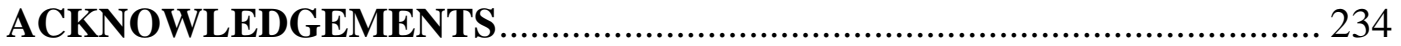

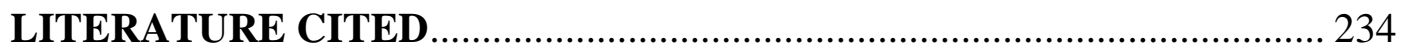

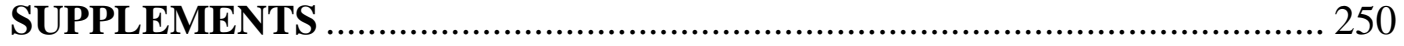

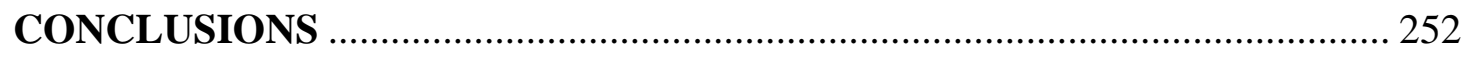

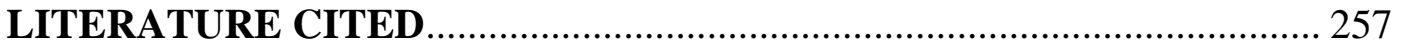

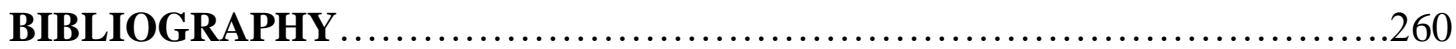




\section{LIST OF TABLES}

TABLE

PAGE

Table 1-1. Model Variants run the larval index calculations with observed and catchability-scaled abundances. Dashes (-) indicate that field is not applicable to the Model Variant. Bold values indicate life history parameters were not estimated at their bounds 45

Table 1-2. Multiple $\mathrm{R}^{2}$ values for correlations between Model Variants constructed using the Richardson et al. (2010) method and the alternative methods: mean abundances by year $\left(\mathrm{LI}_{\mathrm{A} 1}\right)$, abundances corrected for age using mortality function $\left(\mathrm{LI}_{\mathrm{A} 2}\right)$, and abundances corrected for age using mortality function and spawning seasonality with the hurdle model approach $\left(\mathrm{LI}_{\mathrm{A} 3}\right)$. Bold values indicate $\mathrm{p}$-values $<0.05$

Table 1-3. Multiple $\mathrm{R}^{2}$ values for correlations between Model Variant 2 and various population indicators and environmental conditions. Bold values indicate $\mathrm{p}$-values $<0.05$ 48

Table 1-4. Table 4. Mean annual abundances $\left(\# 10 \mathrm{~m}^{-2}\right)$ by year and daily age class from the data as used in the Survey-level analyses

Table 2-1. Model results for the presence/absence and abundance GAMs. Covariates are described in terms of their estimated degrees of freedom (EDF) and p-values. Covariates with p-values $<0.05$ at an alpha of 0.05 are in bold. Model fitness is described using $\mathrm{R}^{2}$ and unbiased risk estimator (UBRE, presence/absence model) and generalized cross validation (GCV, abundance model) scores..... 161

Table 2-2. Confusion matrix describing the presence/absence model validation 
result

Table 2-3. Relative model quality scores (represented as $\Delta \mathrm{AIC}$ ) of the presence/absence and abundance models used for these analyses (Final), only including temperature covariates from the Final model (Temperature) and only including zooplankton covariates from the Final model (Zooplankton).

Table 2-4. Linear slopes for habitat suitability index time series of each ecoregion. Asterisks indicate degree of significance. ${ }^{*} \mathrm{p}<0.10,{ }^{*} * \mathrm{p}<0.05 \ldots \ldots \ldots \ldots \ldots \ldots . \ldots 164$ 


\section{LIST OF FIGURES}

FIGURE

PAGE

Figure 1-1. NOAA EcoMon and MARMAP strata sampled over the Northeast U.S. Continental Shelf for ichthyoplankton. Strata covering traditional Atlantic mackerel spawning grounds are designated in light blue. Circles represent EcoMon and MARMAP stations that caught Atlantic mackerel larvae. Circles are scaled relative to

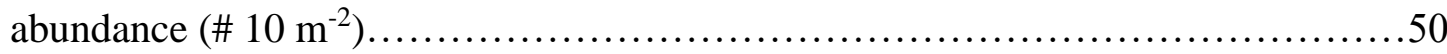

Figure 1-2. Avoidance models based on Night:Day (N:D) catch ratios for the EcoMon (0.333mm mesh) and MARMAP (0.505mm mesh) data using an exponential function (red lines). Parameters used for the models $(\alpha, \beta)$ are the mean values over the 1000 bootstrapped runs. 51

Figure 1-3. Growth data for Atlantic mackerel from Cape Hatteras to Cape Cod (Simard et al., 1992). Model fits are presented using a Gompertz function and coefficients presented in Simard et al., (1992) (black, dashed), refitting the extracted data with a Gompertz function in ADMB (red, dashed) and using a power function in $\mathrm{ADMB}$ on larvae $<20 \mathrm{~mm}$, corresponding to the size range represented in the NOAA Plankton and Sette datasets (blue, solid).

Figure 1-4. Gompertz and Power growth model residuals (observed-predicted) from ADMB fits by mackerel size $(\mathrm{mm})$. Larval sizes $<20 \mathrm{~mm}$ are presented for direct comparisons between the two models.

Figure 1-5. Abundances-by-age (\# $10 \mathrm{~m}^{-2}$ ) over all EcoMon and MARMAP samples. Observed (red) and catchability corrected (blue) abundances are presented (top), with natural $\log$ transformations also provided (bottom) 
Figure 1-6. Proportion of larvae surviving from 5 days old using observed (red) and catchability-corrected (blue) data .55

Figure 1-7. Proportion of all hatch days for all larvae collected from EcoMon and MARMAP samples. Hatch days were estimated as the age of a larvae subtracted from the day of year the sample was collected......................................56

Figure 1-8. Proportion of southern contingent larvae hatching through the year......57 Figure 1-9. Mortality curves estimated during larval index calculations for Model Variants 2 (top), 4 (bottom left), and 5 (bottom right). Model Variants are described in Table 1. .58

Figure 1-10. Spawning seasonality estimated during larval index calculations for Model Variants 2 (top), 4 (bottom left), and 5 (bottom right). Model Variants are described in Table 1. Points represent original data, as expressed in Figure 8 ........59 Figure 1-11. Larval indices produced under Model Variants 2 (left) and 5 (right)....60 Figure 1-12. Larval index residuals against observed abundance $(\sqrt{N})$ under Model Variants 2 (left) and 5 (right) using both observed abundances and catchabilitycorrected abundances.................................................61

Figure 1-13. Larval indices produced under Model Variant 9....................62 Figure 1-14. Ratios of larval indices calculated with catchability-corrected abundances to observed abundances for Survey-level (Model Variants 2 and 5) and Sample-level (Model Variant 9)

Figure 1-15. Start ages for bootstrapped growth curve runs under Model Variant 2 (top) and maximum gradient values for the associated start-age runs. .64 
Figure 1-16. Larval Indices under Model Variant 2 when using a start age of 5 dayolds (left) and 6 day-olds (right)

Figure 1-17. Correlations between annual egg production and spawning stock biomass estimates for the southern contingent and the larval index with and without catchability corrections. Indices were $\log _{10}$ transformed. Coloration of points represent MARMAP (red) and EcoMon (green) years .66

Figure 2-1. Regions of the Northeast U.S. Shelf examined for Atlantic mackerel larval habitat. Assessment was confined to the Mid-Atlantic Bight (MAB), southern New England (SNE), Georges Bank (GB), and the Gulf of Maine (GOM). The area $\left(\mathrm{km}^{2}\right)$ for each of these regions is provided. The dashed line through the Gulf of Maine delineates the western and eastern portions. Locus map illustrates the Northeast U.S. Shelf location within the northwest Atlantic, the southern (SC) and northern (NC) contingent spawning grounds, and the $200 \mathrm{~m}$ isobath (dark line).................. 165 Figure 2-2. Partial additive effects for continuous variables used in the presence/absence GAM. Zooplankton abundances were transformed before modeling: $\ln ($ abundance+1). Dark lines indicate the mean fit for each relationship, with grey bounds indicating the $95 \%$ confidence interval. The horizontal dashed lines represent a neutral effect on the presence/absence for the given covariate. Rug plots along x-axes indicate the values of independent variable observations, with fewer tick marks indicating fewer samples of that quantity of the covariate observed 166

Figure 2-3. Partial additive effects for continuous variables used in the abundance GAM. Larval Atlantic mackerel and zooplankton abundances were transformed before modeling: $\ln ($ abundance+1). Dark lines indicate the mean fit for each relationship, 
with grey bounds indicating the $95 \%$ confidence interval. The horizontal dashed lines represent a neutral effect on the abundance for the given covariate. Rug plots along xaxes indicate the values of independent variable observations, with fewer tick marks indicating fewer samples of that quantity of the covariate observed.................167 Figure 2-4. Grid cell trends in habitat for the five ecoregions: the Mid-Atlantic Bight (MAB, red), southern New England (SNE, blue), Georges Bank (GB, yellow), the western Gulf of Maine (wGOM, green), and the eastern Gulf of Maine (eGOM, orange) (a). Habitat grid cell linear trends (slopes) over time by ecoregion, with quartiles (lines) and outliers (points) presented. Horizontal dotted line represents no change in habitat. Mean grid cell trends (b) in interpolated abundance, representing habitat suitability (solid lines), and observed (dashed lines) abundance..............168 Figure 2-5. Habitat suitability indices within an ecoregion (HSIE) for the Mid-Atlantic Bight (MAB, red), southern New England (SNE, blue), Georges Bank (GB, yellow), the western Gulf of Maine (wGOM, green), the eastern Gulf of Maine (eGOM, orange), and the Northeast U.S. Shelf (NEUS, black). Dashed lines represent linear fits of the indices over time. Index values are in units of $\ln \left(\right.$ number $\left.+10.01 \mathrm{~m}^{-2}\right) \ldots \ldots \ldots 169$ Figure 2-6. Habitat suitability indices within the Northeast U.S. Shelf (HSIs) for the Mid-Atlantic Bight (MAB, red), southern New England (SNE, blue), Georges Bank (GB, yellow), the western Gulf of Maine (wGOM, green), and the eastern Gulf of Maine (eGOM, orange). Dashed lines represent linear fits of the indices over time...170 Figure 2-7. Along (a), across (b), and geographical (c) center positions of larval habitat over the Northeast U.S. Shelf. Along shelf distances $(\mathrm{km})$ are relative to the 200m contour off Cape Hatteras, North Carolina, with increase in values indicating 
further movement north. Across shelf movements $(\mathrm{km})$ represent landward (negative) or seaward (positive) from the $200 \mathrm{~m}$ contour. For further description on the along and across shelf distance calculations, see Nye et al. (2009). Geographical center positions are represented in grey circles, except for start and terminal years (1978 and 2013, black circles). Along and across shelf trends since the late 1970s (dashed lines) and 1995 (dotted lines) are presented.

Figure 3-1. (a) Total removals (commercial and recreational landings, and discards) and (b) selectivity at ages used for the stock reduction analysis. .240 Figure 3-2. Density plots of Goodyear $(\mathrm{K})$ and 1804 recruitment population size $\left(\mathrm{R}_{0}\right)$ drawn from prior distributions for all SSRA runs (black) and those that did not result in population crashes (blue). $\mathrm{K}$ and $\mathrm{R}_{0}$ of successful runs were weakly, negatively correlated $\left(\mathrm{R}^{2}=0.08\right.$, $\mathrm{p}$-value $\left.<0.001\right)$. Mean $\mathrm{K}$ and $\mathrm{R}_{0}$ values (red diamond) and 95\%ile ranges (black bars) are presented.

Figure 3-3. Population trajectories for successful simulation runs. Darker regions represent more probabilistic trajectories based on simulations. Total population numbers (top) and population expressed as proportion of the 1804 population size (bottom) are presented, with median (red, solid) and 95 percentile range (red, dashed) of the simulations indicated. .242 Figure 3-4. Median population sizes by age class since the inception of the northwest Atlantic mackerel fishery (1804) 243

Figure 3-5. Median relative population sizes by age class for more contemporary periods covered in recent stock assessments (1960 onwards). Point sizes are proportional to population sizes represented in Figure 4 
Figure 3-6. Fully recruited fishing mortality rates for successful simulation runs. Darker regions represent more probabilistic trajectories based on simulations. Median F values (red, solid) and the 95-percentile range (red, dashed) of the simulations are indicated. Horizontal dashed lines demarcate the selectivity periods: hook and line (1804-1850), seine (1851-1950), and trawl (1951-2016).... .245

Figure 3-7. Phase plot of annual population size by fishing mortality. Initial (1804) and terminal (2016) years are represented in red and blue, respectively .246

Figure 3-8. Comparison of SSRA runs that best corresponded to available indices data: (a) SSRA population size, (b) historical catch per unit effort reported by Sette and Needler (1934), (c) SSRA spawning tock biomass, and (d) northwest Atlantic spawning stock biomass estimated from annual egg production (Carter and Richardson, 2017). The average population (e) and fishing mortality estimates (f) from the two best-fit runs are presented. 247 Figure 3-9. Median 95\%ile ranges for successful population trajectories of the four different scenarios: base-case using lower natural mortality (dark gray), elevated natural mortality (light blue), incorporating unreported catch (light green), and timevarying recruitment from temperature (light red).

Figure 3-10. Median fully-recruited fishing mortality trajectories for successful runs from the four different scenarios: base-case using lower natural mortality (black, solid), elevated natural mortality (black, dashed), incorporating unreported catch (gray, solid), and time-varying recruitment from temperature (gray, dashed) 


\section{INTRODUCTION}

Atlantic mackerel (Scomber scombrus) is a schooling, pelagic, planktivorous fish found on both sides of the North Atlantic: from Newfoundland to North Carolina in the west, and from Greenland to the Mediterranean Sea in the east (Sette, 1950; Astthorsson et al., 2012; Jansen et al., 2016). The northwest Atlantic population resides in waters extending from Canada through the U.S., but comprises two distinct contingents differing based on their spawning; the northern contingent spawns in the Gulf of St. Lawrence from May into August, while the southern contingent spawns from the Mid-Atlantic Bight through the Gulf of Maine from mid-April through June (Morse, 1980; Anderson, 1982; Berrien, 1982). During late fall and winter, the southern contingent inhabits offshore waters along the continental shelf in the MidAtlantic Bight. From spring through autumn, mackerel migrate north and inshore along southern New England through the Gulf of Maine to spawn and feed (Sette, 1943; Sette, 1950). The northern contingent exhibits similar migratory patterns, moving from Georges Bank and the Scotian Shelf to the Gulf of St. Lawrence in the late spring through summer, and returning south in autumn (Overholtz et al., 1989; Berrien, 1982). For short periods in May and October-December, the two contingents mix in southern New England and Gulf of Maine, respectively (Sette, 1950). With such mixing, the contingents together comprise one population that and considered a single stock.

The northwest Atlantic mackerel stock has supported fisheries since the first half of the seventeenth century (Sette and Needler, 1934). Commercial landings data spanning the last two centuries highlight an evolving fishery and population changes 
(Anderson and Paciorkowski, 1980). For example, increased landings in the early to mid-1800s reflect the advancement of fishing and changes in the stock's vulnerability to commercial industry (Anderson and Paciorkowski, 1980). The stock underwent its greatest exploitation in the 1970s, when Russia and European countries fished northwest Atlantic mackerel. While foreign catches subsided in the late 1970s with the implementation of the 200-nautical-mile exclusive economic zone (DFO, 2014), an agreement between the USSR and U.S. resulted in increased foreign catches in the 1980s compared to the late 1970s, until the agreement was disbanded in 1992.

Landings are also believed to be influenced by changes in mackerel distribution in response to environmental conditions. Climate change has altered the physics and chemistry of marine ecosystems, including ocean temperature, dissolved oxygen, $\mathrm{pH}$, and ocean circulation (Poloczanska et al., 2016), and transformed available habitat for marine fish and invertebrates. As such, species are often forced to geographically move, either with latitude or depth, to remain within optimal habitat conditions. Several studies have documented the changes in adult mackerel distribution in both the northwest Atlantic (Nye et al., 2009; Overholtz et al., 2011) and northeast Atlantic (Astthorsson et al. 2012; Jansen et al. 2016). For the latter, such latitudinal shifts have resulted in new and reduced mackerel fisheries across European countries, ultimately shifting available resources for local economies (Astthorsson et al. 2012; Jansen et al. 2016, Spijkers and Boonstra 2017).

These geographical shifts have been often associated with warming ocean temperatures. Sea temperature has long been suspected to influence distribution and abundance via thermal requirements over multi-decadal scales, causing alternating 
regimes between Atlantic herring (Clupea harengus) and mackerel in the northwest Atlantic (Skud, 1982). Atlantic mackerel are susceptible to changes in sea temperature via growth and mortality rates, particularly during the larval stage (Ware and Lambert, 1985). Increases in sea temperature have also been associated with northwest Atlantic mackerel spatial distributions by size-class, spring migrations, and spawning seasonality (Overholtz et al., 2011; Radlinski et al., 2013). In the northeast Atlantic, several studies have described temperature's influence on adult (Astthorsson et al., 2012) and egg (Beare and Reid, 2002; Hughes et al., 2015) distributions and seasonality of occurrence.

Like temperature, changes in the zooplankton prey field have also been identified as influencing mackerel recruitment and subsequently landings in the northwest Atlantic. Changes in physical conditions affect zooplankton abundance and distribution through species' physiological constraints, differential advective transport and changes in predator-prey interactions. Zooplankton community composition has also changed in the northwest Atlantic, most notably over the last half century (Morse et al., 2016). Altering zooplankton species composition changes the prey available for early life stage fish with prey-specific diets (Friedland et al., 2013) such as Atlantic mackerel. Early-stage mackerel larvae prey primarily on copepods, including Pseudocalanus spp., Temora longicornis, and Calanus finmarchicus (Peterson and Ausubel, 1984; Ringuette et al., 2002; Robert et al., 2008). Poor spatial-temporal match between larvae during the transition from yolk-sac to exogenous-feeding and their preferred prey can influence growth and mortality through increased starvation and susceptibility to predation (Takasuka et al., 2003; Robert et al., 2014). In the 
northern contingent, Atlantic mackerel recruitment has been found to vary annually based on prey availability during the species' exogenous-feeding larval stage (Castonguay et al., 2008; Plourde et al., 2015; Jansen, 2016). Increased landings in the early 2000s have been hypothesized to be linked to high Calanus finmarchicus abundances supporting the strong 1999 year class (DFO, 2014).

In the context of the fishery's history, northwest Atlantic mackerel landings are presently near all-time lows. Recent Canadian (northern contingent) assessments indicate that the stock is near historic low levels. Canadian assessments have attributed the reduced catches and abundances to overharvesting and recruitment overfishing (DFO, 2014; Ploudre et al. 2015). U.S. landings are currently the lowest in the last 40 years (Wiedenmann, 2016). However, U.S. (southern) contingent data provide contradicting information. Abundance indices from fishery-independent trawl surveys and commercial landings indicate opposite trends, with landings declining and bottomtrawl survey abundance indices variable and occasionally higher in recent years. While recent contractions in the length and age structure is apparent in both survey and commercial catches, these contradicting indices have produced large uncertainty and significant retrospective patterns in the most recent stock assessment products (Deroba et al., 2010). In 2017, a U.S. assessment was conducted (awaiting peerreview); however, the U.S. currently declares the northwest Atlantic mackerel stock status as "unknown" (MAFMC, 2016).

Questions over the stock's status and ambiguity of current data have led to efforts to better understand the population's structure at all life stages and the environmental impacts that may, with overfishing, be causing the low numbers. These 
efforts include evaluating ichthyoplankton data to inform population trends. Longterm monitoring surveys of early-life stage fish (eggs and larvae) are used to assess changes in fish populations' abundances and distributions over time (McClatchie et al., 2014). Ichthyoplankton abundance indices have traditionally been used to tune abundance estimates during stock assessment modeling (Scott et al., 1993), assuming that planktonic (egg and larval) abundance indices are directly proportional to those of older age class (spawning stock and recruitment) (Saville, 1964; Armstrong, 2001; Payne et al., 2009; Richardson et al., 2010). Several examples exist indicating how egg abundance indices, with stock fecundity information, can be used as suitable proxies in estimating spawning stock biomass (Stratoudakis et al., 2006). Larval indices have also been used to estimate spawning stock biomass (Richardson et al. 2010), as well as provide insight into year-class strength, as survival through the larval stage and first year of life are critical in fisheries recruitment (Nash and DickeyCollas, 2005; Payne et al., 2009). While egg abundance index calculations often require fewer assumptions regarding catchability and growth, larval abundance indices are of interest for Atlantic mackerel given evidence in the northern contingent of the Atlantic mackerel larval prey environment influencing growth and survival, and ultimately local recruitment (Runge et al., 1999; Ringuette et al., 2002; Castonguay et al., 2008). Thus, evaluating ichthyoplankton data for use in understanding population trends is of great use for future Atlantic mackerel stock assessments.

While significant effort and funding go towards designing and conducting fisheries-independent surveys for assessing fish stocks, several complexities with the surveys (e.g. gear catchability, survey effort and spatial extent changes through time, 
spatial-temporal mismatch with sampling and species presence, and the multi-purpose natures of most fishery-independent surveys) can either disqualify data-rich information from being included in conventional stock assessment models or prevent benchmark assessments from passing peer-review, the latter being the case for the most recent Atlantic mackerel assessment (Deroba et al., 2010). These scenarios lead fisheries scientists and managers to use less quantitatively rigorous and/or more uncertain data to provide management recommendations for acceptable biological catch limits.

Stock reduction analyses (SRAs) have been used for data-poor and datarich/information-poor species to understand population trajectories. SRA uses historical catch and relative stock reduction from fishery removal to understand what population levels would have been required to sustain such removals (Kimura et al., 1984; Walters et al., 2006). SRAs provide an alternative method for understanding population trends and inferring reference points when more conventional assessments prove insufficient. Additionally, this method incorporates rich histories of catch information that the preferred, more rigorous assessment models typically ignore. Stochastic SRAs (SSRAs) use Monte Carlo simulations to iteratively generate population parameters and project forward population trends (Walters et al., 2006; Dick and MacCall, 2011). Population parameter combinations providing abundances greater than catch represent plausible scenarios for stock abundance and life-history characteristics. Ultimately, this method provides a range of values for population abundance and parameters, representing the variability and uncertainty in estimates. In the case of Atlantic mackerel, an SSRA approach could provide an alternative and/or 
complimentary tool for future assessments, while incorporating the rich catch history information available (Anderson and Paciorkowski, 1980).

This dissertation aims to provide (1) additional abundance and population trend information for future northwest Atlantic mackerel benchmark assessments, and (2) a stronger understanding on the extent of Atlantic mackerel habitat changes under climate change. The first chapter uses long-term federal ichthyoplankton data to construct a larval index for the stock's southern contingent. The second chapter uses the same ichthyoplankton data in conjunction with oceanographic (sea temperature) and prey (zooplankton abundance) data concurrently collected to quantify the changes in larval suitable habitat over the last 40 years in the southern contingent. The third and final chapter uses the SSRA approach to infer northwest Atlantic mackerel population trends over the last two centuries, using historical accounts of landings, catch-at-age, and descriptions of the fisheries' evolution.

\section{LITERATURE CITED}

Anderson, E.D. (1982) Status of the northwest Atlantic mackerel stock - 1981. U.S. Natl. Mar. Fish. Serv. Northeast Fish. Cent. Woods Hole Lab Ref. Doc. 81-38: 38p.

Anderson ED, and Paciorkowski AJ (1980) A review of the Northwest Atlantic mackerel fishery. Rapports et Proce`s-Verbaux des Re'unions du Conseil International pour l'Exploration de la Mer, 177: 175-211.

Armstrong, M. (2001) An application of the annual egg production method to estimate the spawning biomass of cod (Gadus morhua L.), plaice (Pleuronectes platessa L.) and sole (Solea solea L.) in the Irish Sea. ICES Journal of Marine Science 58:183203.

Astthorsson, O. S., Valdimarsson, H., Gudmundsdottir, A., and Oskarsson, G. J. (2012) Climate-related variations in the occurrence and distribution of mackerel (Scomber scombrus) in Icelandic waters. ICES Journal of Marine Science, 69: 1289-1297. 
Beare, D. J., and Reid, D. G. (2002) Investigating spatio-temporal change in spawning activity by Atlantic mackerel between 1977 and 1998 using generalized additive models. ICES Journal of Marine Science: Journal du Conseil, 59: 711-724.

Berrien, P. (1982). Atlantic mackerel, Scomber scombrus. In M.D. Grosslein and T.R. Azarovitz eds. Fish distribution. p. 99-102. MESA New York Bight Atlas Monograph 15. N.Y. Sea Grant Institute, Albany, NY.

Castonguay, M., Plourde, S., Robert, D., Runge, J. A., and Fortier, L. (2008) Copepod production drives recruitment in a marine fish. Canadian Journal of Fisheries and Aquatic Sciences 65: 1528-1531.

Deroba, J., Shepherd, G., Gregoire, F., Nieland, J., and Rago, P. (2010) Stock assessment of Atlantic mackerel in the Northwest Atlantic for 2010. Transboundary Resources Assessment Committee, Reference Document 2010/01. $59 \mathrm{pp}$.

Dick, E.J. and MacCall, A.D. (2011) Depletion-Based Stock Reduction Analysis: A catch-based method for determining sustainable yields for data-poor fish stocks. Fisheries Research, 110: 331-341.

DFO (2014) Assessment of the Atlantic Mackerel stock in the Northwest Atlantic (Subareas 3 and 4). DFO Can. Sci. Advis. Sec. Sci. Advis. Rep. 2014/030.

Friedland, K.D., and Hare, J.A. (2007) Long-term trends and regime shifts in sea surface temperature on the continental shelf of the northeast United States. Continental Shelf Research 27: 2313-2328.

Hughes, K. M., Dransfeld, L., and Johnson, M. P. (2015) Climate and stock influences on the spread and locations of catches in the northeast Atlantic mackerel fishery. Fisheries Oceanography, 24: 540-552.

Jansen, T., Post, S., Kristiansen, T., Oskarsson, G. J., Boje, J., MacKenzie, B. R., Broberg, M., et al. (2016) Ocean warming expands habitat of a rich natural resource and benefits a national economy. Ecological Applications. doi: 10.1002/eap.1384.

Kimura, D.K., Balsiger, J.W., and Ito, D.H. (1984) Generalized stock reduction analysis. Canadian Journal of Fisheries and Aquatic Sciences 41:1325-133.

Mid-Atlantic Fisheries Management Council (MAFMC). (2016). Mid-Atlantic Fishery Council - Species Stock Status (as of November 28, 2016). https://static1.squarespace.com/static/511cdc7fe4b00307a2628ac6/t/587e36662e6 9cf391ab50619/1484666472391/2016-11-28_MAFMC_Stock_Status.pdf. (accessed 4 February 2017). 
McClatchie, S., J. Duffy-Anderson, J.C. Field, R. Goericke, D. Griffith, D.S. Hanisko, J.A. Hare, J. Lyczkowski-Shultz, W.T. Peterson, W. Watson, E.D. Weber, and G. Zapfe (2014). Long time series in US fisheries oceanography. Oceanography 27(4):48-67.

Morse, W.W. (1989) Catchability, growth and mortality of larval fishes. Fishery Bulletin US, 87: 417-446.

Nash, R.D.M., and Dickey-Collas, M. (2005). The influence of life history dynamics and environment on the determination of year class strength in North Sea herring (Clupea harengus L.) Fisheries Oceanography, 14(4): 279-291.

Nye, J.A., Link, J.S., Hare, J.A., and Overholtz, W.J. (2009) Changing spatial distribution of fish stocks in relation to climate and population size on the Northeast United States continental shelf. Marine Ecology Progress Series, 393: 111-129.

Overholtz, W.J. (1989) Density-dependent growth in the northwest Atlantic stock of Atlantic mackerel (Scomber scombrus). Journal of the Northwest Atlantic Fishery Science, 9:115-121.

Overholtz, W. J., Hare, J. A., and Keith, C. M. (2011) Impacts of interannual environmental forcing and climate change on the distribution of Atlantic mackerel on the US Northeast continental shelf. Marine and Coastal Fisheries: Dynamics, Management, and Ecosystem Science, 3: 219-232.

Payne, M.R., Hatfield, E.M., Dickey-Collas M., Falkenhaug T., Gallego A., Gröger J., Licandro P., Llope M., Munk P., and Röckmann, C. (2009) Recruitment in a changing environment: the 2000s North Sea herring recruitment failure. ICES Journal of Marine Science: Journal du Conseil 66:272-277.

Peterson, W. T., and Ausubel, S. J. (1984) Diets and selective feeding by larvae of Atlantic mackerel Scomber scombrus on zooplankton. Marine Ecology Progress Series 17: 65-75.

Plourde, S., Grégoire, F., Lehoux, C., Galbraith, P. S., Castonguay, M., and Ringuette, M. (2015) Effect of environmental variability on body condition and recruitment success of Atlantic Mackerel (Scomber scombrus L.) in the Gulf of St. Lawrence. Fisheries Oceanography doi: 10.1111/fog.12113.

Poloczanska, E. S., Burrows, M. T., Brown, C. J., García Molinos, J., Halpern, B. S., Hoegh-Guldberg, O., Kappel, C. V., et al. (2016) Responses of marine organisms to climate change across oceans. Frontiers in Marine Science, 3(62): 1-21.

Radlinski, M. K., Sundermeyer, M. A., Bisagni, J. J., and Cadrin, S. X. (2013) Spatial and temporal distribution of Atlantic mackerel (Scomber scombrus) along the 
northeast coast of the United States, 1985-1999. ICES Journal of Marine Science, 70: 1151-1161.

Richardson, D. E., Hare, J. A., Overholtz, W. J., and Johnson, D. L. (2010) Development of long-term larval indices for Atlantic herring (Clupea harengus) on the northeast US continental shelf. ICES Journal of Marine Science: Journal du Conseil, 67: 617-627.

Ringuette, M., Castonguay, M., Runge, J. A., and Grégoire, F. (2002) Atlantic mackerel (Scomber scombrus) recruitment fluctuations in relation to copepod production and juvenile growth. Canadian Journal of Fisheries and Aquatic Sciences, 59: 646-656.

Robert, D., Castonguay, M., and Fortier, L. (2008) Effects of intra- and inter-annual variability in prey field on the feeding selectivity of larval Atlantic mackerel (Scomber scombrus). Journal of Plankton Research, 30: 673-688.

Robert D, Pepin P, Dower JF, Fortier L (2014) Individual growth history of larval Atlantic mackerel is reflected in daily condition indices. - ICES Journal of Marine Science, 71(4): 1001-1009.

Runge, J.A., Castonguay, M., de Lafontaine, Y., Ringuette, M., and Beaulieu, J.-L. (1999) Covariation in climate, zooplankton biomass and mackerel recruitment in the southern Gulf of St. Lawrence. Fisheries Oceanography 8(2): 139-149.

Saville, A. (1964) Estimation of the abundance of a fish stock from egg and larval surveys. Rapports et Proce`s-Verbaux des Re'unions du Conseil Permanent International pour l'Exploration de la Mer, 155: 154-173.

Scott, G.P., Turner, S.C., Grimes, C.B., Richards, W. J., and Brothers, E.D. (1993) Indices of larval bluefin tuna, Thunnus thynnus, abundance in the Gulf of Mexico; modeling variability in the growth, mortality, and gear selectivity. Bulletin of Marine Science 53(2): 912-929.

Sette, O.E. (1943) Biology of the Atlantic mackerel (Scomber scombrus) of North America. Part I. Early Life history, including growth, drift, and mortality of egg and larval populations. U.S. Fish and Wildlife Service Fishery Bulletin 50: 149237.

Sette, O.E. (1950) Biology of the Atlantic mackerel (Scomber scombrus) of North America. Part II. Migrations and habitat. U.S. Fish and Wildlife Service Fishery Bulletin 51: 251-358.

Sette, O.E. and Needler, A.W.H. (1934) Statistics of the mackerel fishery off the coast of North America. Invest. Rep., US Dept. Commer., 19, 48 p. 
Spijkers, J. and Boonstra, W.J. (2017) Environmental change and social conflict: the northeast Atlantic mackerel dispute. Regional Environmental Change 17:18351851.

Skud, B. E. (1982) Dominance in fishes: the relation between environment and abundance. Science 216: 144-149.

Stratoudakis, Y., Bernal, M., Ganias, K., and Uriate, A. (2006). The daily egg production method: recent advances, current applications, and future challenges. Fish and Fisheries 7:35-57.

Takasuka, A., Aoki, I., and Mitani, I. (2003) Evidence of growth-selective predation on larval Japanese anchovy Engraulis japonicus in Sagami Bay. Marine Ecology Progress Series, 252: 223-238.

Walters CJ, Martell SJD, Korman J (2006) A stochastic approach to stock reduction analysis. Can J Fish Aquat Sci 63:212-223.

Ware, D.M., and Lambert, T.C. (1985) Early life history of Atlantic mackerel (Scomber scombrus) in the southern Gulf of St. Lawrence. Can J Fish Aquat Sci 42:577-592.

Wiedenmann, J. (2016). Application of a data-poor harvest control rules to Atlantic mackerel. Southeast Data, Assessment, and Review, Report \# SEDAR46-RD-09. $53 \mathrm{pp}$. 


\section{MANUSCRIPT 1}

Constructing larval indices for Atlantic mackerel (Scomber scombrus) of the Northeast U.S. Continental Shelf

M. Conor McManus ${ }^{1,2, *}$, David E. Richardson ${ }^{3}$, Kiersten L. Curti ${ }^{4}$, and Jeremy S. Collie $^{1}$

${ }^{1}$ Graduate School of Oceanography, University of Rhode Island, Narragansett, RI, 02882

${ }^{2}$ Rhode Island Department of Environmental Management, Division of Fish and Wildlife, Jamestown, RI, 02835

${ }^{3}$ National Oceanic and Atmospheric Administration, National Marine Fisheries

Service, Northeast Fisheries Science Center, Narragansett, RI, 02818

${ }^{4}$ National Oceanic and Atmospheric Administration, National Marine Fisheries

Service, Northeast Fisheries Science Center, Woods Hole, MA, 02543

*corresponding author: phone: (401) 423-1941, fax: (401) 423-1925; email:

cmcmanus@gso.uri.edu

Key words: Atlantic mackerel, larvae, abundance indices, early life-history, southern contingent, stock assessment

Publication status: in preparation for submission to ICES Journal of Marine Science 


\section{ABSTRACT}

Ichthyoplankton abundances have been used to assess fish population changes through time and provide additional abundance indices for stock assessment modeling. Such abundances metrics are appealing for Atlantic mackerel, as currently available fisheries-independent bottom trawl abundances may not adequately represent population trends. We developed larval indices for Atlantic mackerel spawned in the Northeast U.S. Continental Shelf to provide future mackerel stock assessments with an additional fisheries-independent abundance index. To account for larval population dynamics and sampling survey design, the index methodology incorporates growth, mortality, and spawning seasonality in predicting abundances at a given age, day of year, and year. Larval index sensitivity to catchability corrections, data aggregation, minimizations of residuals, and growth rates are evaluated. From the final model variant selected, southern contingent Atlantic mackerel larval abundances were greatest in 1932, the early 1980s, and the early 2000s. The larval index without catchability corrections exhibited significant, yet weak, correlation to estimated annual egg production and spawning stock biomass; thus, it's unclear how well the larval index represents southern contingent egg production or spawning stock biomass. We recommend future use of the larval index be done without catchability corrections applied, and alternatively have larval index split into segments based on the major ichthyoplankton survey program periods and each have their own correction factor $q$ estimated within the stock assessment model. Given the lack of recruitment indices presently available for the southern contingent, additional research should be conducted to understand the larval index's use in predicting recruitment. 


\section{INTRODUCTION}

Atlantic mackerel (Scomber scombrus) is a schooling, pelagic fish of the North Atlantic. In the northwest Atlantic, mackerel range from Newfoundland to North Carolina (Sette, 1950), with the single stock comprised of two spawning contingents. The northern contingent spawns in the Gulf of St. Lawrence from May through August, while the southern contingent spawns between the Mid-Atlantic Bight and Gulf of Maine from mid-April through June (Anderson, 1982; Berrien, 1982). Both contingents exhibit spring and fall migrations. The southern contingent moves north from offshore continental shelf waters of the Mid-Atlantic Bight in the spring through early summer, towards inshore southern New England and the Gulf of Maine, and returns to the Mid-Atlantic Bight in the fall (Sette, 1950). Similarly, the northern contingent migrates from Georges Bank and the Scotian Shelf to the Gulf of St. Lawrence in the late spring through summer, and returns south in autumn (Overholtz et al., 1989; Berrien, 1982). The population's two contingents are believed to geographically mix in May in southern New England and October through December in the Gulf of Maine (Sette, 1950).

Atlantic mackerel have supported commercial and recreational fisheries since the seventeenth century (Anderson and Paciorkowski, 1980). Commercial landings data spanning the last two centuries highlight changes in harvest influenced by multiple factors, including evolution of fishing gear, introduction and removal of foreign participants in the fishery, and population responses to environmental changes (Sette and Needler, 1934; Anderson and Paciorkowski, 1980; Taylor et al., 1957;

Skud, 1982). Mackerel landings within the southern contingent are near their lowest in 
over the last 40 years (Wiedenmann, 2016). Egg abundance indices from Gulf of St. Lawrence are also currently near time series lows, which have in part been attributed to overharvesting and recruitment overfishing (DFO, 2014; Ploudre et al., 2015). In U.S. waters, contradicting trends from bottom-trawl survey abundance indices and commercial landings have caused significant retrospective patterns in assessment modeling, and thus uncertainty in stock assessment model results (Deroba et al., 2010). As such, the U.S. declaration of northwest Atlantic mackerel stock status is currently "unknown” (MAFMC, 2016). Additional southern contingent fisheriesindependent survey data are sought to corroborate our understanding of northwest Atlantic mackerel population status.

Long-term monitoring surveys of early life stage fish (eggs and larvae) are used to assess changes in fish populations' abundances and distributions over time (McClatchie et al., 2014). Ichthyoplankton abundance indices have traditionally been used to tune abundance estimates during stock assessment modeling (Scott et al., 1993). With stock fecundity information, egg abundance indices have been used to estimate spawning stock biomass (SSB) (Stratoudakis et al., 2006). While further removed from fecund adults than eggs, larval abundance indices have also been compared to spawning stock size estimates (Gledhill and Lyczhowski-Shultz, 2000; Richardson et al., 2010; Able et al., 2011). Larval indices can also provide insight into year class strength, as survival through the larval stage and first year of life can significantly influence fish recruitment (Nash and Dickey-Collas, 2005; Payne et al., 2009). The northern contingent prey environment, and resulting growth and survival of Atlantic mackerel larvae, have been hypothesized to influence Gulf of St. Lawrence 
mackerel recruitment (Runge et al., 1999; Ringuette et al., 2002; Castonguay et al., 2008). Understanding larval abundance trends for the southern contingent may provide insight into the stock's SSB and/or recruitment patterns, and be useful in future stock assessment modeling.

The objective of this work is to construct an annual larval index for Atlantic mackerel spawned in the southern contingent (or the Northeast U.S. Continental Shelf). Annual larval indices have been constructed for fish stocks using various methods (Gledhill and Lyczkowski-Shultz, 2000; Hanisko et al., 2017; Simpson et al., 2016). We have implemented the method developed by Richardson et al. (2010), which unlike previous methods, incorporates growth, mortality, spawning seasonality of the larval population, and the timing of sampling, to predict larval abundances. This method was implemented using several model variants to understand the significance of statistical and data aggregation approaches in the larval index results. The larval indices were compared to those using other larval index methods to infer how the inclusion of early life-history characteristics influence calculation. We hypothesize that the larval index will correspond to other mackerel abundance and fishery trends and/or environmental conditions have been known to influence Atlantic mackerel.

\section{METHODS}

\section{Larval Data}

Atlantic mackerel larvae data were evaluated from ichthyoplankton surveys conducted since 1977 in the Northeast U.S. Continental Shelf through various longterm monitoring programs (Kane, 2003). Further details on the surveys, their designs, and objectives are provided in Richardson et al. (2010). Samples taken in sampling 
strata covering historical spawning grounds within the Mid-Atlantic Bight, Gulf of Maine, and southern New England were included for data analysis (Figure 1). Years of data were only included in larval index calculations if southern contingent spawning ground strata were sampled in May or June of the given year (Supplement 1). Years with such strata sampled included 1977-1987, 2000-2002, 2004-2007, 2009-2013, 2015-2016. With this criterion, NOAA ichthyoplankton data represented samples collected as part of the National Oceanic and Atmospheric Administration (NOAA)'s Marine Resources Monitoring, Assessment, and Prediction (MARMAP, 1977-1987) and Ecosystem Monitoring (EcoMon, 1992-present) Programs (data accessed 21 March 2017).

MARMAP and EcoMon samples were collected with bongo nets towed obliquely through the water column to within five meters of the sea floor, or a maximum of $200 \mathrm{~m}$. Sampling occurred throughout the year at both day and night. Larvae caught were preserved in formalin and later measured for length $(\mathrm{mm})$ to produce abundances-at-length. While most sampling protocols were the same between the MARMAP and EcoMon Programs, the bongo mesh size used to sample ichthyoplankton differed between the two programs. The MARMAP Program used a coarser $0.505 \mathrm{~mm}$ mesh, whereas the EcoMon Program used a finer $0.333 \mathrm{~mm}$ mesh net. Abundances were standardized to number of larvae per $10 \mathrm{~m}^{2}$. Atlantic mackerel larval abundances were as high as 10,819 larvae $10 \mathrm{~m}^{-2}$ (Figure 1), with sizes ranging from 1.3 to $42 \mathrm{~mm}$. For these analyses, larval abundances greater than the $99 \%$ ile of the abundance-weighted length range $(15 \mathrm{~mm})$ were removed from analyses. This removal aimed to exclude large mackerel that are likely not efficiently caught or 
representative of typical bongo catches, and thus not representative of true abundances for those size classes.

Data were also incorporated from a directed sampling effort of Atlantic mackerel eggs and larvae in 1932 (Sette, 1943). Sampling was conducted in the stock's southern contingent, including the Mid-Atlantic Bight, southern New England, and western Gulf of Maine using 1- $\mathrm{m}^{2}$ nets equipped with $0.666 \mathrm{~mm} \mathrm{mesh}^{1}$. Sampling covered the historical spawning months of May and June, and primarily within the inner shelf spawning regions examined for the MARMAP and EcoMon data. From this program, only Cruises I-VII were included; Cruises VIII and VIII were primarily for gear comparisons in catch with a coarser mesh. Length-specific abundances were available to the nearest $1 \mathrm{~mm}$. Larvae ranged from $3-22 \mathrm{~mm}$ in this survey, but those greater than $15 \mathrm{~mm}$ were removed from analyses for consistency with NOAA processing. Hereafter, this dataset is referred to as "Sette".

\section{Catchability Considerations}

Higher catches of Atlantic mackerel larvae at night than at day have been used as evidence that larger larvae can avoid bongo nets when they are visually detectable (Morse, 1989). Mackerel abundances at length were compared between day and night samples to evaluate the influence of larval avoidance with the presence of light. Sunrise and sunset times, along with azimuth, solar zenith, and PAR, were calculated using R package 'AstroCalc' ver. 4 (Jacobson et al., 2011). MARMAP and EcoMon samples were categorized as day, night or twilight. Twilight samples were defined as those within one hour of the day's sun rise or set, and were not included in the

\footnotetext{
1 "15 meshes per lineal cm over first meter, and then 21 meshes per lineal cm over last 3 meters." Sette (1943)
} 
avoidance analyses because this time frame may have captured behavioral transition (from light to dark, or vice versa) and not adequately represent larvae's avoidance capability.

Mean abundances at length were calculated for day and night samples, but separately for EcoMon and MARMAP Programs' mesh types $(0.333$ and $0.505 \mathrm{~mm}$, respectively). Night:Day abundance ratios were calculated at $0.5 \mathrm{~mm}$ length bins to reduce noise in the relationship between ratios and size. Ratios were calculated only if mean catches for a given size from both day and night samples were available. Similar to Weber and McClatchie (2012), an exponential model was constructed to describe the Night:Day catch ratio $(\mathrm{R})$ and larval size $(\mathrm{L}): \mathrm{R}=\alpha \mathrm{e}^{\beta \mathrm{L}}$, with $\alpha$ and $\beta$ representing estimated parameters. Models were fit with maximum likelihood using a gamma error distribution in R using package 'bbmle' (Bolker, 2008). Models were fit using sampling with replacement over 1000 iterations to assess the influence of the data points in the model on parameter estimates $(\alpha$ and $\beta)$.

Larger larvae appeared to avoid the $0.333 \mathrm{~mm}$ mesh net in day samples, and night-day differences in catch were smaller and more variable over size in the $0.505 \mathrm{~mm}$ mesh (Figure 2). The $0.333 \mathrm{~mm}$ exponential model was implemented for all day samples of the same mesh to account for larvae missed due to avoidance.

Estimated catch ratios were then multiplied by corresponding larval abundances-atlength. The model was implemented for larval sizes up to $12.6 \mathrm{~mm}$ (maximum size where Night:Day calculations could be made, and represented in the model) and was not applied when the catch ratio prediction was less than 1 (corresponding to sizes $<1.9 \mathrm{~mm})$. Avoidance corrections were not applied to the $0.505 \mathrm{~mm}$ mesh samples. The 
Sette data were not corrected for avoidance because sample times were not reported in Sette (1943).

Larval extrusion was considered to account for abundances of smaller larvae that likely passed through the coarser $0.505 \mathrm{~mm}$ mesh used in the MARMAP Program. This correction accounts for smaller larvae not retained with $0.505 \mathrm{~mm}$ mesh, and standardizes catches between the EcoMon $(0.333 \mathrm{~mm})$ and MARMAP $(0.505 \mathrm{~mm})$ surveys. Johnson and Morse (1994) examined larval extrusion over the Northeast U.S. Continental Shelf by taking paired bongo net samples using $0.333 \mathrm{~mm}$ and $0.505 \mathrm{~mm}$ mesh nets, and described larval fish catch ratios of $0.333 \mathrm{~mm}$ mesh to $0.505 \mathrm{~mm}$ mesh by length using a Laird-Gompertz model; however, Atlantic mackerel larvae were not present in enough samples to perform model fitting in their study. Dual mesh samples have been collected in recent years during EcoMon surveys when time permits, but currently available data do not have enough positive occurrences of mackerel over an adequate size range to assess Atlantic mackerel larval extrusion (Supplement 2).

Larval extrusion was also investigated in the literature for other Scomber species to evaluate suitable proxy information. Lo et al. (2009) accounted for extrusion in larval production assessments of Pacific mackerel (Scomber japonicus) - a Scombrid with comparable larval hatching size, metamorphosis, ontogonetic diet shifts (Hunter and Kimbrell, 1979) - using a knife-edge multiplier based on the earlier work of Hewitt et al. (1985). Larval abundances less than or equal to $3 \mathrm{~mm}$ and caught in the $0.505 \mathrm{~mm}$ mesh were multiplied by 3.571 (Lo et al. 2009). This approach was implemented for Atlantic mackerel larvae abundances observed in the $0.505 \mathrm{~mm}$ 
MARMAP samples and Sette samples. However, Lo et al. (2009) note that the impact of larval extrusion may be low given previous work on anchovy larvae.

\section{Larval Index Model}

\section{Growth Calculation}

There has been considerable research on Atlantic mackerel larvae and youngof-year growth rates throughout the North Atlantic (Supplement 3). Growth information from Simard et al. (1992) was used to convert MARMAP, EcoMon, and Sette larval abundances-at-length to abundances-at-daily age. This growth information provided the greatest correspondence of size range and sample location with the larval index data. Growth data were extracted from Simard et al. (1992) and refit with a Gompertz function. This new fit and that reported in Simard et al. (1992) were compared to fitting a power function to larvae less than $20 \mathrm{~mm}$ (Figure 3 ) to assess whether including sizes larger than those typically seen in the NOAA and Sette datasets influences the growth models. Gompertz and Power growth curves were:

$$
\begin{gathered}
\text { Gompertz: Length }=d * e^{-e^{-f(A g e-g)}} \\
\text { Power: Length }=a * A g e^{b}
\end{gathered}
$$

with $d, e, f, a$ and $b$ estimated parameters. When reviewing the two models' residuals by size (Figure 4), the power function had a slightly greater bias at larger sizes than the Gompertz model. Thus, the new Gompertz function was used in estimating abundances-at-age. Conversion to abundances-at-age across MARMAP and EcoMon samples revealed that the modal age class was five days old, with younger ages having lower abundance (Figure 5). Without aging the larvae and relying on age estimates using Simard et al. (1992) data, it is difficult to determine if larvae less than five days 
old were not caught adequately by the bongo net, or if these larvae are older than what the growth model predicts. For this work, the former hypothesis is assumed, such that age five was assumed to be the youngest age fully retained by nets (with the larval index normalized to five-day-olds), and larvae less than five days old (approximately $2.7 \mathrm{~mm}$ or less) were removed from the analyses.

\section{Mortality Calculation}

Mortality was calculated as the proportion of larvae that survived from age five to a given age class, referred to as $P_{A}$ (Figure 6, Richardson et al. 2010). The relationship between age and $P_{A}$ was described as an exponential function:

$$
P_{A}=e^{-g * A g e^{h}}
$$

with $g$ and $h$ representing estimated coefficients. To construct starting parameters for the larval index calculation, this model alone was fit with maximum likelihood estimation and data over all years using R package 'bbmle' (Bolker, 2008).

\section{Hatching Seasonality}

Hatch day $(H D)$ for age-specific abundances were calculated by subtracting larval ages from the days of the year the samples were taken. Seasonal hatch day curves are a function of both true spawning and the sampling seasonality (Figure 7). For example, only sampling in spring and late summer would miss spawning occurring in the early-mid summer, and may not represent the exact peak of spawning or true spawning seasonality. Thus, inferences on hatching seasonality from MARMAP and EcoMon data may not be complete representations of larval hatching in the southern contingent. Calculating hatch day over all samples indicated that Atlantic mackerel larvae in the southern contingent and observed in the MARMAP 
and EcoMon samples primarily hatched in May and June (Figure 7). Hatching seasonality was expressed as the proportion of all larvae hatched through a given day of year $\left(P_{H D}\right.$, Figure 8$)$ using a skewed logistic function:

$$
P_{H D}={\frac{e^{-(a+b * H D)}}{1+e^{a+b * H D}}}^{1 / c}
$$

where $a, b$, and $c$ were estimated coefficients (Richardson et al. 2010). As with the mortality function, hatching seasonality function starting parameters for the final larval index modeling were derived using maximum likelihood estimation for data over all years using R package ‘bbmle’ (Bolker, 2008).

\section{Larval Index Calculation}

The larval indices are estimated by modeling larval abundances at a given age, year, and day of year $\left(N_{y, A, D}\right)$ :

$$
N_{y, A, D}=L I_{y} *\left(P_{H D+1}-P_{H D}\right) * P_{A}
$$

Mortality and spawning seasonality provide multipliers for the abundances in each year, varying with larval age, and when within the year the larvae were sampled (Richardson et al., 2010). During the model fitting, up to five life-history parameters were estimated as constant over time (mortality: $g, h$; spawning seasonality: $a, b, c$ ). The larval index was calculated using a time series mean and annual deviations approach (Methot and Wetzel, 2013). Mortality parameter $h$ was held constant at the mean parameter value estimated with maximum likelihood (1.044) when the models had difficulty converging. A mean larval index parameter $(L I)$ was estimated and held constant over time, while year-specific deviations from the constant mean were estimated for each year that was represented in the dataset. Final annual larval indices 
$\left(L I_{y}\right)$ were calculated by adding annual deviations to the $L I$. The larval index was estimated with AD Model Builder (Fournier et al., 2012). Abundances were square root transformed prior to model fitting, predicting $\sqrt{N_{A, Y, D}}$, to reduce the influence of few-older caught larvae from driving annual indices, unless specified (Table 1). The objective function $(f)$ for this scenario was:

$$
f=\ln (\sigma)+\frac{0.5}{\sigma^{2}} * \sum_{i=1}^{i=n} r e s^{2}
$$

The residuals (res) were the differences between observed and predicted abundances squared, and summed over all samples ( $n$ ), with sigma set to 1 . Prior uniform bounds were assigned to several parameters being estimated to aid in model convergence. Lower and upper bounds for the life history parameters $(a, b, c, g, h)$ were originally set as the mean parameter plus and minus the standard deviation, respectively, as estimated with maximum likelihood estimation and described previously. If these ranges resulted in parameter estimates against the bounds, the bounds were expanded.

Larval index models using the Richardson et al. (2010) method and AD Model Builder were evaluated with multiple criteria. If any life-history parameters were estimated at the bounds set, the model variants were deemed unable to converge. If parameters were estimable within bounds, the maximum gradient value (MGV) of each model was used to identify if models adequately converged. Models with observed or catchability-corrected abundances with MGVs less than 0.001 were deemed adequate for analysis of results. Lastly, models were compared using Akaike Information Criteria with correction for sample size (AICc; Bolker, 2008). AICc 
values for models were calculated based on the number of parameters estimated $(k)$, the number of samples used in the model fitting $(n)$, and the likelihood value $(L)$.

$$
A I C C=-2 \ln (L)+2 k+\frac{2 k(k+1)}{n-k-1}
$$

\section{Larval Index Sensitivity}

\section{Observed vs. Catchability-Corrected Abundances}

The larval index calculation was run using both the larval abundances as sampled (termed herein as 'observed') and corrected for catchability using metrics described previously (referred to here as 'catchability-corrected) to understand differences in larval index magnitudes and model fitness when accounting for catchability.

Model Variants: Cruise vs. Sample Level Analyses

For larval index calculations, abundances-at-age were grouped by distinct surveys (Richardson et al., 2010). Aggregating samples by survey reduced biases in sampling effort over stratum and within the shelf over years. However, on occasion (more often during the MARMAP program than EcoMon), multiple vessels simultaneously sampled for a single survey, and were registered as different cruises. In these instances, the vessels' samples were collapsed into a single survey for analyses. As similarly implemented in Richardson et al. (2010), these instances were grouped together to have surveys performed concurrently, represented as one (Supplement 4). Analyses at this Survey-level required aggregating samples' abundances and day of year sampled information to a coarser resolution than the sample level. The nested aggregations for Survey-level analyses occurred over the following steps: abundances of differing lengths but the same age, samples taken within the same strata of a given 
survey, and strata covered within a given survey. The first step for survey aggregation was to sum abundances within a sample $(S)$ of varying length $(L)$, but of the same age (A), into the same daily age class $\left(N_{A, S}\right)$.

$$
N_{A, S}=\sum_{n=L_{\min }}^{n=L_{\max }} N_{A, S, L}
$$

Next, abundances-at-age were averaged over samples within a stratum $\left(N_{A, S t}\right)$ to reduce the reduce sample size bias across unequally sampled strata:

$$
N_{A, S t}=\overline{N_{A, S t, S}}
$$

These abundances were then aggregated to the survey level: abundances-at-age were averaged across strata from the survey $\left(N_{A, S u r}\right)$, and the day of year of a survey (DOY $\left.Y_{\text {Sur }}\right)$ was calculated as the mean day of year of samples taken during the survey.

$$
\begin{gathered}
N_{A, \text { Sur }}=\overline{N_{A, \text { Sur }, \text { St }}} \\
D O Y_{\text {Sur }}=\overline{D O Y_{\text {Sur }, S}}
\end{gathered}
$$

A survey's average day of year was the same across all age classes. When an age class was not caught during a survey, but vulnerable to the bongo nets (5 to 16-day olds, Figure 6) the ages classes' abundances were assigned to zero.

The drawback with the Survey-level aggregation is that averaging across data for a survey assumes the same hatch data for all samples collected for a cruise in a large geographic region, and may mask or alter the true temporal spawning and larval abundance patterns. Further, averaging individual samples' $P_{H D}$ 's or abundances across a survey may misrepresent true spawning seasonality. This concern is influenced by the length of a survey, and is particularly relevant when larvae are 
caught at the beginning and end of a survey only. To assess this concern, larval index calculations were also run when using the samples themselves and not aggregating within surveys. Sample-level processing resulted in only summing abundances-atlength for samples that corresponded to the same age (i.e. the first step of the Surveylevel aggregation). When an age class was not caught in a sample, but vulnerable to the bongo nets, a zero abundance was applied for the age and sample-specific abundance.

\section{Variants in Residual Minimizations}

Given the skew in larval abundances (i.e. many zero-abundance observations), both log-normal and normal error distribution were attempted for the larval index calculations (Table 1). The difference in these error distribution was defined in the residual calculations. Normal error distributions were calculated as described above. For the log-normal error distributions, residuals were calculated as:

$$
\text { residuals }=\ln (\text { observed }+y)-\ln (\text { predicted }+y)
$$

Correction scalars, 'y', were applied in the residual minimization to allow for residual calculations on abundances of zero. The correction scalar for log-normal model variants was set to half of the minimum observed abundance greater than zero. Gamma error distributions were also attempted, but these models did not converge.

\section{Static Growth Assumptions: Bootstrapped Growth Curves}

The mortality function and larval index age-equivalency are driven by the growth curve used, specifically the slope and y-intercept of the growth model. To understand the influence of Simard et al. (1992) samples in dictating the starting age, the growth data were sampled with replacement 220 times (length of the growth data 
series) and fit with the Gompertz model. Larval index calculations were run with these new estimates of abundances-at-age to understand how varying growth curves influence the larval index age-equivalencies and model convergence. After running the larval index once without this bootstrapping growth curve approach, 100 iterations of the larval index calculations with the bootstrapping procedure were performed. Only bootstrap iterations for the model variant with mortality parameter $h$ fixed and using a normal error distribution (Model Variant 2, Table 1) are presented to describe the consequences of assuming static growth.

\section{Alternative Methods}

The Richardson et al. (2010) method is advantageous given that it accounts for larval mortality, spawning seasonality, and temporal sampling dynamics of MARMAP and EcoMon simultaneously during calculations. However, three simpler larval index calculation methods were performed for comparison: arithmetic mean over all agespecific abundances, abundances corrected for differences using a mortality function (Glendhill and Lyczkowski-Shultz, 2000), and predicting total larval production of these mortality-adjusted abundances using a delta model approach (Maunder and Punt, 2004; Hanisko et al. 2017) to describe spawning seasonality and integrate abundances over the year. These alternative approaches used the same Sample and Survey-level datasets (Supplement 5).

\section{Correspondence to Other Population Indices and the Environment}

External data sources were used to assess how the larval indices compared to other Atlantic mackerel abundance metrics. Commercial U.S. landings (K. Curti, personal communication) were compared to the larval index to assess if stock removal 
from the fishery influences larval production. Concurrent work on constructing egg abundance indices for the southern contingent (Carter and Richardson, 2017) have also provided an opportunity to assess the corroboration in abundance trends across early life stages. Annual egg production from this work, and estimated spawning stock biomass (Carter and Richardson, 2017) were compared to the larval index to assess whether the larval index is suitable for estimating spawning stock biomass.

Climate indices were also compared to the larval index to assess prospective environmental drivers on the larval population. Sea surface temperatures in May and June (i.e. the spawning period) were used to understand if temperature during the spawning period may influence larval survival (Ware and Lambert, 1985), and ultimately annual abundance. Sea surface temperatures were derived from the Optimum Interpolation Sea Surface Temperature (OISST) database (Banzon et al., 2016). Climate oscillation indices representing large-scale North Atlantic conditions were also compared to the larval index to evaluate the influence of multidecadal climate trends on the southern contingent's larval production. The North Atlantic Oscillation (NAO) is a measure of atmospheric pressure over the North Atlantic, influencing water column mixing and stratification and ocean circulation (Hurrell, 1995; McManus et al., 2016). The Atlantic Multidecal Oscillation (AMO) represents the large-scale changes in sea surface temperatures, sea level pressure, and ocean circulation driven by the Atlantic Meridional Overturning Circulation. Both the NAO and the AMO have been extensively linked to changes in marine fish abundance and distribution (Drinkwater et al., 2003; Nye et al., 2014), including Atlantic mackerel (Nye et al., 2009). NAO indices were obtained from Hurrell and NCAR (2017), and 
AMO indices were accessed via NOAA's Earth System Research Laboratory (Enfield et al., 2001).

\section{RESULTS}

Model variants using the Richardson et al. (2010) approach converged successfully at both the Survey- and Sample-levels (Table 1). Sample-level model variants only converged when the mortality parameter $h$ was held constant. Based on AICc scores, using observed data provided better fits than when using catchabilitycorrected data (Table 1). Based on acceptance criteria (MGVs), the Model Variant 9 with observed abundances was deemed well-fit. At the Survey-level, various model versions using normal and log-normal error distributions, both fitting or holding parameter $h$ constant, (Model Variants 2, 4, and 5) converged.

\section{Estimated Life History of Atlantic Mackerel Larvae}

Mortality rates over the larval stage varied between the four well-fitted model variants at the Survey-level. In Model Variant 2, mortality rates were greater for catchability corrected abundances than for observed abundances, with the highest mortality at younger ages (Figure 9). The greatest difference in mortality rates between observed and catchability-corrected runs was at eight days old; approximately $13 \%$ of five day-old larvae survived to eight days old using catchability-corrected abundances, whereas $46 \%$ of five day-old larvae reached eight days old using observed abundances. Estimating parameter $h$ in Model Variant 4 resulted in mortality predictions much different than the data suggested (Supplement 6), with mortality lower at younger ages than moderate ages (Figure 9). Mortality rates in Model Variant 5 were most comparable to those of Model Variant 2; however, there were little 
differences between the catchability and observed abundance mortality curves in Model Variant 5 (Figure 9). Approximately 30-35\% of five day-old larvae were estimated to survive to eight days old.

Spawning seasonality predicted with Model Variant 2 indicated that the spawning period spanned primarily from early April through the end of July (Figure 10). Predictions for both observed and catchability corrected abundances indicated more spawning in the beginning of the period and less towards the end compared to the data, with the predicted peaks well aligned with the data. Model Variants 4 and 5 were similar in spawning seasonality estimates, as were the estimates using observed and catchability-corrected abundances (Figure 10). Spawning seasonality predictions for these Model Variants indicated that most of spawning occurs between early May through late June/early July, similar to the observed data. However, the peaks in spawning predicted by Model Variants 4 and 5 are slightly later than the data suggest (Figure 10).

\section{Larval Indices}

Based on unlikely mortality rates produced in Model Variant 4, only larval indices produced in Variants 2 and 5 are presented. Under Model Variant 2, larval indices calculated with catchability corrections were up to an order of magnitude greater than indices using observed abundances (Figure 11). Larval indices with and without catchability-corrections indicated the greatest larval production year was in 1932 (Figure 11). The difference between the 1932 larval index and MARMAP and EcoMon periods' larval index peaks contrasted between observed and catchabilitycorrected data; peak years across the time periods were comparable for observed 
abundances, whereas the 1932 index was more than double than the next greatest peak in the time series when using catchability corrected abundances. Under Model Variant 2, indices were high in 1980 and 1981, and decreased thereafter. Similarly, 1999-2001 were relatively strong larval years, with lower larval production through the 2000s. In the 2010s, an uptick in larval production appears to occur (Figure 11).

Smaller differences between observed and catchability-corrected abundances were evident for Model Variant 5, except for the late 1990s-early 2000s (Figure 11). The highest larval production was in 2000, with other relatively high larval indices in Model Variant 2 (1932, 1980, 1981, 1999, 2001) of similar size. Residuals for Model Variant 2 indicated uneven error in predictions, with greater inaccuracy in predicting low abundances (i.e. zeros). Model Variant 5, however, had much more evenly distributed error (Figure 12).

Larval indices at the Sample-level (Model Variant 9) indicated comparable patterns to Survey-level Model Variant 2 (Figure 14), likely reflecting the similarities in the performance of normal error distribution models with mortality parameter $h$ fixed. However, the differences between models using catchability-corrected and observed abundances was smaller in Model Variant 9 than Model Variant 2 (Figure 14).

\section{Bootstrapped Growth Curves}

Start ages used in the larval index were sensitive to the variability in data collected by Simard et al. (1992). In the 100 bootstrapped runs, 30 of the model iterations of Model Variant 2 using observed abundances had MGVs $<1 \mathrm{E}-3$ and were deemed well fit for interpretation (Figure 15). Start ages ranged from 3 to 7 days old; 
while 6 was the modal start age of these qualifying model runs, the MGVs for different start ages did not differ much, except for start ages at 3 (Figure 15). However, larval indices did not vary much between different start ages (Figure 16).

\section{Alternative Methods}

The Richardson et al. (2010) method implemented with ADMB correlated to the other larval index methods (Supplement 5, Table 2). Model Variant 2 (using normal error distribution with parameter $h$ held constant) was more correlated to larval indices from the alternative methods than Model Variant 5 (log-normal error distribution with parameter $h$ held constant). Larval indices accounting for differences in larval age and mortality only (Glendhill and Lyczkowski-Shultz, 2000) better corresponded to indices produced with the Richardson et al. (2010) method than simply using mean abundances regardless of age to represent annual indices. Larval indices contracted with the delta model approach also correlated with larval indices built with the Richardson et al. (2010) approach (Table 2). The Sample-level larval indices across all methods were correlated.

\section{Correspondence to Alternate Abundance Indicators and the Environment}

Southern contingent larval indices, annual egg production (AEP) and spawning stock biomass estimates on $\log _{10}$ scale were significantly correlated at an alpha of 0.05

(Table 3, Figure 17). Total northwest mackerel landings and the larval index, however, did not significantly correlate. Similarly, there was little or no correspondence between the larval indices and spawning sea temperature, the NAO or the AMO (Table 3). 


\section{DISCUSSION}

\section{Larval Index Selection and Review of Sensitivity Analyses}

Given the model diagnostics, sensitivity analyses, and comparison to alternative larval index methods, the larval index calculated with a normal error distribution and parameter $h$ fixed (Model Variant 2) appeared to provide the most sensible larval index (Figure 11, Supplement 7). Model residuals from Model Variant 2 were more skewed than using the log-normal error distribution (Model Variant 5, Figure 12), yet of Survey-level model variants, corresponded best to the alternative methods.

Mortality and spawning seasonality predictions for Model Variant 5 matched well with the data (Figures 9 and 10), but the larval indices weakly corresponded to those of the alternative methods and Model Variant 2. These discrepancies are likely due to the differing age composition of the larvae over time (Table 4). Peaks in larval indices using the log-normal error distribution corresponded to years with high abundances of the older larvae, and reducing the influence of the younger larvae abundances. Thus, when using a log-normal error distribution, the age-equivalency scaling using the mortality curve had the greatest influence on the larval indices and did not properly account for years with high, younger larval abundances.

Varying the growth curve for the larval index calculations did not distort the overall trends, but it did influence the start age of the modeling, and thus mortality curves used. Assuming the Simard et al. (1992) Gompertz growth curve is the true growth function for Atlantic mackerel larvae, the smallest age caught in the MARMAP and EcoMon survey is between three and seven days old. The start age does not affect the larval index trends much, but it can alter mortality estimates 
between eggs and larvae if the index is used in further analyses with annual egg production. While varying the growth curve investigated one source of uncertainty, age estimation of the larvae using this approach still required multiple assumptions, such as static growth rates through time and within the Northeast U.S. Shelf, and that larvae estimated at ages less than five days old or of smaller sizes not represented in the original data are estimated accurately with the regression used. Given the variations in Atlantic mackerel larval growth noted throughout the North Atlantic and with latitude (Supplement 3), the growth assumptions made for this modeling are likely not representative of the true environment, and add a source of variability not accounted for in the modeling.

Only slight differences were observed between the larval index patterns at the Survey-level (Model Variant 2) and Sample-level (Model Variant 9) results. Thus, the sampling effort over and within spawning ground does not appear to influence the larval index. Further, the concern of the Survey-level masking spawning seasonality and abundance patterns through extensive data aggregation does not appear to influence the indices. It should be noted that the scales or magnitudes of Survey- and Sample-level indices are different, as well as the difference between catchabilitycorrected abundances and observed abundance runs (Figures 11, 13, 14). The benefit of the Survey-level is that the smaller, but still significant, sample size contains fewer zero abundances, which can aid in model convergence (Table 1). Other life-history parameters (e.g. spawning seasonality parameter ' $c$ ') could be held constant (at either 1 or alternative value), or adjusting bounds to aid in model fitness in bootstrapped scenarios and better refine the indices. 


\section{Influence of Catchability}

Incorporating catchability influences both model convergence and the magnitude of the larval index (Table 1, Figure 11). The scalar adopted from Lo et al. (2009) is within the range of extrusion factors examined by Johnson and Morse (1994), but future research should be directed at both Atlantic mackerel larvae-specific calibrations as well as with finer mesh, as the $0.333 \mathrm{~mm}$ likely misses some component of the larval abundance (1-3mm). Avoidance corrections likely had a larger impact on abundances than the extrusion, both in terms of the size range impacted and the magnitude of the scalar applied. Further Day/Night analyses would also improve catchability estimates and identify the extent of Atlantic mackerel avoidance from finer nets during day tows (Morse, 1989).

While catchability corrections increased abundances for 1932, catchability concerns remain for the Sette data given the 3.571 multiplier of extrusion is likely insufficient in scaling abundances of the $0.666 \mathrm{~mm}$ mesh. Further, these scalars are only effective for size classes of concern where abundance was greater than zero. In the example of extrusion, if zero larvae below $3 \mathrm{~mm}$ were caught during the MARMAP surveys $(0.505 \mathrm{~mm})$, then the catchability metrics are essentially nonexistent (given they are multiplied by zero). Given the limitations of the catchability corrections and lack of improvement in model fitting, observed abundances may be of better use in future stock assessments. Moving forward, to account for the differences in mesh size between MARMAP and EcoMon, these two periods should be treated separately in the stock assessment modeling, with each assigned its own catchability quotient $q$, as done with other abundance metrics (Deroba et al., 2010). 


\section{Estimating Life History Patterns}

Sette (1943) reported that over the first 50 days of life, southern contingent mackerel mortality was greatest during the developmental period at $10-14 \mathrm{~mm}$, but up to $30-34 \%$ per day from 8 to $10 \mathrm{~mm}$ during rapid fin development. In 1932, survival from spawned eggs to $50 \mathrm{~mm}$ fish was approximately 1 to 10 fish per million eggs spawned (Sette, 1943). Mortality rates for the northern contingent larvae have been reported at $42 \%$ per day, and positively related to temperature (Ware and Lambert, 1985). Observed and predicted mortality for Model Variant 2 suggested similar rates in the early larval ages ( 5-8 days) but with reduced mortality thereafter (Figures 7 , 10). Spawning patterns from the observed and predicted data used in Model Variant 2 corroborate with the reported periods of mid-May through mid-July (Berrien, 1988), except for the predicted spawning in late July/early August (Figures 8, 9, 11). The models assumed static mortality and spawning seasonality over time, which have likely varied interannually with temperature, predation, wind patterns and ocean circulation, and food availability. Further, while MARMAP and EcoMon sampling timing were assumed to be consistent through time, there is variability (Supplement 8).

\section{Larval Index Trends}

Atlantic mackerel larvae in the southern contingent appear to have been most abundant in 1932, the early 1980s and early 2000s. Larval records from 1932 provide the earliest account of Atlantic mackerel larvae in the southern contingent (Sette 1943). These data provide a unique opportunity to assess larval production prior to the foreign fleets harvest pressure in the 1970s and before the stock was significantly 
depleted (Anderson and Paciorkowski, 1980). While the larval index results indicate 1932 was the strongest year class of the time series, the coarse mesh used by Sette (1943) likely underestimated larval abundances, thus we presume the magnitude of the 1932 index is larger than the model predicts.

The peaks in the early 1980s and early 2000s correspond to documented strong recruitment years for the stock. Southern contingent peak years of 1980 and 1981 from the larval index may be representative of the strong recruitment observed in the northern contingent (Gulf of St. Lawrence) in 1982 (Ringuette et al., 2002), if recruitment patterns are consistent across the stock. Similarly, the larval index peaks in 2000-2002 may the result of strong spawning and recruitment for the southern contingent in the years prior; in the northern contingent, a strong year class was present in 1999 (Robert et al., 2007; Castonguay et al., 2008) with perhaps the same being true for the southern contingent. These strong year classes in the Gulf of St. Lawrence are believed to be driven by the dense prey availability, particularly copepod nauplii such as Calanus finmarchicus, decreasing larval mortality and increasing the number of larvae recruiting to the fishery (Runge et al., 1999; Castonguay et al., 2008).

Anecdotally, these strong recruitment years have also translated to responses from the fishery, as evidence in the increased landings in the early 2000s (DFO, 2014). However, there was no correlation between the larval index and landings (Table 3). Mackerel landings have been historically driven by non-biological factors, including the market for mackerel and evolution of fishing practices (Sette and Needler, 1934). 
Thus, it is not surprising that the larval abundance indices do not correlate well with landings.

Significant correlation between annual egg production, spawning stock biomass, and the larval index suggests that high AEP and SSB should result in strong years of larval production (Figure 17). The variability between larvae and egg indices could be due to larval extrusion and the change in mesh size through time. However, regardless of extrusion, breakdown of correlations between successive early life-stages through time can be caused due to variations in mortality, such as changes in predation or temperature. For example, Payne et al. (2009) found that survival from early to late life-stage North Sea herring larvae changed though time in the later $20^{\text {th }}$ century, with more recent years indicating high mortality rates, poor recruitment, and reduced correspondence between successive early-life stage abundance indices. The mortality rates from egg to larvae have likely varied interannually for southern contingent Atlantic mackerel, which also contributes to the observed relationship.

Lack of correspondence between the larval index and the NAO and AMO may be due to the lagged responses of the population to these climate oscillations not accounted for the in the correlations, or indicate mackerel larvae responses to the environment are related more to locally varying conditions than the larger, longer-term changes in the North Atlantic basin. Low correlation between temperature data and mackerel larval abundances may represent spatial or temporal mismatch between ichthyoplankton sampling and temperature-induced spawning.

The larval index appears to be a weak indicator of egg production or spawning stock biomass (Table 3). Without southern contingent information on recruitment, it is 
unclear whether the larval index serves as an adequate proxy for recruitment or age-1 biomass. While larval abundances have been considered a strong indicator for Atlantic mackerel recruitment in the Gulf of St. Lawrence (Runge et al., 1999; Ringuette et al., 2002; Castonguay et al., 2008) it remains unclear whether the same is true for the southern contingent, given relaible southern contingent recruitment information is currently unavailable. Recruitment information should be further constructed to assess the larval index's usage as a recruitment proxy in future stock assessments.

\section{ACKNOWLEDGEMENTS}

We thank all scientists and crew members that have helped in collecting the ichthyoplankton data used for these analyses over many decades. The authors thank K. Marancik for assistance with data compilation and quality assurance. Participants of the Atlantic Mackerel Stock Assessment Workshop/Stock Assessment Review Committee 64 Data Meeting provided insightful comments for this work. The views expressed in this work are those of the authors and do not necessarily reflect the views of their agencies.

\section{FUNDING}

MCM was funded by The Nature Conservancy Global Marine Initiative Student Research Award Program. Views expressed in this publication are those of the authors and do not necessarily reflect those of The Nature Conservancy.

\section{LITERATURE CITED}

Able, K.W., Sullivan, M.C., Hare, J.A., Bath-Martin, G., Taylor, J.C., and Hogan, R. 2011. Larval abundance of summer flounder (Paralichthys denatus) as a measure of recruitment and stock status. Fishery Bulletin 109: 68-78.

Bailey, K.M. 1982. The early life history of the Pacific hake, Merluccius productus. Fishery Bulletin, 80(3):589-598. 
Berrien, P. 1988. Atlantic mackerel, Scomber scombrus, total annual egg production and spawner biomass estimates for the Gulf of St. Lawrence and northeastern United States waters, 1987. NOAA Sandy Hook Laboratory Report, No. 88-02. $18 \mathrm{pp}$.

Banzon, V., Smith, T. M., Chin, T. M., Liu, C., and Hankins, W., 2016: A long-term record of blended satellite and in situ sea-surface temperature for climate monitoring, modeling and environmental studies. Earth Syst. Sci. Data, 8, 165176.

Bolker, B.M. 2008. Ecological Models and Data in R. Princeton University Press. Woodshire, UK. 396 pp.

Carter, L., and D. Richardson. 2017. Development of an egg index for Atlantic mackerel (Scomber scombrus) on the northeast U.S. continental shelf. SARC 64 Atlantic Mackerel Data Meeting Working Paper. 13 pp.

Deroba, J., Shepherd, G., Gregoire, F., Nieland, J., and Rago, P. (2010) Stock assessment of Atlantic mackerel in the Northwest Atlantic for 2010.Transboundary Resources Assessment Committee, Reference Document 2010/01. 59 pp.

Drinkwater, K.F., Belgrano, A., Borja, A., Conversi, A. et al. 2003. The response of marine ecosystems to climate variability associated with the North Atlantic Oscillation. In: Hurrell JW, Kushnir Y, Ottersen G, Visbeck M (eds) The North Atlantic Oscillation. American Geophysical Union, Washington, DC, p 211-234.

Enfield, D.B., A.M. Mestas-Nunez, and P.J. Trimble. 2001. The Atlantic Multidecadal Oscillation and its relationship to rainfall and river flows in the continental U.S., Geophys. Res. Lett., 28: 2077-2080.

Fournier, D.A., H.J Skaug, J. Ancheta et al. 2012. AD Model Builder: using automatic differentiation for statistical inference of highly parameterized complex nonlinear models. Optim. Methods. Softw. 27:233-249.

Glendhill, C.T. and Lyczkowski-Shultz, J. 2000. Indices of larval king mackerel (Scomberomorus cavalla) abundance in the Gulf of Mexico for use in population estimates. Fishery Bulletion, 98:684-691.

Hanisko, D.S., A. Pollack, G. Zapfe, and Ingram Jr., G.W. 2017. King mackerel (Scomberomorus cavalla) larval indices of relative abundance from SEAMAP fall plankton surveys in the Gulf of Mexico, 1986 to 2014. SCRS/2017/095. 32pp.

Hewit, R.P., G.H. Theilacker, and N.C.H. Lo. 1985. Causes of mortality in young jack mackerel. Marine Ecology Progress Series 26:1-10. 
Hunter, J.R., and Kimbrell, C.A. 1979. Early life history of Pacific mackerel, Scomber japonicus. Fishery Bulletin 78(1): 89-101.

Hurrell, J., and National Center for Atmospheric Research Staff (Eds.) 2017. The Climate Data Guide: Hurrell North Atlanitc Oscillation (NAO) Index (stationbased): https://climatedataguide.ucar.edu/climate-data/hurrell-north-atlanticoscillation-nao-index-station-based. Accessed 7 Jul 2017.

Jacobson L., A. Seaver, and J. Tang. 2011. AstroCalc4R: software to calculate solar zenith angle; time at sunrise, local noon and sunset; and photosynthetically available radiation based on date, time and location. US Dept Commer, Northeast Fish Sci Cent Ref Doc. 11-14; 10 p.

Johnson, D.J., and W.W. Morse. 1994. Net Extrusion of Larval Fish: Correction Factors for $0.333 \mathrm{~mm}$ Versus $0.505 \mathrm{~mm}$ Mesh Bongo Nets. NAFO Sci. Coun. Studies, 20: 85-92.

Lo, N.C.H. 2007. Daily larval production of Pacific hake (Merluccius productus) off California in 1951-2006. CalCOFI Rep. 48:147-164.

Lo, N.C.H., Y. Huang, and E. Dorval. 2009. Daily larval production of Pacific mackerel (Scomber japonicus) off California from 1951-2006. Appendix 3B in Pacific mackerel (Scomber japonicus) stock assessment for USA management in the 2009-10 fishing year (Crone, P. R., K. T. Hill, J. D. McDaniel, and N. C. H. Lo, eds.), p. 172-185. Pacific Fishery Management Council.

McManus, M.C., P. Licandro, and S.H. Coombs. Is the Russell Cycle a true cycle? Multidecadal zooplankton and climate trends in the western English Channel. ICES Journal of Marine Science 73(2): 227-238.

Methot Jr., R.D., and Wetzel, C.R. 2013. Stock synthesis: A biological and statistical framework for fish stock assessment and fishery management. Fisheries Research 142: 86-99.

Morse, W.W. 1989. Catchability, growth, and mortality of larval fishes. Fisheries Bulletin 87: 417-446.

Nye, J.A., Link, J.S., Hare, J.A., Overholtz, W.J. 2009. Changing spatial distribution of fish stocks in relation to climate and population size on the Northeast United States continental shelf. Mar. Ecol. Prog. Ser. 393, 111-129.

Nye, J.A., Baker, M.R., Bell, R., Kenny, A., Kilbourne, K.H., Friedland, K.D., Martino, E., Stachura, M.M., Van Houtan, K.S., and Wood, R. 2014. Ecosystem effects of the Atlantic Multidecadal Oscillation. Journal of Marine Systems 133: 103-116. 
Payne, M.R., Hatfield, E.M., Dickey-Collas M., Falkenhaug T., Gallego A., Gröger J., Licandro P., Llope M., Munk P., and Röckmann, C. (2009) Recruitment in a changing environment: the 2000s North Sea herring recruitment failure. ICES Journal of Marine Science: Journal du Conseil 66:272-277.

Richardson, D.E., J.A. Hare, W.J. Overholtz, and D.L. Johnson. 2010. Development of long-term larval indices for Atlantic herring (Clupea harengus) on the northeast US continental shelf. ICES Journal of Marine Science: Journal du Conseil 67:617-627.

Richardson, D.E., K. Marancik, and H. Walsh. 2014. A larval index for Georges Bank yellowtail flounder with comparisons of relative larval production between yellowtail flounder stock areas. Transboundary Resource Assessment Committee 2014/19: 1-9.

Robert, D., Castonguay, M., Fortier L. 2007. Early growth and recruitment in Atlantic mackerel: discriminating the effects of fast growth and selection for fast growth. Marine Ecology Progress Series 337: 209-219.

Ringuette M, Castonguay M, Runge JA, Grégoire F (2002) Atlantic mackerel (Scomber scombrus) recruitment fluctuations in relation to copepod production and juvenile growth. Can J Fish Aquat Sci 59:646-656.

Runge JA, Castonguay M, de Lafontaine Y, Ringuette M, Beaulieu JL (1999) Covariation in climate, zooplankton biomass and mackerel recruitment in the southern Gulf of St Lawrence. Fish Oceanogr 8:139-149.

Sette, O.E. (1943) Biology of the Atlantic mackerel (Scomber scombrus) of North America. Part I. Early Life history, including growth, drift, and mortality of egg and larval populations. U.S. Fish and Wildlife Service Fishery Bulletin 50: 149237.

Sette, O.E. (1950) Biology of the Atlantic mackerel (Scomber scombrus) of North America. Part II. Migrations and habitat. U.S. Fish and Wildlife Service Fishery Bulletin 51: 251-358.

Simard, P. M. Castonguay, D. D’Amours, and P. Magnan. 1992. Growth comparison between juvenile Atlantic mackerel (Scomber scombrus) for the two spawning groups in the Northwest Atlantic. Canadian Journal of Fisheries and Aquatic Sciences, 49: 2242-2248.

Simpson, C.A., M.J. Wilberg, H. Bi, A.M. Schueller, G.M. Nesslage, and H.J. Walsh. 2016. Trends in relative abundance and early life survival of Atlantic menhaden during 1977-2013 from long-term ichthyoplankton programs. Transactions of the American Fisheries Society, 145(5): 1139-1151. 
Taylor, C.C., Bigelow, H.B., and Graham, H.W. 1957. Climatic trends and the distribution of marine animals in New England. Fishery Bulletin 115(57): 293345 .

Ware, D.M., and T.C. Lambert. 1985. Early life history of Atlantic mackerel (Scomber scombrus) in the southern Gulf of St. Lawrence. Canadian Journal of Fisheries and Aquatic Sciences, 42: 577-592.

Weber E.D., and S. McClatchie. 2012. Effect of environmental conditions on the distribution of Pacific mackerel (Scomber japonicus) larvae in the California Current system. Fishery Bulletin 110:85-97.

Wiedenmann, J. (2016). Application of a data-poor harvest control rules to Atlantic mackerel. Southeast Data, Assessment, and Review, Report \# SEDAR46-RD-09. 53pp. 
Table 1. Model Variants run the larval index calculations with observed and catchability-scaled abundances. Dashes (-) indicate that field is not applicable to the Model Variant. Bold values indicate life history parameters were not estimated at their bounds.

\begin{tabular}{|c|c|c|c|c|c|c|c|c|}
\hline $\begin{array}{c}\text { Model } \\
\text { Variant } \\
\text { Number } \\
\end{array}$ & Description & Method & Data Level & Abundance & $h$ Constant & $\begin{array}{c}\text { Error } \\
\text { Distribution }\end{array}$ & $\begin{array}{l}\text { MGVs (Obs., } \\
\text { Catch Corr) }\end{array}$ & $\mathrm{AICc}$ \\
\hline 1 & $\begin{array}{l}\text { Abundance square-rooted, fit with } \\
\text { a normal error distribution. }\end{array}$ & $\begin{array}{l}\text { Richardson } e t \\
\text { al.. (2010) }\end{array}$ & Survey & $\sqrt{N}$ & - & Normal & 2.5E-4, 7.6E-4 & 1208,2494 \\
\hline 2 & $\begin{array}{l}\text { Abundance square-rooted, fit with } \\
\text { a normal error distribution and } \\
\text { holding the second morality } \\
\text { parameter (h) fixed. }\end{array}$ & $\begin{array}{l}\text { Richardson et } \\
\text { al.. (2010) }\end{array}$ & Survey & $\sqrt{N}$ & 1.044 & Normal & 5.9E-6, 1.8E-4 & 1208,2692 \\
\hline 3 & $\begin{array}{l}\text { Abundance fit with a log normal } \\
\text { error distribution }\end{array}$ & $\begin{array}{c}\text { Richardson } e t \\
\text { al.. (2010) }\end{array}$ & Survey & $N$ & - & Log-normal & $0.002,0.001$ & 1658,1772 \\
\hline 4 & $\begin{array}{l}\text { Abundance square-rooted, fit with } \\
\text { a log normal error distribution. }\end{array}$ & $\begin{array}{l}\text { Richardson et } \\
\text { al.. (2010) }\end{array}$ & Survey & $\sqrt{N}$ & - & Log-normal & 8.5E-5, 2.9E-4 & 16541704 \\
\hline 5 & $\begin{array}{l}\text { Abundance square-rooted, fit with } \\
\text { a log normal error distribution } \\
\text { and holding the second morality } \\
\text { parameter (h) fixed. }\end{array}$ & $\begin{array}{l}\text { Richardson et } \\
\text { al.. (2010) }\end{array}$ & Survey & $\sqrt{N}$ & 1.044 & Log-normal & $9.2 \mathrm{E}-5,8.6 \mathrm{E}-6$ & 1729,1779 \\
\hline 6 & $\begin{array}{l}\text { Abundance square-rooted, fit with } \\
\text { a normal error distribution }\end{array}$ & $\begin{array}{l}\text { Richardson et } \\
\text { al.. (2010) }\end{array}$ & Sample & $\sqrt{N}$ & - & Normal & $0.017,0.012$ & $\begin{array}{l}158485 \\
248632\end{array}$ \\
\hline 7 & $\begin{array}{l}\text { Abundance square-rooted, fit with } \\
\text { a log-normal error distribution } \\
\text { and holding the second morality } \\
\text { parameter (h) fixed. }\end{array}$ & $\begin{array}{l}\text { Richardson et } \\
\text { al.. (2010) }\end{array}$ & Sample & $\sqrt{N}$ & 1.044 & Normal & $0.002,0.006$ & $\begin{array}{l}158833 \\
249234\end{array}$ \\
\hline 8 & $\begin{array}{l}\text { Abundance square-rooted, fit with } \\
\text { a log-normal error distribution. }\end{array}$ & $\begin{array}{l}\text { Richardson } e t \\
\text { al.. (2010) }\end{array}$ & Sample & $\sqrt{N}$ & - & Log-Normal & $0.002,0.001$ & 12552,13254 \\
\hline 9 & $\begin{array}{l}\text { Abundance square-rooted, fit with } \\
\text { a log-normal error distribution } \\
\text { and holding the second morality } \\
\text { parameter (h) fixed. }\end{array}$ & $\begin{array}{l}\text { Richardson et } \\
\text { al.. (2010) }\end{array}$ & Sample & $\sqrt{N}$ & 1.044 & Log-Normal & 4.8E-4, 0.002 & 12673,13367 \\
\hline $\mathrm{LI}_{\mathrm{A} 1}$ & Mean abundances by Year & NA & $\begin{array}{l}\text { Sample and } \\
\text { Survey }\end{array}$ & $N$ & - & - & - & \\
\hline
\end{tabular}




\begin{tabular}{|c|c|c|c|c|c|c|c|}
\hline $\mathrm{LI}_{\mathrm{A} 2}$ & $\begin{array}{l}\text { Mean abundances, scaled to } 5 \\
\text { day-old equivalencies, by Year }\end{array}$ & $\begin{array}{c}\text { Gledhill and } \\
\text { Lyczhowski } \\
\text { (2000) }\end{array}$ & $\begin{array}{l}\text { Sample and } \\
\text { Survey }\end{array}$ & $N$ & - & - & - \\
\hline $\mathrm{LI}_{\mathrm{A} 3}$ & $\begin{array}{l}\text { Integrated predicted abundances } \\
\text { with a delta model approach }\end{array}$ & $\begin{array}{l}\text { Hanisko et al.. } \\
\text { (2017) }\end{array}$ & $\begin{array}{l}\text { Sample and } \\
\text { Survey }\end{array}$ & $N$ & - & - & - \\
\hline
\end{tabular}


Table 2. Multiple $\mathrm{R}^{2}$ values for correlations between Model Variants constructed using the Richardson et al. (2010) method and the alternative methods: mean abundances by year $\left(\mathrm{LI}_{\mathrm{A} 1}\right)$, abundances corrected for age using mortality function $\left(\mathrm{LI}_{\mathrm{A} 2}\right)$, and abundances corrected for age using mortality function and spawning seasonality with the hurdle model approach $\left(\mathrm{LI}_{\mathrm{A} 3}\right)$. Bold values indicate $\mathrm{p}$-values $<0.05$.

\begin{tabular}{llll}
\multicolumn{1}{c}{ Model Type } & $\mathrm{LI}_{\mathrm{A} 1}$ & $\mathrm{LI}_{\mathrm{A} 2}$ & $\mathrm{LI}_{\mathrm{A} 3}$ \\
\hline Model Variant 2 - Observed & $\mathbf{0 . 3 5}$ & $\mathbf{0 . 5 1}$ & $\mathbf{0 . 3 3}$ \\
Model Variant 2 - Catchability & $\mathbf{0 . 6 1}$ & $\mathbf{0 . 7 0}$ & $\mathbf{0 . 2 6}$ \\
Model Variant 5 - Observed & 0.05 & $\mathbf{0 . 3 0}$ & $\mathbf{0 . 2 7}$ \\
Model Variant 5 - Catchability & 0.01 & $\mathbf{0 . 5 0}$ & $\mathbf{0 . 2 5}$ \\
Model Variant 9 - Observed & $\mathbf{0 . 4 3}$ & $\mathbf{0 . 5 2}$ & $\mathbf{0 . 5 3}$ \\
Model Variant 9 - Catchability & $\mathbf{0 . 6 3}$ & $\mathbf{0 . 8 0}$ & $\mathbf{0 . 5 8}$
\end{tabular}


Table 3. Multiple $\mathrm{R}^{2}$ values for correlations between Model Variant 2 and various population indicators and environmental conditions. Bold values indicate $\mathrm{p}$-values $<0.05$.

\begin{tabular}{lcc}
\multicolumn{1}{c}{ Data Source } & $\begin{array}{c}\text { Model Variant 2 } \\
\text { Observed }\end{array}$ & $\begin{array}{c}\text { Model Variant 2 - } \\
\text { Catchability }\end{array}$ \\
\hline Population & & 0.04 \\
Total Landings & $\mathbf{0 . 2 6}$ & 0.18 \\
$\log _{10}$ (Annual Egg Production) & $\mathbf{0 . 2 5}$ & 0.17 \\
$\log _{10}$ (Spawning Stock Biomass) & & 0.003 \\
Environmental & $4 \mathrm{E}-4$ & 0.01 \\
Sea Surface Temperature & 0.02 & 0.04 \\
North Atlantic Oscillation & 0.006 &
\end{tabular}


Table 4. Mean annual abundances $\left(\# 10 \mathrm{~m}^{-2}\right)$ by year and daily age class from the data as used in the Survey-level analyses.

\begin{tabular}{l|ccccccccccccc} 
Year & \multicolumn{1}{c}{ Age (days) } \\
& 5 & 6 & 7 & 8 & 9 & 10 & 11 & 12 & 13 & 14 & 15 & 16 & 17 \\
\hline 1932 & 249.3 & 0.0 & 86.9 & 31.3 & 12.4 & 5.7 & 3.8 & 1.5 & 0.3 & 0.1 & 0.1 & 0.1 & 0.0 \\
1977 & 2.0 & 1.4 & 0.5 & 0.3 & 0.2 & 0.3 & 0.2 & 0.1 & 0.0 & 0.0 & 0.0 & 0.0 & 0.0 \\
1978 & 0.0 & 0.0 & 0.1 & 0.1 & 0.1 & 0.1 & 0.3 & 0.1 & 0.0 & 0.0 & 0.0 & 0.0 & 0.0 \\
1979 & 1.7 & 0.3 & 0.2 & 0.0 & 0.0 & 0.0 & 0.0 & 0.0 & 0.0 & 0.0 & 0.0 & 0.0 & 0.0 \\
1980 & 19.0 & 12.1 & 13.2 & 11.2 & 5.3 & 2.0 & 0.5 & 0.1 & 0.4 & 0.0 & 0.0 & 0.0 & 0.0 \\
1981 & 11.9 & 7.9 & 4.7 & 1.9 & 1.0 & 1.8 & 0.6 & 0.3 & 0.0 & 0.0 & 0.0 & 0.0 & 0.0 \\
1982 & 0.4 & 0.3 & 1.1 & 0.7 & 0.8 & 0.9 & 0.2 & 0.2 & 0.2 & 0.0 & 0.0 & 0.0 & 0.0 \\
1983 & 0.9 & 0.4 & 1.5 & 0.9 & 0.8 & 0.3 & 0.1 & 0.0 & 0.0 & 0.0 & 0.0 & 0.0 & 0.0 \\
1984 & 0.3 & 0.2 & 0.2 & 0.1 & 0.1 & 0.1 & 0.0 & 0.0 & 0.0 & 0.0 & 0.0 & 0.0 & 0.0 \\
1985 & 0.1 & 0.0 & 0.0 & 0.0 & 0.0 & 0.0 & 0.0 & 0.0 & 0.0 & 0.0 & 0.0 & 0.0 & 0.0 \\
1986 & 0.4 & 0.4 & 0.4 & 0.2 & 0.1 & 0.0 & 0.0 & 0.0 & 0.0 & 0.0 & 0.0 & 0.0 & 0.0 \\
1987 & 0.6 & 0.5 & 1.6 & 0.6 & 0.2 & 0.1 & 0.1 & 0.0 & 0.0 & 0.0 & 0.0 & 0.0 & 0.0 \\
2000 & 17.6 & 11.3 & 9.5 & 5.2 & 1.5 & 0.3 & 0.0 & 0.1 & 0.0 & 0.0 & 0.0 & 0.0 & 0.0 \\
2001 & 7.5 & 4.1 & 11.3 & 11.7 & 7.0 & 3.2 & 0.6 & 0.5 & 0.3 & 0.3 & 0.2 & 0.1 & 0.0 \\
2002 & 9.3 & 6.5 & 5.7 & 3.4 & 0.8 & 1.1 & 1.4 & 0.8 & 0.2 & 0.1 & 0.0 & 0.0 & 0.0 \\
2004 & 1.4 & 1.1 & 3.8 & 4.1 & 1.9 & 1.3 & 0.7 & 0.3 & 0.0 & 0.0 & 0.0 & 0.0 & 0.0 \\
2005 & 1.0 & 0.1 & 0.0 & 0.0 & 0.0 & 0.1 & 0.0 & 0.0 & 0.0 & 0.0 & 0.0 & 0.0 & 0.0 \\
2006 & 0.5 & 0.0 & 0.0 & 0.0 & 0.0 & 0.0 & 0.0 & 0.0 & 0.0 & 0.0 & 0.0 & 0.0 & 0.0 \\
2007 & 0.1 & 0.0 & 0.0 & 0.0 & 0.0 & 0.0 & 0.0 & 0.0 & 0.0 & 0.0 & 0.0 & 0.0 & 0.0 \\
2009 & 0.1 & 0.0 & 0.0 & 0.0 & 0.0 & 0.0 & 0.0 & 0.0 & 0.0 & 0.0 & 0.0 & 0.0 & 0.0 \\
2010 & 0.9 & 0.2 & 0.3 & 0.2 & 0.1 & 0.0 & 0.0 & 0.0 & 0.0 & 0.0 & 0.0 & 0.0 & 0.0 \\
2011 & 0.0 & 0.0 & 0.0 & 0.0 & 0.0 & 0.0 & 0.0 & 0.0 & 0.0 & 0.0 & 0.0 & 0.0 & 0.0 \\
2012 & 0.0 & 0.0 & 0.0 & 0.0 & 0.0 & 0.0 & 0.0 & 0.0 & 0.0 & 0.0 & 0.0 & 0.0 & 0.0 \\
2013 & 10.0 & 2.8 & 0.3 & 0.9 & 0.3 & 0.0 & 0.3 & 0.0 & 0.0 & 0.0 & 0.0 & 0.0 & 0.0 \\
2015 & 0.5 & 0.1 & 0.0 & 0.0 & 0.0 & 0.0 & 0.0 & 0.0 & 0.0 & 0.0 & 0.0 & 0.0 & 0.0 \\
2016 & 11.7 & 4.1 & 2.9 & 0.6 & 0.3 & 0.0 & 0.0 & 0.0 & 0.0 & 0.0 & 0.0 & 0.0 & 0.0
\end{tabular}




\section{FIGURES}

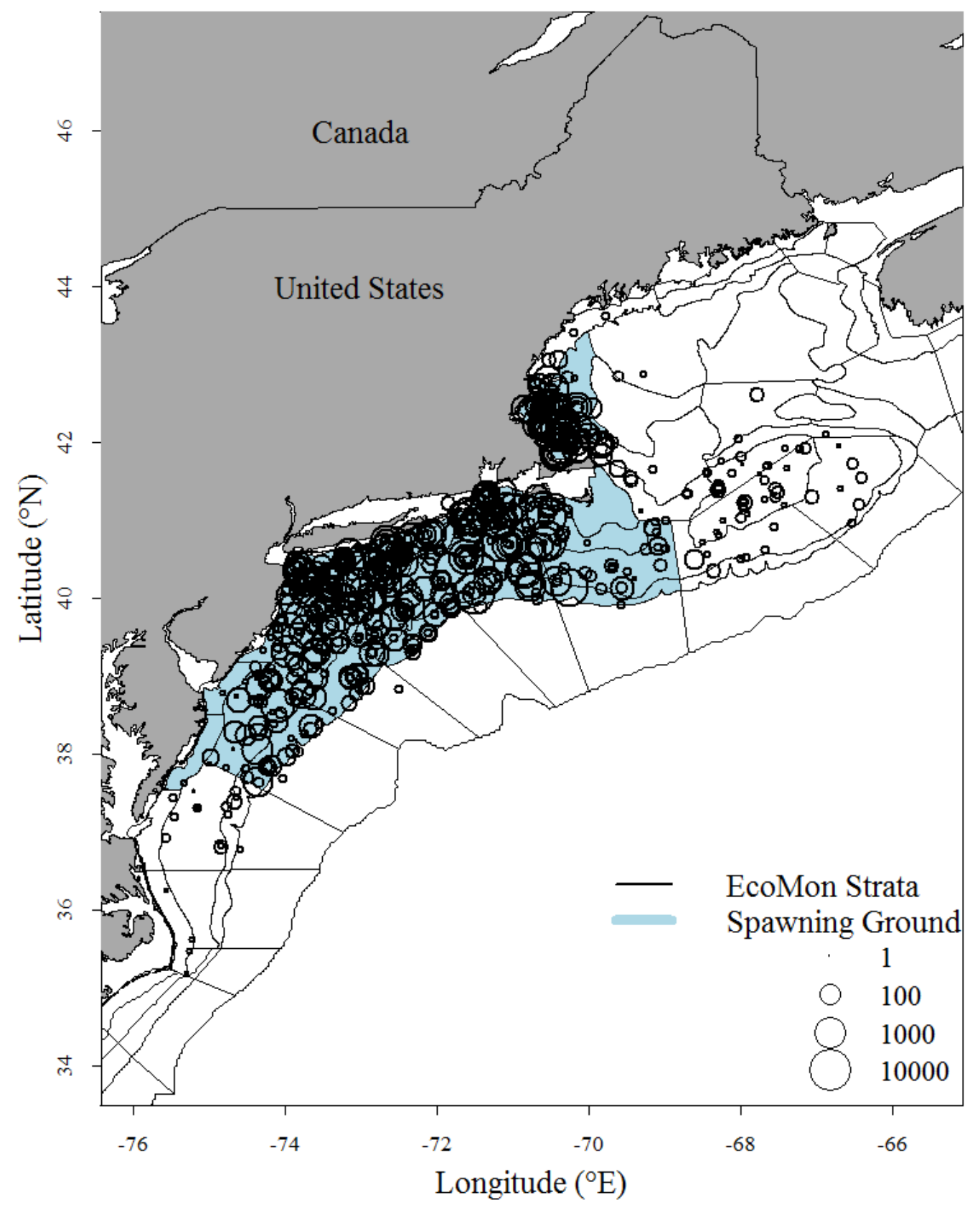

Figure 1. NOAA EcoMon and MARMAP strata sampled over the Northeast U.S. Continental Shelf for ichthyoplankton. Strata covering traditional Atlantic mackerel spawning grounds are designated in light blue. Circles represent EcoMon and MARMAP stations that caught Atlantic mackerel larvae. Circles are scaled relative to abundance $\left(\# 10 \mathrm{~m}^{-2}\right)$. 

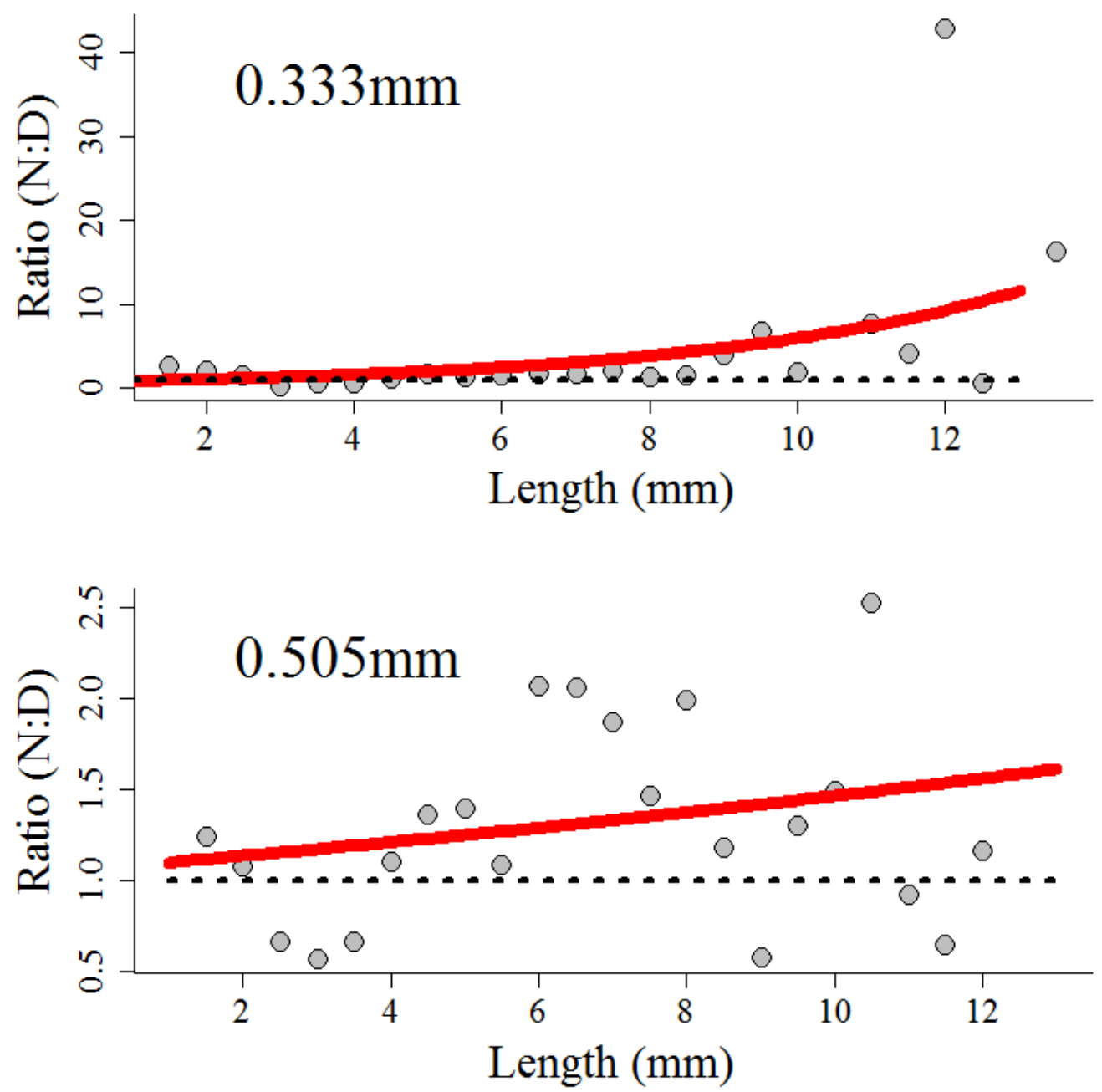

Figure 2. Avoidance models based on Night:Day (N:D) catch ratios for the EcoMon $(0.333 \mathrm{~mm}$ mesh) and MARMAP $(0.505 \mathrm{~mm}$ mesh $)$ data using an exponential function (red lines). Parameters used for the models $(\alpha, \beta)$ are the mean values over the 1000 bootstrapped runs. 


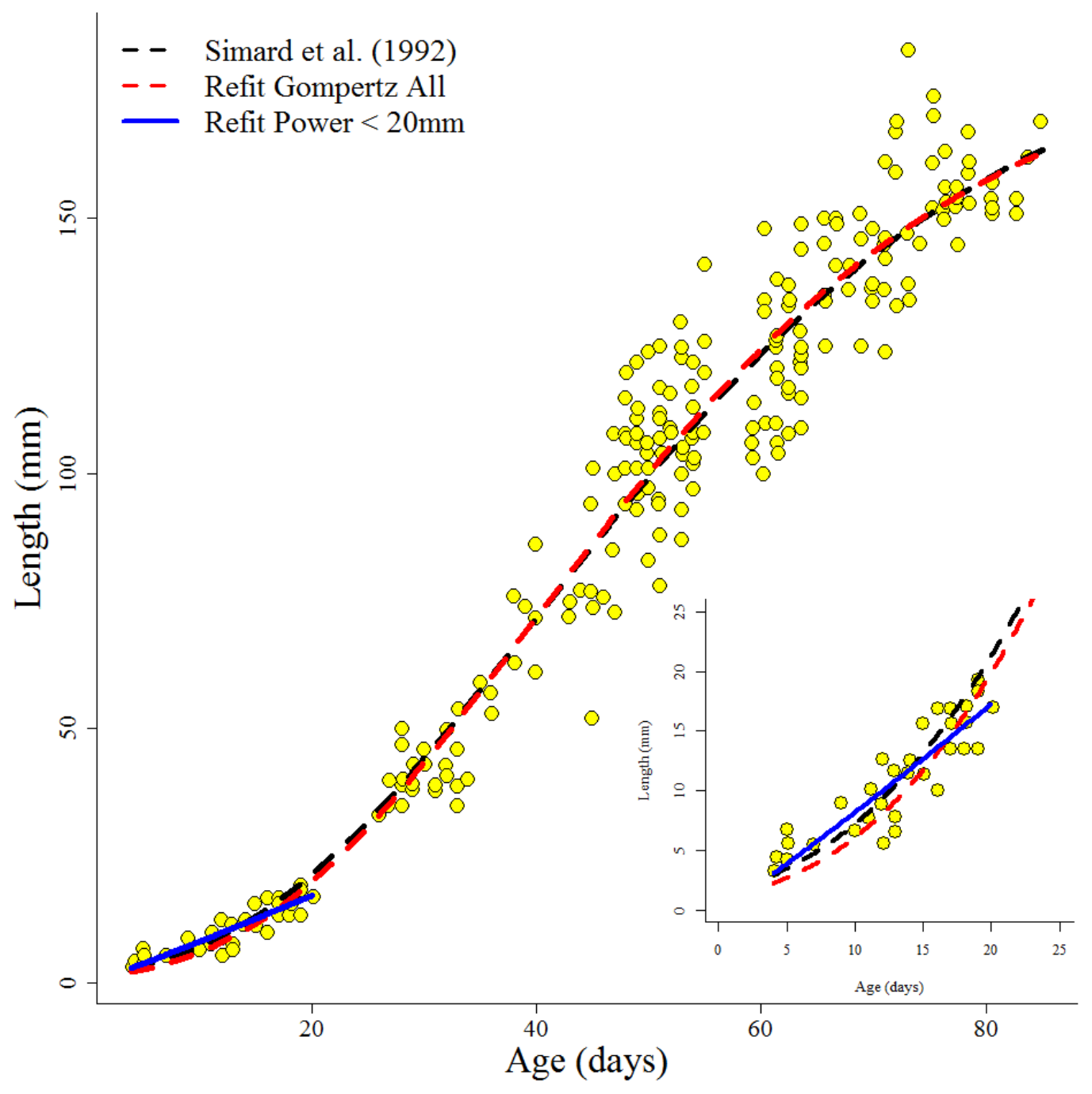

Figure 3. Growth data for Atlantic mackerel from Cape Hatteras to Cape Cod (Simard et al., 1992). Model fits are presented using a Gompertz function and coefficients presented in Simard et al., (1992) (black, dashed), refitting the extracted data with a Gompertz function in ADMB (red, dashed) and using a power function in ADMB on larvae $<20 \mathrm{~mm}$, corresponding to the size range represented in the NOAA Plankton and Sette datasets (blue, solid). Insert figure has smaller ages and lengths relevant to size and age ranges for Atlantic mackerel larvae examined in this study. 

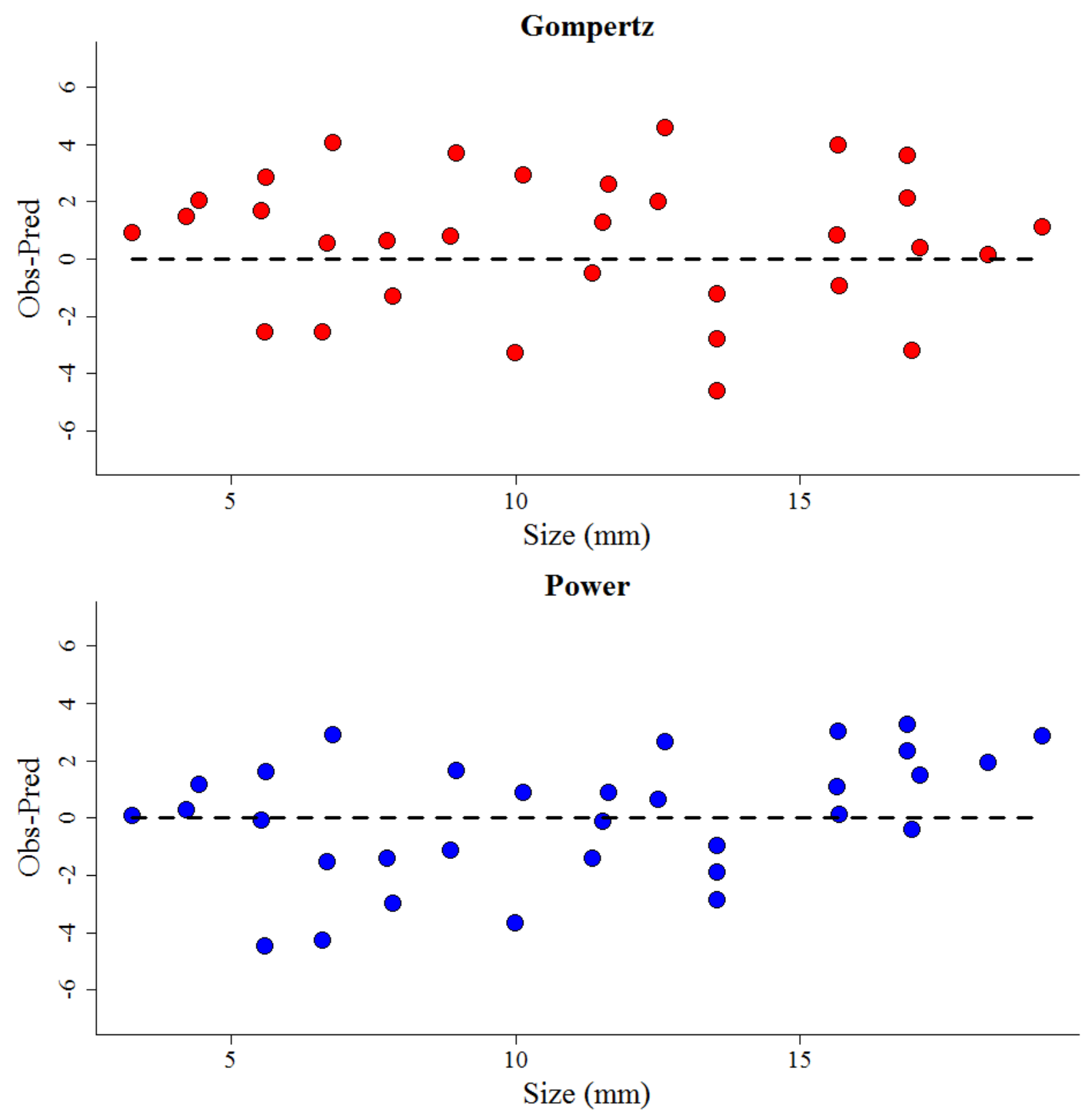

Figure 4. Gompertz and Power growth model residuals (observed-predicted) from ADMB fits by mackerel size $(\mathrm{mm})$. Larval sizes $<20 \mathrm{~mm}$ are presented for direct comparisons between the two models. 

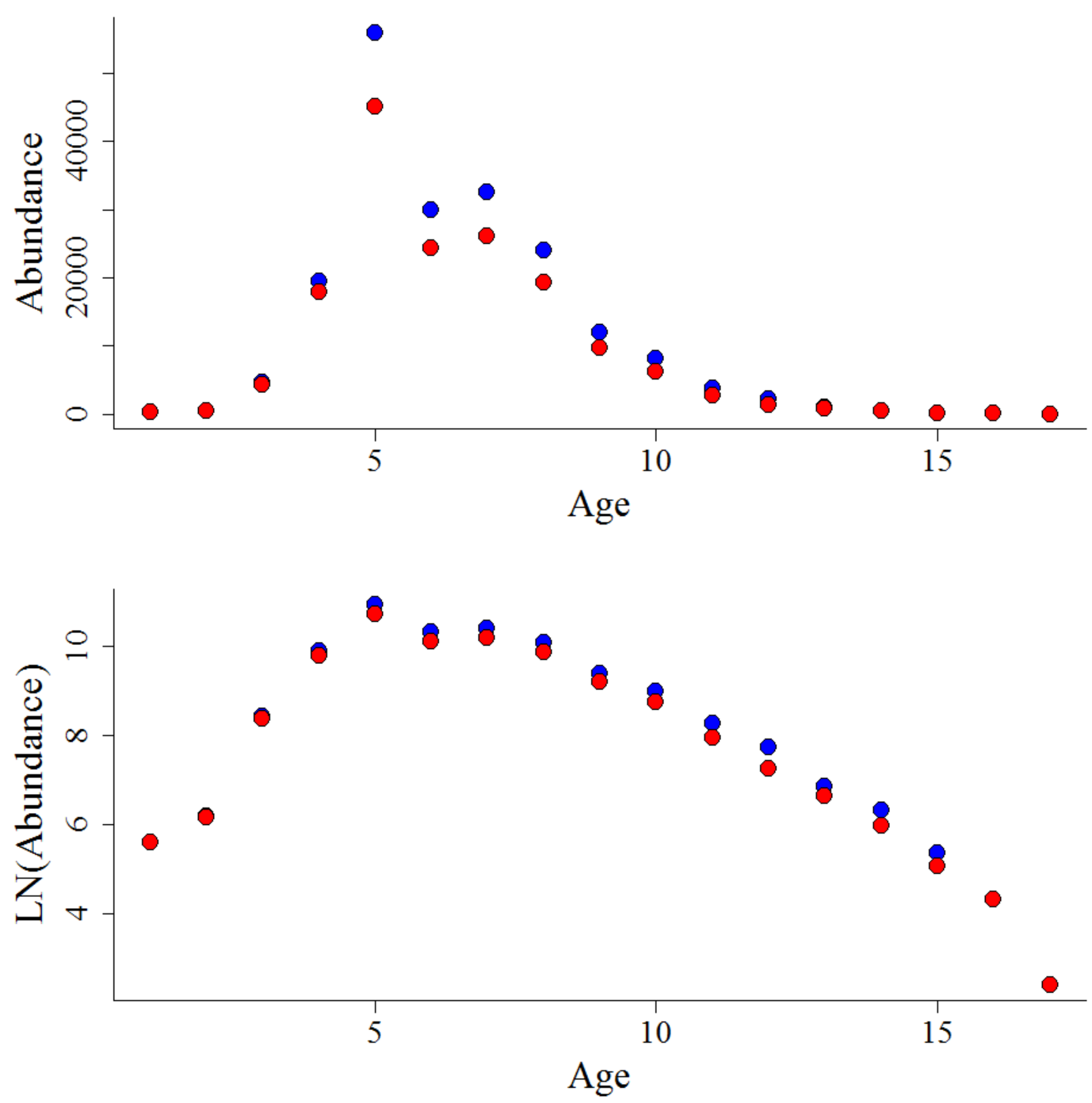

Figure 5. Abundances-by-age (\# 10m²) over all EcoMon and MARMAP samples. Observed (red) and catchability-corrected (blue) abundances are presented (top), with natural log transformations also provided (bottom). 


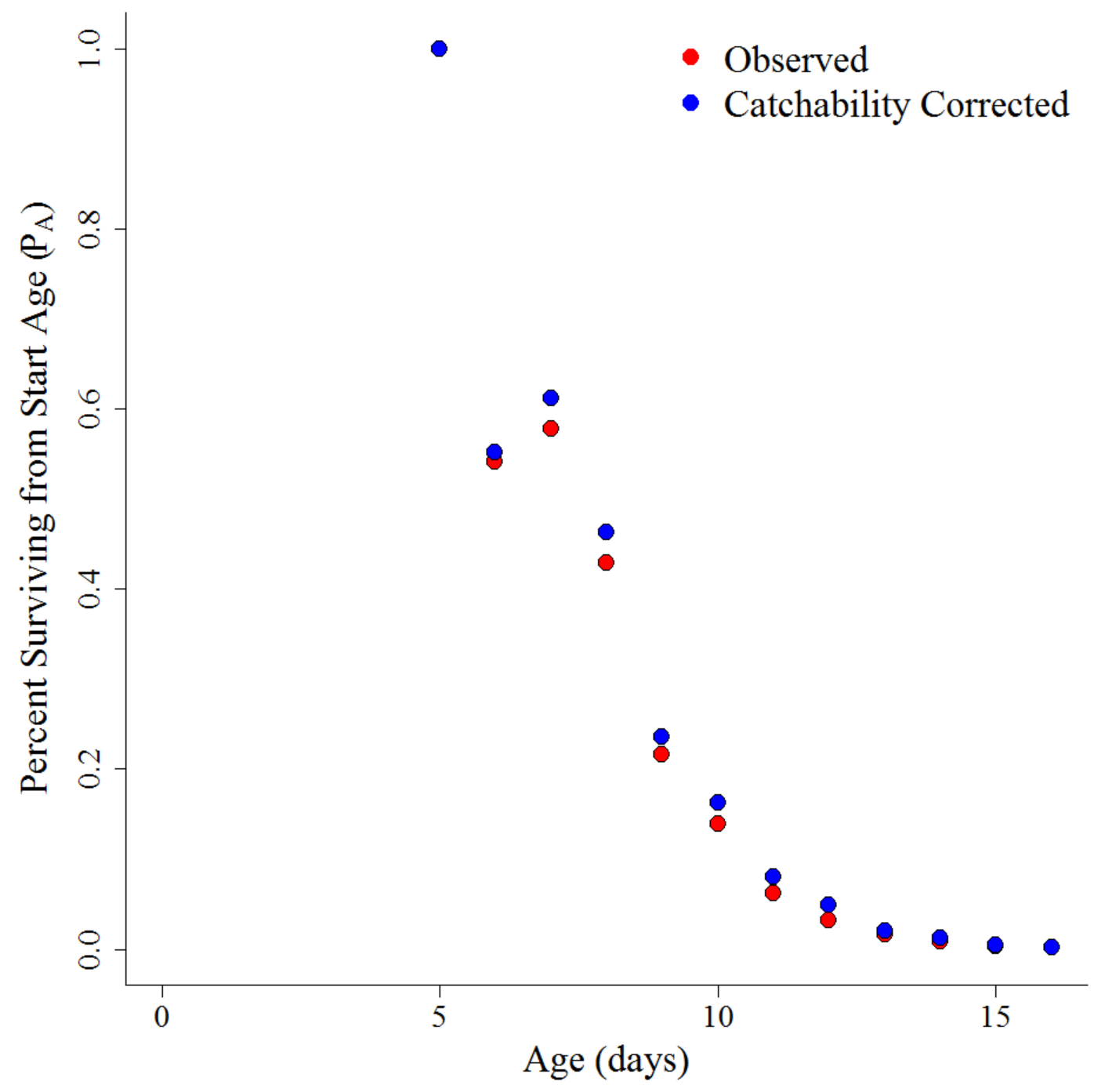

Figure 6. Proportion of larvae surviving from 5 days old using observed (red) and catchability-corrected (blue) data. 


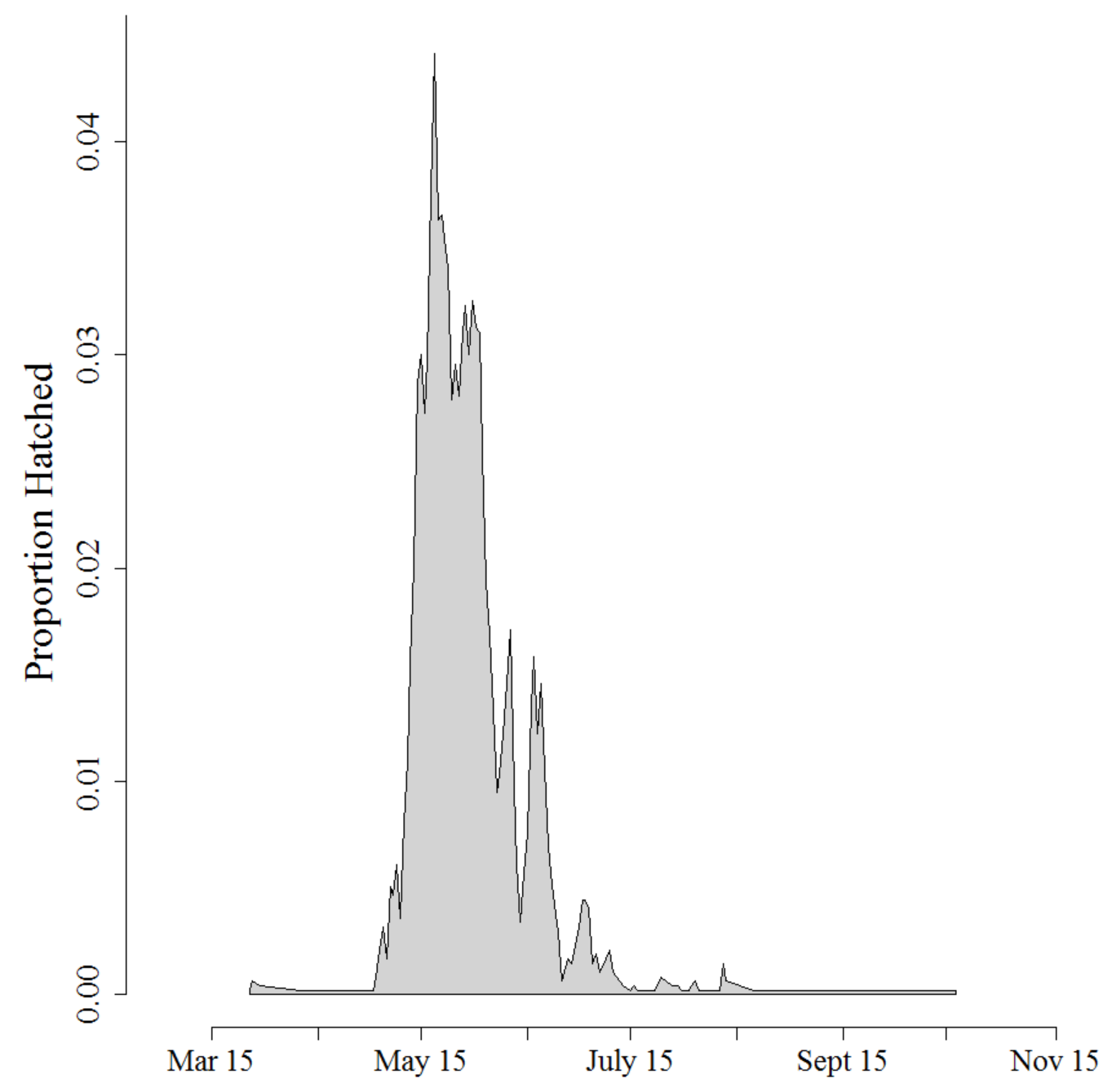

Figure 7. Proportion of all hatch days for all larvae collected from EcoMon and MARMAP samples. Hatch days were estimated as the age of a larvae subtracted from the day of year the sample was collected. 


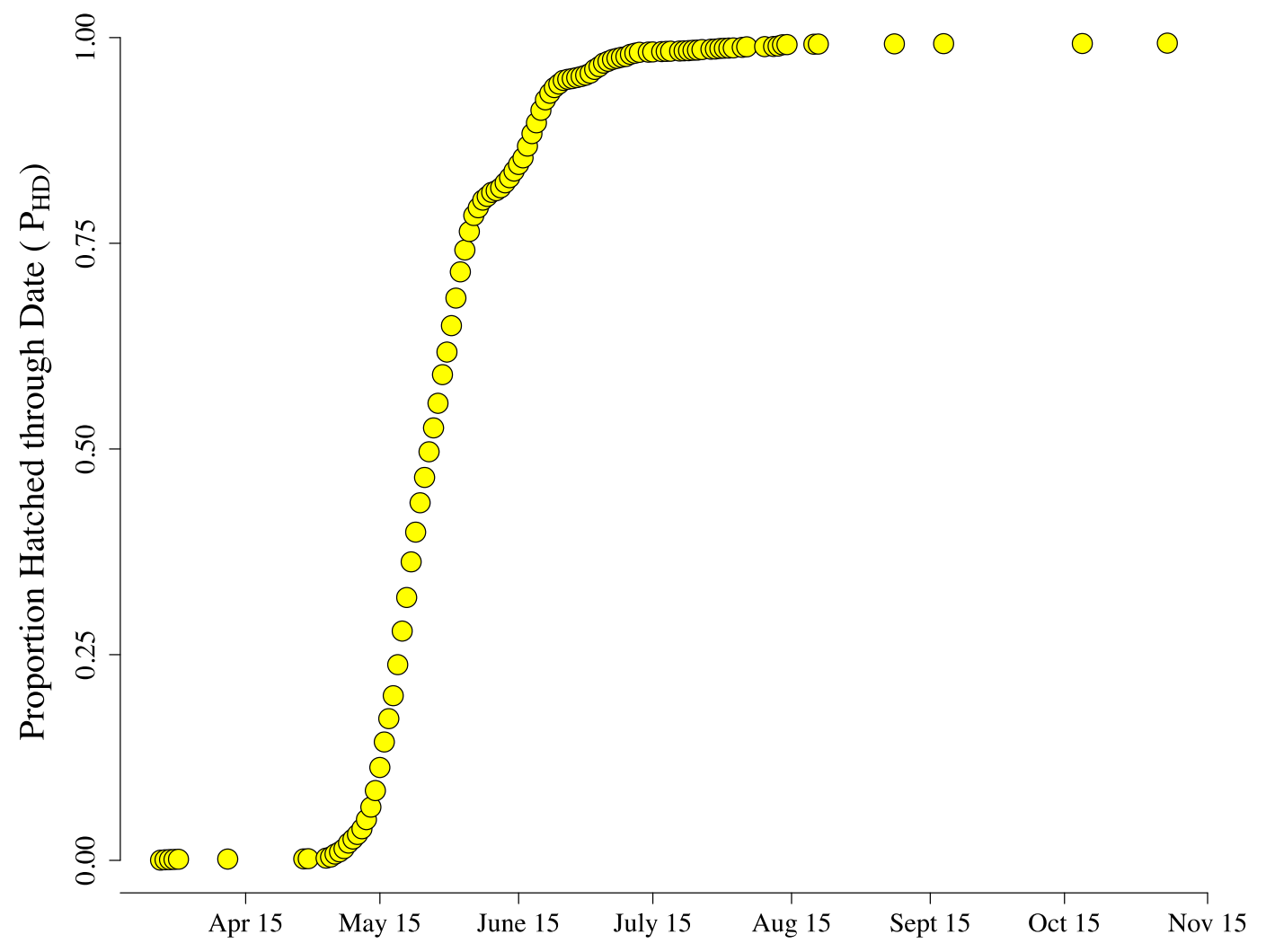

Figure 8. Proportion of southern contingent larvae hatching through the year. 

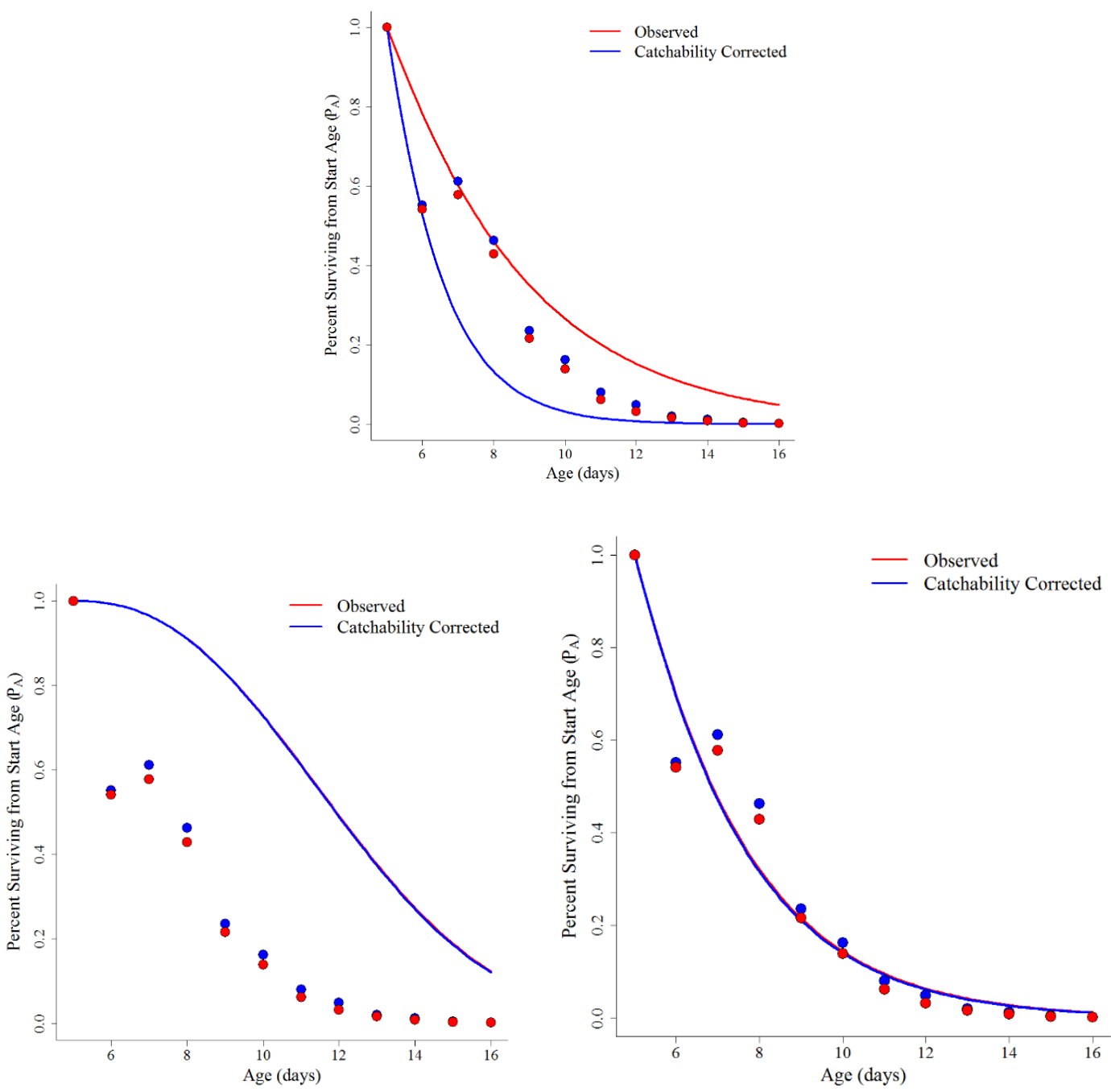

Figure 9. Mortality curves estimated during larval index calculations for Model Variants 2 (top), 4 (bottom left), and 5 (bottom right). Model Variants are described in Table 1. Points represent original data, as expressed in Figure 6. 

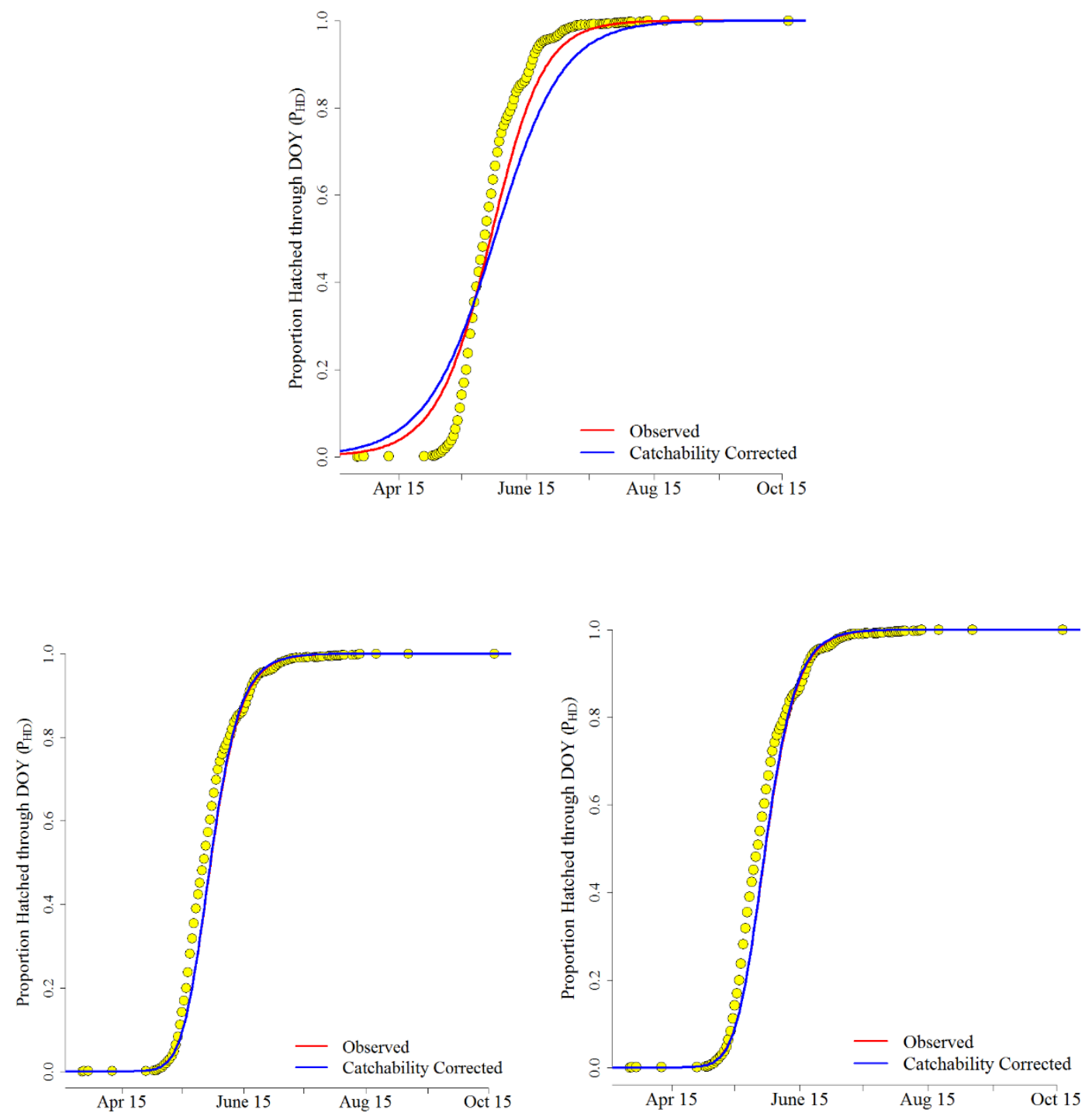

Figure 10. Spawning seasonality estimated during larval index calculations for Model Variants 2 (top), 4 (bottom left), and 5 (bottom right). Model Variants are described in Table 1. Points represent original data, as expressed in Figure 8. 

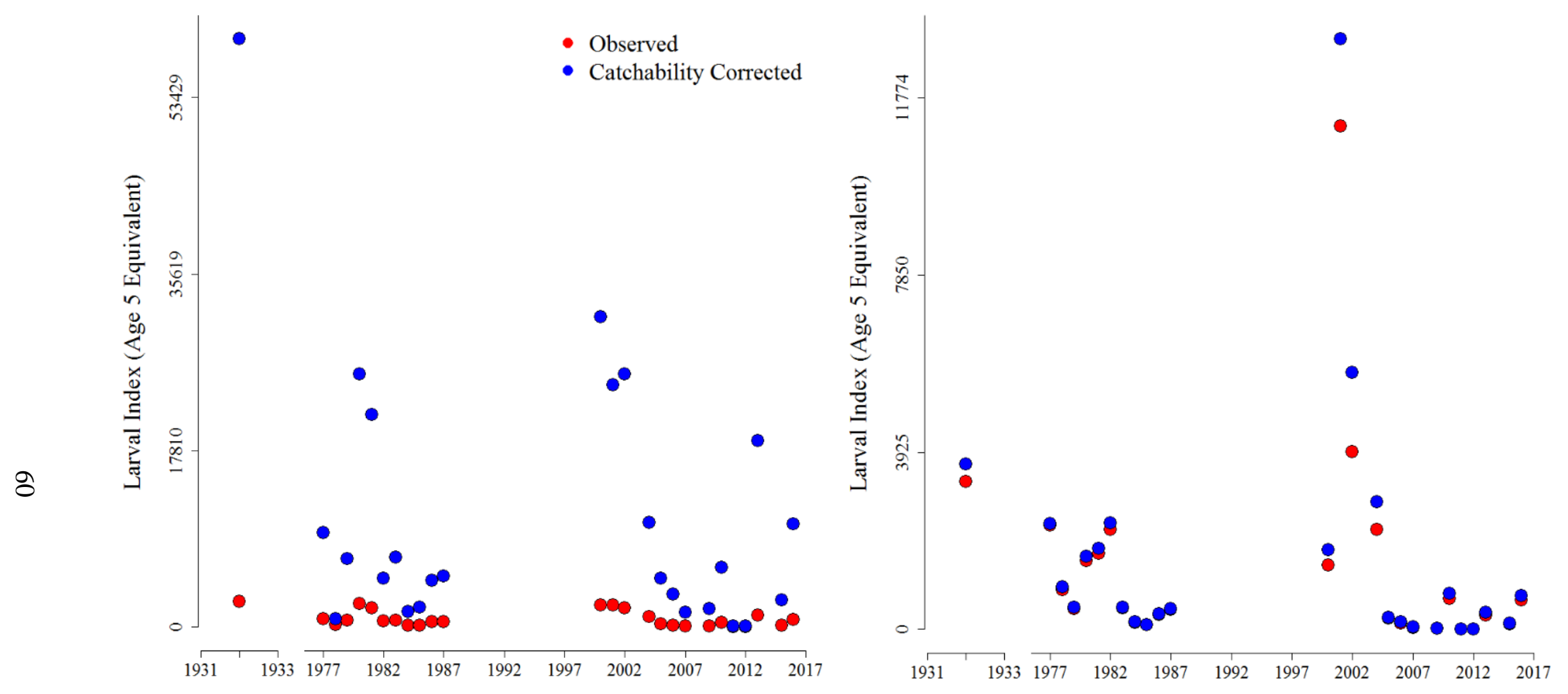

Figure 11. Larval indices produced under Model Variants 2 (left) and 5 (right). 

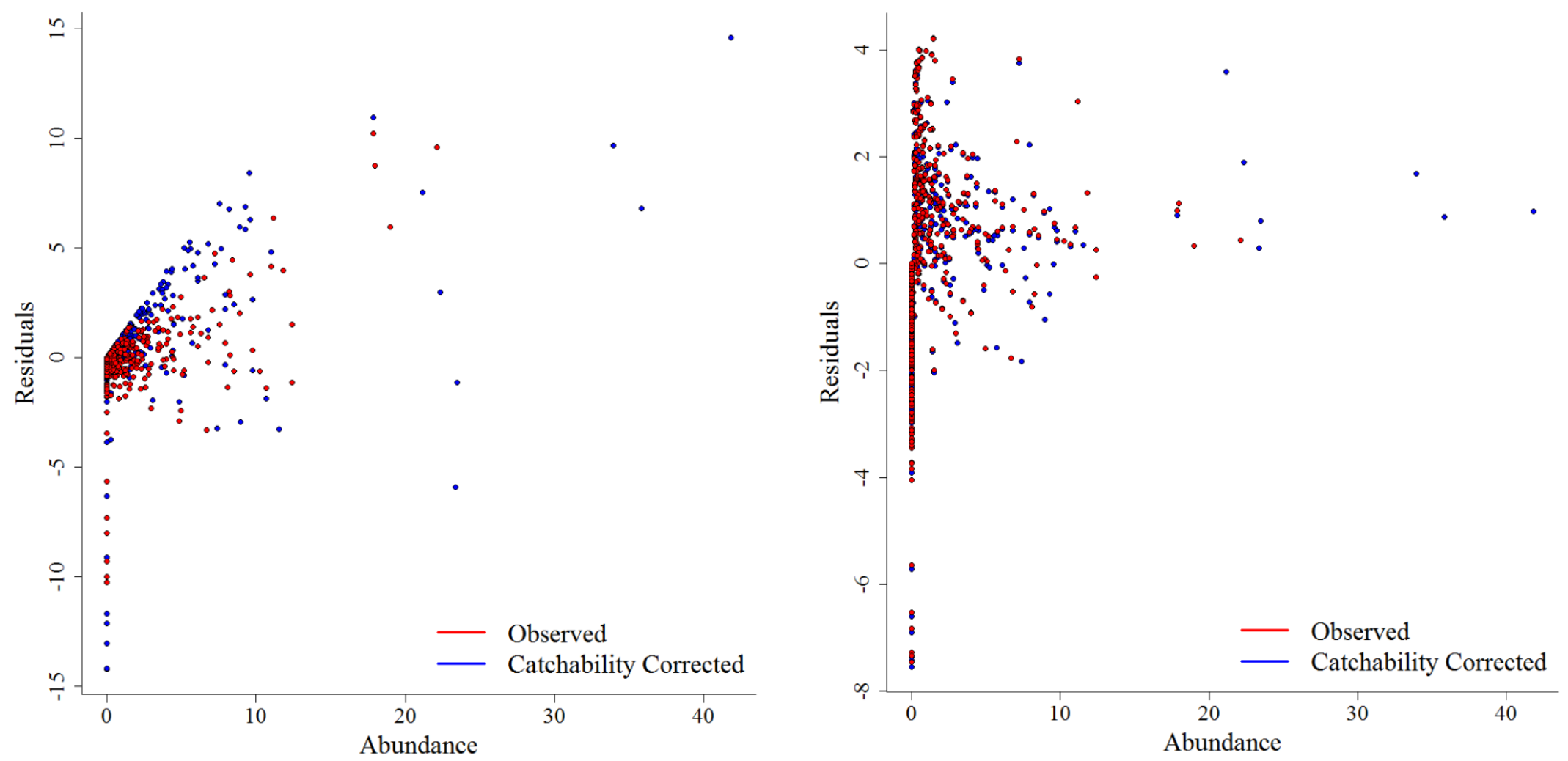

Figure 12. Larval index residuals against observed abundance $(\sqrt{N})$ under Model Variants 2 (left) and 5 (right) using both observed abundances and catchability-corrected abundances. 


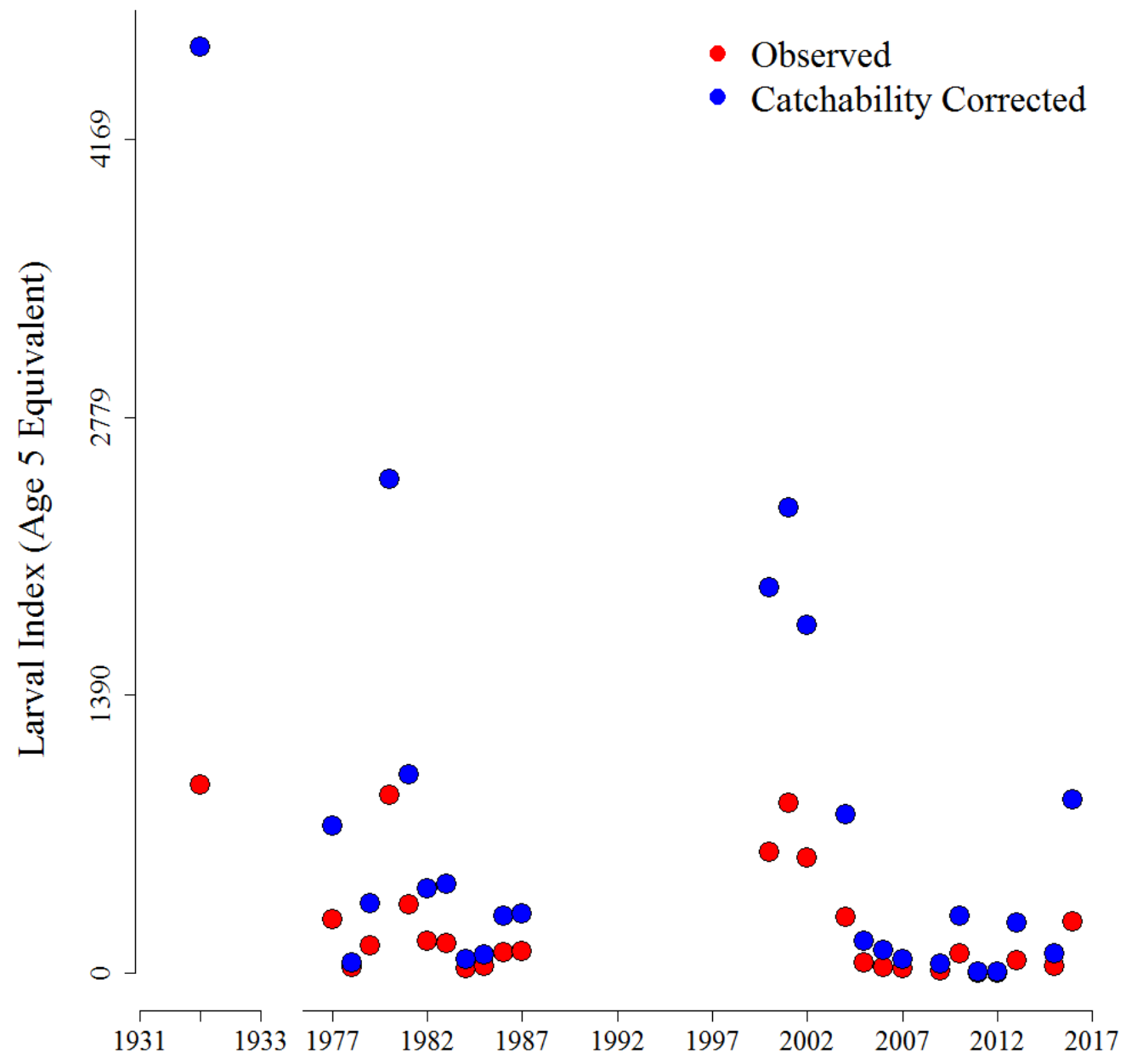

Figure 13. Larval indices produced under Model Variant 9. 


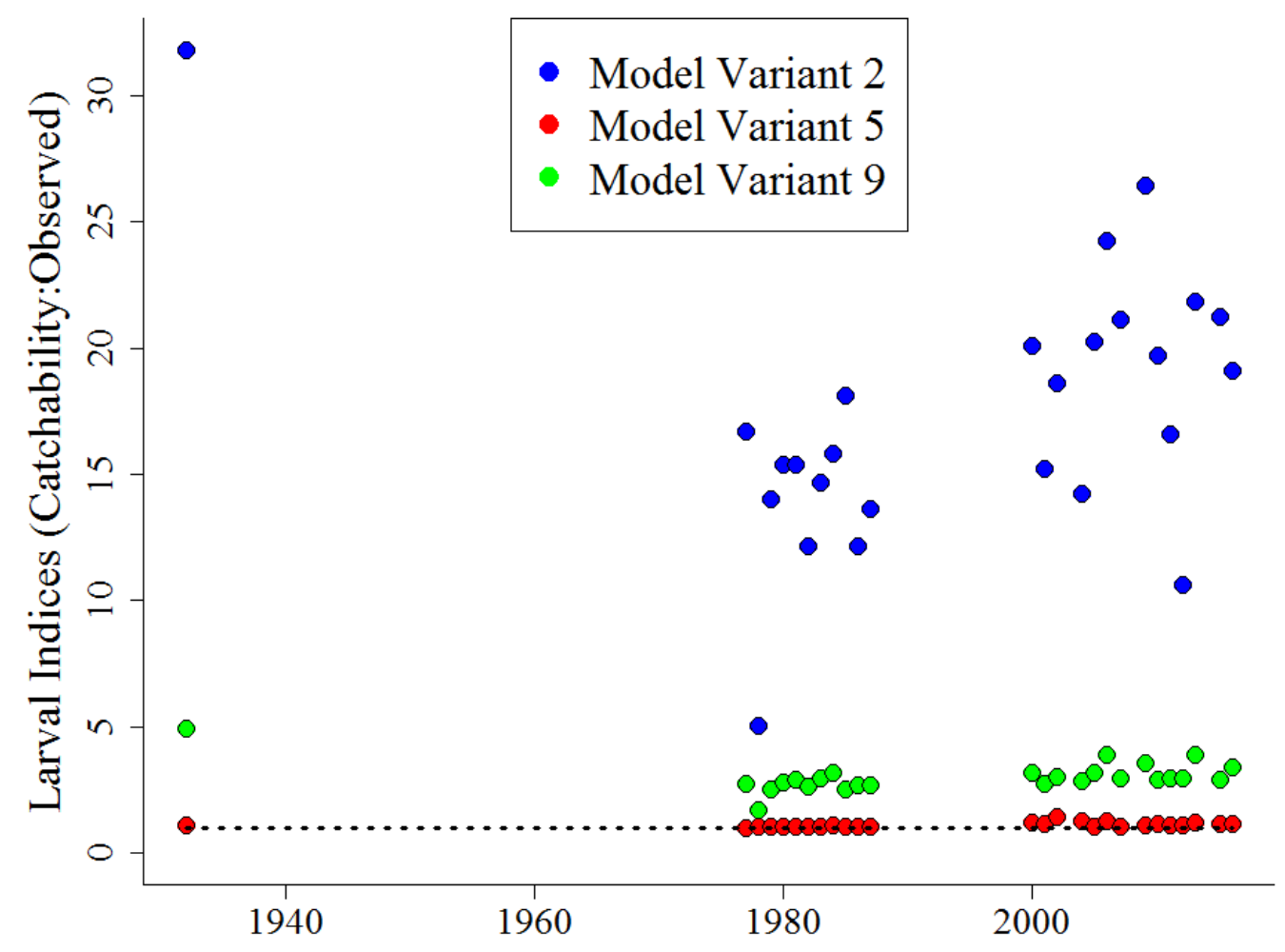

Figure 14. Ratios of larval indices calculated with catchability-corrected abundances to observed abundances for Survey-level (Model Variants 2 and 5) and Sample-level (Model Variant 9). 
Youngest (Start) Ages From Bootstrapped Runs
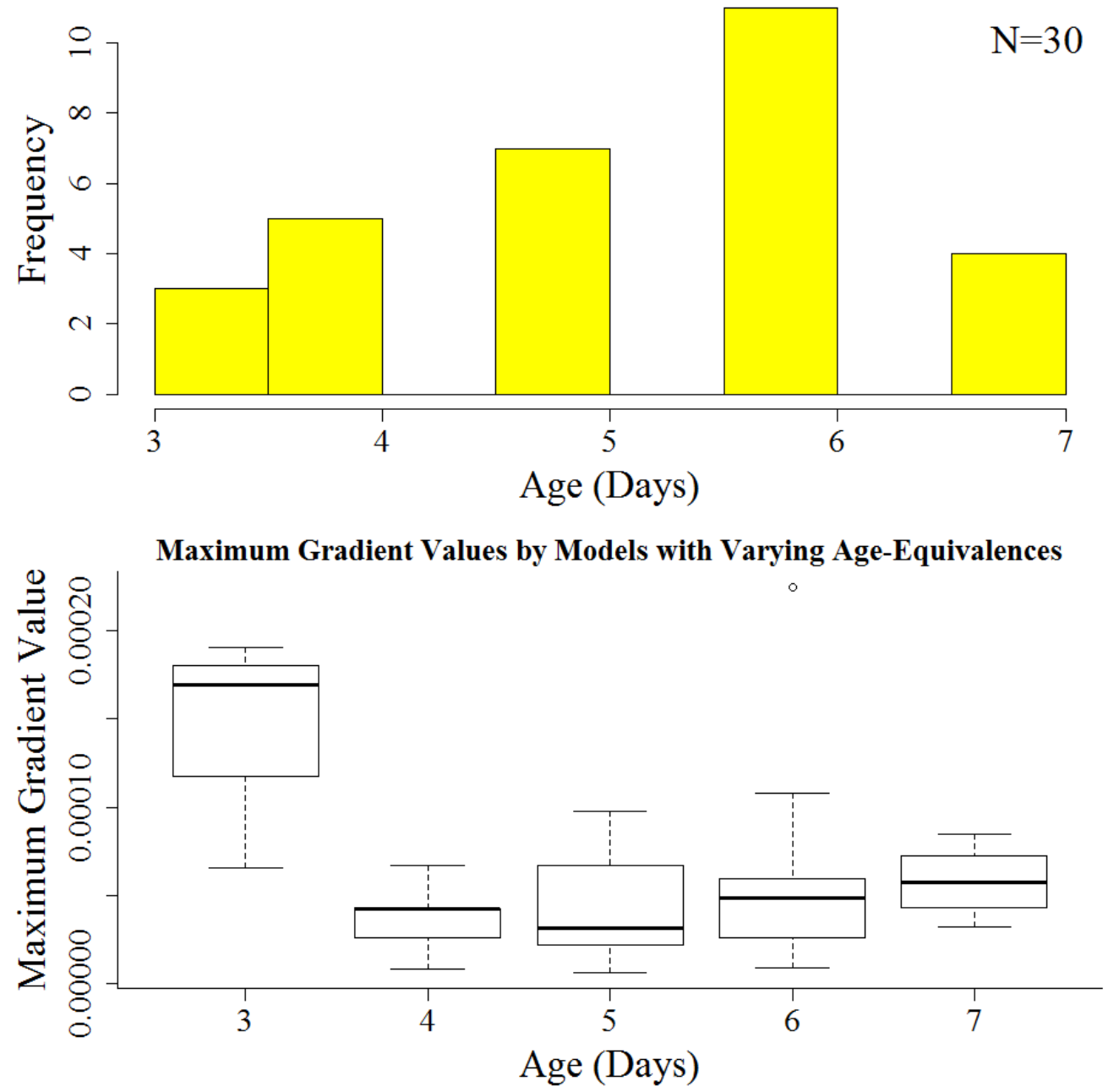

Figure 15. Start ages for bootstrapped growth curve runs under Model Variant 2 (top) and maximum gradient values for the associated start-age runs. 

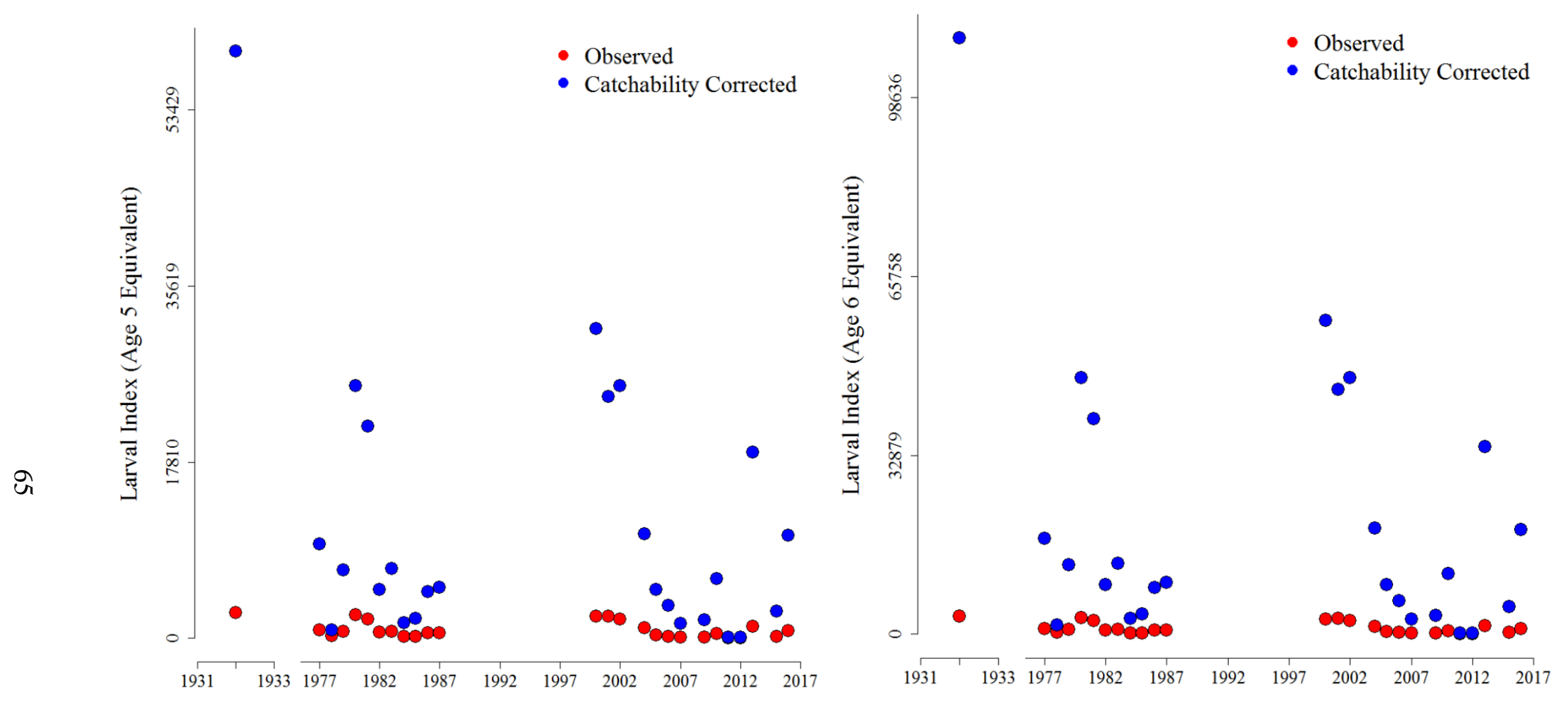

Figure 16. Larval Indices under Model Variant 2 when using a start age of 5 day-olds (left) and 6 day-olds (right). 

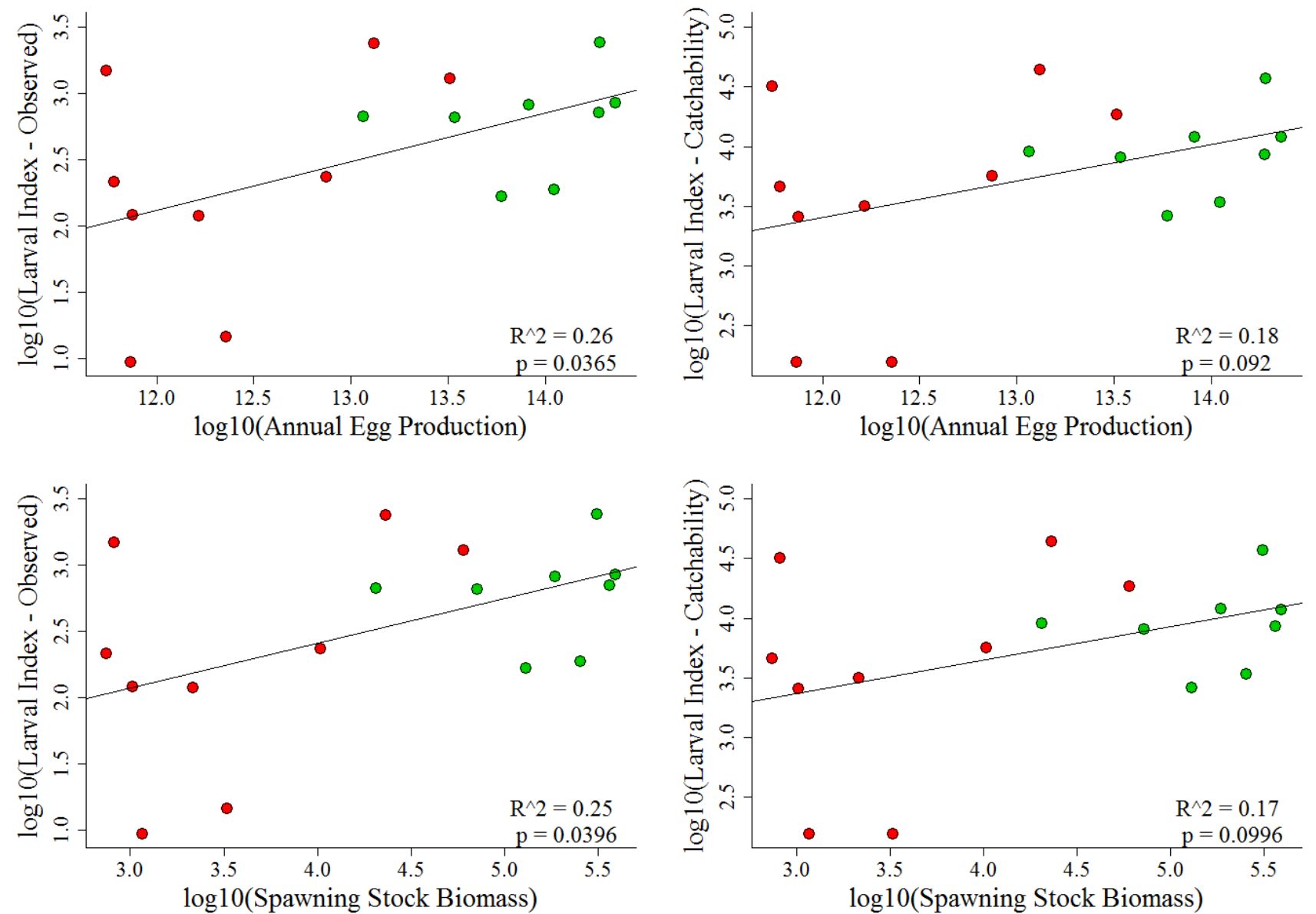

Figure 17. Correlations between annual egg production and spawning stock biomass estimates for the southern contingent and the larval index with and without catchability corrections. Indices were $\log _{10}$ transformed. Coloration of points represent MARMAP (red) and EcoMon (green) years. 


\section{SUPPLEMENTS}

Supplement 1. MARMAP and EcoMon sampling by year over the Northeast U.S. Continental Shelf. All standard samples are displayed (black), with those taken during the spawning season (May-June, red) and spawning grounds (blue) indicated.

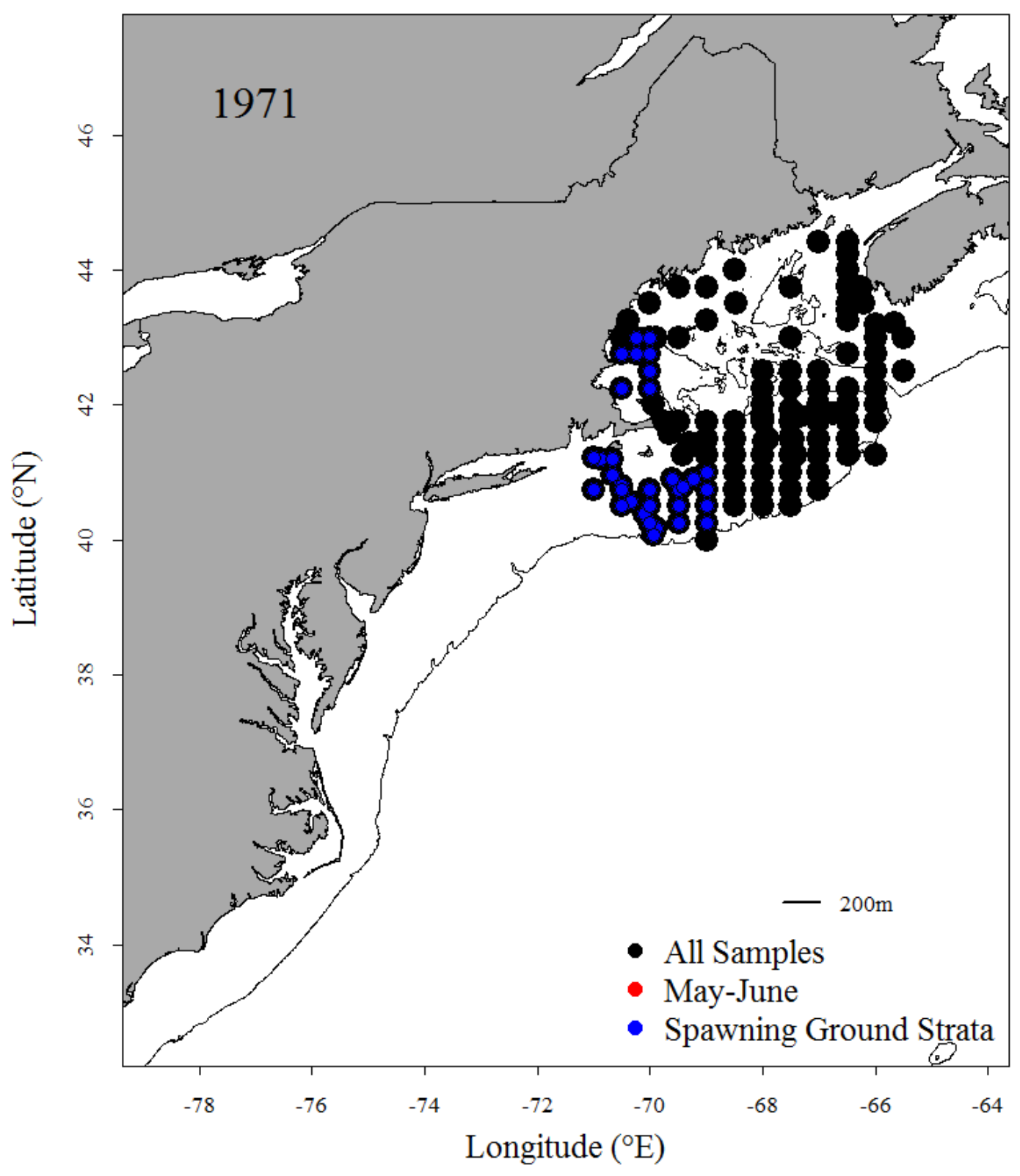




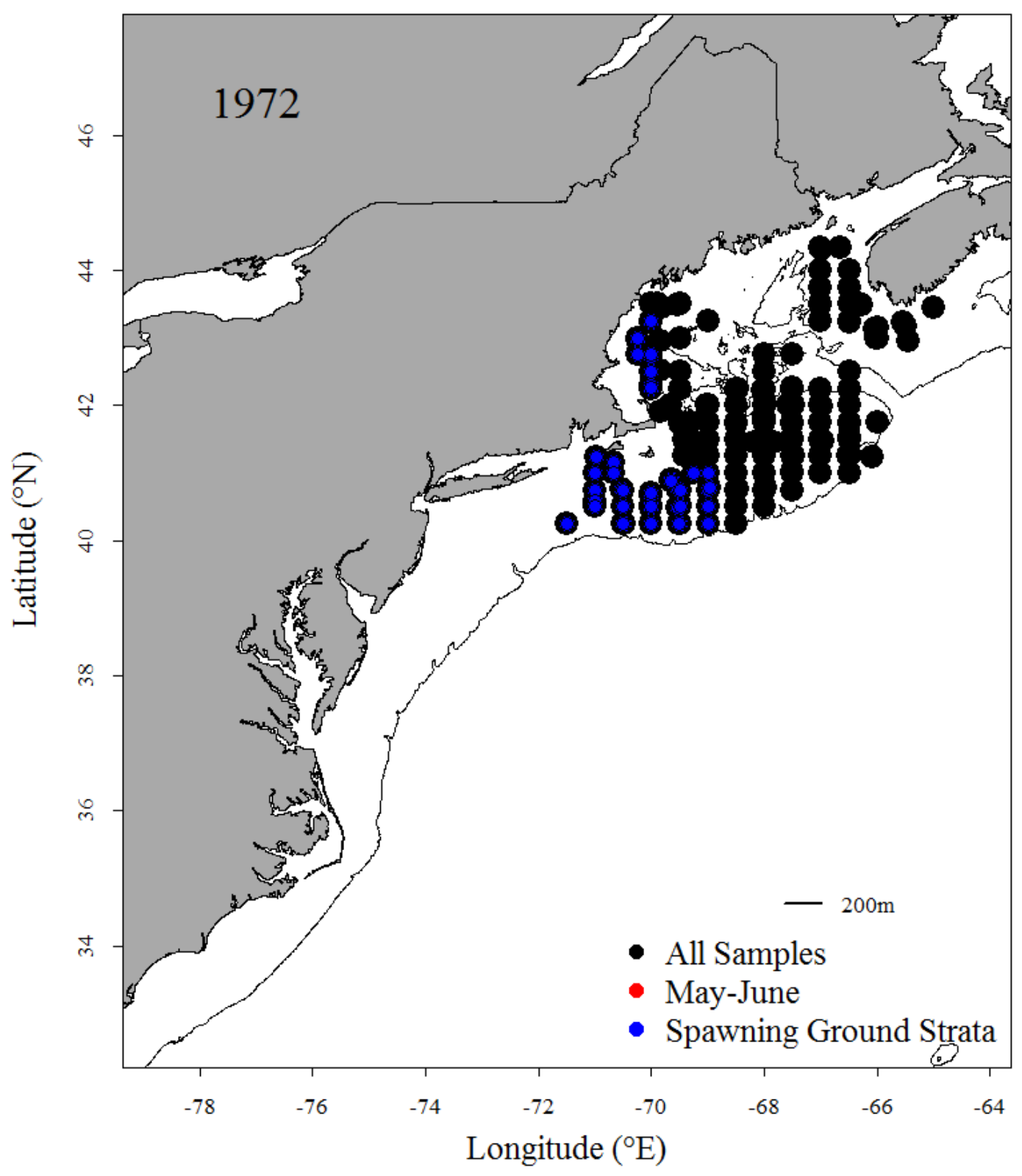




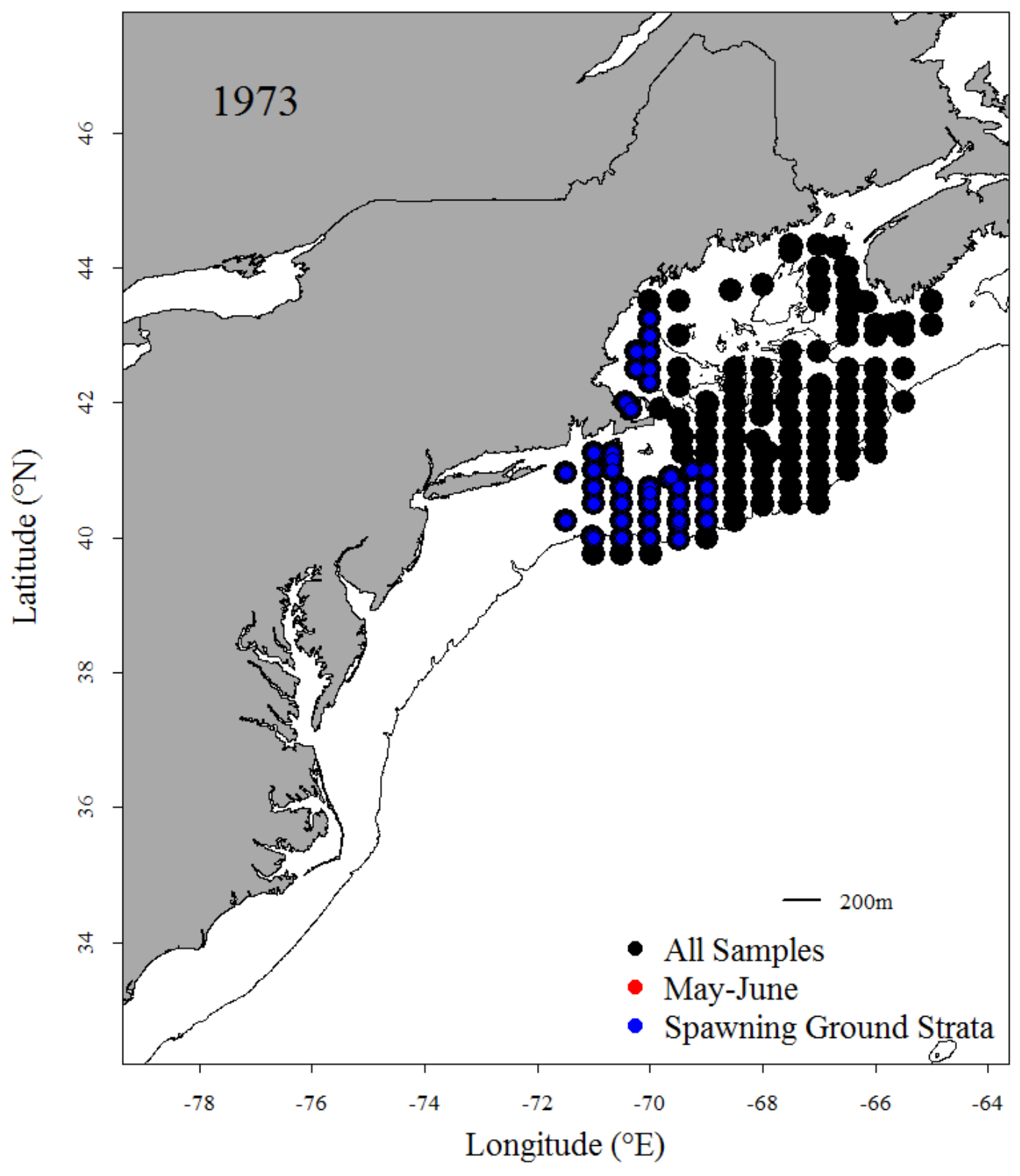




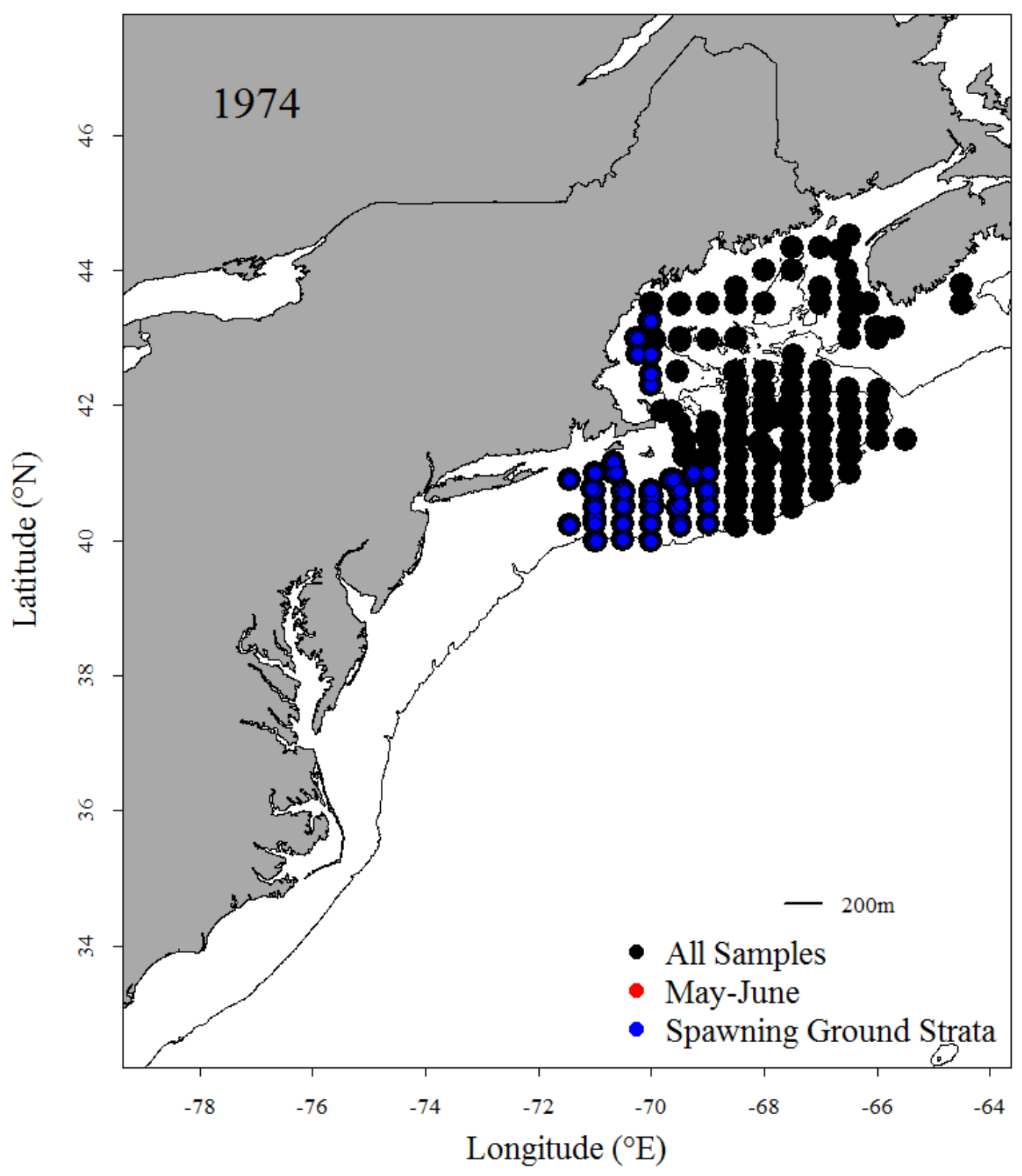




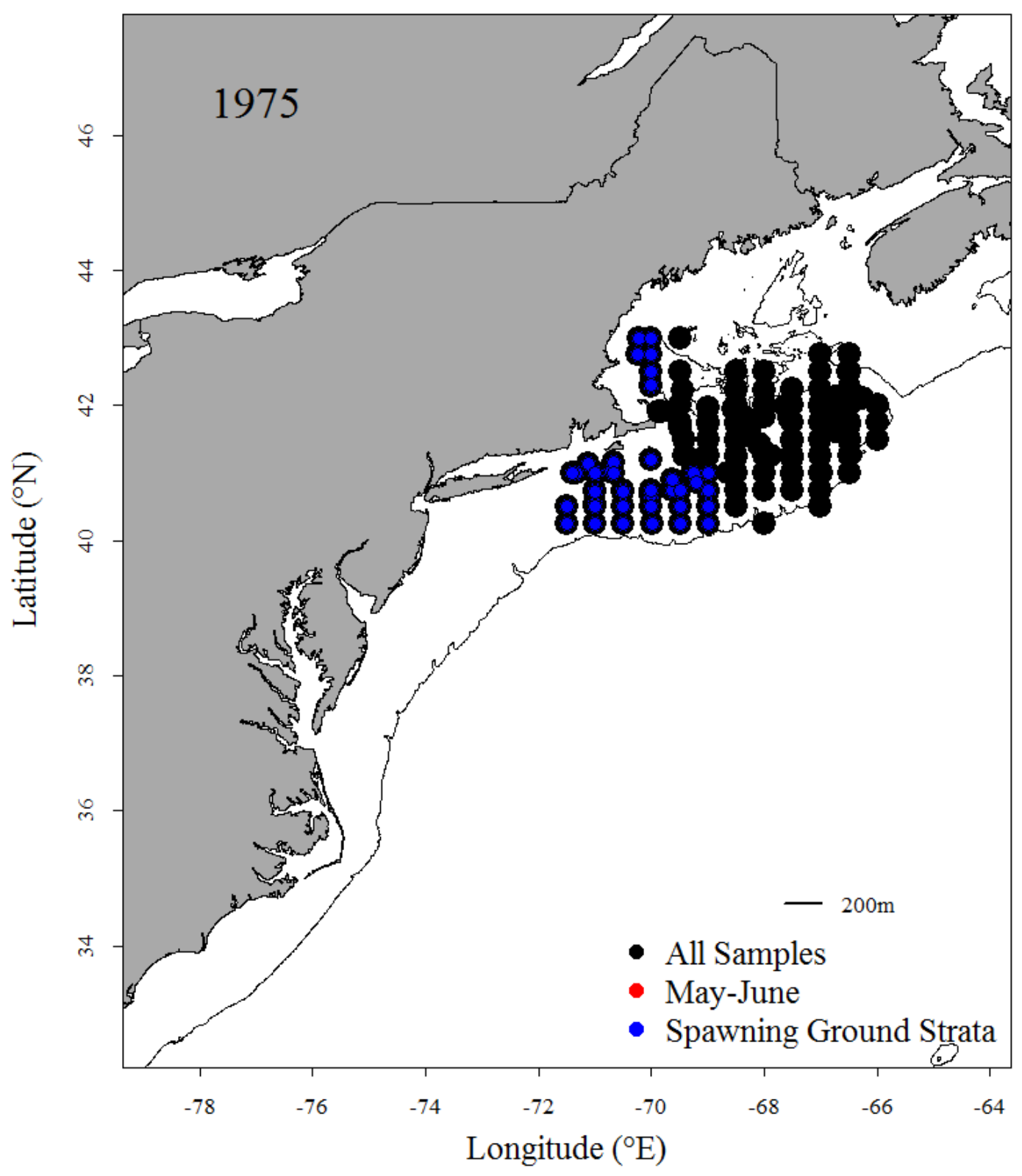




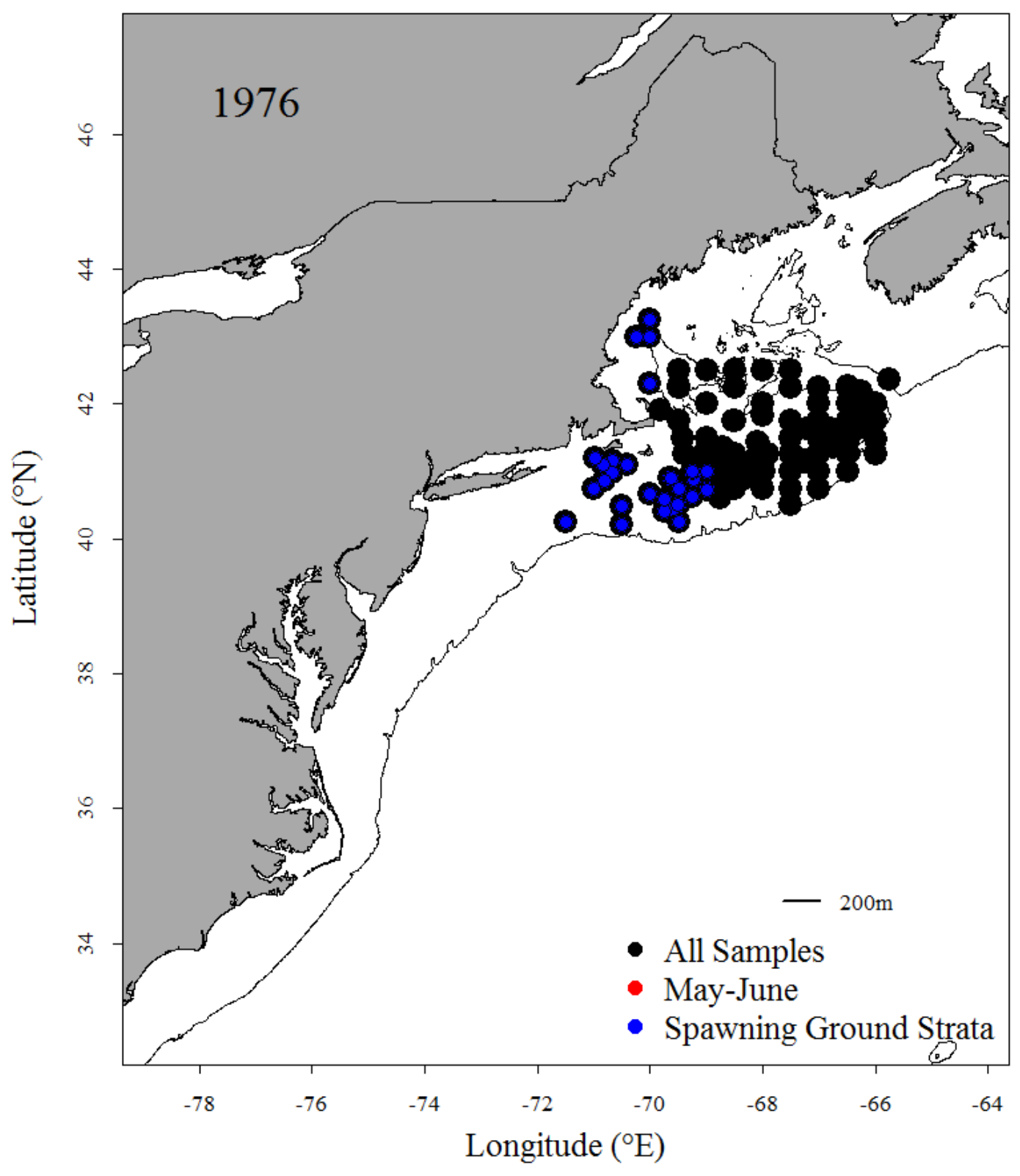




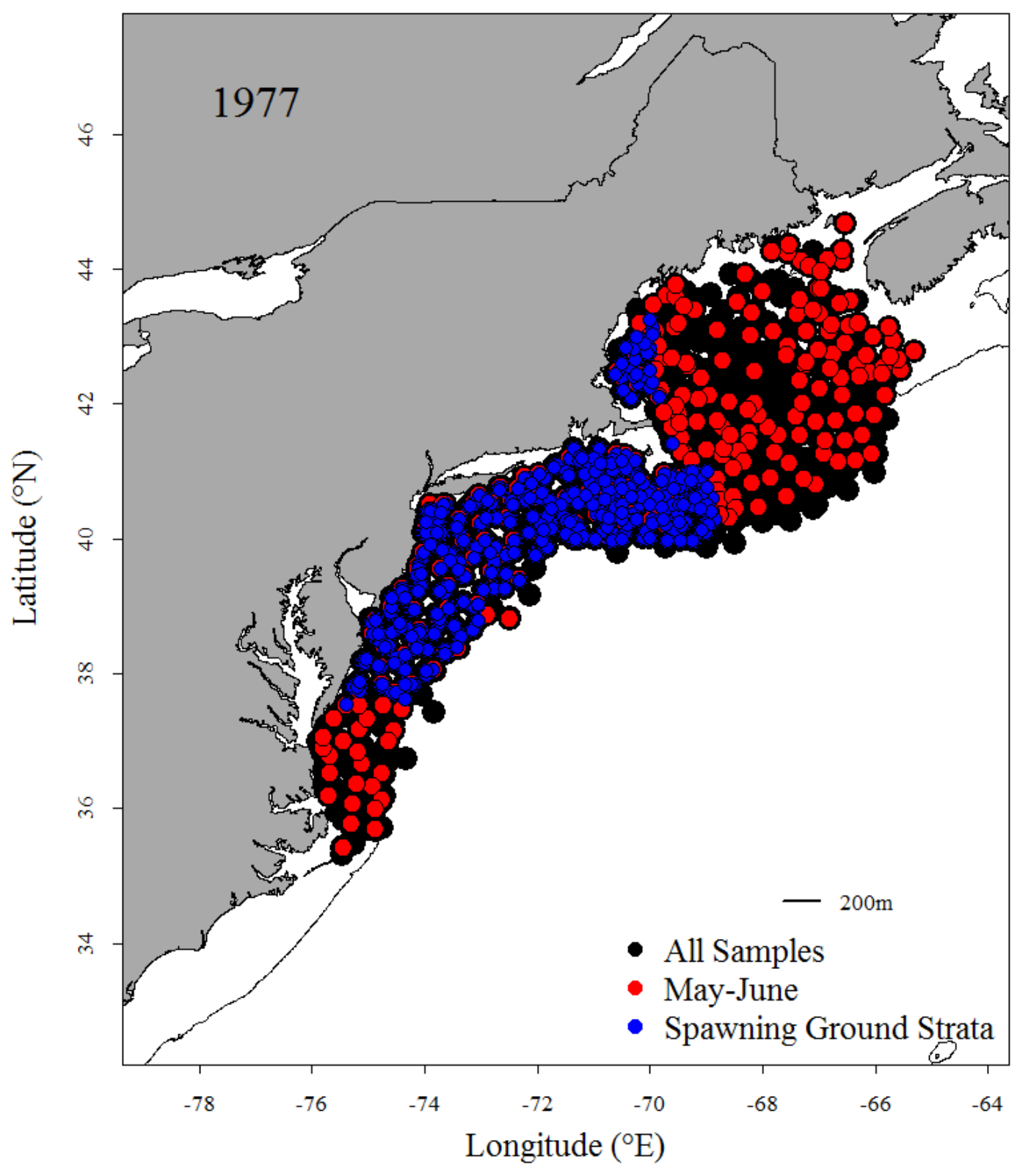




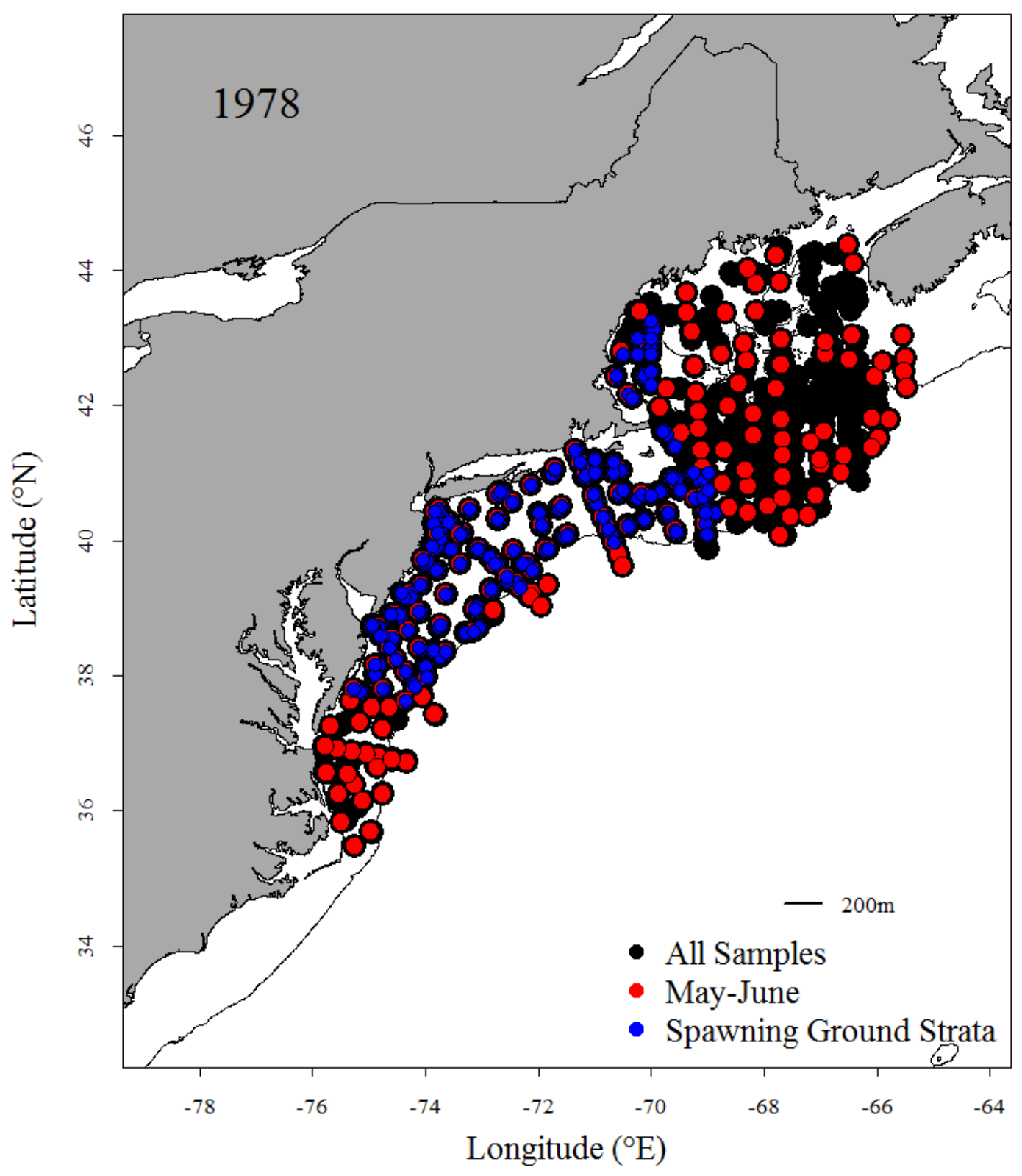




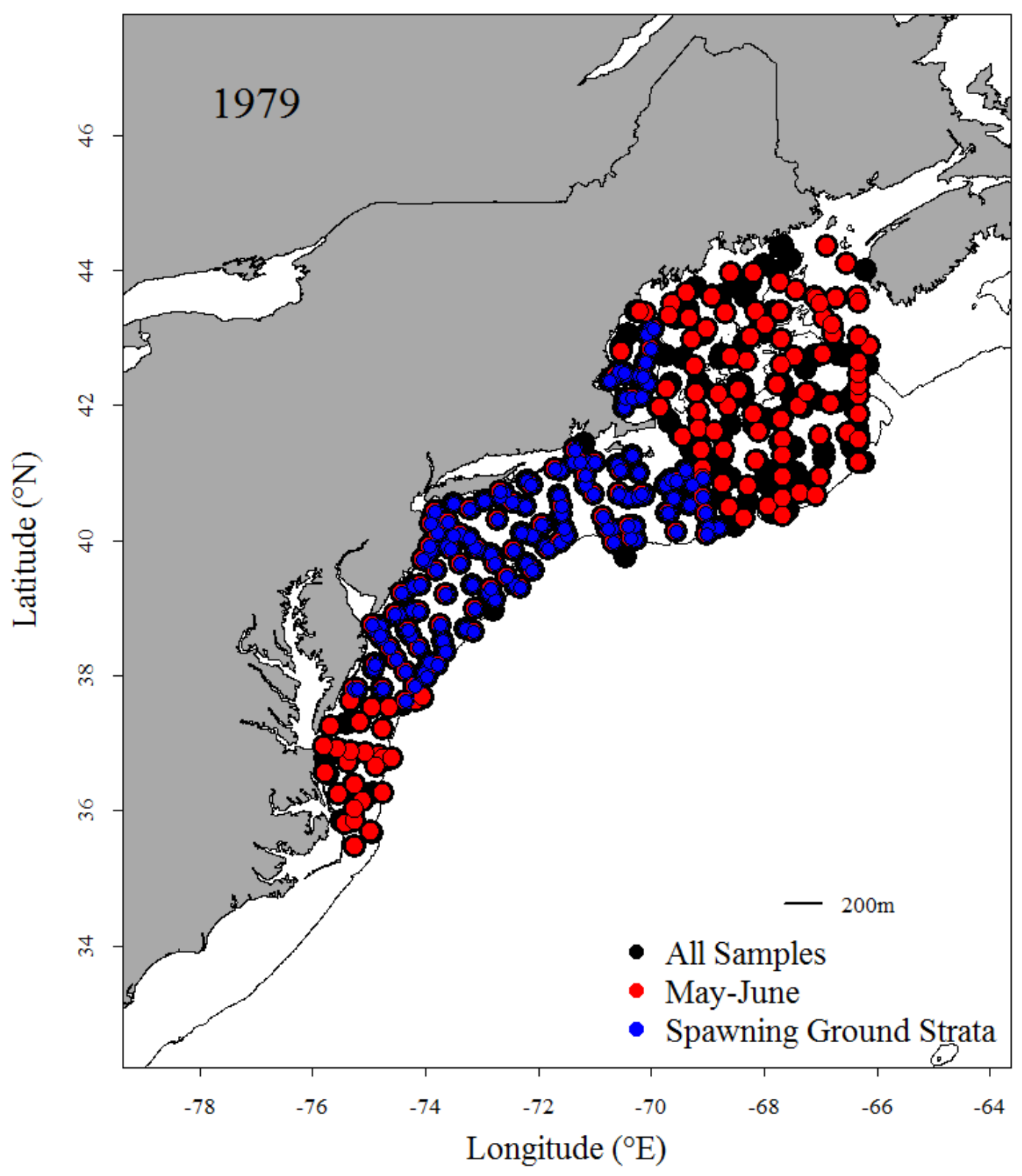




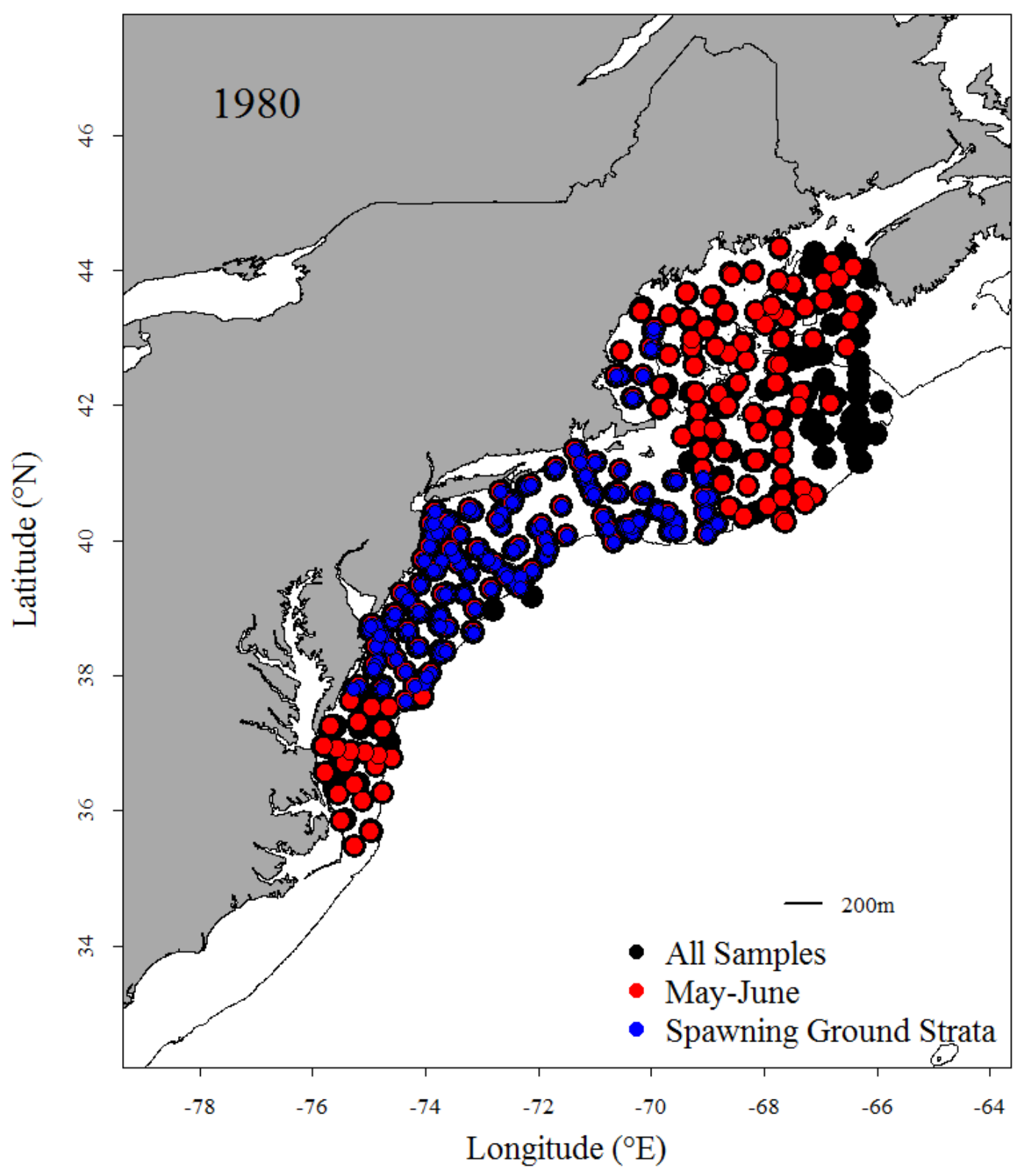




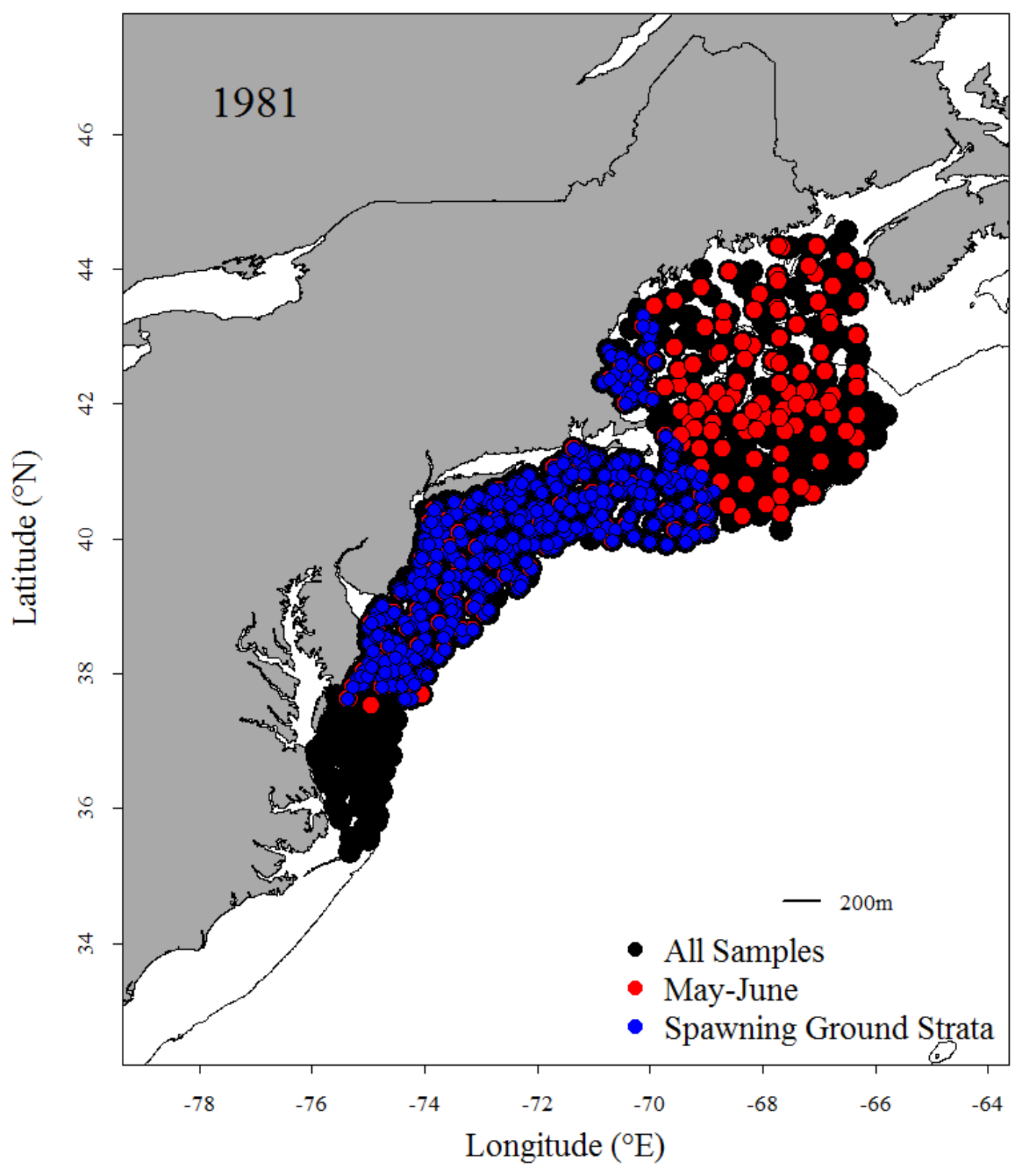




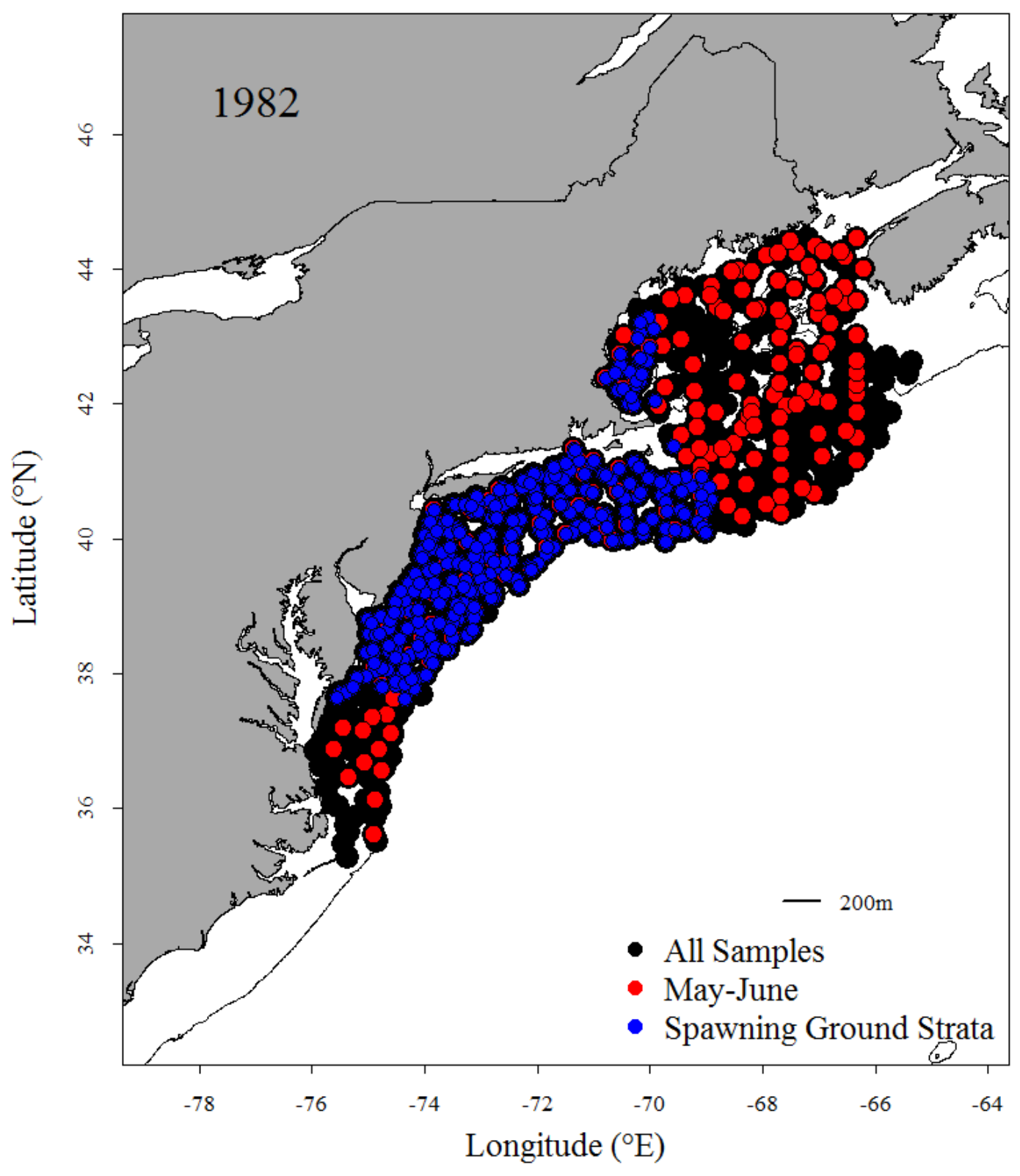




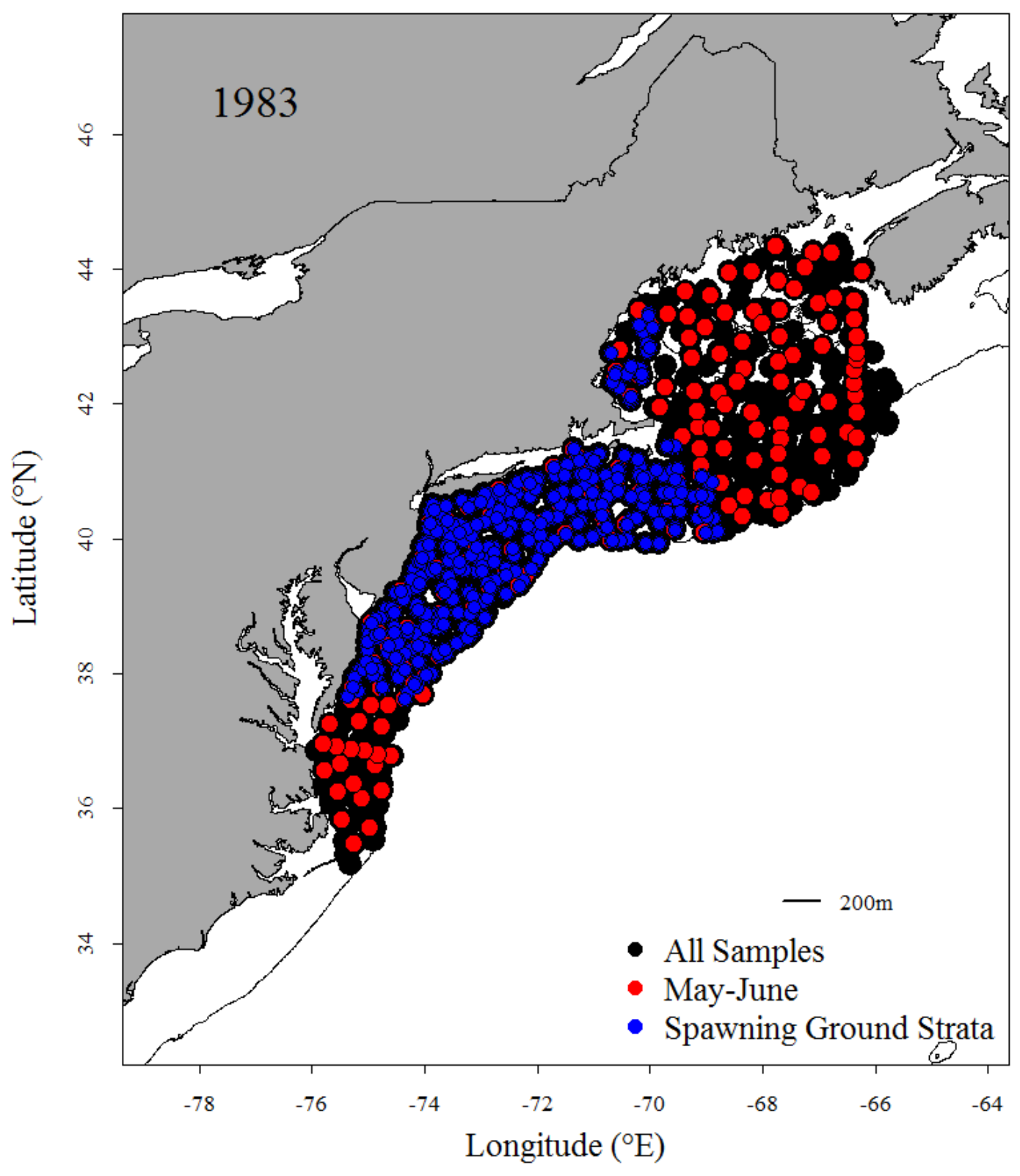




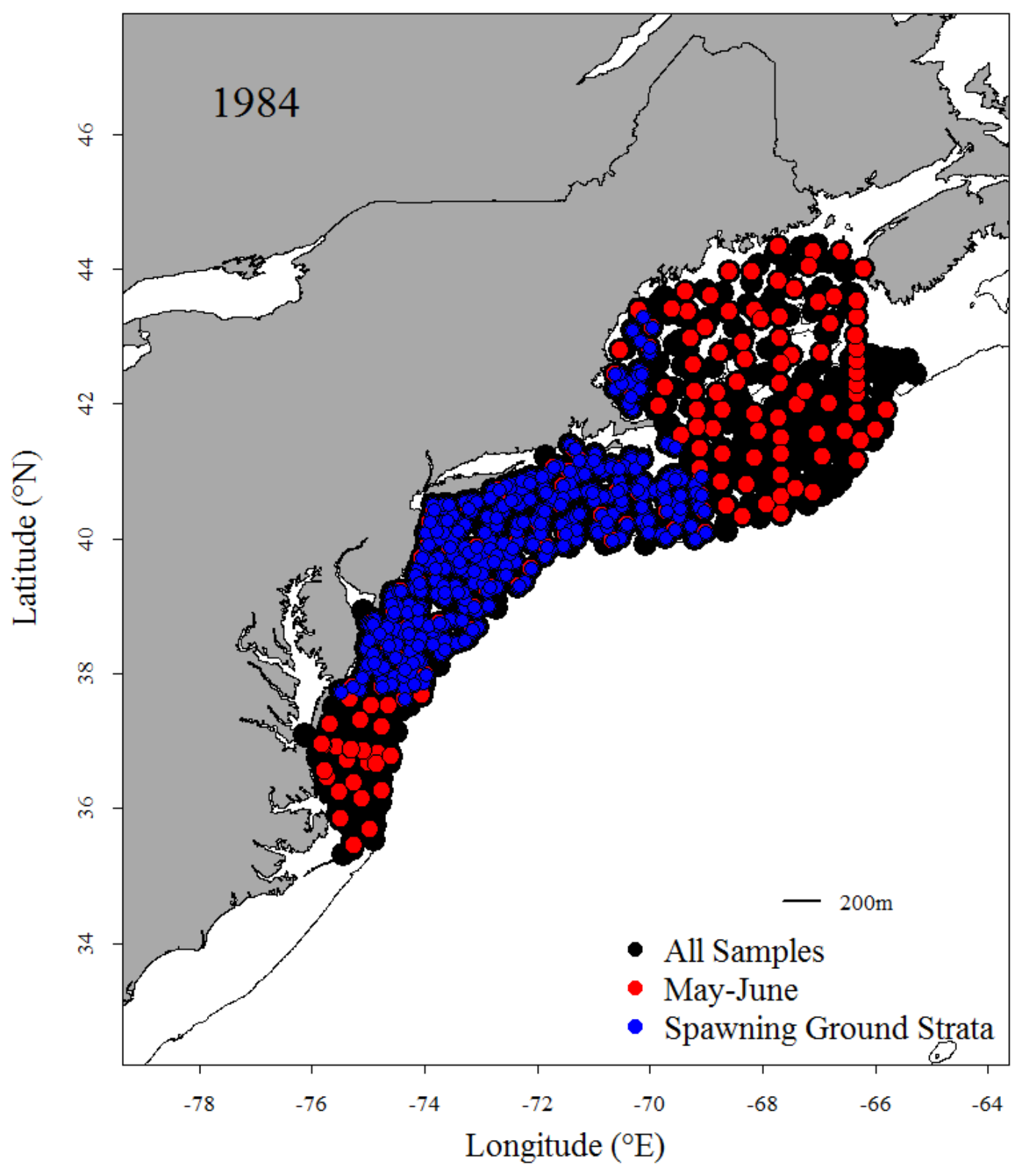




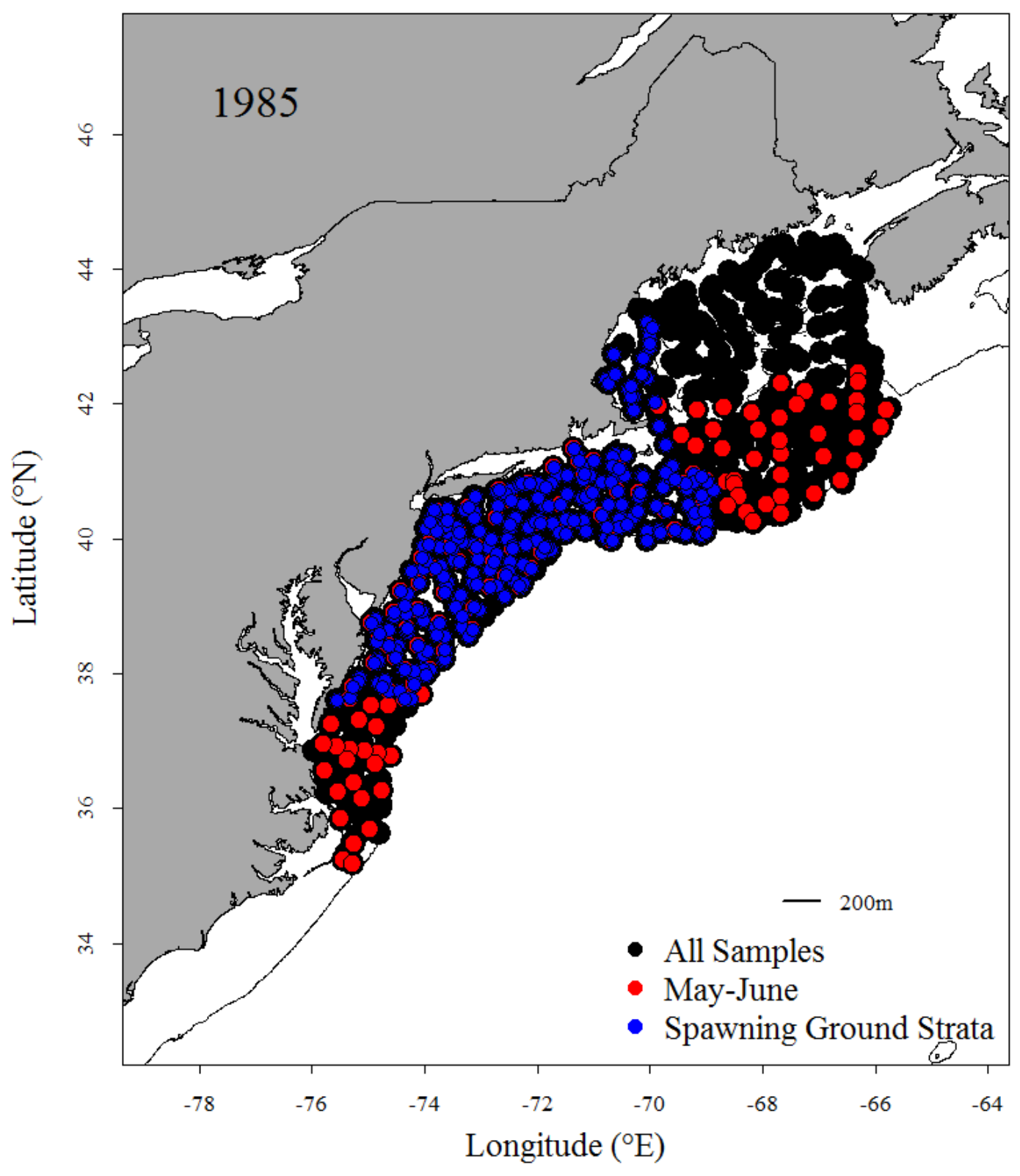




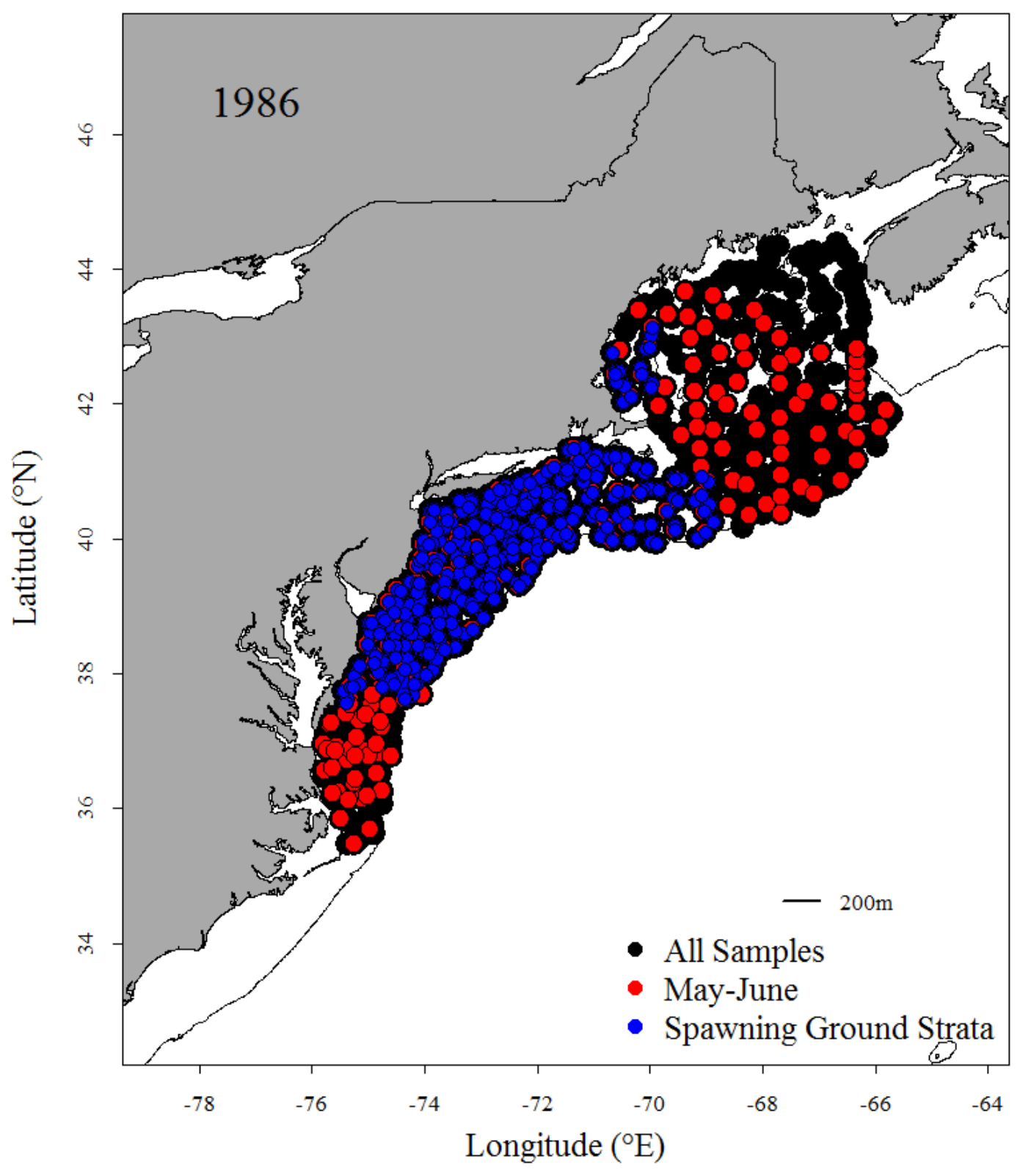




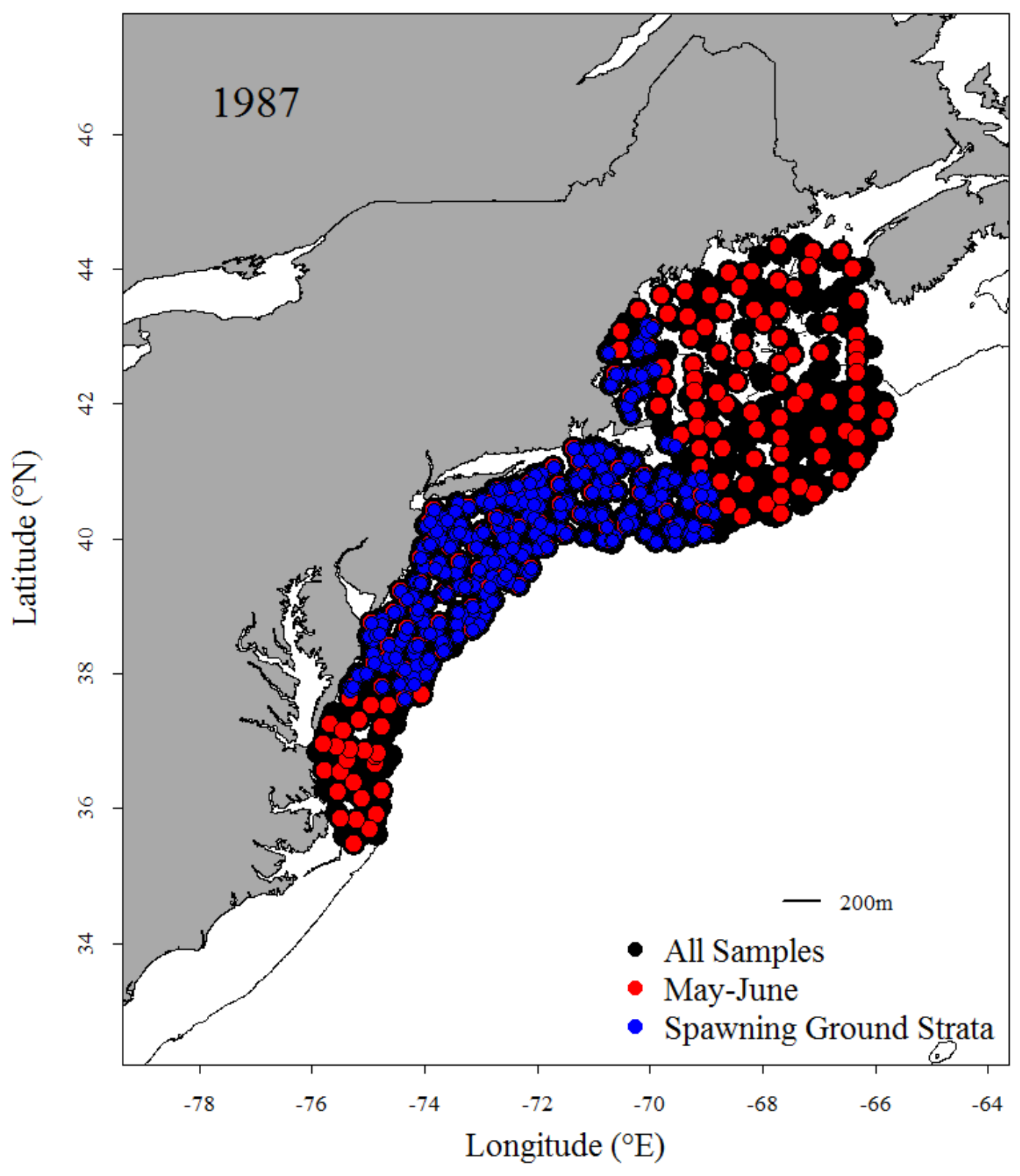




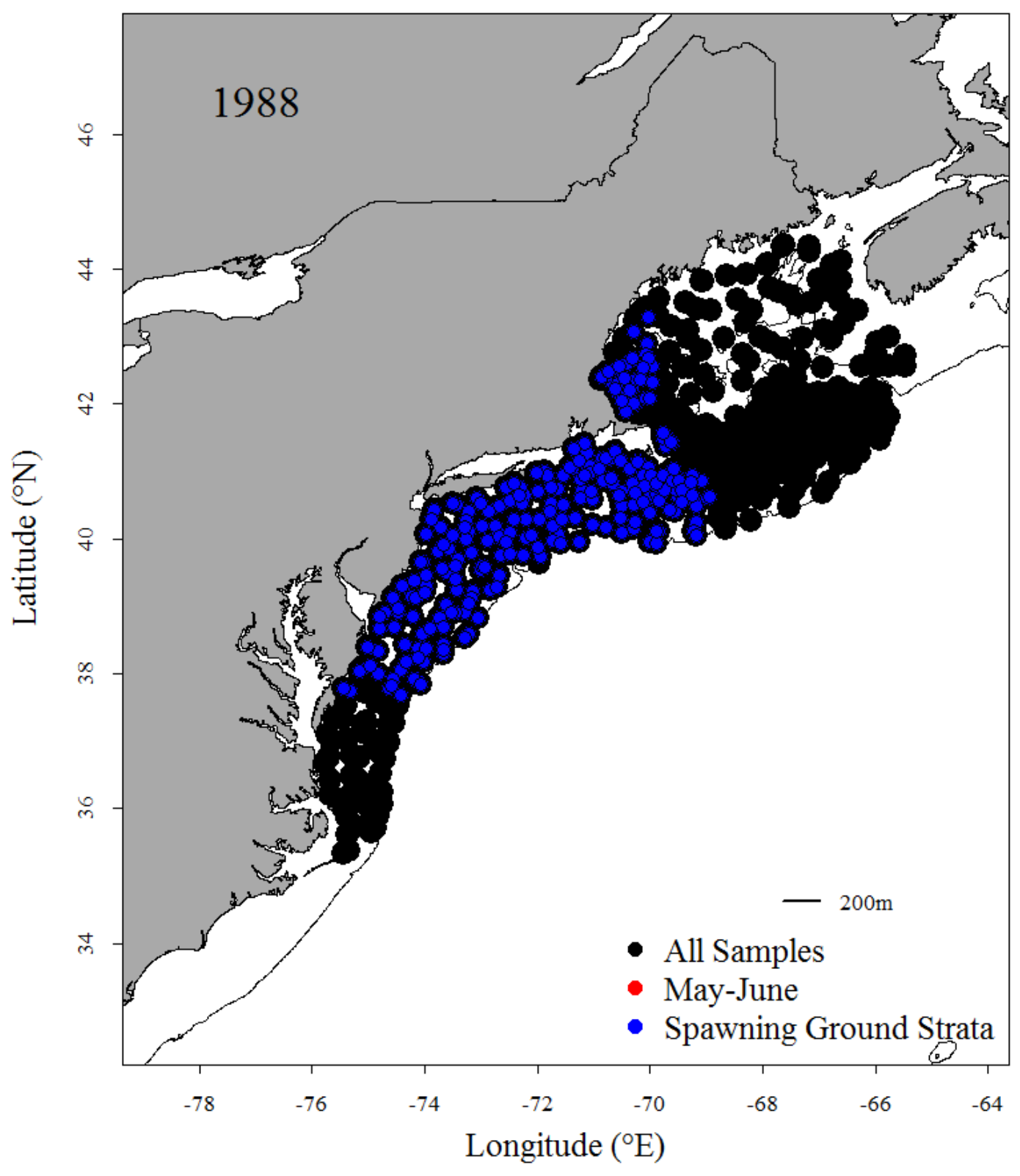




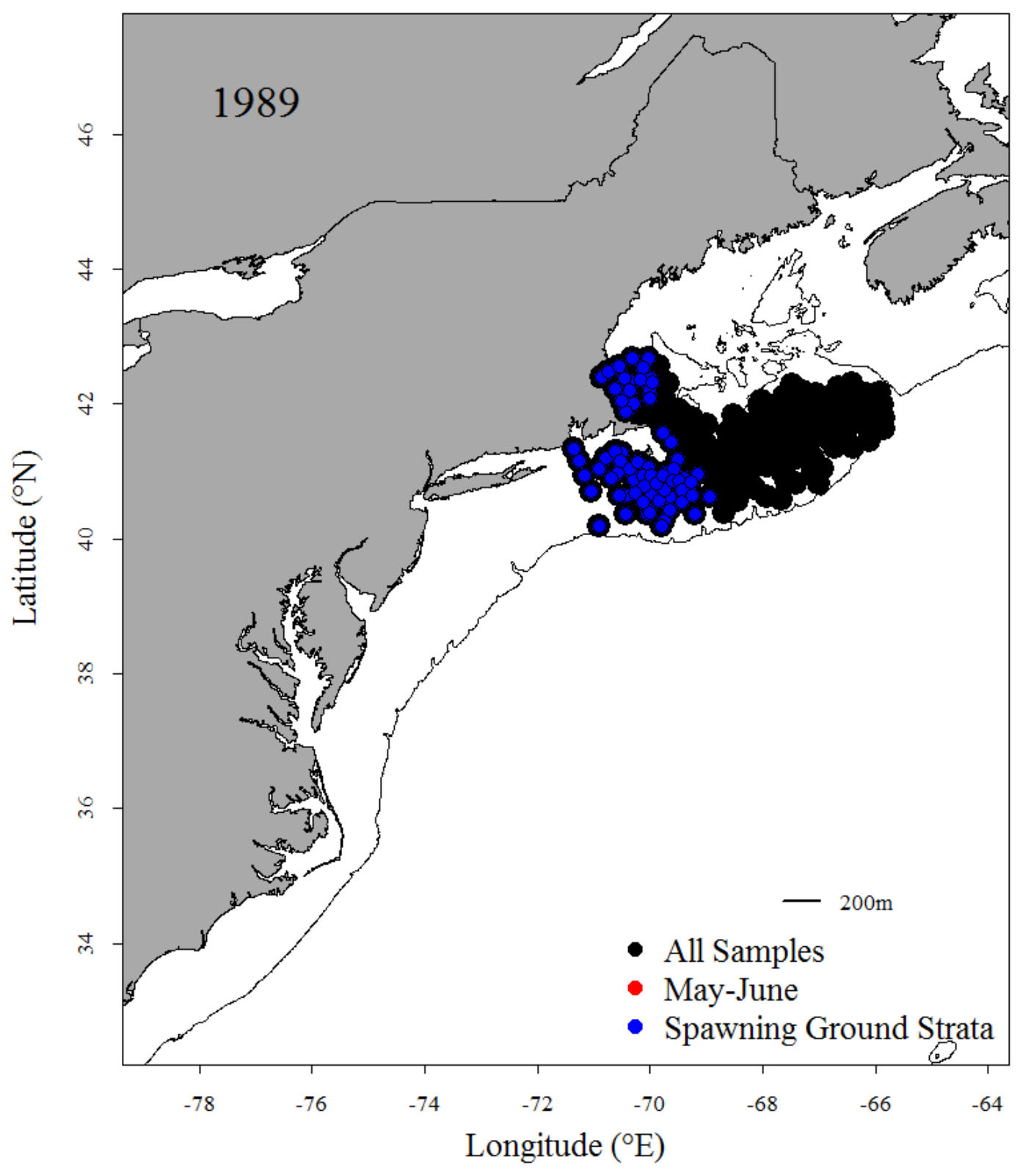




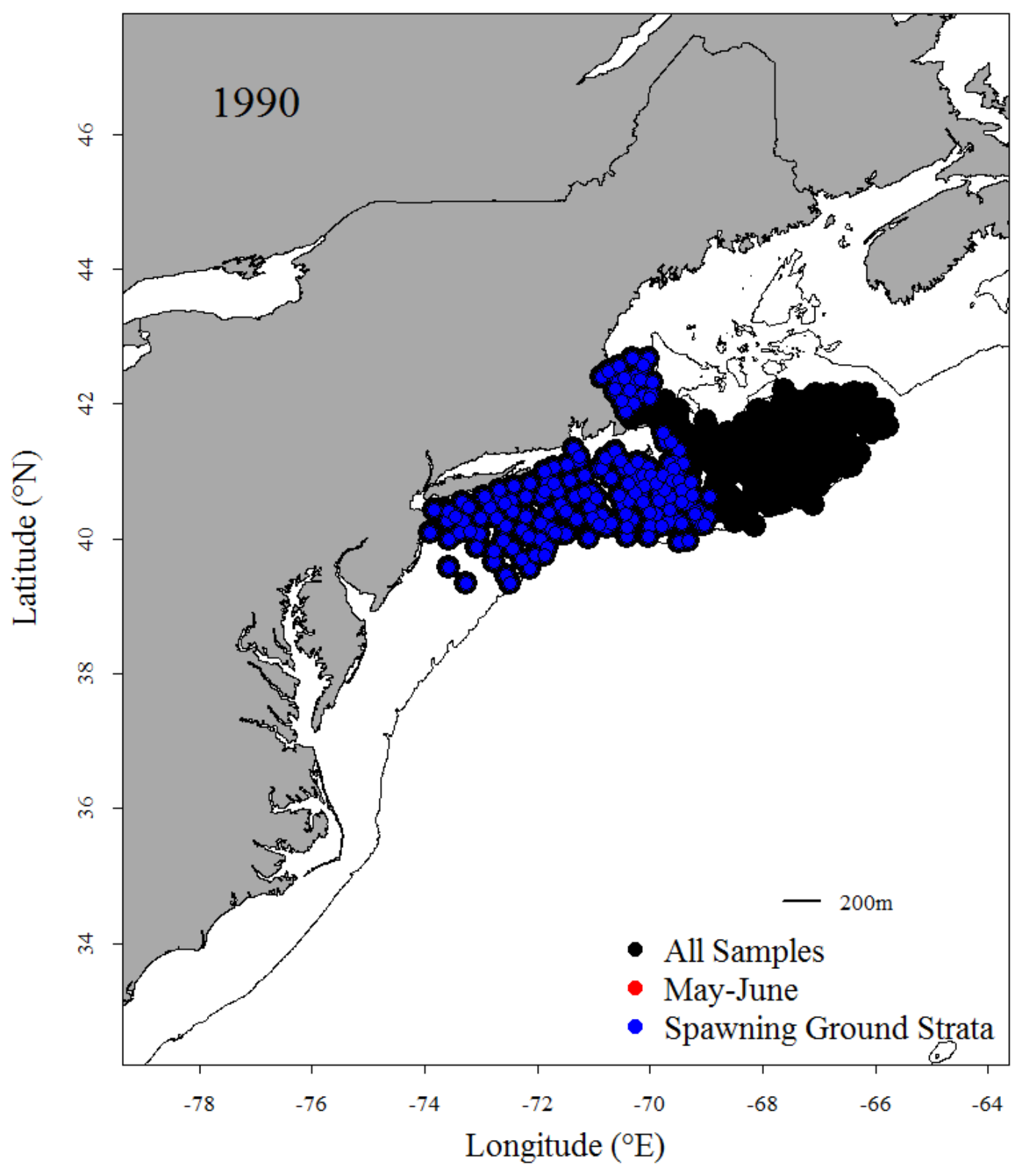




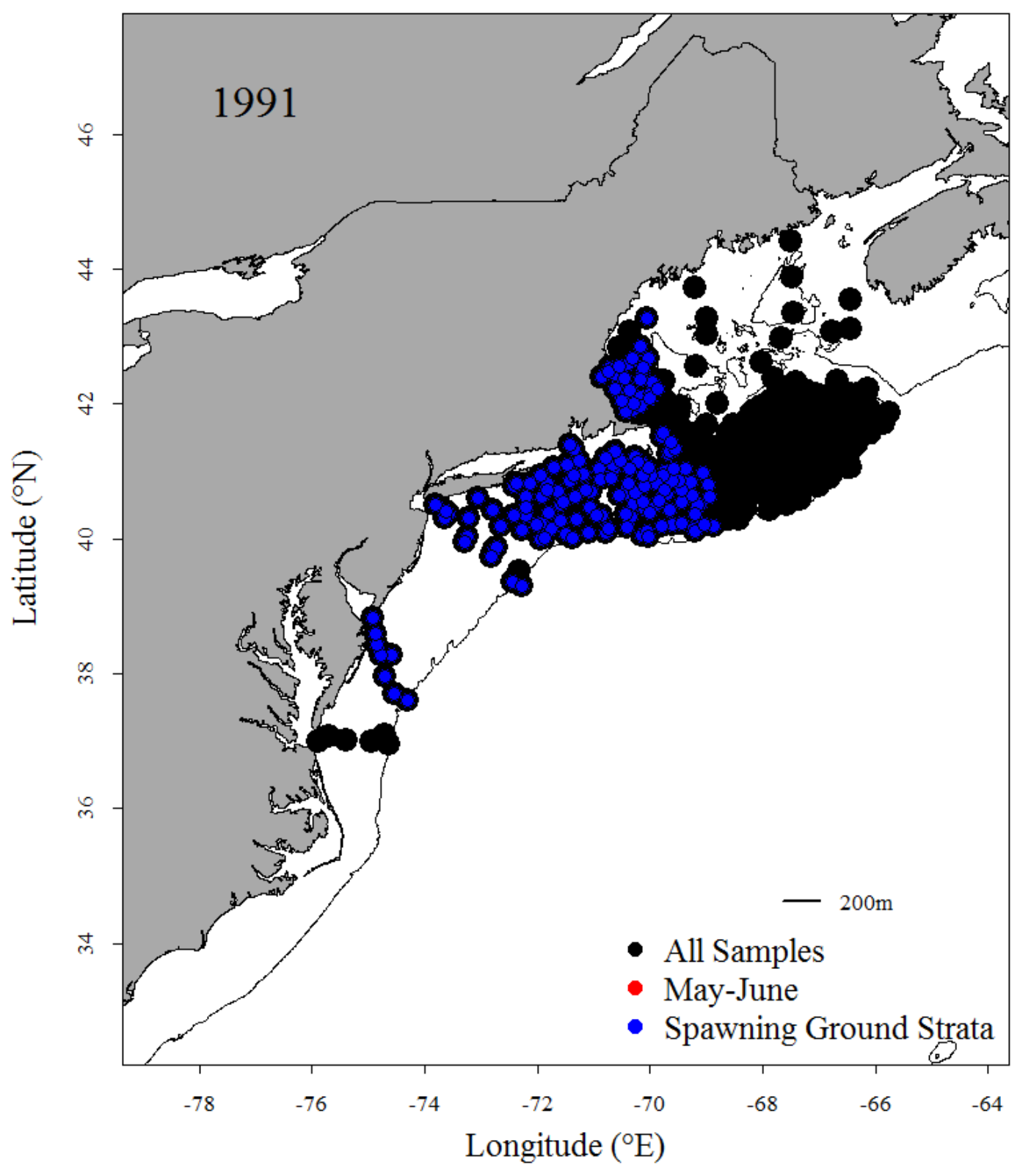




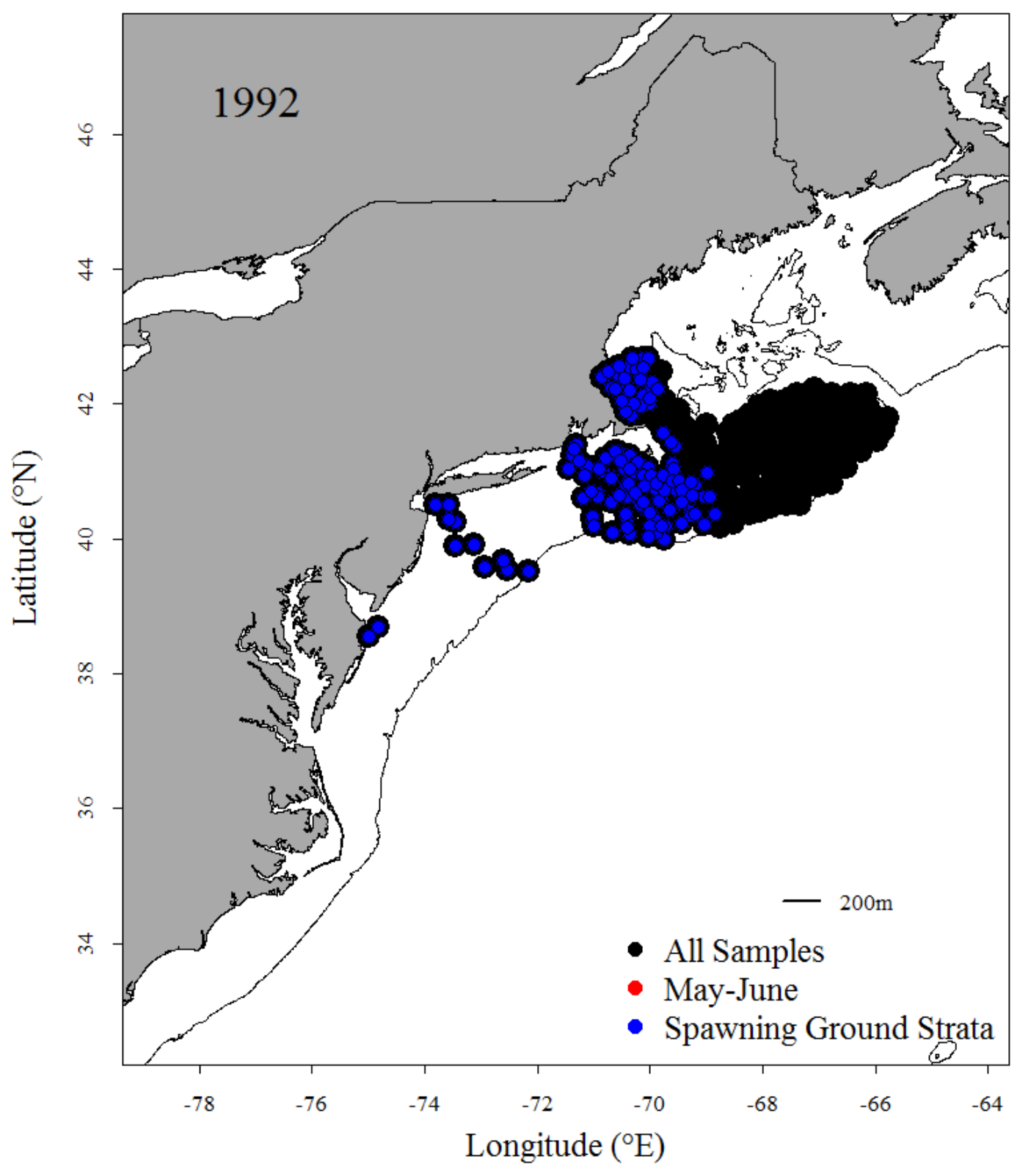




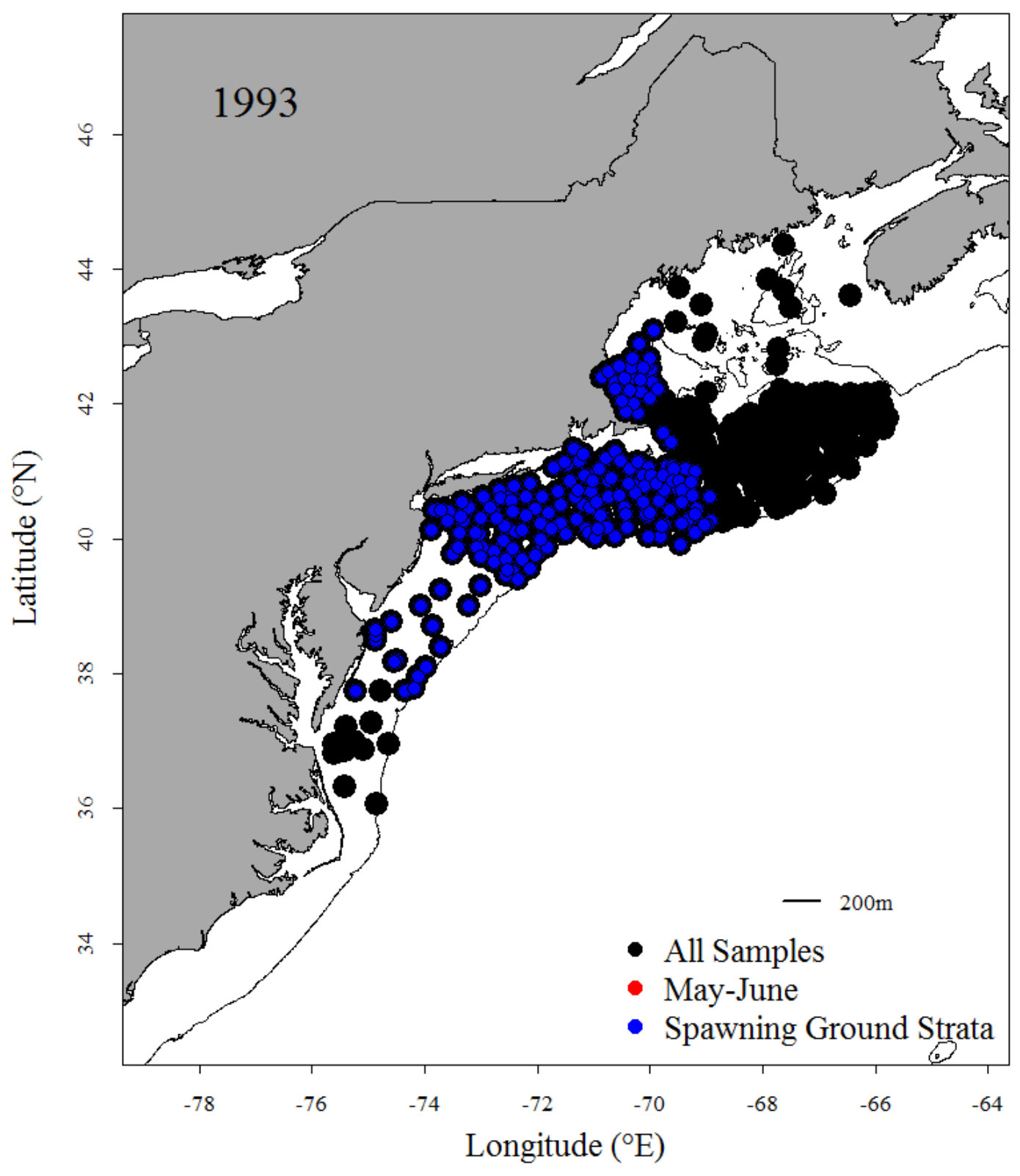




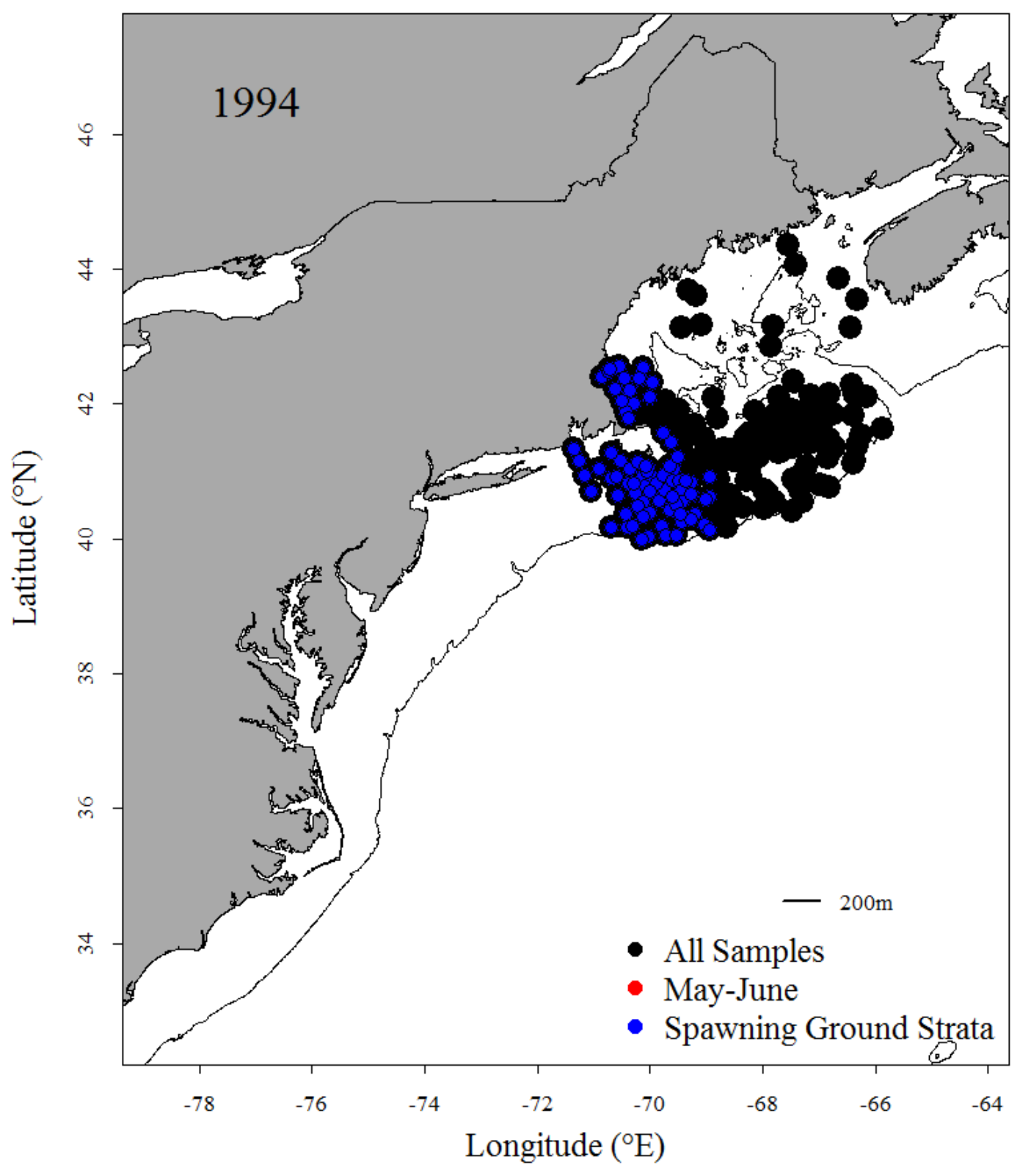




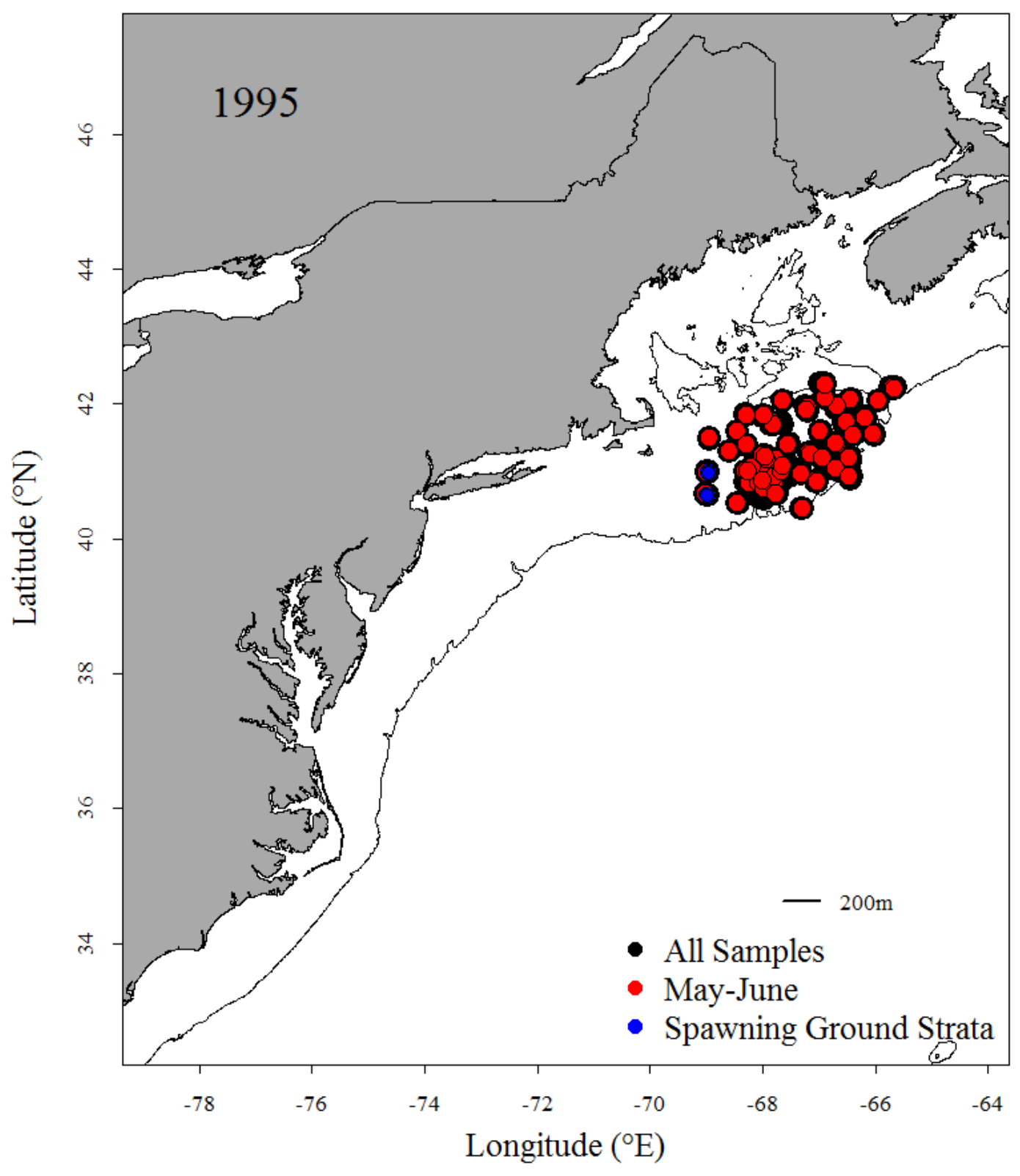




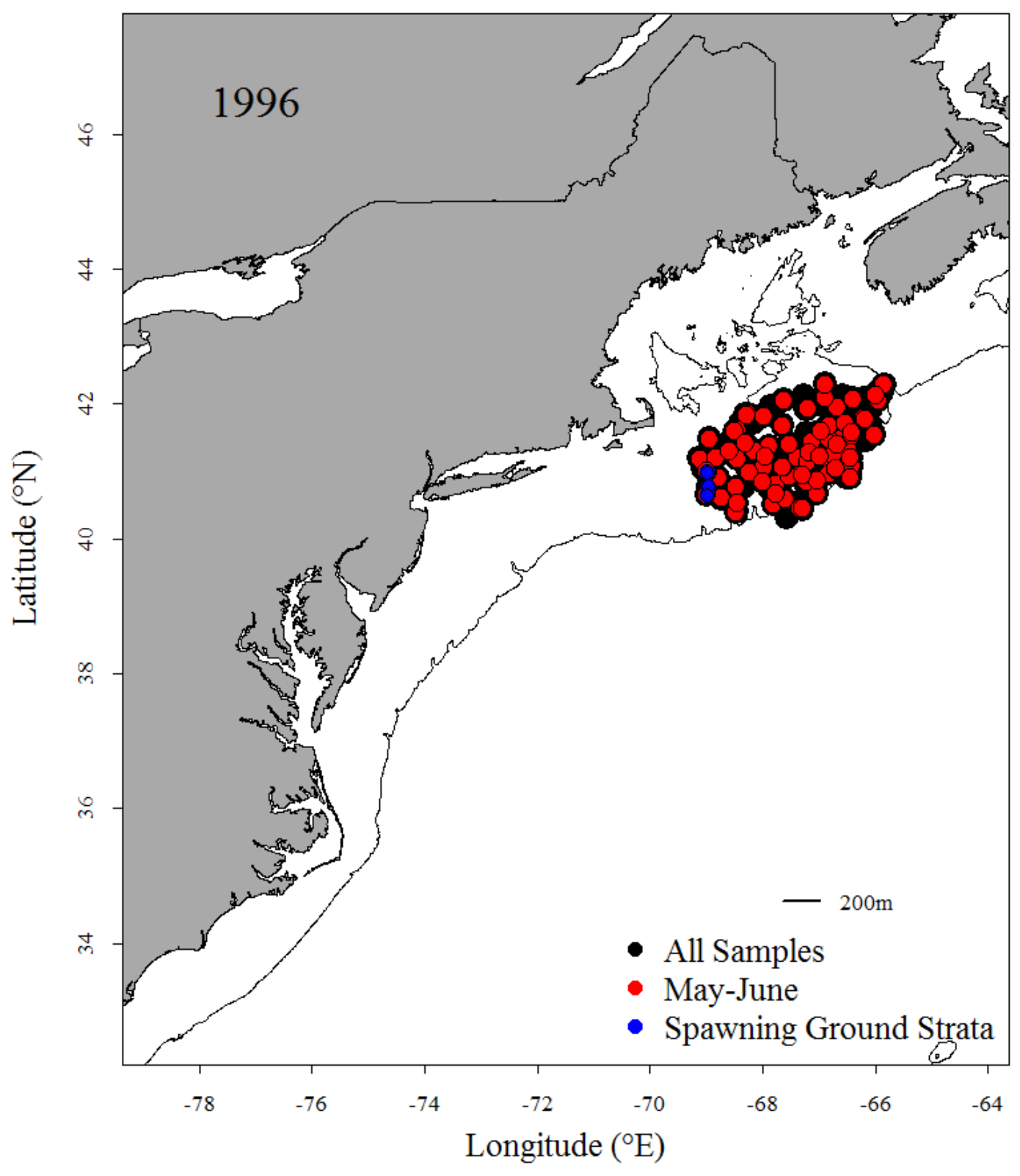




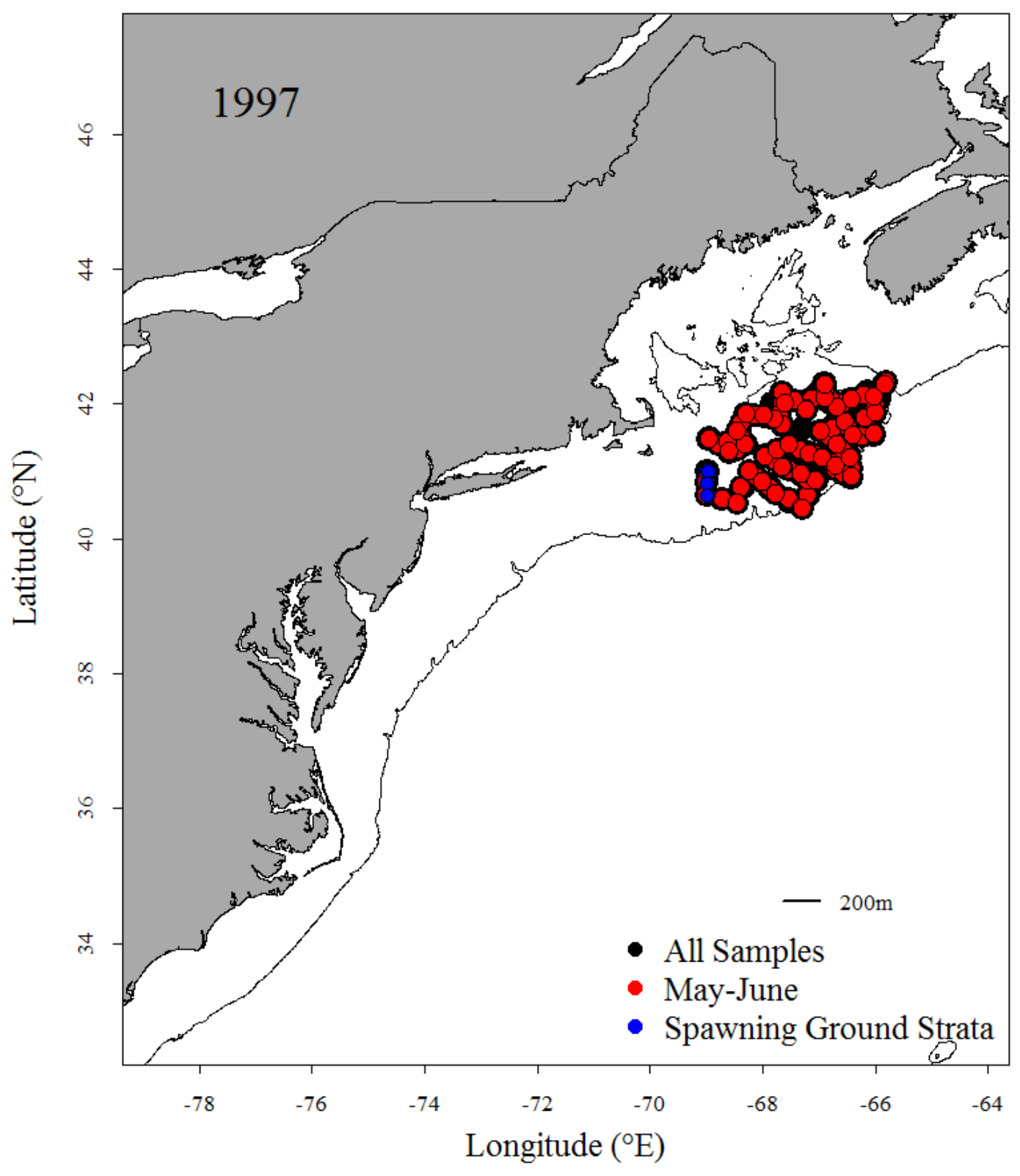




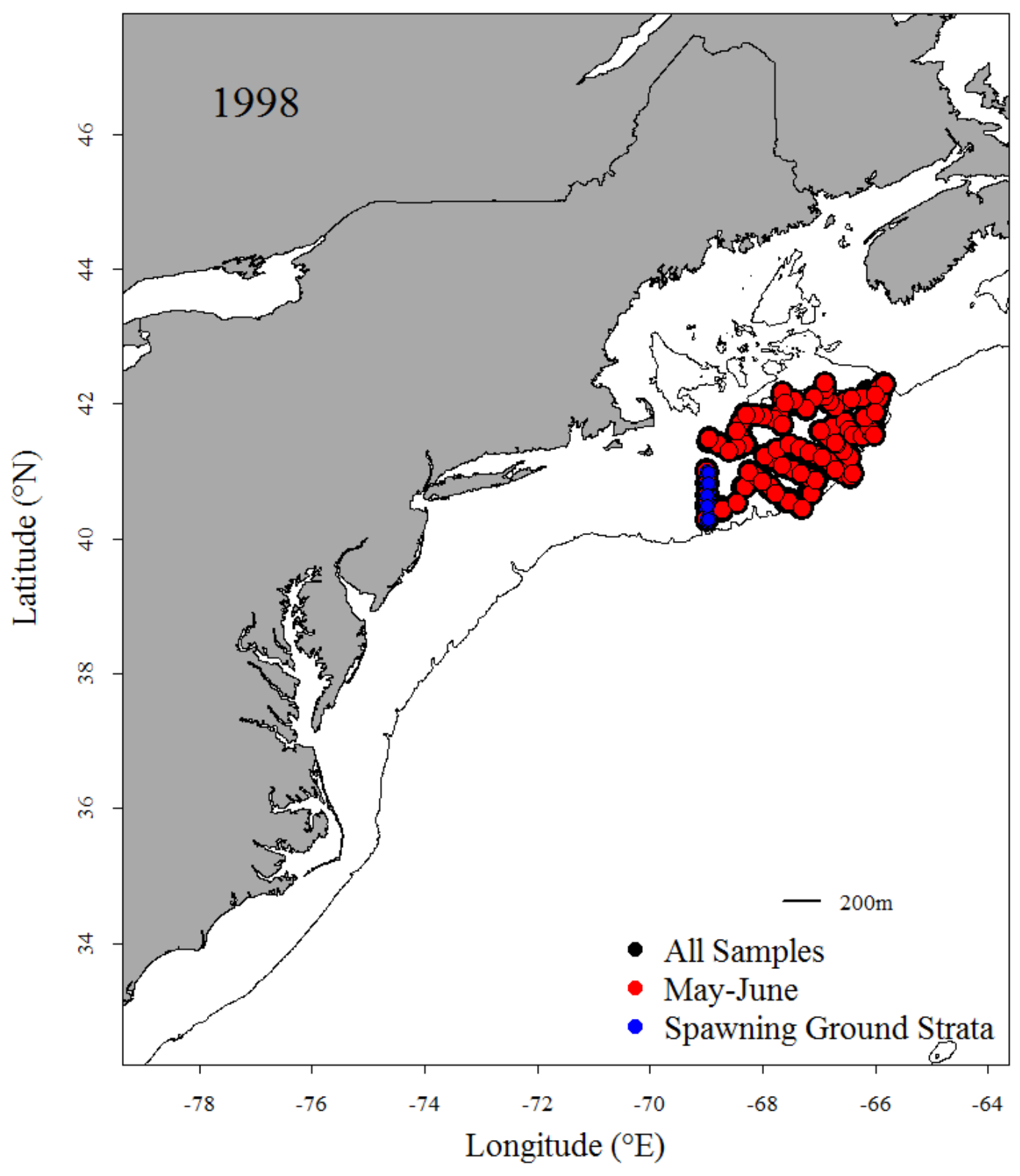




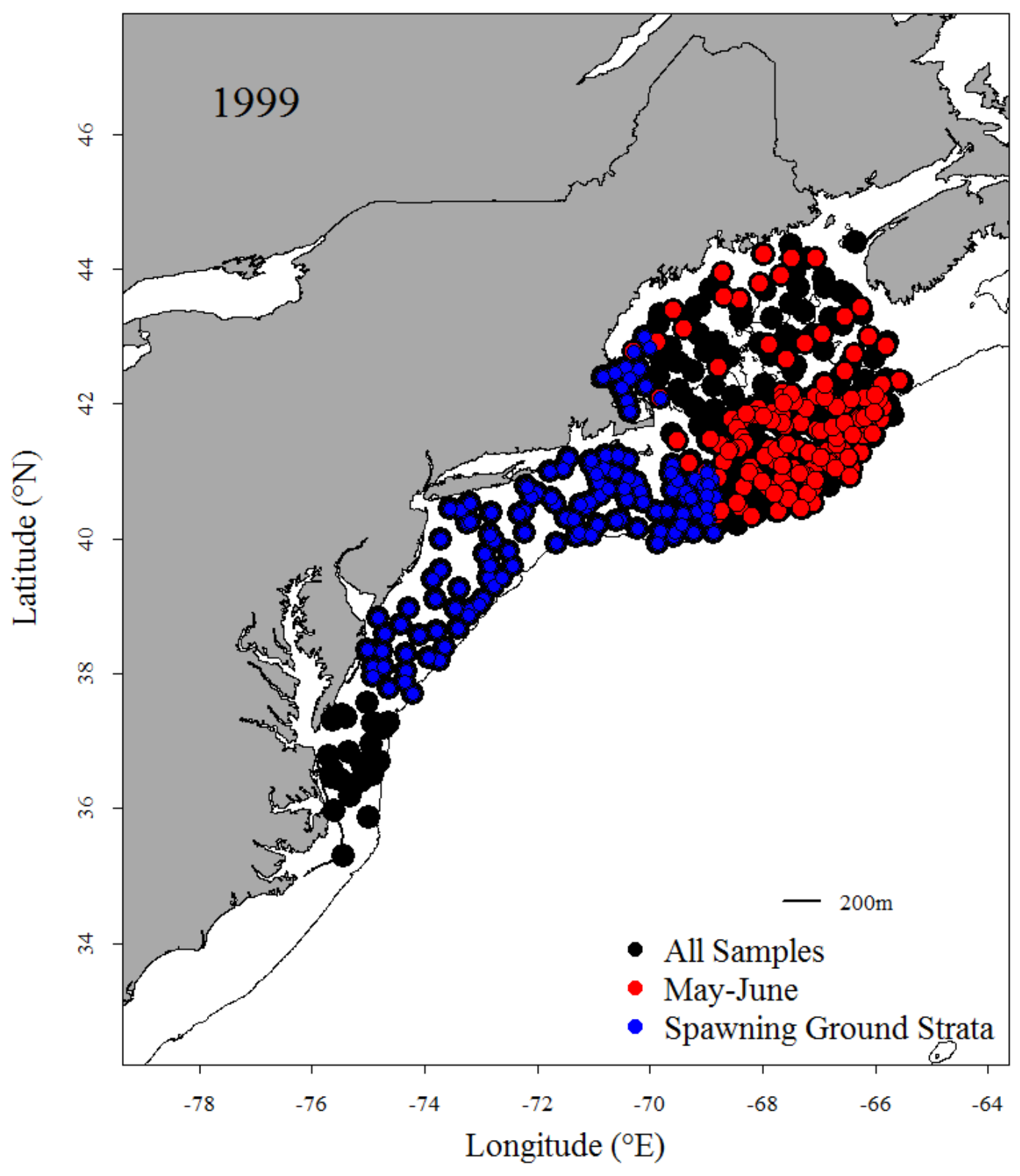




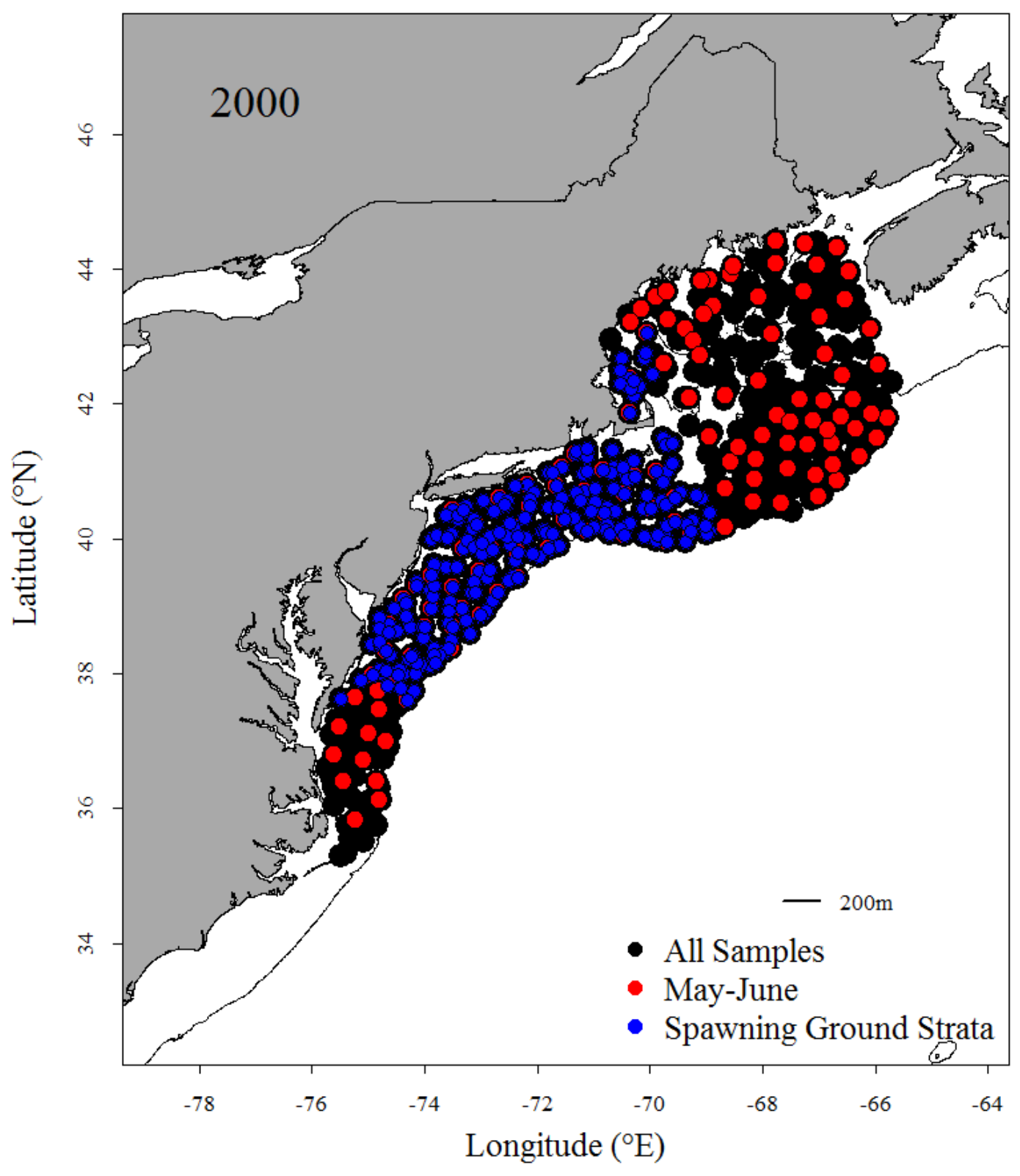




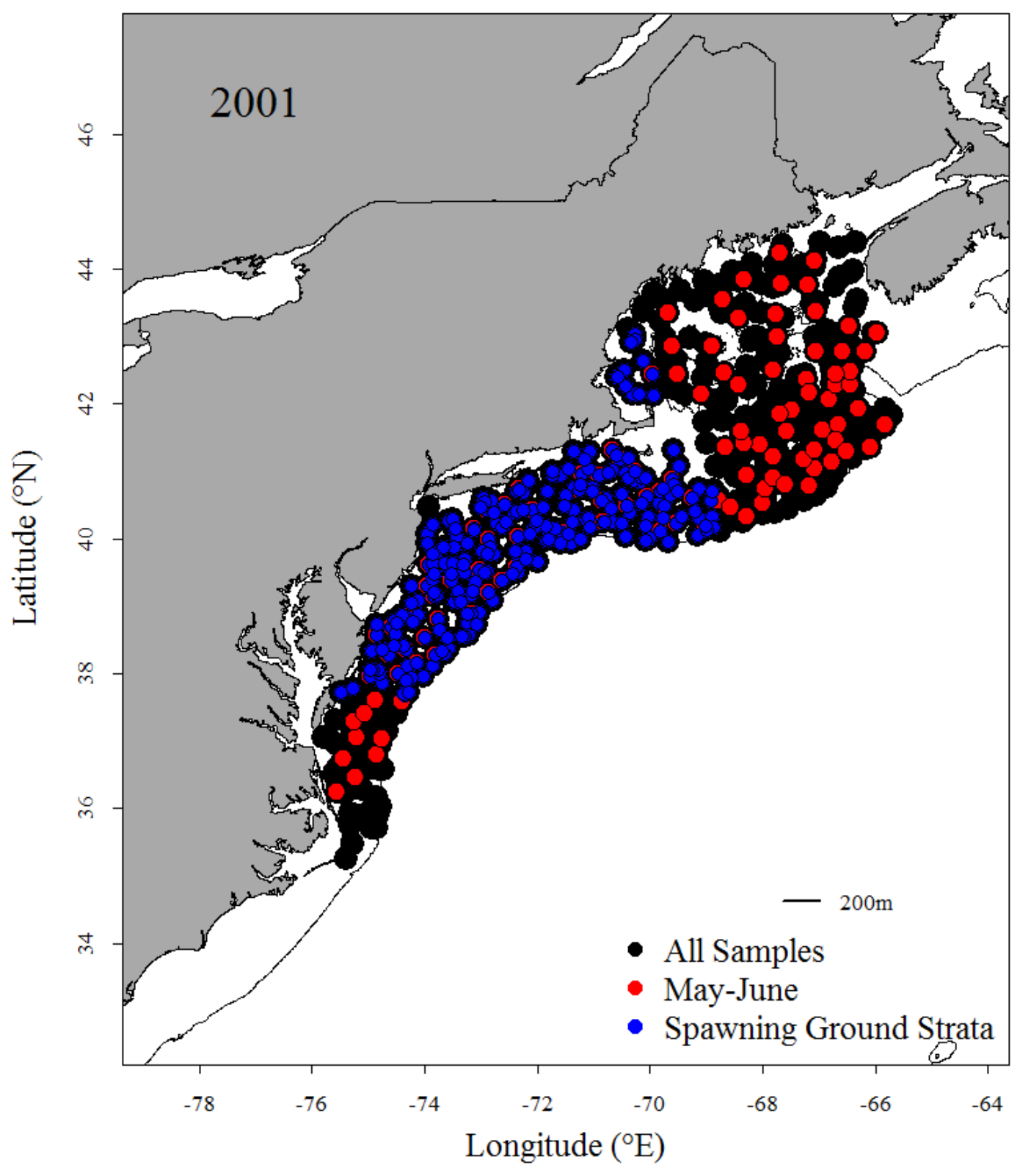




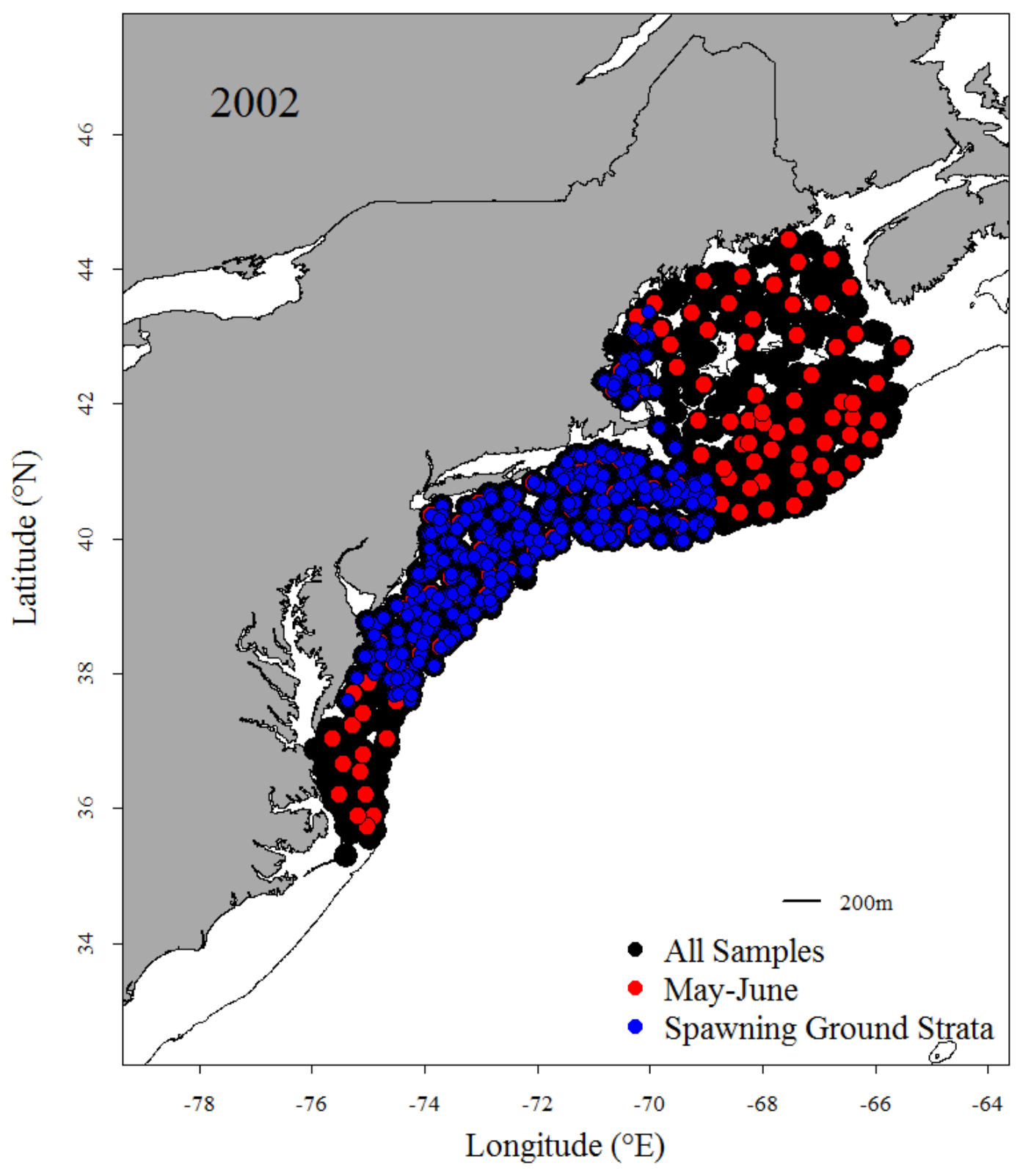




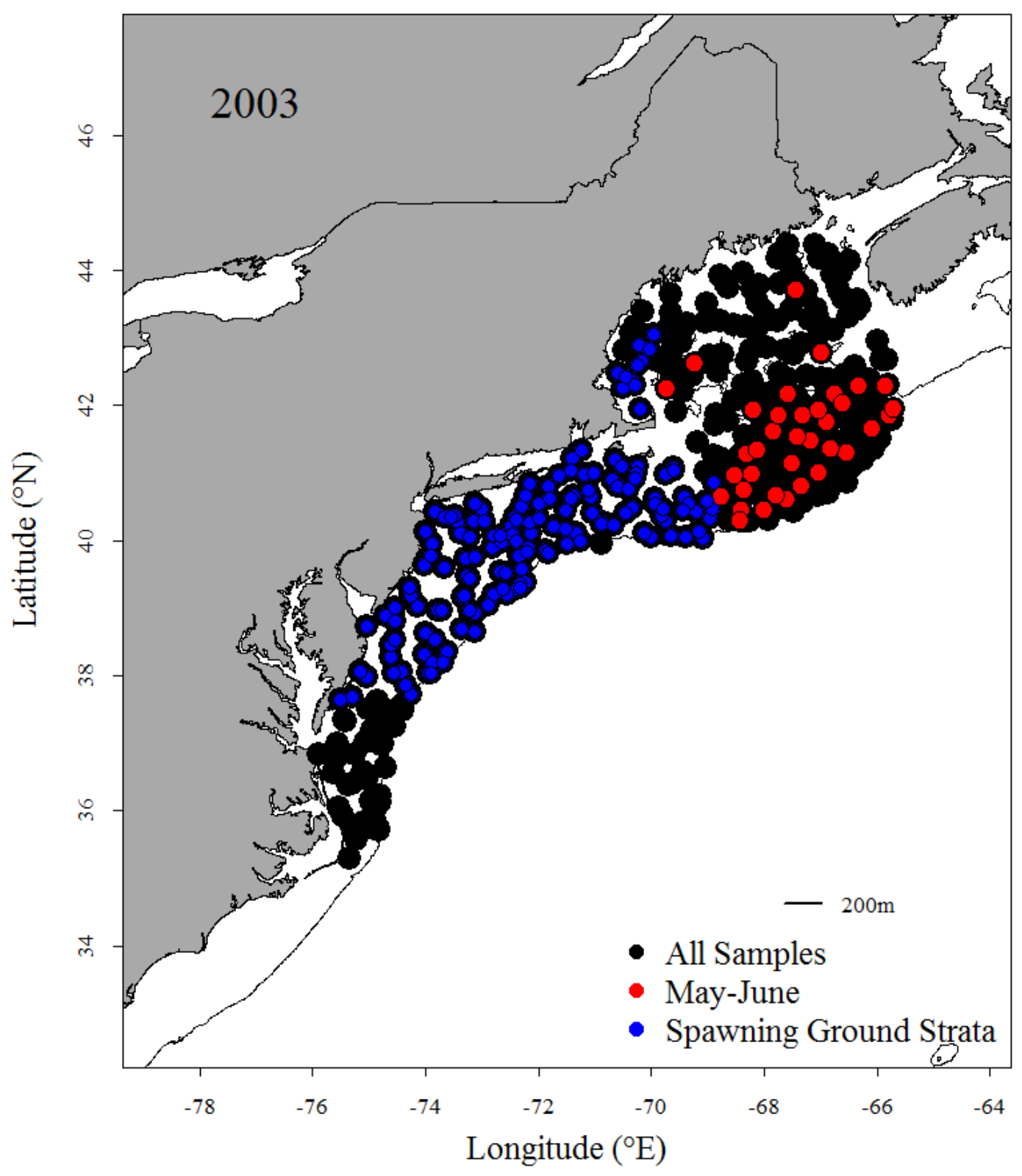




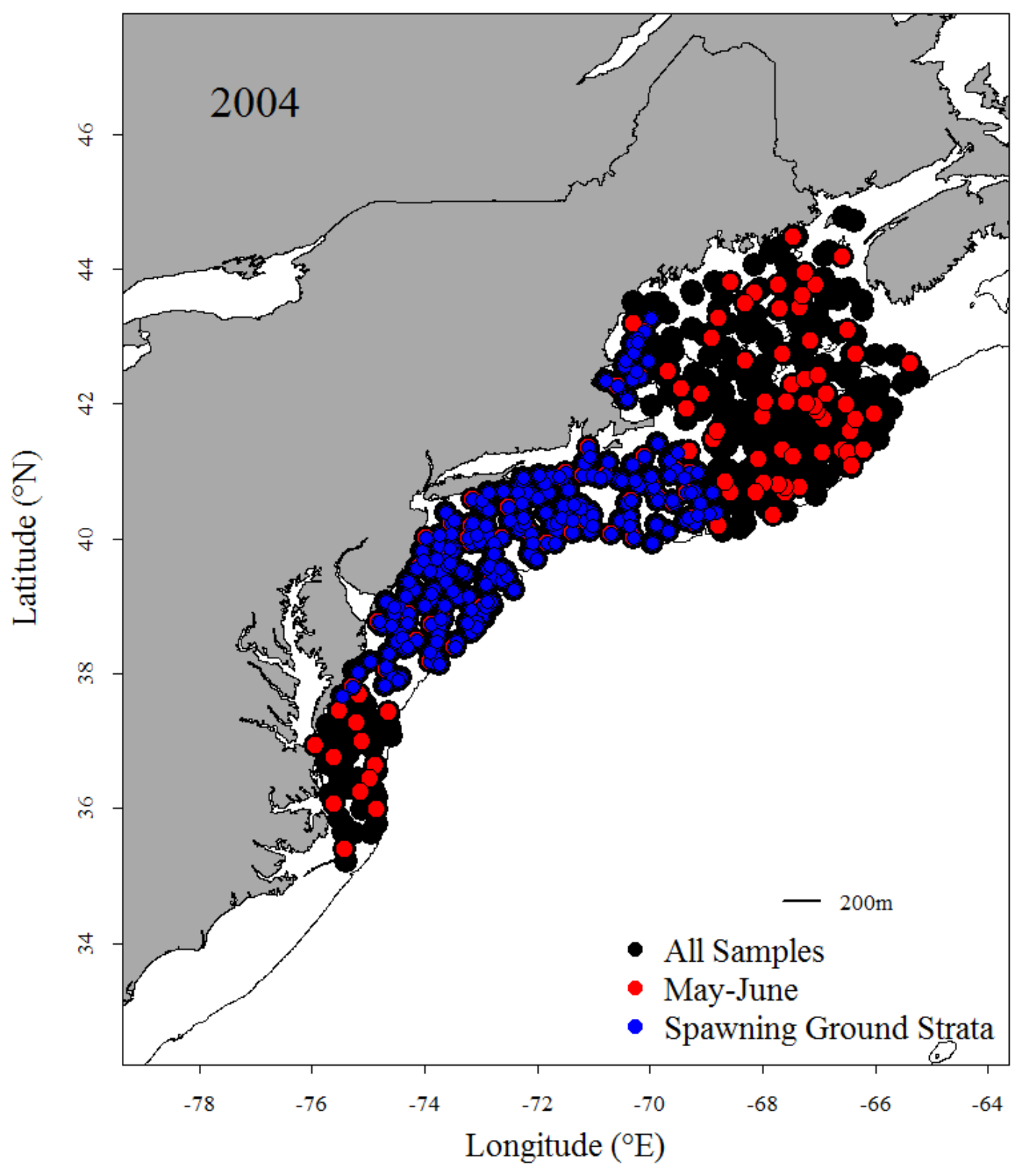




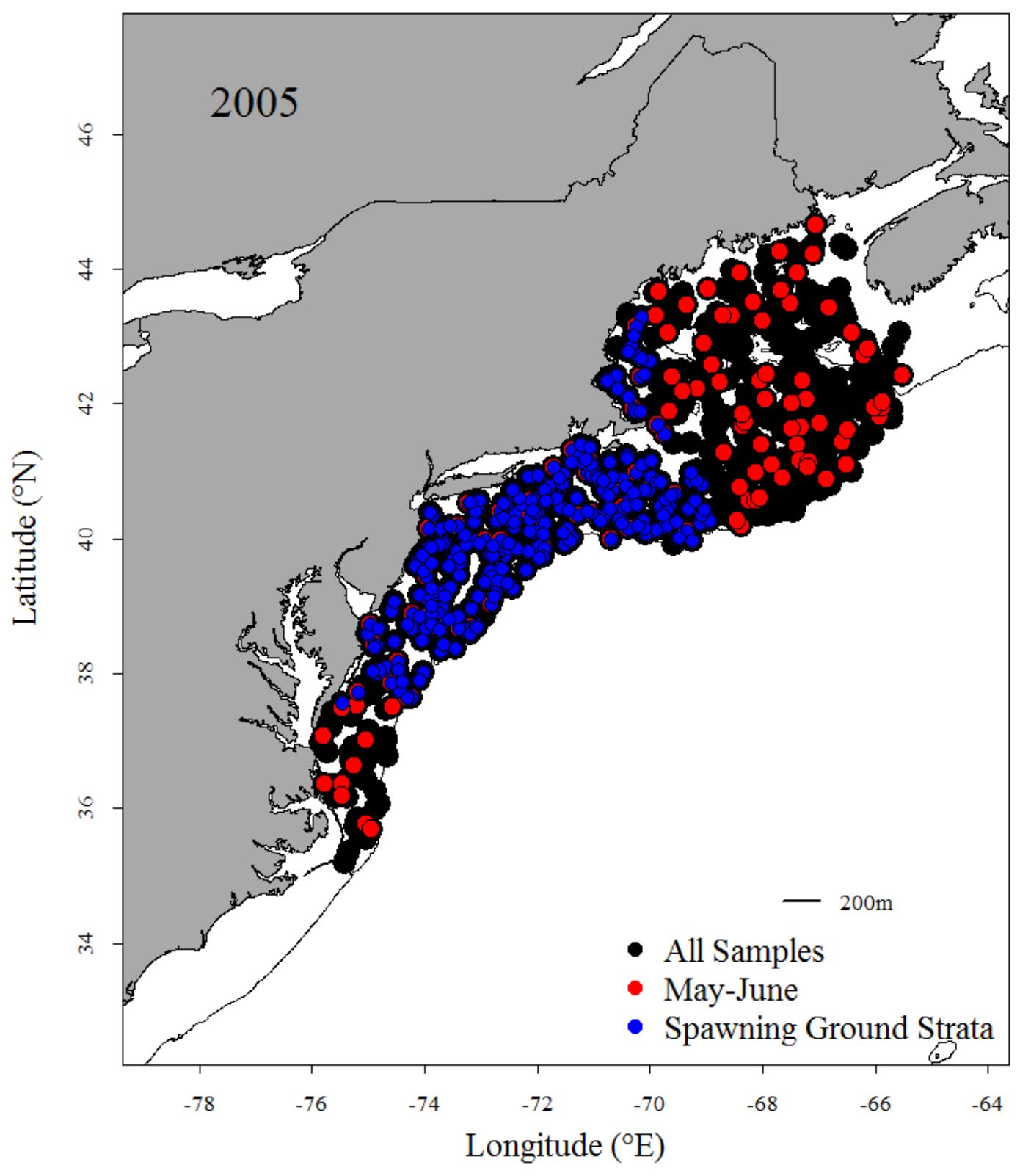




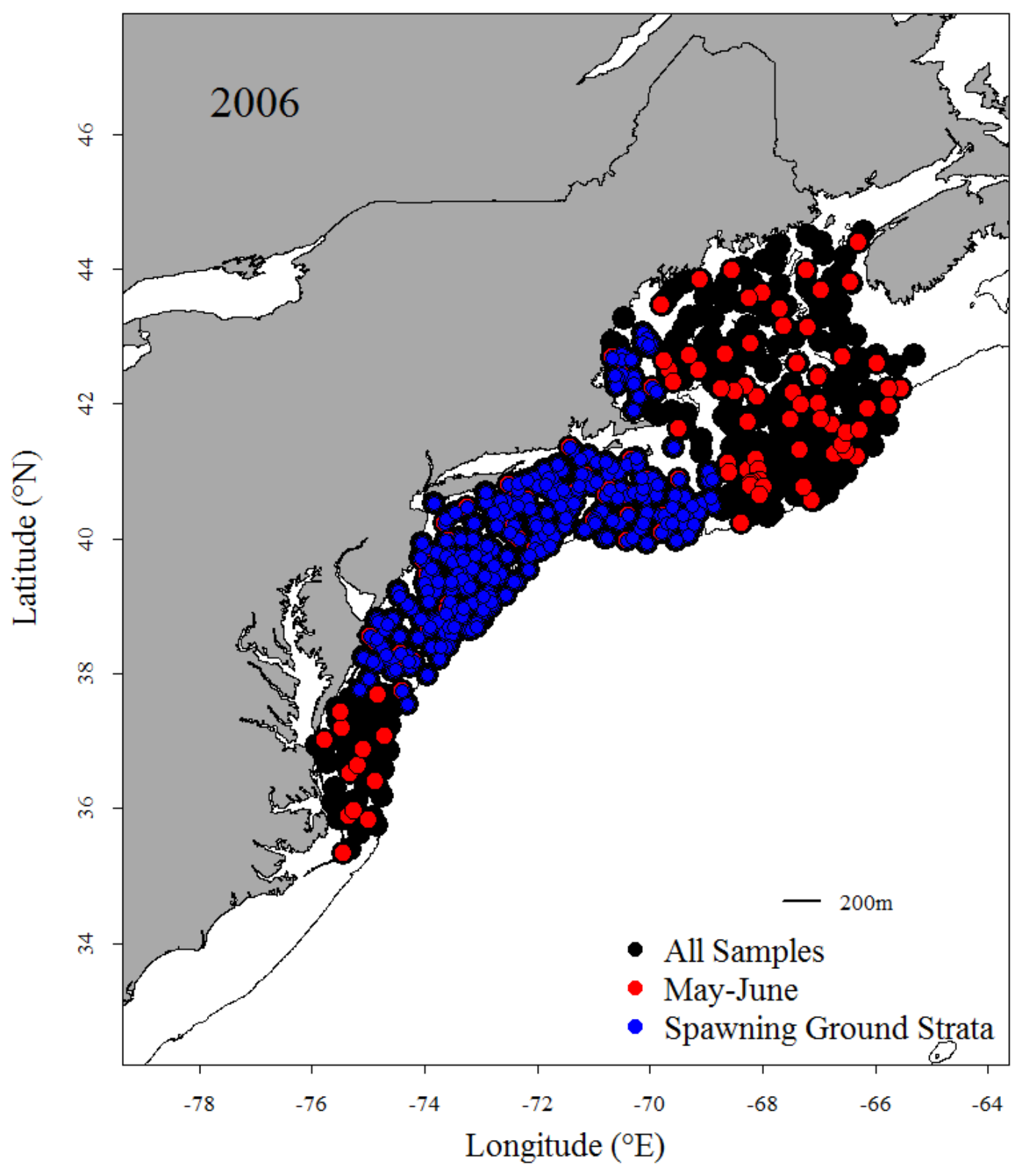




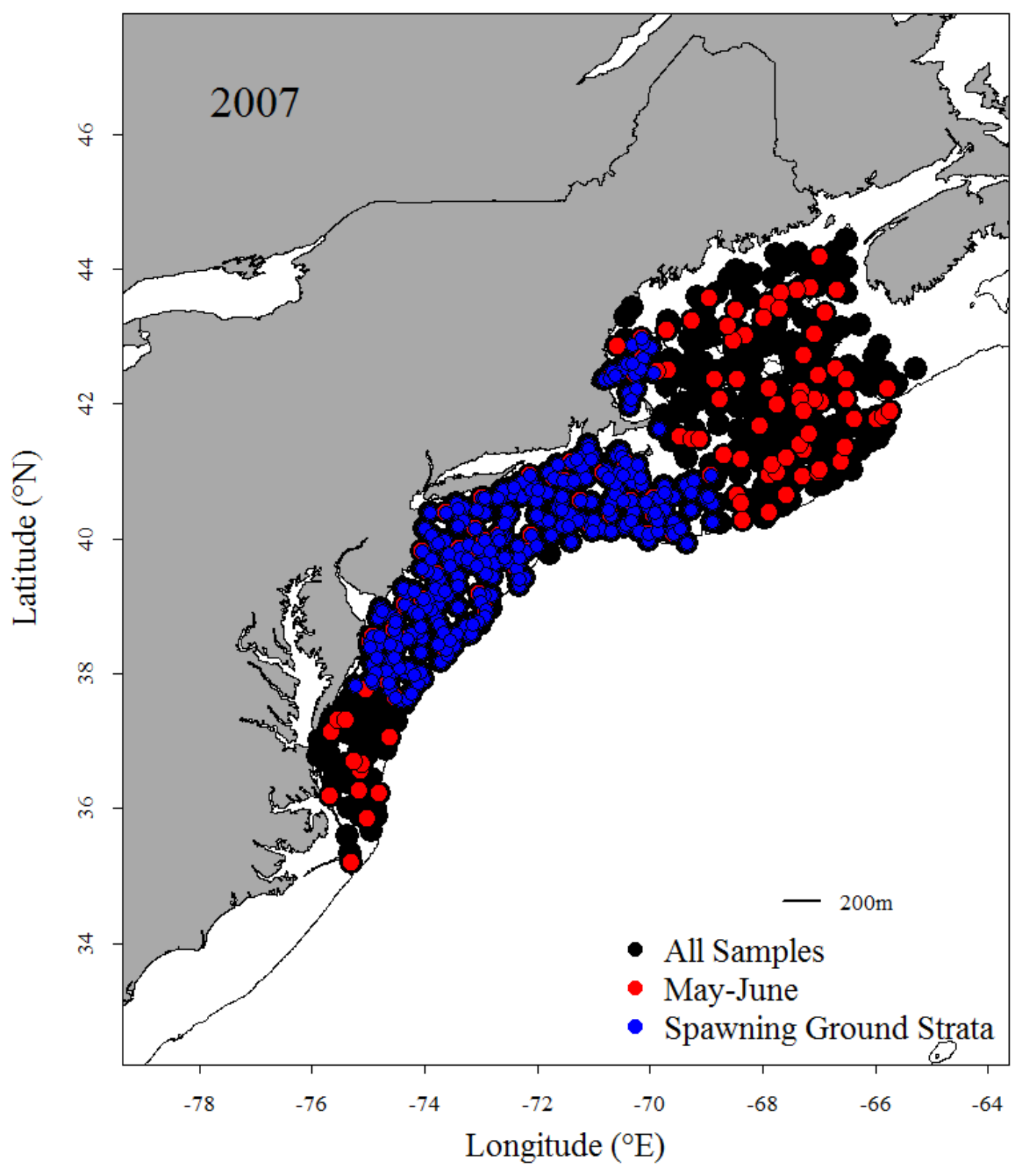




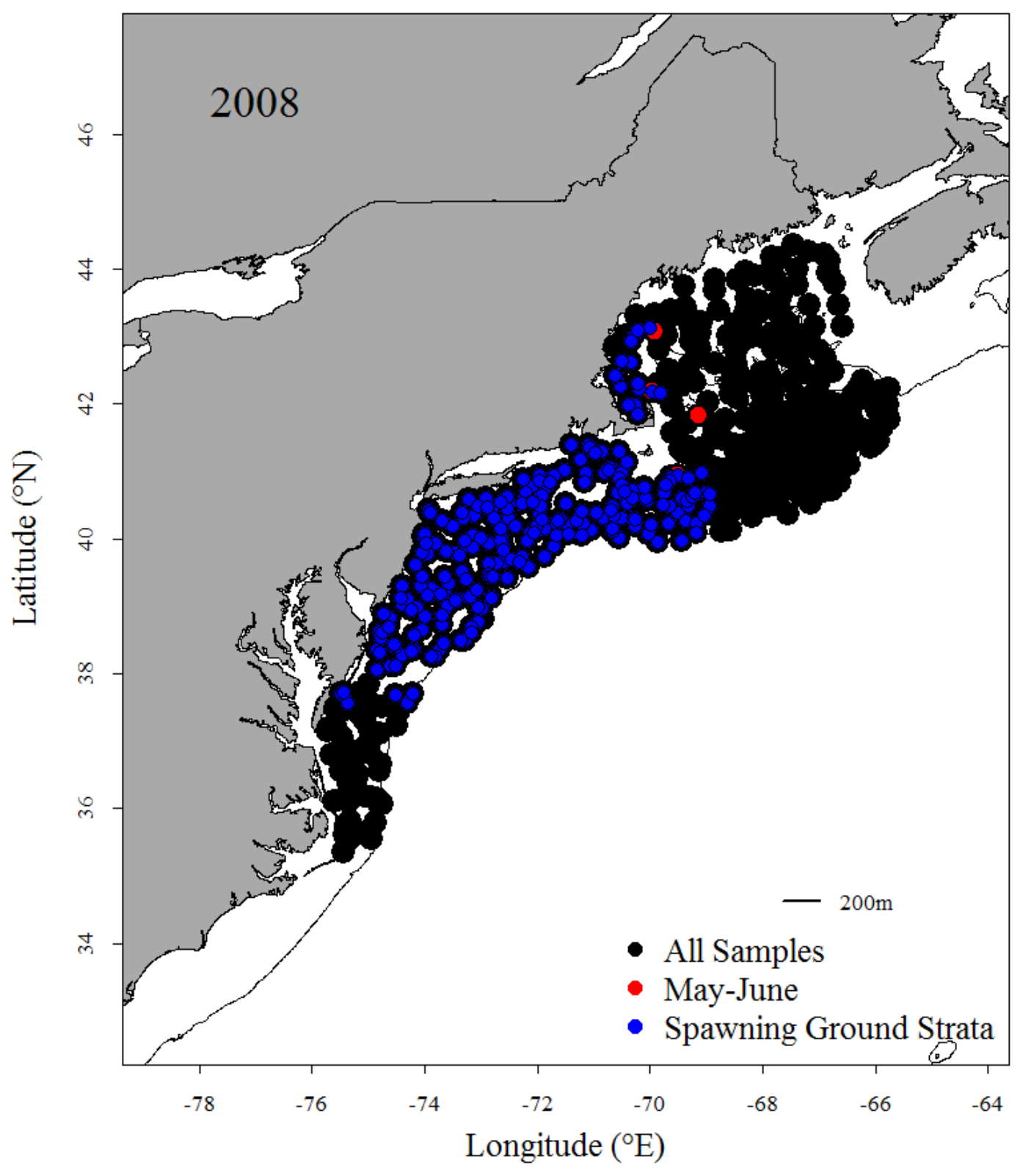




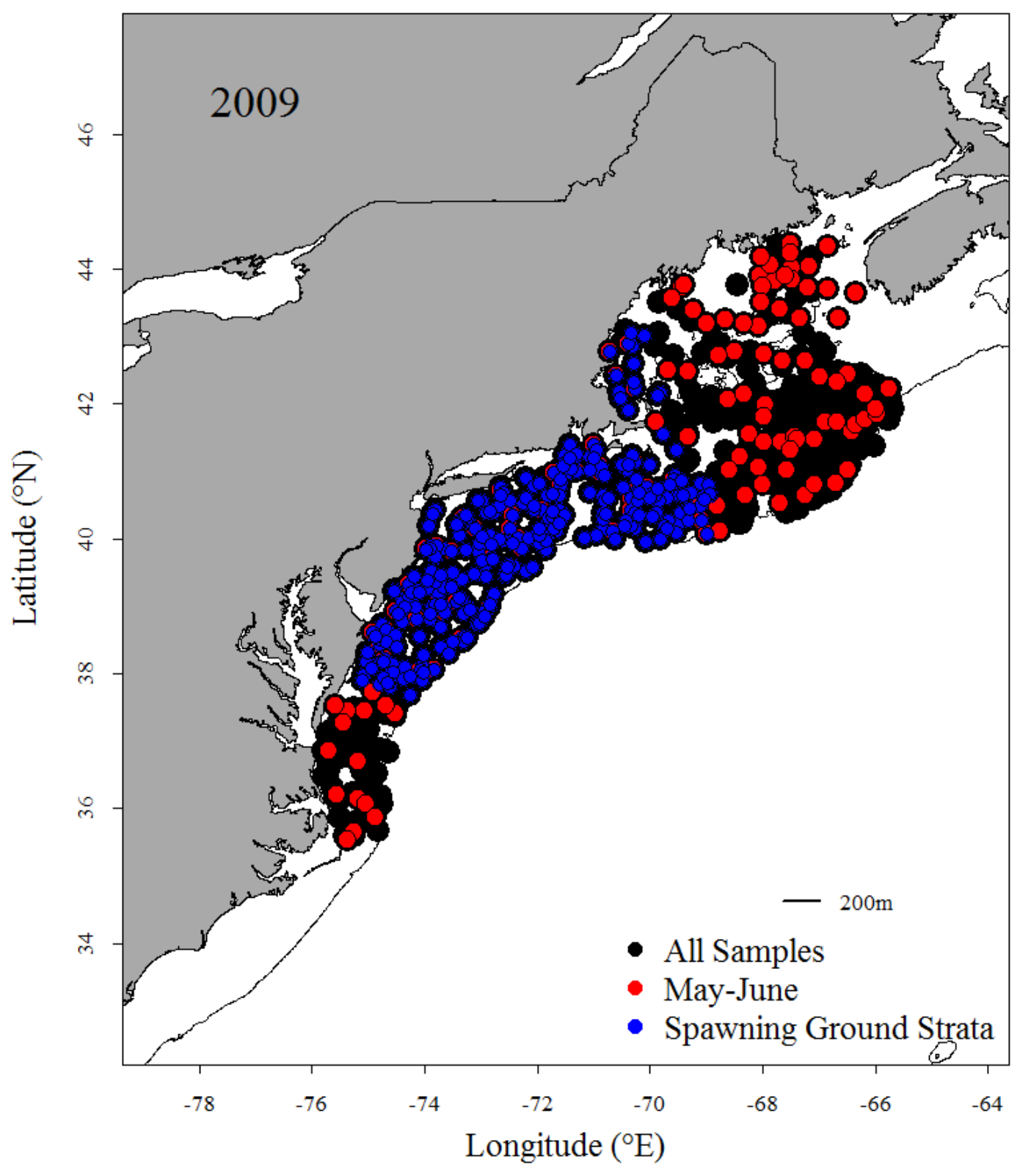




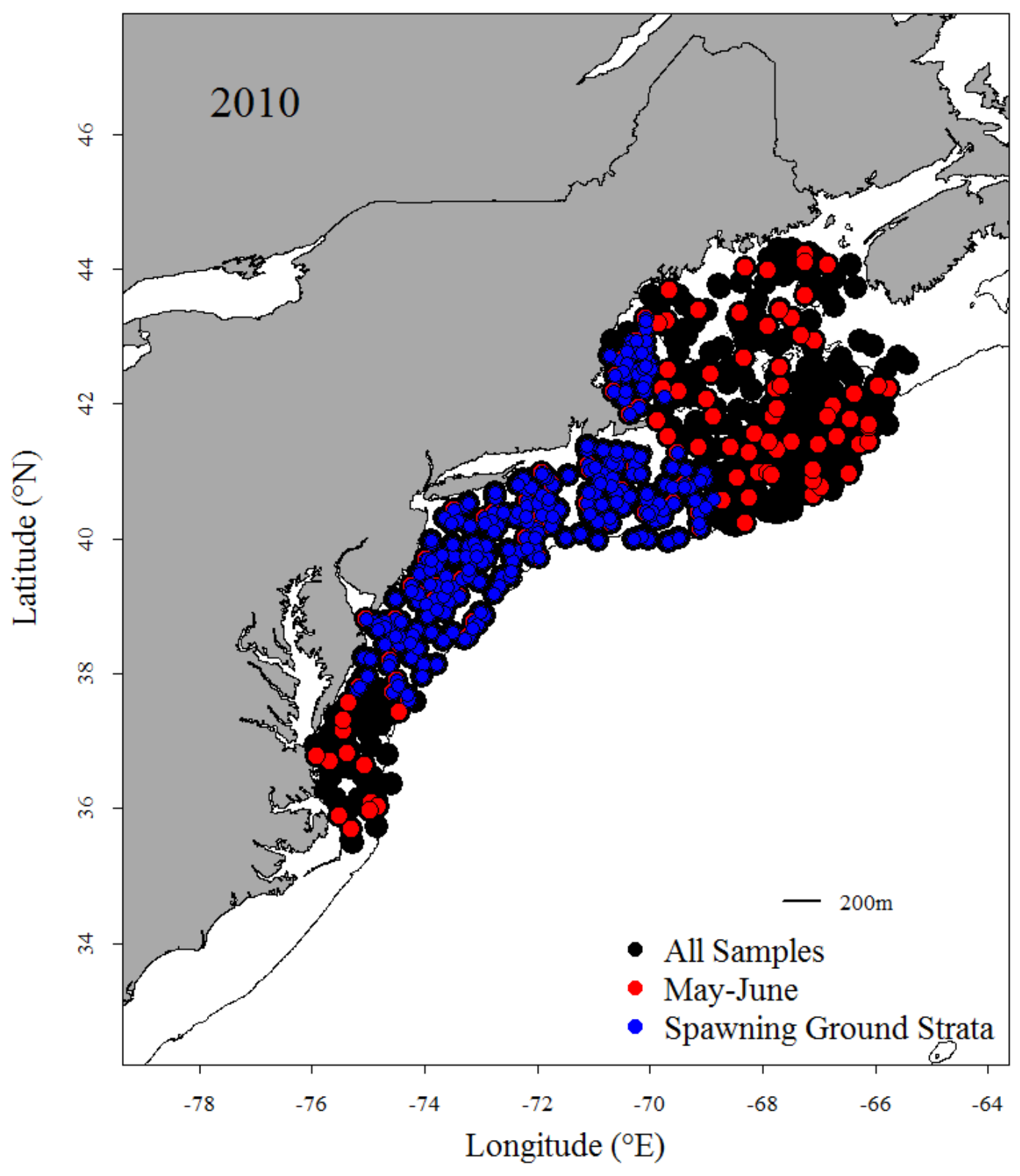




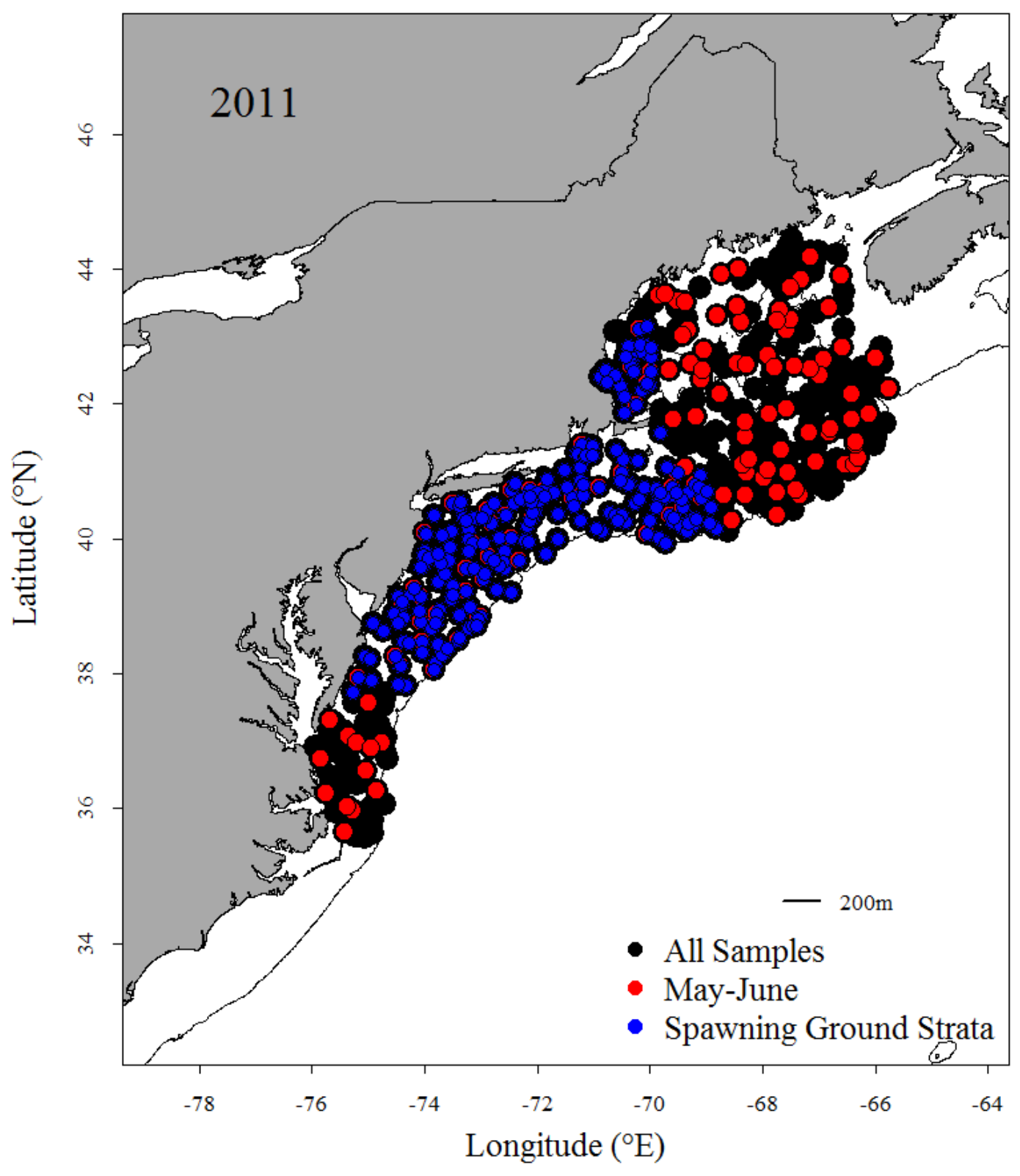




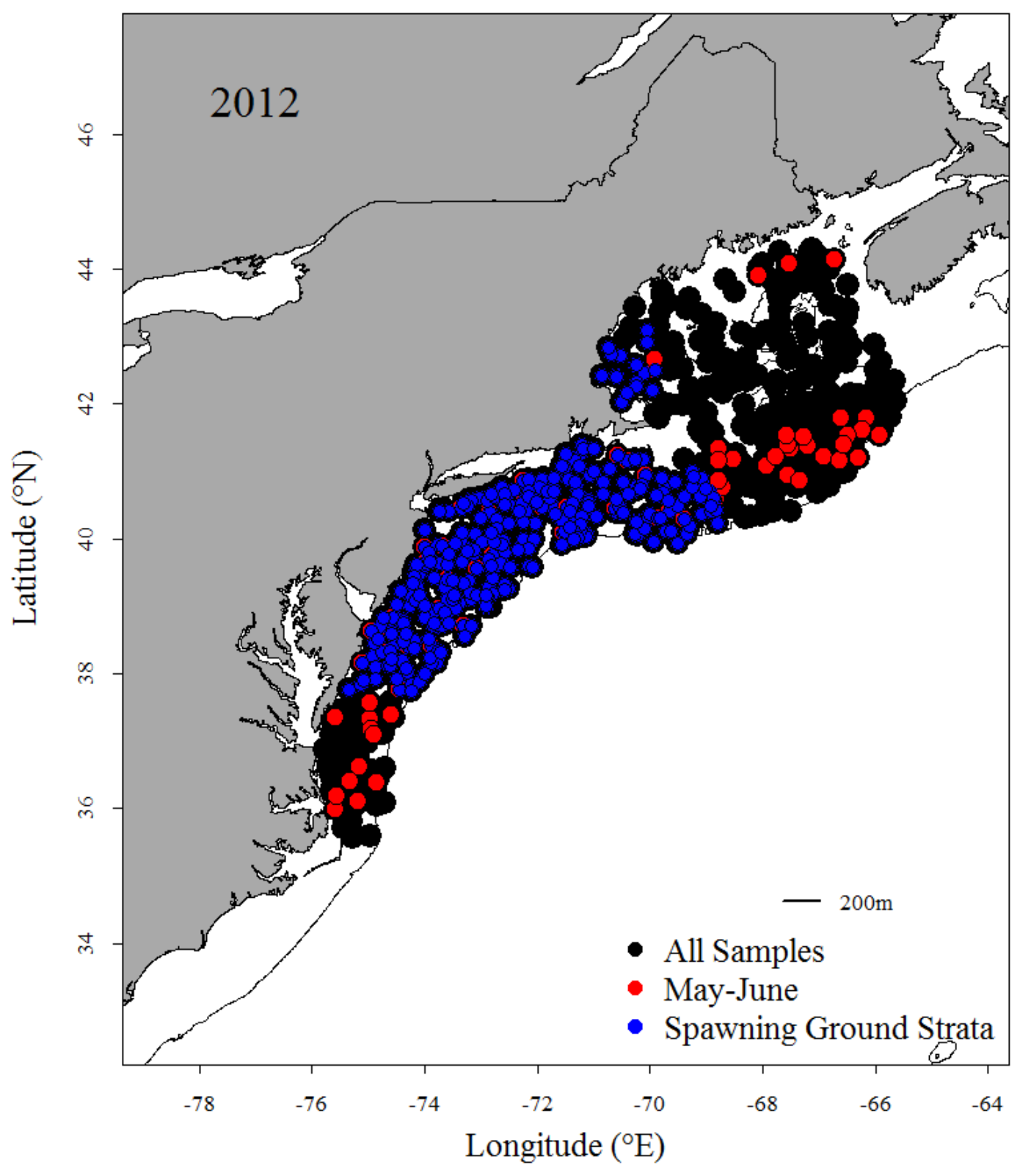




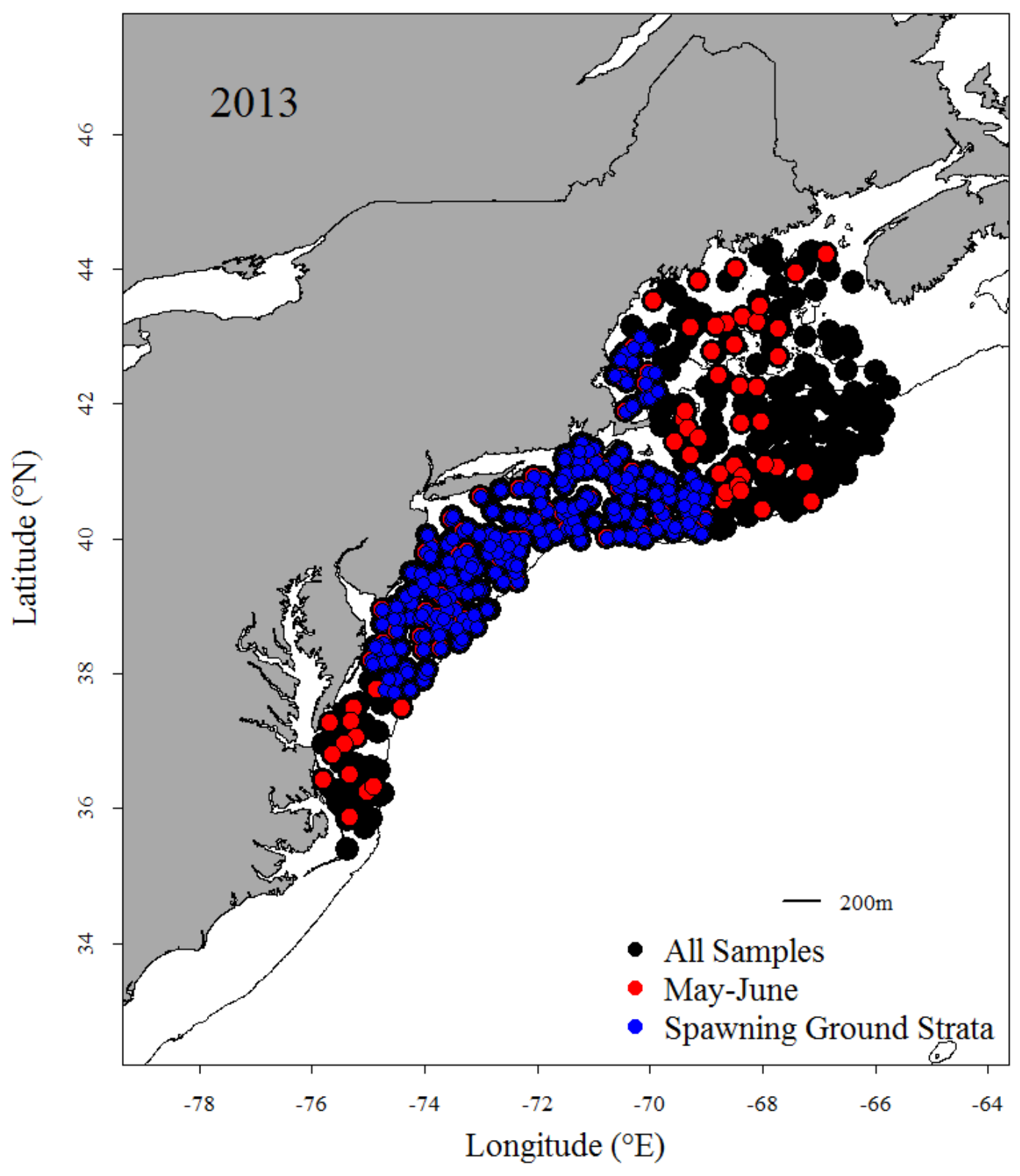




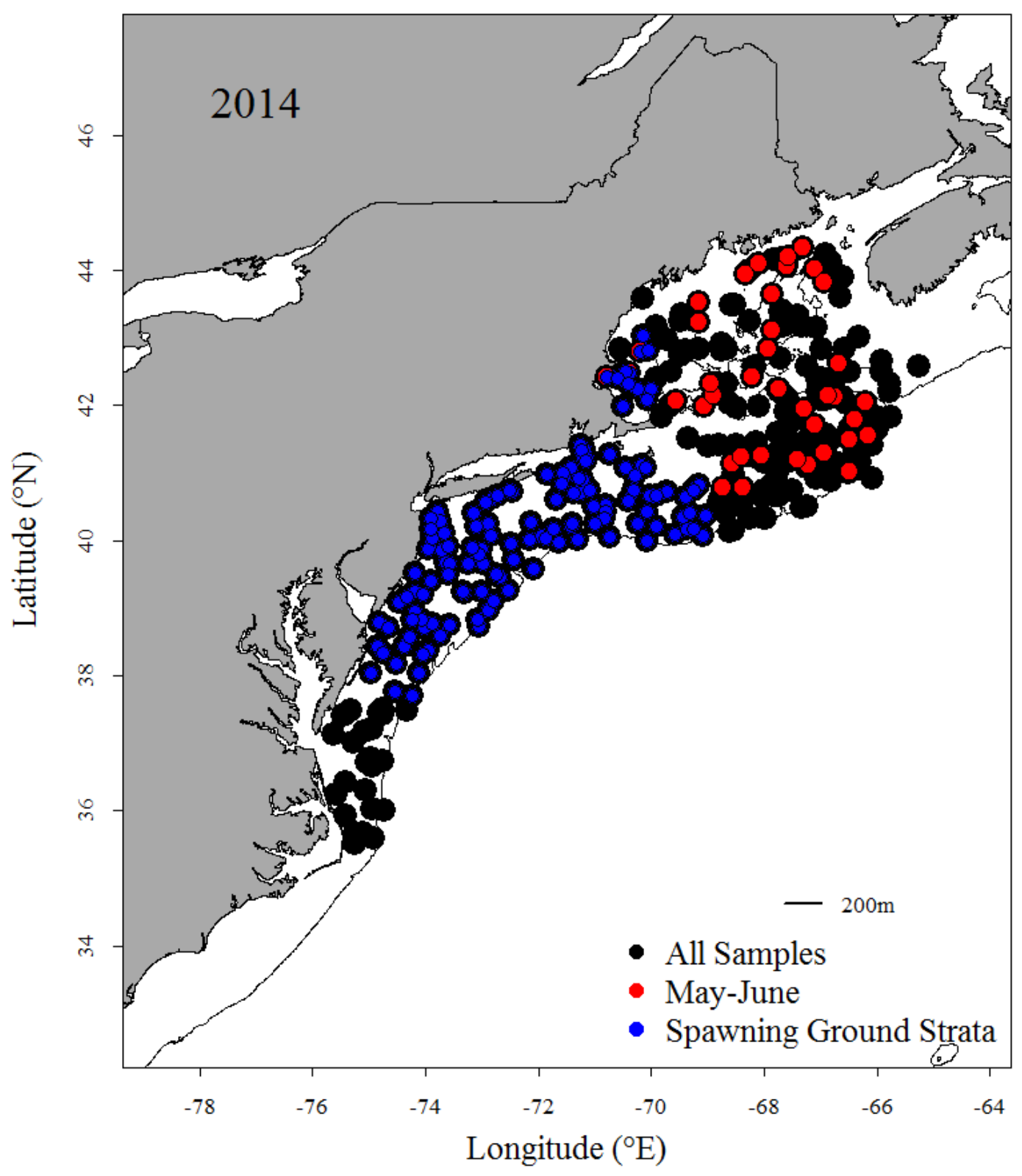




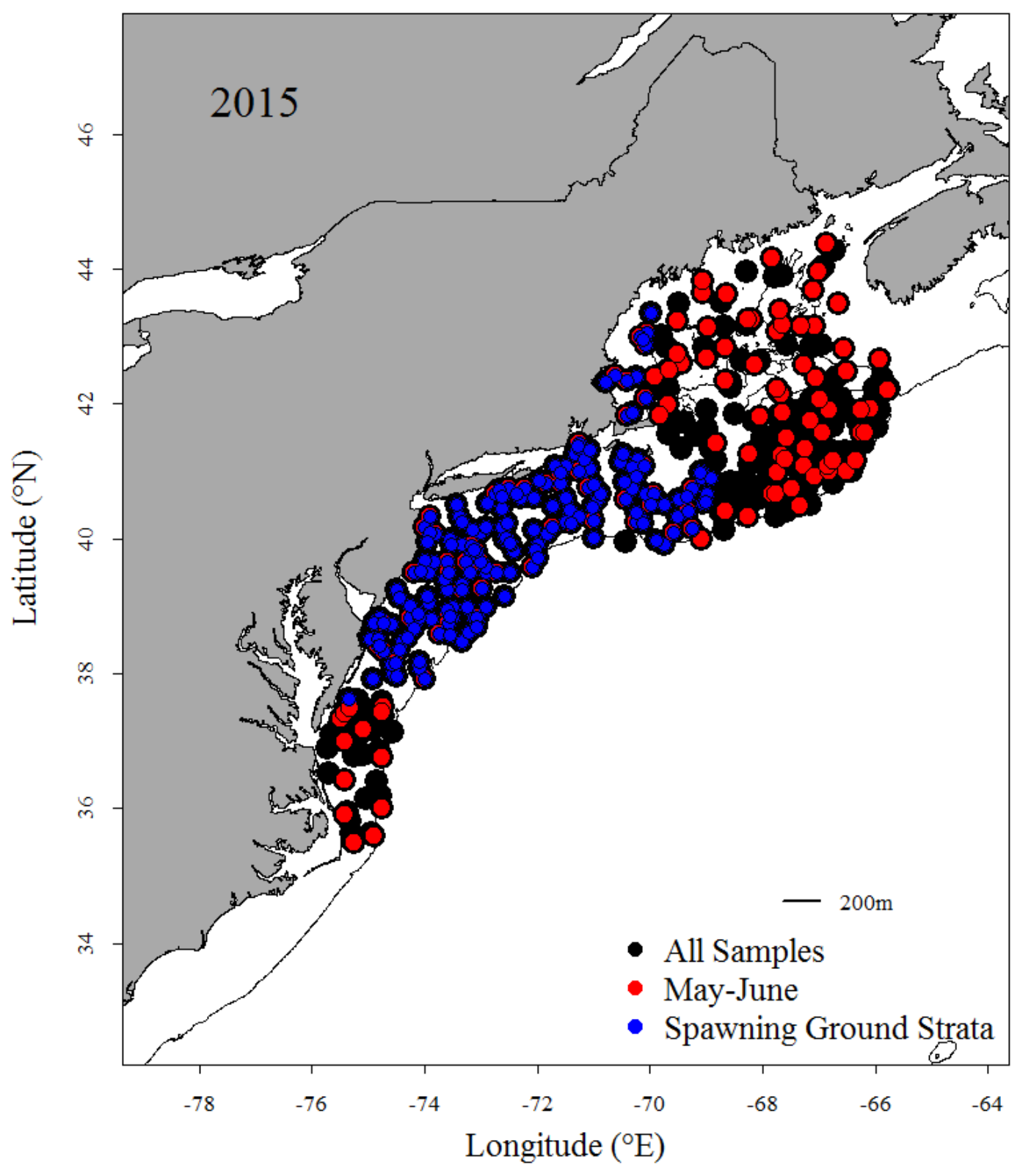




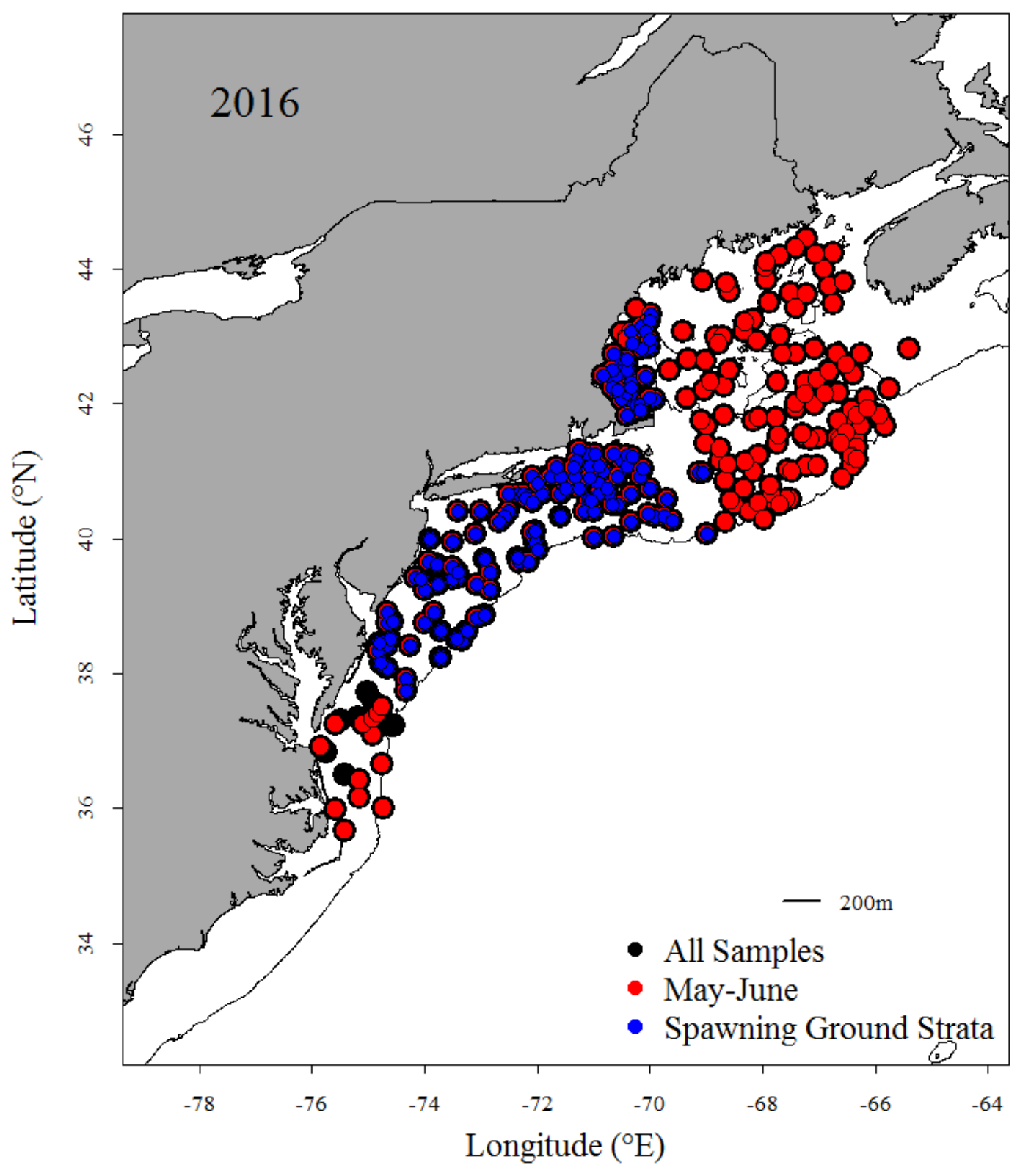


Supplement 2. Summary of extrusion work conducted to date by the Northeast Fisheries Science Center, with emphasis on data available for Atlantic mackerel.

NEFSC staff have begun collecting dual-mesh samples during the EcoMon cruises to build on the work of Johnson and Morse (1994) and standardize catches between EcoMon and MARMAP samples. Dual mesh sample data are available from 2010-2014. These data were evaluated to determine if there was enough information for Atlantic mackerel to construct a model describing catch ratio by length. These samples captured larvae ranging in size from 2-5mm (Figure S2.A). Linear and power functions were used to describe the relationship between catch ratios and length. The two models fit equally well, and reflected little change in catch between the mesh sizes over length. Estimated catch ratios were all above 1, suggesting that extrusion is not apparent or that $0.505 \mathrm{~mm}$ mesh is better at sampling larvae than $0.333 \mathrm{~mm}$ mesh (contrary to our hypothesis). Predicted relationships indicated stable or slightly increasing catch ratios over size, suggesting that all sizes within this range are equally sampled by the $0.505 \mathrm{~mm}$ mesh net. This finding also contradicts the hypothesis that smaller larvae are extruded greater than larger larvae. Lack of corroboration between these fits and our hypothesis could be for several reasons. Data used represent few samples $(\mathrm{N}=16)$ over three days $(6 / 18 / 2011,6 / 19 / 2011,6 / 2 / 2012)$ in the Gulf of Maine only. Additionally, observed lengths only covered a small portion of the larval length range. Given the small sample size and size range represented, these data have not been used to correct samples for extrusion.

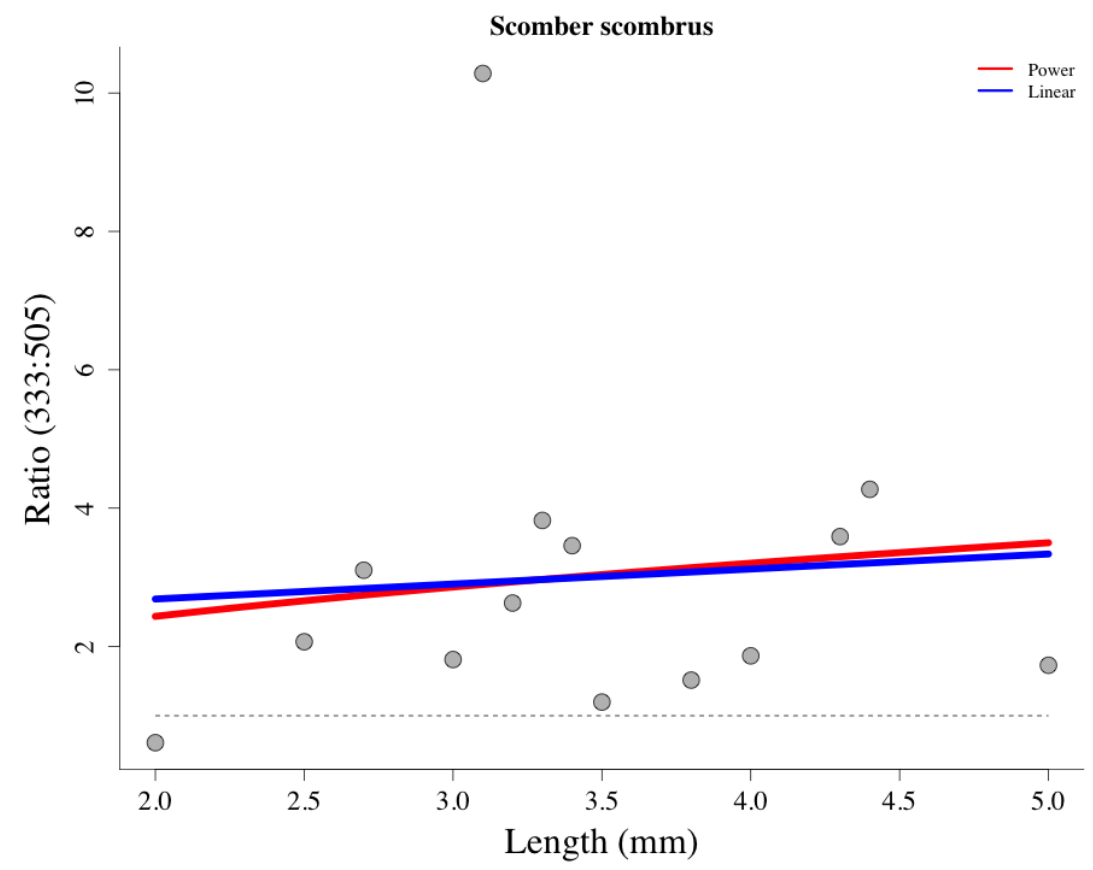

Figure S2.A. Larval catch ratios between dual mesh nets $(0.333: 0.505 \mathrm{~mm})$ by length $(0.1$ $\mathrm{mm})$. Dotted line represents 1:1 line. AIC scores indicated little difference between model fits. 
Supplement 3. Growth rates for larval and young-of-year Atlantic mackerel available from the literature.

\begin{tabular}{|c|c|c|c|c|c|}
\hline Formula Type & Regression & Size Range & $\begin{array}{l}\text { North } \\
\text { Atlantic }\end{array}$ & Region & Reference \\
\hline Linear & $\mathrm{L}=\mathrm{mA}+\mathrm{b}$ & $3-18 \mathrm{~mm}$ & $\mathrm{~W}$ & Gulf of St. Lawrence & Robert et al. (2014) \\
\hline Gompertz & $\mathrm{L}=23 \mathrm{e}^{-\mathrm{e}^{-0.028(\mathrm{~A}-234)}}$ & $\sim 5-19 \mathrm{~cm}$ & $\mathrm{~W}$ & Gulf of St. Lawrence & $\begin{array}{l}\text { Ware and Lambert* } \\
\text { (1985) }\end{array}$ \\
\hline Gompertz & $\mathrm{L}=180.8 \mathrm{e}^{-\mathrm{e}^{-0.043(A-37.7)}}$ & $7-192 \mathrm{~mm}$ & $\mathrm{~W}$ & Gulf of St. Lawrence & D'Amours et al. (1990) \\
\hline Gompertz & $\mathrm{L}=194.2 \mathrm{e}^{-\mathrm{e}^{-0.028(\mathrm{~A}-62.1)}}$ & $3.6-215 \mathrm{~mm}$ & $\mathrm{E}$ & Bay of Biscay & Cotano et al. (2003) \\
\hline Gompertz & $\mathrm{L}=169.1 \mathrm{e}^{-\mathrm{e}^{-0.047(\mathrm{~A}-36.2)}}$ & $\begin{array}{l}4-143 \mathrm{~mm}, 168- \\
190 \mathrm{~mm}\end{array}$ & W & $\begin{array}{c}\text { Gulf of St. Lawrence \& St. } \\
\text { Georges Bay }\end{array}$ & Simard et al. (1992) \\
\hline Gompertz & $\mathrm{L}=192.5 \mathrm{e}^{-\mathrm{e}^{-0.040(A-39.7)}}$ & $3-183 \mathrm{~mm}$ & $\mathrm{~W}$ & $\begin{array}{c}\text { Cape Cod, Cape Cod-Cape } \\
\text { Hatteras }\end{array}$ & Simard et al. (1992) \\
\hline Gompertz & $\mathrm{L}=200.2 \mathrm{e}^{-\mathrm{e}^{-0.038(\mathrm{~A}-55.2)}}$ & $\begin{array}{l}2.3-38.8 \mathrm{~mm}, 119- \\
208 \mathrm{~mm}\end{array}$ & $\mathrm{E}$ & Iberian Peninsula & Villamor et al. (2004) \\
\hline Gompertz & $\mathrm{L}=74.2712\left(1-\mathrm{e}^{\left.-\mathrm{e}^{-0.1385(\mathrm{I}-36.1064)}\right)^{0.6174}}\right.$ & $3.4-81 \mathrm{~mm}$ & W & Cape Lookout-Montauk & $\begin{array}{l}\text { Kendall and Gordon } \\
(1981)^{* *}\end{array}$ \\
\hline
\end{tabular}

*234 represents 0 day olds

**In units of otolith increment, not daily age. They assumed a 9 day lag between the time of spawning and the appearance of the first otolith increment. This lag was added to the growth curve and an initial point at $3.0 \mathrm{~mm}$ at 9 days was added to represent size and time at initial increment formation. 


\section{Literature Cited}

Cotano, U., and P. Álvarez. 2003. Growth of young-of-year mackerel in the Bay of Biscay. Journal of Fish Biology, 62:1010-1020.

D’Amours D., J.G. Landry, and T.C. Lambert. 1990. Growth of juvenile (0-group) Atlantic mackerel (Scomber scombrus) in the Gulf of St. Lawrence. Canadian Journal of Fisheries and Aquatic Sciences, 47: 2212-2218.

Kendall A.W., and D. Gordon. 1981. Growth rate of Atlantic mackerel (Scomber scombrus) larvae in the middle Atlantic Bight. Rapp PV Reun Cons Int Explor Mer 178:337-341.

Robert, D., P. Pepin, J.F. Dower, and L. Fortier. 2014. Individual growth history of larval Atlantic mackerel is reflected in daily condition indices. ICES Journal of Marine Science, 71(4): 1001-1009.

Simard, P. M. Castonguay, D. D’Amours, and P. Magnan. 1992. Growth comparison between juvenile Atlantic mackerel (Scomber scombrus) for the two spawning groups in the Northwest Atlantic. Canadian Journal of Fisheries and Aquatic Sciences, 49:2242-2248.

Villamor, B., M. Bernal, and C. Hernandez. 2004. Models describing mackerel (Scomber scombrus) early life growth in the North and Northwest of the Iberian Peninsula in 2000. Scientia Marina, 68(4): 571-583.

Ware, D.M., and T.C. Lambert. 1985. Early life history of Atlantic mackerel (Scomber scombrus) in the southern Gulf of St. Lawrence. Canadian Journal of Fisheries and Aquatic Sciences, 42: 577-592. 
Supplement 4. MARMAP and EcoMon surveys evaluated for inclusion in larval index calculations. Start and end dates are provided to assess temporal coverage within a year. The updated SurveyID used for aggregating samples in the larval index calculation are presented. SurveyID with 'NA' indicates that the survey was not used in the larval index calculations.

\begin{tabular}{|c|c|c|c|}
\hline NOAA SURVEY ID & START DATE & END DATE & SurveyID \\
\hline MM7701 & $02 / 13 / 77$ & $02 / 24 / 77$ & 33 \\
\hline GO7701 & 03/04/77 & $04 / 06 / 77$ & 34 \\
\hline DE7703 & 03/19/77 & 04/08/77 & 33 \\
\hline DE7704 & $04 / 13 / 77$ & $04 / 29 / 77$ & 34 \\
\hline AL7702 & $04 / 14 / 77$ & $05 / 19 / 77$ & 35 \\
\hline DE7705 & 05/04/77 & $05 / 27 / 77$ & 35 \\
\hline NO7702 & $05 / 23 / 77$ & $06 / 05 / 77$ & 36 \\
\hline DE7707 & $06 / 12 / 77$ & $06 / 30 / 77$ & 36 \\
\hline DE7709 & $07 / 30 / 77$ & 08/03/77 & 38 \\
\hline YU7702 & $07 / 31 / 77$ & 09/01/77 & 38 \\
\hline WI7706 & $10 / 05 / 77$ & $10 / 22 / 77$ & 39 \\
\hline AR7701 & $10 / 18 / 77$ & $11 / 09 / 77$ & 40 \\
\hline AD7703 & $11 / 01 / 77$ & $11 / 15 / 77$ & 41 \\
\hline MM7711 & $11 / 13 / 77$ & $11 / 19 / 77$ & 42 \\
\hline KE7711 & $11 / 28 / 77$ & $12 / 13 / 77$ & 42 \\
\hline DE7713 & $12 / 08 / 77$ & $12 / 19 / 77$ & 42 \\
\hline AL7802 & $02 / 15 / 78$ & $02 / 28 / 78$ & 44 \\
\hline DE7802 & $02 / 16 / 78$ & $03 / 17 / 78$ & 44 \\
\hline AR7804 & $04 / 18 / 78$ & $05 / 23 / 78$ & 45 \\
\hline AL7804 & $04 / 26 / 78$ & $05 / 16 / 78$ & 45 \\
\hline AL7807 & $06 / 24 / 78$ & $07 / 16 / 78$ & 46 \\
\hline BE7801 & $08 / 12 / 78$ & $09 / 04 / 78$ & 47 \\
\hline BE7803 & $10 / 06 / 78$ & $11 / 01 / 78$ & 48 \\
\hline WI7804 & $10 / 14 / 78$ & $10 / 31 / 78$ & 48 \\
\hline DE7806 & $10 / 28 / 78$ & $11 / 11 / 78$ & 48 \\
\hline BE7804 & $11 / 16 / 78$ & $11 / 29 / 78$ & 50 \\
\hline DE7903 & $02 / 25 / 79$ & $03 / 14 / 79$ & 51 \\
\hline AL7903 & $04 / 01 / 79$ & $05 / 07 / 79$ & 52 \\
\hline DE7904 & $04 / 11 / 79$ & $04 / 29 / 79$ & 52 \\
\hline DE7905 & $05 / 06 / 79$ & $05 / 29 / 79$ & 53 \\
\hline AL7906 & $06 / 17 / 79$ & $07 / 13 / 79$ & 54 \\
\hline BE7901 & $08 / 11 / 79$ & $09 / 02 / 79$ & 55 \\
\hline AL7911 & $10 / 04 / 79$ & $10 / 28 / 79$ & 56 \\
\hline AL7913 & $11 / 15 / 79$ & $12 / 20 / 79$ & 57 \\
\hline WI7903 & $11 / 15 / 79$ & $11 / 21 / 79$ & 57 \\
\hline WI8002 & $02 / 20 / 80$ & $03 / 10 / 80$ & 58 \\
\hline AL8002 & $02 / 28 / 80$ & $04 / 04 / 80$ & 58 \\
\hline EK8001 & $04 / 16 / 80$ & $05 / 14 / 80$ & 59 \\
\hline AL8003 & $04 / 27 / 80$ & $04 / 30 / 80$ & 59 \\
\hline DE8002 & $05 / 01 / 80$ & $05 / 06 / 80$ & 59 \\
\hline DE8003 & $05 / 23 / 80$ & $06 / 12 / 80$ & 60 \\
\hline EK8004 & $06 / 25 / 80$ & $06 / 29 / 80$ & 60 \\
\hline EK8006 & $07 / 16 / 80$ & $08 / 09 / 80$ & 61 \\
\hline AL8010 & $09 / 26 / 80$ & $10 / 29 / 80$ & 62 \\
\hline AL8012 & $11 / 19 / 80$ & $12 / 21 / 80$ & 63 \\
\hline AL8101 & $02 / 18 / 81$ & $03 / 24 / 81$ & 64 \\
\hline
\end{tabular}




\begin{tabular}{|c|c|c|c|}
\hline KE8103 & 03/19/81 & 04/08/81 & 65 \\
\hline DE8102 & 03/19/81 & $05 / 13 / 81$ & 66 \\
\hline DE8103 & $05 / 21 / 81$ & 06/17/81 & 67 \\
\hline DE8104 & $06 / 27 / 81$ & 07/19/81 & 68 \\
\hline AL8107 & $07 / 12 / 81$ & $07 / 21 / 81$ & 68 \\
\hline DE8105 & 08/04/81 & 08/19/81 & 69 \\
\hline AL8110 & 08/28/81 & $09 / 02 / 81$ & 69 \\
\hline DE8106 & 09/17/81 & $11 / 09 / 81$ & 70 \\
\hline AL8113 & $11 / 03 / 81$ & $11 / 09 / 81$ & 70 \\
\hline AL8114 & $11 / 17 / 81$ & $12 / 21 / 81$ & 71 \\
\hline AL8202 & $02 / 17 / 82$ & $03 / 23 / 82$ & 72 \\
\hline DE8202 & $03 / 11 / 82$ & 05/08/82 & 73 \\
\hline DE8203 & 05/18/82 & $06 / 11 / 82$ & 74 \\
\hline AL8206 & $06 / 02 / 82$ & $06 / 11 / 82$ & 74 \\
\hline AL8208 & $07 / 13 / 82$ & 08/06/82 & 75 \\
\hline DE8205 & $07 / 27 / 82$ & 08/10/82 & 75 \\
\hline AL8211 & $09 / 15 / 82$ & $11 / 11 / 82$ & 76 \\
\hline DE8209 & $11 / 17 / 82$ & $12 / 20 / 82$ & 77 \\
\hline DE8301 & $01 / 18 / 83$ & $02 / 11 / 83$ & 78 \\
\hline DE8302 & $02 / 17 / 83$ & $02 / 24 / 83$ & 78 \\
\hline AL8301 & $02 / 27 / 83$ & $03 / 01 / 83$ & 78 \\
\hline AL8302 & $03 / 09 / 83$ & $05 / 01 / 83$ & 79 \\
\hline AL8304 & $05 / 26 / 83$ & $06 / 21 / 83$ & 80 \\
\hline AL8307 & $07 / 27 / 83$ & $08 / 30 / 83$ & 81 \\
\hline DE8307 & $08 / 16 / 83$ & $09 / 04 / 83$ & 82 \\
\hline AL8308 & $09 / 14 / 83$ & $11 / 09 / 83$ & 83 \\
\hline DE8309 & $11 / 16 / 83$ & $12 / 19 / 83$ & 84 \\
\hline DE8401 & $01 / 10 / 84$ & $02 / 08 / 84$ & 85 \\
\hline AL8402 & $03 / 02 / 84$ & $04 / 25 / 84$ & 86 \\
\hline AL8403 & $05 / 09 / 84$ & $06 / 02 / 84$ & 87 \\
\hline DE8405 & $06 / 17 / 84$ & $06 / 24 / 84$ & 88 \\
\hline AL8406 & $07 / 04 / 84$ & $07 / 18 / 84$ & 89 \\
\hline DE8406 & $07 / 10 / 84$ & $07 / 30 / 84$ & 90 \\
\hline AL8407 & $07 / 25 / 84$ & $08 / 30 / 84$ & 91 \\
\hline AL8408 & $09 / 17 / 84$ & $11 / 03 / 84$ & 92 \\
\hline DE8409 & $11 / 01 / 84$ & $12 / 05 / 84$ & 93 \\
\hline DE8501 & $01 / 08 / 85$ & $02 / 06 / 85$ & 94 \\
\hline AL8502 & $02 / 27 / 85$ & $04 / 12 / 85$ & 95 \\
\hline DE8503 & $04 / 02 / 85$ & $04 / 30 / 85$ & 96 \\
\hline AL8504 & $05 / 09 / 85$ & $06 / 04 / 85$ & 97 \\
\hline GY8507 & $07 / 17 / 85$ & $07 / 22 / 85$ & 98 \\
\hline AL8507 & $07 / 23 / 85$ & $08 / 29 / 85$ & 98 \\
\hline DE8507 & $08 / 29 / 85$ & $09 / 22 / 85$ & 99 \\
\hline DE8508 & $10 / 01 / 85$ & $10 / 25 / 85$ & 100 \\
\hline AL8508 & $10 / 23 / 85$ & $11 / 15 / 85$ & 100 \\
\hline DE8510 & $11 / 07 / 85$ & $12 / 12 / 85$ & 101 \\
\hline DE8601 & $01 / 10 / 86$ & $02 / 12 / 86$ & 102 \\
\hline AL8602 & $03 / 04 / 86$ & $04 / 27 / 86$ & 103 \\
\hline DE8603 & $05 / 08 / 86$ & 06/06/86 & 104 \\
\hline DE8604 & $06 / 17 / 86$ & $07 / 17 / 86$ & 105 \\
\hline AL8604 & $07 / 29 / 86$ & 08/29/86 & 106 \\
\hline DE8607 & $08 / 28 / 86$ & $09 / 24 / 86$ & 107 \\
\hline AL8605 & $09 / 14 / 86$ & $11 / 06 / 86$ & 108 \\
\hline
\end{tabular}




\begin{tabular}{|c|c|c|c|}
\hline DE8608 & 09/30/86 & $10 / 10 / 86$ & 108 \\
\hline DE8610 & $11 / 05 / 86$ & $12 / 11 / 86$ & 109 \\
\hline DE8701 & $01 / 07 / 87$ & $02 / 08 / 87$ & 110 \\
\hline AL8701 & $03 / 24 / 87$ & $04 / 28 / 87$ & 111 \\
\hline AA8704 & $04 / 13 / 87$ & $04 / 22 / 87$ & 112 \\
\hline DE8703 & $04 / 21 / 87$ & $04 / 28 / 87$ & 112 \\
\hline DE8704 & $05 / 07 / 87$ & 06/07/87 & 113 \\
\hline WI8701 & $05 / 31 / 87$ & $07 / 14 / 87$ & 114 \\
\hline AL8705 & $07 / 07 / 87$ & 08/10/87 & 115 \\
\hline DE8708 & $08 / 19 / 87$ & $09 / 20 / 87$ & 116 \\
\hline AL8707 & $09 / 01 / 87$ & $10 / 30 / 87$ & 117 \\
\hline DE8710 & $11 / 04 / 87$ & $12 / 10 / 87$ & 118 \\
\hline AL8802 & $03 / 05 / 88$ & $04 / 20 / 88$ & 119 \\
\hline AL8807 & 07/09/88 & 08/10/88 & 120 \\
\hline AL8809 & $09 / 13 / 88$ & $10 / 28 / 88$ & 121 \\
\hline LH8819 & $10 / 29 / 88$ & $11 / 09 / 88$ & 122 \\
\hline DE8812 & $10 / 31 / 88$ & $11 / 10 / 88$ & 122 \\
\hline AL8811 & $11 / 30 / 88$ & $12 / 09 / 88$ & 123 \\
\hline DE8901 & 01/06/89 & 01/19/89 & 339 \\
\hline DE8906 & $10 / 03 / 89$ & $10 / 25 / 89$ & 338 \\
\hline DE8907 & $11 / 07 / 89$ & $11 / 16 / 89$ & 337 \\
\hline DE8909 & $11 / 27 / 89$ & $12 / 15 / 89$ & 336 \\
\hline DE9001 & $01 / 04 / 90$ & $01 / 17 / 90$ & 335 \\
\hline DE9003 & $02 / 20 / 90$ & $03 / 02 / 90$ & 334 \\
\hline DE9004 & 03/06/90 & $04 / 13 / 90$ & 333 \\
\hline DE9011 & $09 / 24 / 90$ & $10 / 25 / 90$ & 332 \\
\hline DE9012 & $10 / 30 / 90$ & $11 / 08 / 90$ & 331 \\
\hline DE9014 & $11 / 29 / 90$ & $12 / 12 / 90$ & 330 \\
\hline DE9101 & $01 / 04 / 91$ & $01 / 16 / 91$ & 329 \\
\hline DE9103 & $02 / 07 / 91$ & $02 / 22 / 91$ & 328 \\
\hline DE9105 & 03/18/91 & $04 / 16 / 91$ & 327 \\
\hline AM9101 & $07 / 21 / 91$ & 08/01/91 & NA \\
\hline DE9110 & $09 / 11 / 91$ & $10 / 24 / 91$ & 326 \\
\hline DE9111 & $11 / 04 / 91$ & $11 / 16 / 91$ & 325 \\
\hline DE9113 & $12 / 04 / 91$ & $12 / 13 / 91$ & 324 \\
\hline DE9201 & $01 / 06 / 92$ & $01 / 20 / 92$ & 323 \\
\hline DE9202 & $01 / 29 / 92$ & $02 / 12 / 92$ & 322 \\
\hline AL9203 & $03 / 03 / 92$ & $04 / 15 / 92$ & 142 \\
\hline PA9201 & $05 / 28 / 92$ & $05 / 29 / 92$ & 186 \\
\hline AL9211 & $09 / 10 / 92$ & $10 / 27 / 92$ & 143 \\
\hline DE9212 & $10 / 26 / 92$ & $11 / 04 / 92$ & 321 \\
\hline DE9214 & $12 / 01 / 92$ & $12 / 18 / 92$ & 320 \\
\hline DE9301 & $01 / 06 / 93$ & $01 / 21 / 93$ & 319 \\
\hline AL9303 & $02 / 04 / 93$ & $02 / 26 / 93$ & 147 \\
\hline AL9304 & 03/10/93 & 05/01/93 & NA \\
\hline DE9302 & $03 / 30 / 93$ & $04 / 11 / 93$ & 318 \\
\hline DE9311 & 09/09/93 & $10 / 26 / 93$ & 317 \\
\hline DE9312 & $11 / 02 / 93$ & $11 / 10 / 93$ & 310 \\
\hline DE9314 & $11 / 30 / 93$ & $12 / 10 / 93$ & 315 \\
\hline DE9401 & $01 / 06 / 94$ & $01 / 14 / 94$ & 31 \\
\hline DE9402 & $02 / 17 / 94$ & $02 / 22 / 94$ & 313 \\
\hline DE9403 & $04 / 05 / 94$ & $04 / 27 / 94$ & 312 \\
\hline AL9409 & $09 / 07 / 94$ & $10 / 26 / 94$ & 25 \\
\hline
\end{tabular}




\begin{tabular}{|c|c|c|c|}
\hline DE9410 & $10 / 18 / 94$ & $10 / 28 / 94$ & 311 \\
\hline AL9501 & $01 / 06 / 95$ & $01 / 14 / 95$ & 187 \\
\hline AL9503 & $02 / 08 / 95$ & $03 / 02 / 95$ & NA \\
\hline EN261 & $02 / 11 / 95$ & 02/19/95 & 156 \\
\hline AL9504 & $03 / 07 / 95$ & $04 / 27 / 95$ & NA \\
\hline EN263 & $03 / 13 / 95$ & $03 / 22 / 95$ & 157 \\
\hline EN265 & $04 / 12 / 95$ & $04 / 21 / 95$ & 158 \\
\hline AL9505 & $05 / 09 / 95$ & $05 / 17 / 95$ & 159 \\
\hline KT9503 & $06 / 01 / 95$ & $06 / 15 / 95$ & 253 \\
\hline AL9506 & $06 / 05 / 95$ & $06 / 14 / 95$ & 160 \\
\hline AL9507 & $06 / 19 / 95$ & $07 / 01 / 95$ & 188 \\
\hline AL9508 & $07 / 11 / 95$ & $07 / 19 / 95$ & 161 \\
\hline AL9509 & $07 / 25 / 95$ & $08 / 05 / 95$ & 189 \\
\hline AL9512 & $09 / 06 / 95$ & $10 / 24 / 95$ & 190 \\
\hline MC9501 & $11 / 09 / 95$ & $11 / 22 / 95$ & NA \\
\hline EN276 & $01 / 11 / 96$ & $01 / 21 / 96$ & 162 \\
\hline EN278 & $02 / 13 / 96$ & $02 / 24 / 96$ & 163 \\
\hline OC275 & $03 / 12 / 96$ & $03 / 22 / 96$ & 164 \\
\hline EN282 & $04 / 09 / 96$ & $04 / 19 / 96$ & 165 \\
\hline AL9605 & $05 / 07 / 96$ & $05 / 16 / 96$ & 166 \\
\hline AL9607 & 06/04/96 & $06 / 12 / 96$ & 167 \\
\hline AL9701 & $01 / 14 / 97$ & 01/19/97 & 168 \\
\hline OC298 & $02 / 12 / 97$ & $02 / 22 / 97$ & 169 \\
\hline OC300 & $03 / 17 / 97$ & $03 / 28 / 97$ & 170 \\
\hline OC302 & $04 / 22 / 97$ & 05/01/97 & 171 \\
\hline AL9705 & $05 / 20 / 97$ & $05 / 28 / 97$ & 172 \\
\hline AL9707 & $06 / 19 / 97$ & $06 / 27 / 97$ & 173 \\
\hline DE9710 & $11 / 05 / 97$ & $11 / 20 / 97$ & 310 \\
\hline AL9801 & $01 / 08 / 98$ & $01 / 18 / 98$ & 174 \\
\hline OC317 & $02 / 07 / 98$ & $02 / 17 / 98$ & 175 \\
\hline OC319 & $03 / 16 / 98$ & $03 / 26 / 98$ & 176 \\
\hline OC322 & $04 / 16 / 98$ & $04 / 26 / 98$ & 177 \\
\hline AL9806 & $05 / 13 / 98$ & $05 / 21 / 98$ & 178 \\
\hline AL9808 & $06 / 17 / 98$ & $06 / 25 / 98$ & 179 \\
\hline AL9901 & $01 / 13 / 99$ & $01 / 23 / 99$ & 180 \\
\hline OC336 & $02 / 11 / 99$ & $02 / 22 / 99$ & 181 \\
\hline EN320 & $03 / 11 / 99$ & $03 / 22 / 99$ & 182 \\
\hline OC341 & $04 / 16 / 99$ & $04 / 26 / 99$ & 183 \\
\hline AL9904 & $05 / 20 / 99$ & $05 / 27 / 99$ & 184 \\
\hline AJ9901 & $06 / 03 / 99$ & 06/11/99 & 191 \\
\hline AL9906 & $06 / 15 / 99$ & 06/23/99 & 185 \\
\hline IS9901 & $08 / 21 / 99$ & 09/02/99 & 192 \\
\hline AL9910 & $09 / 21 / 99$ & $11 / 10 / 99$ & 193 \\
\hline NP9901 & $11 / 06 / 99$ & $11 / 11 / 99$ & 194 \\
\hline AL9911 & $11 / 13 / 99$ & $11 / 22 / 99$ & 194 \\
\hline AL0001 & $02 / 10 / 00$ & $02 / 29 / 00$ & 195 \\
\hline AL0002 & 03/16/00 & 05/03/00 & 196 \\
\hline DE0006 & $05 / 23 / 00$ & 06/08/00 & 309 \\
\hline AL0005 & $08 / 23 / 00$ & 08/29/00 & 198 \\
\hline AL0006 & 09/06/00 & $10 / 20 / 00$ & 199 \\
\hline AL0007 & $10 / 31 / 00$ & $11 / 15 / 00$ & 200 \\
\hline AL0102 & $01 / 30 / 01$ & $02 / 21 / 01$ & 246 \\
\hline AL0103 & $02 / 28 / 01$ & $04 / 29 / 01$ & 247 \\
\hline
\end{tabular}




\begin{tabular}{|c|c|c|c|}
\hline AL0106 & $05 / 20 / 01$ & $05 / 25 / 01$ & 248 \\
\hline DE0105 & $05 / 29 / 01$ & 06/06/01 & 248 \\
\hline AL0109 & $08 / 21 / 01$ & 08/28/01 & 249 \\
\hline AL0110 & $09 / 05 / 01$ & $10 / 22 / 01$ & 201 \\
\hline AL0111 & $10 / 30 / 01$ & $11 / 16 / 01$ & 202 \\
\hline AL0202 & $01 / 23 / 02$ & $01 / 30 / 02$ & 203 \\
\hline AL0203 & $02 / 08 / 02$ & $03 / 02 / 02$ & 204 \\
\hline AL0204 & 03/08/02 & $04 / 24 / 02$ & 205 \\
\hline AL0206 & $05 / 23 / 02$ & 06/06/02 & 206 \\
\hline NS0201 & 08/14/02 & 08/29/02 & 207 \\
\hline AL0210 & 09/04/02 & $10 / 24 / 02$ & 208 \\
\hline DE0210 & $10 / 29 / 02$ & $11 / 14 / 02$ & 307 \\
\hline DE0301 & $01 / 23 / 03$ & $01 / 31 / 03$ & 306 \\
\hline DE0302 & $02 / 07 / 03$ & 03/01/03 & 306 \\
\hline DE0303 & 03/06/03 & $04 / 25 / 03$ & 305 \\
\hline DE0305 & $05 / 25 / 03$ & $05 / 29 / 03$ & 304 \\
\hline AM0301 & $08 / 20 / 03$ & 08/28/03 & 214 \\
\hline AL0305 & 09/07/03 & $10 / 31 / 03$ & 215 \\
\hline AL0306 & $11 / 03 / 03$ & $11 / 12 / 03$ & 217 \\
\hline AL0401 & $01 / 25 / 04$ & $01 / 27 / 04$ & 218 \\
\hline AL0402 & $02 / 05 / 04$ & $02 / 24 / 04$ & 218 \\
\hline AL0403 & $03 / 03 / 04$ & $04 / 21 / 04$ & 219 \\
\hline AL0405 & $05 / 25 / 04$ & 06/08/04 & 220 \\
\hline AL0408 & $08 / 17 / 04$ & 08/31/04 & 221 \\
\hline AL0409 & $09 / 11 / 04$ & $10 / 27 / 04$ & 222 \\
\hline AL0410 & $11 / 02 / 04$ & $11 / 18 / 04$ & 223 \\
\hline DE0501 & $01 / 26 / 05$ & $02 / 04 / 05$ & 225 \\
\hline AL0502 & $02 / 01 / 05$ & $02 / 23 / 05$ & 225 \\
\hline AL0503 & $03 / 04 / 05$ & $04 / 21 / 05$ & 226 \\
\hline AL0505 & $05 / 24 / 05$ & $06 / 08 / 05$ & 227 \\
\hline AL0507 & $08 / 13 / 05$ & $08 / 25 / 05$ & 228 \\
\hline AL0508 & $09 / 07 / 05$ & $11 / 04 / 05$ & 229 \\
\hline AL0509 & $11 / 06 / 05$ & $11 / 18 / 05$ & 230 \\
\hline DE0602 & $01 / 25 / 06$ & $02 / 05 / 06$ & 232 \\
\hline AL0602 & $02 / 08 / 06$ & $03 / 02 / 06$ & 232 \\
\hline AL0603 & 03/08/06 & $04 / 17 / 06$ & 233 \\
\hline AL0605 & $06 / 01 / 06$ & $06 / 14 / 06$ & 234 \\
\hline AL0607 & $08 / 15 / 06$ & 08/30/06 & 235 \\
\hline AL0608 & $09 / 06 / 06$ & $10 / 25 / 06$ & 236 \\
\hline DE0616 & $11 / 04 / 06$ & $11 / 15 / 06$ & 299 \\
\hline DE0701 & $01 / 30 / 07$ & $02 / 07 / 07$ & 238 \\
\hline AL0702 & $02 / 07 / 07$ & 03/01/07 & 238 \\
\hline AL0703 & 03/08/07 & $04 / 27 / 07$ & 239 \\
\hline DE0706 & $05 / 22 / 07$ & 06/05/07 & 303 \\
\hline DE0709 & $08 / 15 / 07$ & 08/28/07 & 302 \\
\hline AL0707 & $09 / 07 / 07$ & $11 / 01 / 07$ & 242 \\
\hline DE0711 & $10 / 29 / 07$ & $11 / 15 / 07$ & 301 \\
\hline DE0802 & $01 / 23 / 08$ & 02/07/08 & 300 \\
\hline AL0801 & 03/07/08 & 05/03/08 & 245 \\
\hline HB0802 & $03 / 10 / 08$ & $04 / 23 / 08$ & 245 \\
\hline DE0808 & 08/13/08 & 08/27/08 & 261 \\
\hline AL0803 & $09 / 03 / 08$ & $10 / 30 / 08$ & 257 \\
\hline HB0807 & $09 / 04 / 08$ & $11 / 05 / 08$ & 257 \\
\hline
\end{tabular}




\begin{tabular}{|c|c|c|c|}
\hline DE0810 & $10 / 23 / 08$ & $11 / 10 / 08$ & 258 \\
\hline DE0902 & $01 / 26 / 09$ & $02 / 12 / 09$ & 259 \\
\hline НВ0901 & 03/04/09 & 05/05/09 & 260 \\
\hline DE0905 & $05 / 27 / 09$ & 06/11/09 & 262 \\
\hline DE0909 & 08/17/09 & 08/29/09 & 263 \\
\hline НB0905 & 09/13/09 & $11 / 17 / 09$ & 265 \\
\hline DE0911 & $11 / 03 / 09$ & $11 / 20 / 09$ & 264 \\
\hline DE1001 & $02 / 02 / 10$ & $02 / 17 / 10$ & 270 \\
\hline HB1002 & $02 / 28 / 10$ & $05 / 01 / 10$ & 271 \\
\hline DE1004 & $05 / 26 / 10$ & $06 / 09 / 10$ & 272 \\
\hline DE1009 & 08/19/10 & $09 / 01 / 10$ & 273 \\
\hline HB1005 & $09 / 11 / 10$ & $11 / 17 / 10$ & 274 \\
\hline DE1012 & $11 / 05 / 10$ & $12 / 05 / 10$ & 275 \\
\hline DE1102 & $02 / 01 / 11$ & $02 / 18 / 11$ & 276 \\
\hline HB1 102 & $03 / 03 / 11$ & $05 / 08 / 11$ & 277 \\
\hline DE1105 & $06 / 02 / 11$ & $06 / 21 / 11$ & 278 \\
\hline HB1 105 & $09 / 11 / 11$ & $11 / 13 / 11$ & 279 \\
\hline DE1109 & $10 / 31 / 11$ & $11 / 19 / 11$ & 280 \\
\hline DE1110 & $12 / 01 / 11$ & $12 / 08 / 11$ & 280 \\
\hline DE1202 & $02 / 03 / 12$ & $02 / 21 / 12$ & 281 \\
\hline HB1201 & $02 / 29 / 12$ & $05 / 04 / 12$ & 282 \\
\hline HB1202 & $05 / 31 / 12$ & $06 / 13 / 12$ & 283 \\
\hline HB1205 & $08 / 07 / 12$ & $08 / 24 / 12$ & 284 \\
\hline HB1206 & $09 / 07 / 12$ & $11 / 10 / 12$ & 285 \\
\hline PC1207 & $10 / 26 / 12$ & $11 / 14 / 12$ & 286 \\
\hline PC1301 & $02 / 10 / 13$ & $02 / 26 / 13$ & 287 \\
\hline HB1301 & $03 / 05 / 13$ & $05 / 09 / 13$ & 288 \\
\hline GU1302 & $06 / 09 / 13$ & $06 / 24 / 13$ & 289 \\
\hline HB1303 & $07 / 02 / 13$ & $08 / 18 / 13$ & 290 \\
\hline EX1305 & $08 / 25 / 13$ & $09 / 05 / 13$ & 290 \\
\hline HB1304 & $09 / 04 / 13$ & $11 / 19 / 13$ & 290 \\
\hline GU1305 & $11 / 14 / 13$ & $11 / 24 / 13$ & 291 \\
\hline GU1401 & $03 / 01 / 14$ & $03 / 08 / 14$ & 292 \\
\hline HB1401 & $04 / 02 / 14$ & $05 / 31 / 14$ & 293 \\
\hline HB1405 & $09 / 10 / 14$ & $11 / 13 / 14$ & 294 \\
\hline PC1405 & $11 / 04 / 14$ & $11 / 19 / 14$ & 294 \\
\hline HB1501 & $03 / 14 / 15$ & $05 / 07 / 15$ & 295 \\
\hline HB1502 & $05 / 19 / 15$ & $06 / 02 / 15$ & 296 \\
\hline HB1506 & $09 / 02 / 15$ & $11 / 05 / 15$ & 297 \\
\hline GU1506 & $10 / 12 / 15$ & $10 / 25 / 15$ & 297 \\
\hline HB1601 & $04 / 08 / 16$ & $06 / 07 / 16$ & 298 \\
\hline GU1608 & $05 / 21 / 16$ & $06 / 20 / 16$ & 298 \\
\hline
\end{tabular}


Supplement 5. Description of the alternative larval index methods used to compare to the Richardson et al. (2010) methods. Datasets used for these analyses were the same as those used as inputs for the Richardson et al. (2010) method to allow for direct comparisons.

\section{$\underline{\text { Alternative 1: Arithmetic Means }}$}

This method averaged all abundances-at-age $\left(\mathrm{N}_{\mathrm{A}}\right)$ together within a given year as a representation of larval production in each year $\left(\mathrm{LI}_{\mathrm{A} 1}\right)$ :

$$
L I_{A 1, y}=\overline{N_{A, y}}
$$

The means included absences ( 0 abundances) and was performed similarly over the Survey and Sample level datasets. This calculation was conducted with observed and catchability-corrected abundances.

\section{Alternative 2: Mortality-Based}

This method used a mortality curve (static through time) to allow for comparison between abundances of different age (day) classes. First, abundances were summed by age over years to estimate a time-invariant morality rate. These summed abundances at age $\left(\mathrm{N}_{\mathrm{A}}\right)$ were modeled using an exponential decay function:

$$
N_{A}=N_{5} e^{-\alpha A}
$$

where $A$ represents age, and estimated parameters $N_{5}$ and $\alpha$ represent abundance age- 5 and the mortality rate, respectively. The negative exponential model was fit with a gamma error distribution in R using package 'bbmle' (Bolker, 2008). The mortality rate estimated in this function $(\alpha)$ was then used to scale abundances-at-age $\left(\mathrm{N}_{\mathrm{A}}\right)$ from the Survey and Sample-level datsets to the 5-day-old equivalences $\left(\mathrm{N}_{5}\right)$ :

$$
N_{5}=\frac{N_{A}}{e^{(-\alpha * A)}}
$$


The 5-day old equivalent abundances were averaged within years and hatch days, and then averaged within a year to construct the mortality-based index $\left(\mathrm{LI}_{\mathrm{A} 2}\right)$. This calculation was performed for both observed and catchability-corrected abundances. Alternative 3: Seasonality-Based

Using the 5-day-old equivalent abundances summed within years and hatch days (constructed in the Alternative 2 approach), a delta (hurdle) model approach was then implemented to account for the hatching seasonality and interannual temporal sampling variability. The hurdle model uses two models to predict presence and abundance separately. Both presence and absence were modeled based on the hatch day of the 5-day-old equivalent abundances and the year the samples were taken. Generalized additive models (GAMs) were used to describe the relationships:

$$
\begin{gathered}
\text { Presence }=s(H D)+\text { Year } \\
\text { Abundance }=s(H D)
\end{gathered}
$$

GAMs were constructed using the R package 'mgcv'. GAMs were chosen over generalized linear models (GLMs) given the parabolic or dome-shaped response of presence and abundance with hatch day. Presence was modeled with a binomial model with a "logit" link function using all samples. The abundance model only used data with positive occurrences (i.e. abundance > 0) naturally-log transformed (ln[abundance+0.001]), and a Gaussian framework with an "identity" link function. The abundance model did not include 'Year' given some years caught zero mackerel larvae (e.g., 2011). Both models had gamma set to 1.4 to reduce overfitting. Predictions were made for each day of the year in each year that sampling occurred. Presence/absence and abundance predictions for each date and year were multiplied 
together, and abundance predictions were then summed within a year, representing the integrated or cumulative predicted 5-day old larval production per year $\left(\mathrm{LI}_{\mathrm{A} 3}\right)$. This calculation was performed for both observed and catchability-corrected abundances. 
Supplement 6. Mean life history parameter estimates from each Model Variant. Parameter estimates using abundances observed (first number) and with catchabilitycorrections applied (second number) are separated by a comma. Model Variant descriptions are in Table 1 of main text.

\begin{tabular}{cccccc}
$\begin{array}{c}\text { Model } \\
\text { Variant } \\
\text { Number }\end{array}$ & $g$ & \multicolumn{2}{c}{ Mortality } & \multicolumn{3}{c}{ Spawning Seasonality } \\
& & & & & \\
& & & & & $c$ \\
2 & $0.92,33.11$ & $0.64,0.10$ & $12.51,9.71$ & $0.082,0.064$ & $1.19,1.09$ \\
3 & $0.25,0.64$ & $1.044,1.044$ & $12.64,9.78$ & $0.083,0.064$ & $1.21,1.12$ \\
4 & $0.0032,0.0037$ & $2.78,2.74$ & $25.082,24.19$ & $0.17,0.17$ & $0.77,0.73$ \\
5 & $0.0067,0.0067$ & $2.39,2.40$ & $15.86,16.20$ & $0.11,0.12$ & $0.43,0.45$ \\
6 & $4.5 \mathrm{E}-5,4.5 \mathrm{E}-5$ & $1.044,1.044$ & $16.43,16.73$ & $0.12,0.12$ & $0.47,0.49$ \\
7 & $0.19,0.19$ & $1.044,1.17$ & $18.64,18.70$ & $0.12,0.12$ & $1.28,1.33$ \\
8 & $0.0067,2.72$ & $2.30,0.44$ & $18.86,18.88$ & $0.12,0.12$ & $1.30,1.34$ \\
9 & $0.21,0.35$ & $1.044,1.044$ & $21.26,14.50$ & $0.13,0.091$ & $1.95,1.56$ \\
& & & & $0.13,0.093$ & $1.96,1.59$
\end{tabular}


Supplement 7. Model Variant 2 observed (red, top) and catchability (blue, bottom) larval indices with standard deviations of the annual indices (dashes).
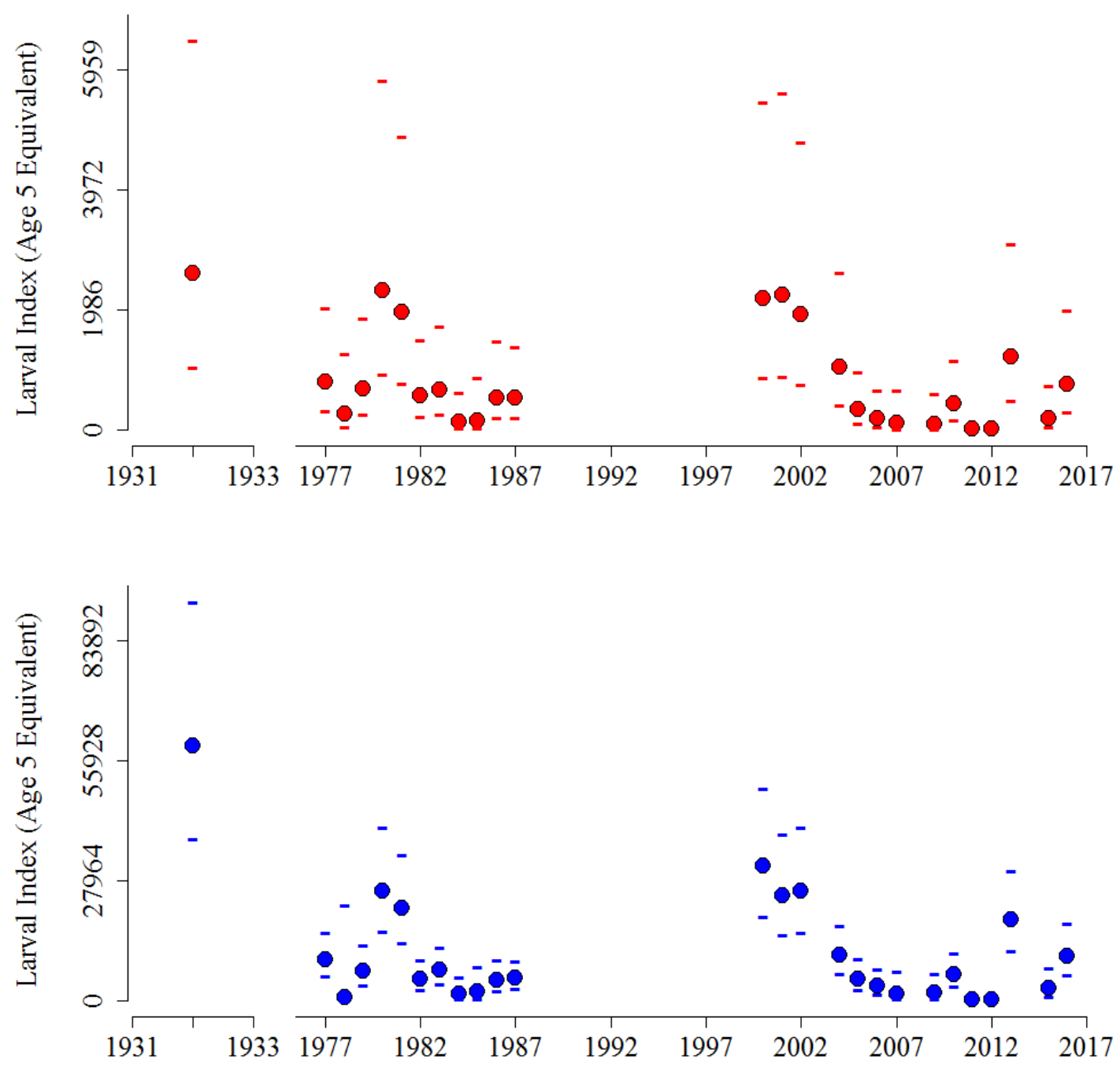
Supplement 8. Southern contingent Atlantic mackerel spawning ground strata from the MARMAP and EcoMon cruises, with color delineations for the Mid-Atlantic Bight (red), southern New England (blue), and western Gulf of Maine (green) regions. Insert figures illustrate the mean day of year (dashed) sampled for each region, and the corresponding mean hatch day (solid) of larvae caught during the cruises. The time series mean hatch day for each region is also presented in the respective plot.

Differences in annual hatch and sampling days reflect age of larvae sampled and how close sampling was to spawning events (e.g. larger differences, older larvae sampled, temporally farther from spawning events than years that sampled younger larvae).

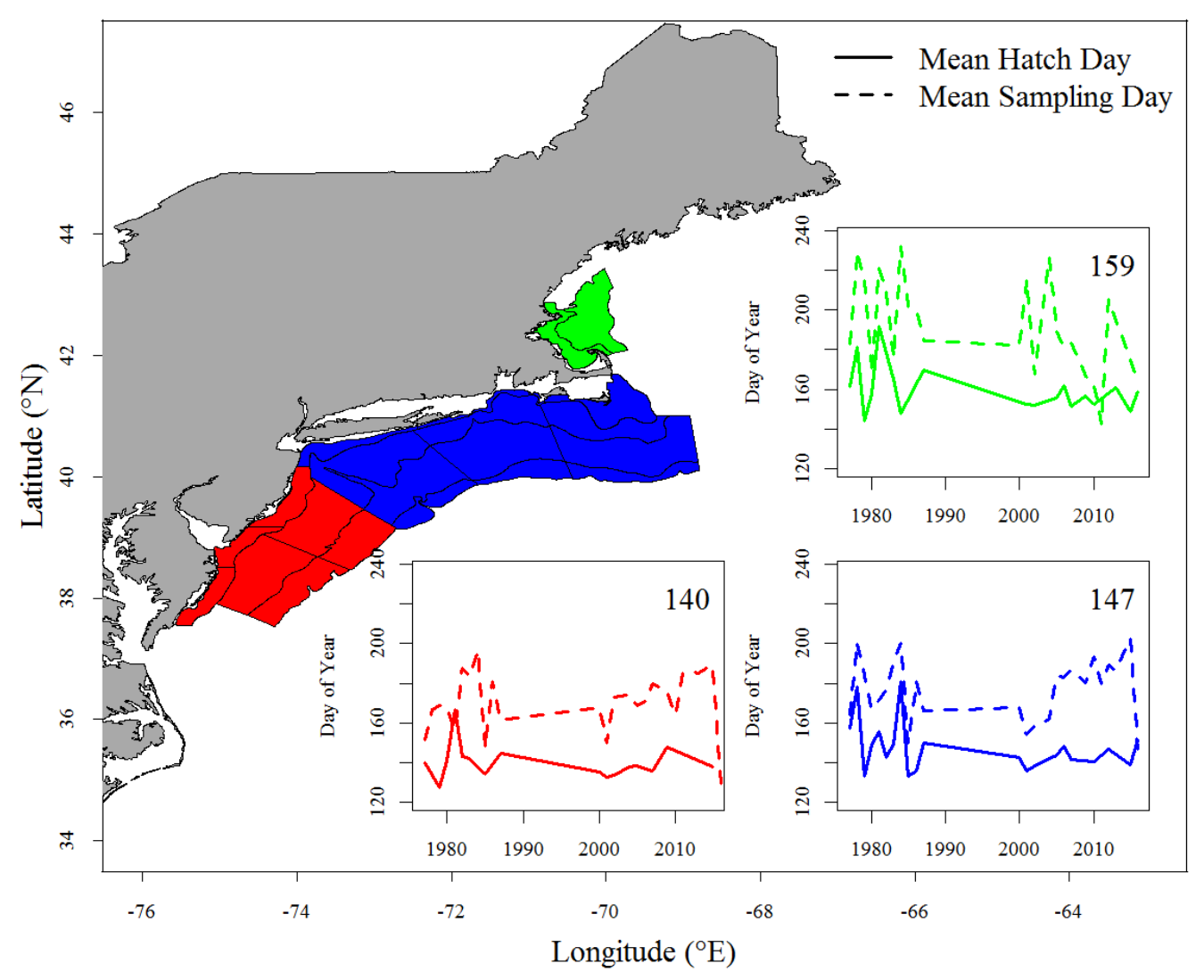




\section{MANUSCRIPT 2}

Tracking shifts in Atlantic mackerel (Scomber scombrus) larval habitat suitability on the Northeast U.S. Continental Shelf

M. Conor McManus ${ }^{1,2, *}$, Jonathan A. Hare ${ }^{3}$, David E. Richardson ${ }^{4}$, and Jeremy S. Collie $^{1}$

${ }^{1}$ Graduate School of Oceanography, University of Rhode Island, Narragansett, RI, 02882

${ }^{2}$ Rhode Island Department of Environmental Management, Division of Marine Fisheries, Jamestown, RI, 02835

${ }^{3}$ National Oceanic and Atmospheric Administration, National Marine Fisheries Service, Northeast Fisheries Science Center, Woods Hole, MA, 02543

${ }^{4}$ National Oceanic and Atmospheric Administration, National Marine Fisheries Service, Northeast Fisheries Science Center, Narragansett, RI, 02818

*corresponding author: phone: (401) 423-1941, fax: (401) 423-1925; email: cmcmanus@gso.uri.edu

Key words: Atlantic mackerel, larvae, habitat suitability, Northeast U.S. Shelf, species distribution models

Publication status: published in Fisheries Oceanography, citation is as follows:

McManus MC, Hare JA, Richardson DE, Collie JS. 2017. Tracking shifts in Atlantic mackerel (Scomber scombrus) larval habitat suitability on the Northeast U.S.

Continental Shelf. Fisheries Oceanography, 00:1-14. https://doi.org/10.1111/fog.12233 


\section{ABSTRACT}

Climate change has altered the oceanographic environment and subsequently the habitats of marine species. Fish and invertebrate populations' responses to habitat include movement with latitude and depth to remain within their fundamental niches. The northwest Atlantic mackerel (Scomber scombrus) population has fluctuated over the last century due in part to changes in the environment. We used species distribution models to understand the influence of the physical (temperature) and biological (zooplankton) environment on mackerel larval abundance, and how such relations determined larval habitat suitability in the Northeast U.S. Shelf since the late 1970s. Atlantic mackerel larval presence and abundance correlated with sea temperature and copepod abundances, suggesting that larval survival may be sensitive to specific temperatures and zooplankton prey. Predicted abundances were spatially interpolated to estimate the suitable habitat for Atlantic mackerel larvae. Multiple metrics for habitat quality indicate that the Mid-Atlantic Bight has become less suitable over time. Since the 1970s the proportion of the Northeast U.S. Shelf suitable habitat located in the Mid-Atlantic Bight has decreased as southern New England and the western Gulf of Maine regions have become more suitable ecoregions. Habitat suitability within the Northeast U.S. Shelf has shifted northeast: from the Mid-Atlantic Bight-southern New England border towards the northeast portion of southern New England. While total Northeast U.S. Shelf habitat suitability has decreased since the 1970s, the decline in the time series trend was not statistically significant. Thus, while select ecoregions have decreased in habitat suitability, larval habitat does not appear to be the only contributor to decreases in the U.S. Atlantic mackerel contingent. 


\section{INTRODUCTION}

Climate change has altered the physics and chemistry of marine ecosystems, including ocean temperature, dissolved oxygen, $\mathrm{pH}$, and ocean circulation (Poloczanska et al., 2016). These environmental changes have also transformed available habitat for marine fish and invertebrates. Climate change has been linked to changes in marine fish distribution through population shifts poleward or to new depths (Nye et al., 2009). These distribution shifts reflect adjustments by species to remain within their optimal habitat (Anderson et al., 2013). Adult fish distributional shifts and associated environmental conditions have been extensively documented along the Northeast U.S. Continental Shelf Large Marine Ecosystem (hereafter Northeast U.S. Shelf) (Nye et al., 2009; Pinsky and Fogarty, 2012; Kleisner et al., 2016), as well as spatial and temporal shifts in adult and larval fish distributions (Walsh et al., 2015).

Atlantic mackerel (Scomber scombrus) is one Northeast U.S. Shelf species identified as vulnerable and exposed to climate change (Hare et al., 2016). A schooling, pelagic, planktivorous fish, Atlantic mackerel is found on both sides of the North Atlantic: from Newfoundland to North Carolina in the west, and from Greenland to the Mediterranean Sea in the east (Sette, 1950, Astthorsson et al. 2012; Jansen et al., 2016). The northwest Atlantic stock comprises two contingents; the northern contingent spawns in the Gulf of St. Lawrence from May into August, while the southern contingent spawns from the Mid-Atlantic Bight through the Gulf of Maine from mid-April through June (Fig. 1; Anderson, 1982; Berrien, 1982). During late fall and winter, the southern contingent inhabits offshore waters along the 
continental shelf in the Mid-Atlantic Bight, and from spring through autumn migrates north and inshore along southern New England through the Gulf of Maine to spawn and feed (Sette, 1943; Sette, 1950). The northern contingent exhibits similar migratory patterns, moving from Georges Bank and the Scotian Shelf to the Gulf of St. Lawrence in the late spring through summer, and returning south in autumn (Overholtz et al., 1989; Berrien, 1982). Atlantic mackerel have historically supported a large commercial and recreational fishery (Anderson and Paciorkowski, 1980) and served as prey for marine fish, birds and mammals (Studholme et al., 1999). Therefore, climate influences on the Atlantic mackerel stock may have significant consequences for both commercial fisheries and ecosystem function.

Changes in ocean temperatures have implications for Atlantic mackerel available habitat over all life stages. Atlantic mackerel are susceptible to changes in sea temperature via growth and mortality rates, particularly during the larval stage (Ware and Lambert, 1985). Sea temperature has long been suspected to influence population size via thermal requirements over multi-decadal scales, causing alternating regimes between Atlantic herring (Clupea harengus) and mackerel in the northwest Atlantic (Skud, 1982). Increases in sea temperature have also been associated with northwest Atlantic mackerel spatial distributions by size-class, spring migrations, and spawning seasonality (Overholtz et al., 2011; Radlinski et al., 2013). In the northeast Atlantic, several studies have described temperature's influence on adult (Astthorsson et al., 2016) and egg (Beare and Reid, 2002; Hughes et al., 2014) distributions and seasonality of occurrence. 
Zooplankton community composition shifts also influence suitable habitat for Atlantic mackerel larvae. Changes in physical conditions affect zooplankton abundance and distribution through species' physiological constraints, differential advective transport and changes in predator-prey interactions. Altering zooplankton species composition changes the prey available for early life stage fish (Friedland $e t$ al., 2013), affecting fish larvae that have prey-specific diets, such as Atlantic mackerel. Early stage mackerel larvae prey primarily on copepods, including Pseudocalanus spp., Temora longicornis, and Calanus finmarchicus (Peterson and Ausubel, 1984; Ringuette et al., 2002; Robert et al., 2008). Poor spatial-temporal match between larvae during the transition from yolk-sac to exogenous-feeding and their preferred prey can influence growth and mortality through increased starvation and susceptibility to predation (Takasuka et al., 2003; Robert et al., 2013). In the northern contingent, Atlantic mackerel recruitment has been found to vary annually based on prey availability during the species' exogenous-feeding larval stage (Castonguay et al., 2008; Plourde et al., 2015; Jansen, 2016). Changes in dominant zooplankton taxa could also influence future mackerel recruitment of the southern contingent.

While several studies have evaluated the environmental (e.g. temperature, larval prey field) influence on Atlantic mackerel recruitment and distribution patterns, such ecological relationships have yet to be used to describe and estimate suitable habitat available. Our work aims to understand the physical and biological habitat requirements for larvae of the northwest Atlantic mackerel southern contingent via ichthyoplankton, zooplankton, and oceanographic data. We used species distribution 
models to relate larval observations with environmental conditions and identify larval habitat (Hutchinson 1957; Elith and Leathwick, 2009). The species distribution models were implemented to hindcast larval abundance spatially, quantify Atlantic mackerel larvae habitat, and understand how the species' habitat suitability has changed over time. By quantifying larval habitat changes, our work provides a tool to understand influences of environmental shifts on Atlantic mackerel and evaluate possible mechanisms influencing observed Atlantic mackerel abundance trends.

\section{MATERIAL AND METHODS}

\section{Field Sampling}

Ichthyoplankton, zooplankton, and oceanographic data have been collected over the last five decades in the Northeast U.S. Shelf through various long-term monitoring programs (Kane, 2003; Richardson et al., 2010). Data used in this study were derived from two programs conducted by the National Oceanic and Atmospheric Administration (NOAA): the Marine Resource Monitoring, Assessment, and Prediction (MARMAP) program and the Ecosystem Monitoring (EcoMon) program (Richardson et al., 2010). The MARMAP program operated from 1977-1987, and the EcoMon program has been active since 1992. Both programs were designed to describe and assess changes in oceanography and planktonic community structure of the Northeast U.S. Shelf. Surveys were performed four to eight times per year over the continental shelf, spanning from Cape Hatteras, North Carolina, to Cape Sable, Nova Scotia (Richardson et al., 2010; Walsh et al., 2015).

MARMAP and EcoMon samples were taken throughout the year at both day and night. Deployments were performed with a $61-\mathrm{cm}$ bongo net. Flowmeters were 
suspended in the bongo nets to measure the volume of water filtered. Bongo nets were towed at approximately 1.5 knots obliquely through the water column to within $5 \mathrm{~m}$ of the bottom, or a maximum of 200m (Richardson et al., 2010; Walsh et al., 2015). Plankton samples collected by the bongo nets were processed for zooplankton or ichthyoplankton, with one net processed following one protocol (e.g., zooplankton) and the other net processed following the other protocol (e.g., ichthyoplankton). Over the years, plankton samples have been processed primarily by Morski Instytut Rybacki (Poland), with fewer samples processed by the Northeast Fisheries Science Center (United States), and the Atlantic Reference Center (Canada). However, the same protocols have been followed over the different programs. Zooplankton samples were reduced to 500 organism subsamples using a box splitter, and the subsample specimens were identified to the lowest possible taxa (Kane, 2008). Select zooplankton taxa were identified to specific life stages, with staging protocols varying by taxa. Ichthyoplankton were removed from the whole sample and identified to the lowest possible taxa (Walsh et al., 2015). Abundances were standardized to number per $10 \mathrm{~m}^{2}$ based on the proportion of the sample processed, the volume filtered by the nets, and the depths the nets sampled. During the MARMAP period, surface and bottom oceanographic conditions were measured alongside plankton tows, and sea temperatures were measured with a thermometer or bathythermograph. During the EcoMon program, a CTD was used to collect depth-discrete oceanographic measurements over the water column (Simpson et al., 2016). For further descriptions of the monitoring programs, please see Richardson et al. (2010) and Kane (2003). 
Two differences in sampling between the MARMAP and EcoMon programs should be noted. First, the mesh size on the bongo nets for ichthyoplankton sampling differed between the MARMAP and EcoMon programs; the MARMAP program used a $0.505 \mathrm{~mm}$ mesh, whereas the EcoMon used a $0.333 \mathrm{~mm}$ mesh net. This discrepancy over time does not apply to zooplankton sampling, as zooplankton samples were taken with a $0.333 \mathrm{~mm}$ mesh net during both MARMAP and EcoMon programs. Second, the processing of the ichthyoplankton samples early in the EcoMon period (1992-1999) was inconsistent owing to budget constraints during the transition from MARMAP to EcoMon; the availability of zooplankton and oceanographic data is more consistent later in the EcoMon program (1999-present; Supplement 1).

Analyses incorporated May and June samples only, in order to model the typical Atlantic mackerel spawning period (Berrien and Sibunka, 1999). Additionally, only samples from the Mid-Atlantic Bight, southern New England, Georges Bank, and the Gulf of Maine were used; samples south of Cape Hatteras and off the shelf were excluded to focus analyses on the historical latitudinal range of the stock's southern contingent (Fig. 1). Oceanographic, zooplankton, and ichthyoplankton data were available for various years from 1978 through 2013. Model development only incorporated data from years with adequate coverage of the Northeast U.S. Shelf during May and June: 1977-1984, 1986-1987, 2000-2002, 2004-2007, and 2009-2013 (Supplement 1). In some years, weather or ship availability resulted in reduced spatial coverage of the shelf. Larvae were present in $11.87 \%$ of the May and June samples, with abundances as high as 10,819 larvae $10 \mathrm{~m}^{-2}$ and sizes ranging from 1.3 to $42 \mathrm{~mm}$. Of larvae caught, $96.3 \%$ were $7 \mathrm{~mm}$ or less, representing those selecting zooplankton 
prey (Robert et al. 2008) and 99.6\% were smaller than the post-larval stage, $11 \mathrm{~mm}$, when individuals can actively avoid plankton nets (Sette, 1943).

Species Distribution Models

Generalized additive models (GAMs) were implemented to describe the relationships between larval abundances and the environment (Venables and Dichmont, 2004). GAMs use several smooth additive functions, resulting in curvature or splines in the predictions (Hastie and Tibshirani, 1986). Atlantic mackerel larval abundances were modeled with a delta (or hurdle) model approach (Maunder and Punt, 2004). This method has two components, combining predictions from a presence/absence model with those from an abundance-when-present model. The approach is beneficial when analyzing species data with a large number of absences (or zero abundance), and is commonly used in the analysis of fisheries independent survey data (Grüss et al., 2014; Lynch et al., 2014).

Several variables were tested to construct presence/absence and abundance GAMs for Atlantic mackerel larvae. Additionally, only variables that have been previously found to influence larvae or catchability were considered. Sea surface and bottom temperatures were tested, as water temperatures influence time of spawning (Radlinski et al., 2013) and affects Atlantic mackerel larval growth and survival (Morse, 1989; Ware and Lambert, 1985). Several zooplankton species were considered to represent food available during the time of sampling. Zooplankton taxa that have been identified in mackerel larvae gut content, including Pseudocalanus spp., Temora longicornis, Calanus finmarchicus, Centropages typicus, and Oithona spp. (Robert et al., 2008; Robert et al., 2009), were tested. Zooplankton abundances 
were transformed, $\ln ($ abundance +1$)$, prior to analyses. Water depth was also incorporated to identify regions over the shelf preferred for spawning.

Additional variables were tested in the models to account for catchability influences on the observed abundances. Information regarding light availability, such as solar zenith, photosynthetically active radiation (PAR), and a Day/Night categorical variable, were calculated for all samples using R statistical package "AstroCalc4R" to discern any diurnal variability in larval catchability (Jacobson et al., 2011). Mesh size of the bongo nets for ichthyoplankton sampling $(0.333 \mathrm{~mm}$ vs. $0.505 \mathrm{~mm})$ was also included to account for larval extrusion differences between the gears over the time series (Johnson and Morse, 1994). GAMs were constructed using R statistical software package "mgcv".

Variables' significance in predicting larval presence and abundance were evaluated using a backwards stepwise selection approach (Wood, 2006). This process started by including all covariates in the model and then removing covariates that appeared to have little impact on the predictions one-by-one, and comparing the revised model's fit to the previous fit. The models' un-biased risk estimator (UBRE, presence/absence model) or generalized cross validation (GCV, abundance model) scores, and the variables' degrees of freedoms and p-values were used to determine if the covariates did not significantly increase model fit and should be removed. To reduce model overfitting without degrading prediction error performance, models' degrees of freedom in UBRE/GCV scores were penalized by setting the gamma parameter to 1.4 (Wood, 2006). The best-fit presence/absence and abundance models differed in variables used in predicting Atlantic mackerel larvae. To maintain 
ecological consistency between the presence/absence and abundance models, variables found insignificant in one model, but significant in the other were reinserted into the former model. As a result, the models contained the same covariates. This approach has been used in several previous studies (Grüss et al., 2014; Lynch et al., 2014). Presence/absence and abundance were modeled as:

$$
\begin{array}{r}
\text { Presence } / \text { Absence or } \ln (\text { Abundance }+1)=s(\text { Surface Temperature })+ \\
s(\text { Bottom Temperature })+s(\text { Depth })+\text { Mesh Size }+s(\text { Calanus finmarchicus })+ \\
s(\text { Pseudocalanus spp. })+s(\text { Temora longicornis })+s(\text { Oithona spp. })+ \\
s(\text { Centropages typicus })
\end{array}
$$

Larval presence/absence was modeled using a binomial GAM with a logit-link function. The binomial model outputs were expressed as probability of larval occurrence between 0 and 1; however, such predictions do not allow for model validation given that observations are either absence (0) or present (1). Thus, a threshold was required to define binary presence/absence from continuous probability of occurrence. The threshold for conversion was set to the value that resulted in the greatest fraction of true positives (selectivity) and negatives (specificity), while minimizing false positives (commission errors) and negatives (omission errors) (Lobo et al., 2008; Murtaugh, 1996). The kappa coefficient for the confusion matrix was calculated to quantify the agreement between the predictions and observations (Carletta 1996). Larval abundances were transformed, $\ln ($ abundance+1), prior to analysis, and modeled using a gamma GAM with an identity-link function. Presence/absence and abundance models were compared to models only using temperature and zooplankton covariates, separately, to assess the relative contributions of physical and biological factors to larval presence and abundance. These variants of 
the presence/absence and abundance models were compared using Akaike's information criterion (AIC; Akaike, 1973).

Predictions from the final presence/absence and abundance models were multiplied together to construct a zero-inflated adjusted abundance, representing the delta GAM results (Grüss et al., 2014). Predictions were made for all samples where zooplankton and hydrographic measurements were taken, including some years early in the EcoMon period that did not have ichthyoplankton data for use in model development. Predictions were interpolated over a $0.1^{\circ}$ resolution grid encompassing the Northeast U.S. Shelf using inverse distance weighting with a power parameter of two. Spatial autocorrelation was assessed prior to inverse distance weighting to determine and correct potential autocorrelation between predicted points (Dormann et al., 2007). Spatial autocorrelation was examined by incorporating latitude and longitude as covariates in spatial variograms (using ordinary and universal kriging). Only latitude and longitude were incorporated in the variogram and kriging trials given that the predictions were based on environmental data, and not all GAM inputs were available over the prediction grid. Annual variograms indicated that either spatial autocorrelation was not an issue with interpolations in space, or could not be resolved with variograms. Thus, kriging with variogram corrections were not used in the spatial interpolation between predicted points.

\section{Habitat Suitability Calculations}

Habitat suitability was assessed for Northeast U.S. Shelf ecoregions where Atlantic mackerel are known to occur: the Mid-Atlantic Bight, southern New England, Georges Bank, and the Gulf of Maine. Habitat in the Gulf of Maine was evaluated for 
the western and eastern sides separately given the areas' contrasts in oceanography (Townsend et al., 2006), resulting in five distinct ecoregions. Trends in interpolated grid abundance predictions were evaluated to understand fine-scale habitat changes within an ecoregion over time. An ecoregion's overall annual habitat suitability was assessed by summing predictions within an ecoregion and dividing by the regions' surface areas $\left(\mathrm{km}^{2}\right)$. Habitat suitability indices (HSI) were calculated with predicted abundances using two different metrics: (1) assessing habitat changes within a given ecoregion over time $\left(\mathrm{HSI}_{\mathrm{E}}\right)$, and (2) changes in ecoregions' contribution in overall habitat suitability within the Northeast U.S. Shelf (HSIS).

$$
\begin{gathered}
\mathrm{HSI}_{\mathrm{E}}=\mathrm{H}_{\mathrm{R}, \mathrm{Y}} \\
\mathrm{HSI}_{\mathrm{S}}=\mathrm{H}_{\mathrm{R}, \mathrm{Y}} / \sum \mathrm{H}_{\mathrm{Y}}
\end{gathered}
$$

$\mathrm{H}_{\mathrm{R}, \mathrm{Y}}$ represents the estimated habitat $(\mathrm{H})$ within a given ecoregion $(\mathrm{R})$ and year $(\mathrm{Y})$, and $\Sigma \mathrm{H}_{\mathrm{Y}}$ is the sum of habitat over all regions in a given year. The first method aimed to identify absolute changes in suitable habitat available in each ecoregion. HSIE values were also summed over ecoregions to evaluate total $\mathrm{HSI}_{\mathrm{E}}$ for the Northeast U.S. Shelf. The second method assessed each region's relative contribution to the total suitable habitat within a given year, with all ecoregions in a given year summing to one. $\mathrm{HSI}_{\mathrm{E}}$ indices were calculated for all years in which the respective ecoregions were sampled, resulting in differing $\mathrm{HSI}_{\mathrm{E}}$ time series lengths by ecoregion (Supplement 1). HSIS indices were only calculated if all ecoregions were adequately sampled within a year.

Along and across shelf changes in larval habitat suitability were calculated using HSIS's to quantify directional habitat movement over the Northeast U.S. Shelf. 
Along and across shelf distances for ecoregion's center points were calculated as the distance north of Cape Hatteras, North Carolina and distance from the 200m isobath, respectively (Nye et al., 2009). This method accounts for curvilinear dynamics of the continental shelf. Annual along and across shelf values were calculated by multiplying these center point positions by the ecoregions' HSIS values, and summing results over ecoregions within a given year. Thus, the along and across shelf positions of larval habitat suitability represented positions weighted by the relative habitat suitability each ecoregion provided for each year. Annual along and across shelf habitat locations were then converted to latitude and longitude coordinates to understand geographical changes in suitable larval habitat.

\section{RESULTS}

\section{Habitat Model}

Variability in larval presence and abundance was well explained by the biological and physical covariates. The presence/absence model explained approximately 58\% of the variability in Atlantic mackerel occurrence, and the abundance model accounted for $69 \%$ of the variability in larval abundance (Table 1). Covariates used also indicated low collinearity (Supplement 2). When converting predicted probabilities of occurrences to binary presence/absence, a threshold of 0.111 maximized true positives and negatives. After applying the threshold to probability predictions, $86.2 \%$ of the observations from the validation dataset were accurately predicted: $75.5 \%$ true negative, $10.7 \%$ true positive (Table 2). The presence model accuracy was greater than random chance: the hypothetical probability of agreement 
was estimated at 0.70 , and the kappa coefficient statistic for the confusion matrix was 0.53 .

Presence/absence of Atlantic mackerel larvae was significantly affected by all covariates included. Sea surface temperatures between roughly 11 and $22^{\circ} \mathrm{C}$ had a positive influence on the presence of larvae, with temperatures above and below having a negative impact on presence (Fig. 2). Bottom water temperatures had a neutral effect on larval presence until roughly $15^{\circ} \mathrm{C}$, with warmer bottom waters in May and June having a negative effect. Shallower depths (approximately $<65 \mathrm{~m}$ ) had a positive influence on larval presence. Bongo nets equipped with a $0.505 \mathrm{~mm}$ mesh predicted higher larval presence probabilities than $0.333 \mathrm{~mm}$ mesh bongo nets. Significant zooplankton taxa had varying influences on larval presence at low zooplankton abundances, but all seemed to have similar positive influences at higher zooplankton abundance. At lower abundances, zooplankton taxa had neutral or negative influences on larval presence (Fig. 2). Using only zooplankton covariates appeared to better predict larval presence better than a model with only sea temperature (Table 3).

Abundance of Atlantic mackerel larvae was significantly related to surface water temperature, mesh size, and zooplankton taxa $C$. finmarchicus, Pseudocalanus spp., T. longicornis, and Oithona spp. (Fig. 3). Sea surface temperatures between roughly 12 and $16^{\circ} \mathrm{C}$ had a positive influence on larval abundance, with temperatures above and below having a negative impact. Mesh sizes of $0.505 \mathrm{~mm}$ predicted higher mackerel abundances compared to $0.333 \mathrm{~mm}$ mesh. Relationships between significant taxa C. finmarchicus, Pseudocalanus spp., T. longicornis, and Oithona spp. and larval 
abundance were similar to those in the presence/absence model: at low larval abundance, the taxa had negative influences, and positive influences with greater copepod prey densities (Fig. 3). As with the presence/absence model, zooplankton covariates were better predictors for abundance than sea temperature, but by a smaller margin (Table 3).

\section{Temporal and Spatial Trends in Larval Habitat Suitability}

The amount of suitable habitat compared to observed abundances changed over space and time (Supplement 3). Of the different ecoregions, habitat suitability trends within ecoregions (represented by changes in predicted abundances over time) decreased the greatest and most often for the Mid-Atlantic Bight and southern New England (Fig. 4a). Greatest positive trends were in the western Gulf of Maine. Habitat suitability trends were most variable in the Mid-Atlantic Bight, southern New England and the western Gulf of Maine, representing the greatest changes in larval habitat suitability and heterogeneity within these ecoregions. Smaller variability in habitat suitability in Georges Bank and the eastern and western Gulf of Maine represent stronger homogeneity in habitat suitability for these ecoregions; these two regions remained fairly constant in suitable habitat over time (Fig. 4a). Mean habitat suitability trends within ecoregions were greater than observed abundance trends, except in southern New England prior to the mid 1980s. Habitat suitability and observed abundances in southern New England have decreased over time, but observed larval abundances have decreased at a faster rate (Fig. 4b). Mid-Atlantic Bight habitat suitability has been greater than observed abundances over the entire time series, with both decreasing. Georges Bank habitat suitability has increased 
slightly over time, with slight decreases in larval abundances. The eastern Gulf of Maine suitable habitat and observed abundances have slightly decreased since the late 1970s, whereas western Gulf of Maine suitable habitat has slightly decreased over time with marginal increases in the region's abundance (Fig. 4b).

Trends in habitat suitability indices differed among ecoregions in the Northeast U.S. Shelf. HSIE's were greatest for Mid-Atlantic Bight, southern New England, and western Gulf of Maine, with less habitat in Georges Bank and the eastern Gulf of Maine (Fig. 5). HSI $\mathrm{I}_{\mathrm{E}}$ in the Mid-Atlantic Bight and southern New England have decreased over time, whereas habitat HSIE in Georges Bank, western Gulf of Maine and eastern Gulf of Maine changed little. HSIE for the entire Northeast U.S. Shelf decreased, but not significantly (Fig. 5). Only Mid-Atlantic Bight HSIE linear trends indicated a significant decrease (Table 4), while non-significant trends for other HSIE's reflected high interannual variabilities in suitable habitat. When evaluating proportional habitat suitability shifts within the Northeast U.S. Shelf (HSIs), the MidAtlantic Bight and southern New England have contained much of the suitable habitat for Atlantic mackerel larvae since the late 1970s (Fig. 6). However, the Mid-Atlantic Bight contribution to Northeast U.S. Shelf suitable habitat has decreased significantly, while southern New England now contains the most suitable habitat for Atlantic mackerel (Fig. 6). In the 2000s, the western Gulf of Maine surpassed the Mid-Atlantic Bight as the second largest contributor to total Northeast U.S. Shelf suitable habitat. Georges Bank and eastern Gulf of Maine contributions to total habitat suitability in the Northeast U.S. Shelf were low and changed little over the time series (Fig. 6, Table 4). 
The center of larval habitat suitability has remained within northern MidAtlantic Bight and southern New England since the late 1970s (Fig. 7). Larval habitat suitability moved between the Mid-Atlantic Bight and southern New England ecoregions from the late 1970s through the 1980s, with suitable habitat from the mid 1990s through the early 2010s concentrated in southern New England (Fig. 7a,c). Across and along shelf movement has been variable over the time series (Fig. 7a,b), while geographical changes in the center of larval suitable habitat have moved north and closer to shore towards the southern New England-Gulf of Maine border (Fig. 7c). While linear trends from the late 1978-2013 for across and along shelf movement are insignificant, since 1995, the center of suitable habitat has moved significantly inshore $(\mathrm{p}$-value $=0.01)$ and north along the shelf $(\mathrm{p}$-value $=0.02)($ Fig 7a,b). Since 1978, the geographical center of larval habitat suitability has moved north as much as $211 \mathrm{~km}$, with relative distance changes between 119-175km since 2009 .

\section{DISCUSSION}

Suitable Atlantic mackerel larval habitat in the Northeast U.S. Shelf has changed over the last 40 years. Habitat suitability indices indicate spatial shifts in the leading areas of suitable larval habitat (Fig. 5,6). The Mid-Atlantic Bight has become less suitable over time (Fig. 5,6), and been succeeded by northern regions such as southern New England and the western Gulf of Maine (Fig. 6). Spatial variability in habitat suitability is also high within ecoregions. Areas increasing and decreasing in overall habitat suitability have strong heterogeneity in habitat changes over the time series (Fig. 4a,5,6). The Mid-Atlantic Bight habitat has varied in rate of habitat change, yet nearly the entire ecoregion has experienced decreased habitat suitability. 
While southern New England has experienced similar decreases (Fig 4a, 5), this region retains the most suitable habitat within the Northeast U.S. Shelf (Fig. 6). The western Gulf of Maine has the greatest positive change in habitat suitability trends (Fig. 4a) and is becoming a greater source of larval habitat for the stock's southern contingent. Areas that have historically had little suitable habitat, such as the eastern Gulf of Maine, have greater homogeneity in habitat suitability within their respective ecoregions (Fig. 4a).

Latitudinal shifts in larval habitat suitability are consistent with other reports on Atlantic mackerel shifts in the northwest Atlantic. Overholtz et al. (2011) found that adult mackerel abundances in the Northeast U.S. Shelf have shifted approximately $250 \mathrm{~km}$ northeast and from deeper to shallower waters, which is of similar magnitude to the shift in larval habitat from the late 1970s to 2010s (Fig. 7). Walsh et al. (2015) found that spring adult mackerel have shifted north and inshore, and during the spawning period (May-June), larval abundances have shifted inshore and appear later in the season. Suitable larval habitat changes across and along the shelf since the 1990s and geographical movement corroborate these findings, as the center of larval habitat has moved inshore and further north within southern New England (Fig. 7c). A northwestward population expansion has been documented for the northeast Atlantic mackerel population. Northeast Atlantic mackerel spawning has shifted at a rate of $0.9 \mathrm{~km}$ year $^{-1}$ from the early $1990 \mathrm{~s}$ through early $2010 \mathrm{~s}$, and is projected to expand west and north up to $117 \mathrm{~km}$ and $328 \mathrm{~km}$, respectively (Bruge et al., 2016).

While larval habitat suitability has changed spatially over time, total suitable habitat available for the stock's southern contingent has not significantly decreased 
(Fig.5). Absolute changes in larval habitat (HSIE) over the entire Northeast U.S. Shelf appear to have decreased, but strong interannual variability in habitat suitability persists (Fig. 5f); thus, despite variability within and among ecoregions, habitat has been available over the ecoregions for spawning and larvae. Only Mid-Atlantic Bight suitable habitat has significantly decreased (Fig. 5a). All ecoregions have provided habitat to support larval abundances greater than observed abundances for many decades (Fig. 4b). Over the time series, spawning and larvae appeared to be habitat limited only in southern New England from the late 1970s through the 1980s (Fig. 4b).

Latitudinal shifts in larval habitat suitability calculated with the species distribution models suggest the spatial movements are related to sea water temperature and zooplankton abundances (Table 1). Shifts in habitat over time coincide with warming sea waters in the Northeast U.S. Shelf (Friedland and Hare, 2007; Belkin 2009). The influence of surface sea temperature on suitable larval habitat is not surprising, given adult Atlantic mackerel distributions, migrations and time of spawning are sensitive to sea temperature (Jansen and Gislason, 2011; Overholtz et al. 2011). Nye et al. (2009) and Astthorsson et al. (2012) found adult mackerel abundance and distribution metrics corresponded to sea temperatures and climate oscillations that correlate to large-scale sea temperature patterns (such as the North Atlantic Oscillation and Atlantic Multidecadal Oscillation). Bruge et al. (2016) also found relationships between planktonic (egg) mackerel and sea temperatures in the northeast Atlantic. The authors noted that the thermal spawning niche for northeast Atlantic mackerel has moved north with thermal habitat changes at a rate of $28 \pm 9 \mathrm{~km}$ per ${ }^{\circ} \mathrm{C}$ (Bruge et al., 2016). However, the variance explained with this thermal niche 
model is less than those found using these species distribution models for northwest Atlantic mackerel larvae (Table 1).

The species distribution models highlight the functional relationship between Atlantic mackerel larvae and sea temperature. The observed larval temperature range (Fig. 2) agrees with previously reported ranges for spawning $\left(9-14^{\circ} \mathrm{C}\right)$ and larval presence $\left(6-22^{\circ} \mathrm{C}\right)$ in the northwest Atlantic, as well as the $9-14^{\circ} \mathrm{C}$ spawning temperature range in the northeast Atlantic (Beare and Reid, 2002; Jansen and Gislason, 2011; Studholme et al., 2011). The dome-shaped responses to temperature suggests an optimal thermal window for Atlantic mackerel larvae, theoretically driven by the bioenergetic and growth requirements (Buckley and Caldarone, 2004). Neutral influence of bottom sea temperature on larval presence and abundance suggests that surface environments are more influential, corroborating with reports of Atlantic mackerel larvae predominantly residing in surface layers (Fortier and Villeneuve, 1996).

Shifts in suitable larval habitat also coincide with oceanographic and climate oscillation induced changes in zooplankton community composition in the Northeast U.S. Shelf (Morse et al., 2016). However, there are two hypotheses for the significant relationship between larval presence and the abundance of specific zooplankton taxa: (1) spawning and higher larval survival occurs in areas where larval prey is abundant, and (2) oceanographic processes concentrate egg and larval mackerel and zooplankton similarly. Both hypotheses are likely operating to varying degrees, given the planktonic nature of the larvae analyzed in this study. Some of the zooplankton taxa that significantly contributed to predicting larval presence and abundance likely 
represent true prey or habitat dependency for Atlantic mackerel larvae, such as $T$. longicornis, Pseudocalanus spp. nauplii, Oithona spp., and C. finmarchicus (Kane 1984; Peterson and Ausbel, 1984; Robert et al. 2008; Paradis et al. 2012).

Centropages typicus is highly abundant, yet a less frequent mackerel larval prey item, and may merely coexist with mackerel larvae due to similar habitat requirements and oceanographic processes. Stomach-content analyses of Atlantic mackerel larvae in the study area would better identify copepod species' contributions to mackerel larval diet.

Sizes and/or life stages of copepods sampled during the MARMAP and EcoMon cruises may also confound true relations between copepod and larval abundances. Atlantic mackerel less than $7 \mathrm{~mm}$ primarily eat copepod nauplii and copepodites (Fortier and Villeneuve, 1996; Robert et al., 2008; Robert et al., 2009), which are not sampled efficiently by $0.333 \mathrm{~mm}$ mesh nets (Runge et al., 1999). Copepods sampled during the MARMAP and EcoMon cruises with $0.333 \mathrm{~mm}$ mesh nets are older, typically stage IV through adults (Supplement 4). Previous studies have used late-staged female copepods as proxies for egg production and nauplii abundances when evaluating available Atlantic mackerel larval prey and mackerel recruitment (Runge et al., 1999; Castonguay et al. 2008). However, given the multipurpose nature of the MARMAP and EcoMon surveys, sex-specific zooplankton abundance information is not available for refined egg production estimates. Thus, analyses presented here use later stage abundances to represent fecund female copepods and subsequent nauplii production, and assumes that variability in the sampled zooplankton population corresponds to that of the female-specific population. 
Sampling and identifying smaller copepod nauplii with a finer mesh net or female identification of copepods for fecundity estimates may better estimate the Atlantic mackerel larval prey field.

The depth influence on presence suggests that spawning primarily occurs within waters less than 60 or 70m, corroborating historical recordings and observations of inshore spawning (Studholme et al., 1999). However, depending on the ecoregion, depth may act as a proxy for the physical environment influencing mackerel. For instance, years with warmer March sea temperatures in the Mid-Atlantic Bight corresponded to mackerel concentrated father inshore, while in colder years mackerel congregated further offshore (Radlinski et al., 2013). Additionally, mackerel have been shown to respond to tidal and shelf fronts as they move in response to advection and ocean circulation, which can displace them from their preferred habitat (Garrison, et al., 2000). Observed and predicted abundances in various years along the shelf-break (Supplement 3) suggest that suitable spawning and larval conditions may exist beyond the historical shallow habitats. In the northeast Atlantic, mackerel spawn along the shelf-break from Portugal through the North Sea (Trenkel et al., 2014), with migrations to nursery areas correlated with the temporal patterns of the warm shelf edge current (Jansen et al., 2014). Additional shelf-break sampling would help clarify depth's confounding influence on Atlantic mackerel larvae in relation to thermal and prey preferences, and whether the hydrodynamics farther offshore can provide suitable habitat. Higher predicted larval presence and abundances with $0.505 \mathrm{~mm}$ mesh net compared with the $0.333 \mathrm{~mm}$ may be a temporal artifact given the changes in mesh 
over time: the coarser mesh may have predicted more larvae because more larvae were present during the 1980s when such gear happened to be used.

Higher predicted abundances than those observed (Fig. 4b) and greater spatial discrepancies in predicted and observed abundances in recent years (Supplement 3) suggest that temperature and prey described in the species distribution models are not significantly limiting available habitat for larvae over the entire Northeast U.S. Shelf (Fig. 5). Other habitat features, such as additional oceanographic characteristics (e.g. fronts) or predator fields not represented in the GAMs may also be contributing to changes in larval abundance over time. While variables chosen to predict larval presence and abundance were based on known influences on larval survival and recruitment to assess changes in the fundamental niche, changes in the adult stock also contribute to the abundance and distribution of larvae (Parker, 1985). Atlantic mackerel landings in the Northeast U.S. Shelf are currently the lowest in the last 40 years (Wiedenmann, 2016). Contradicting abundance indices and age structures in U.S. landings and bottom-trawl surveys have produced high uncertainty and significant retrospective patterns in stock assessment products (Deroba et al., 2010). As such, the U.S. declares the northwest Atlantic mackerel stock status as unknown (MAFMC, 2016). Gulf of St. Lawrence abundance indices based on egg survey data also reflect recent time series lows in mackerel abundance (DFO, 2014). Canadian assessments have attributed recent reduced catches to overharvesting and recruitment overfishing, and indicate that the stock is at historic low levels (DFO, 2014; Ploudre et al., 2015). Thus, lower stock abundances may also be contributing to the absence of larvae across ecoregions where they are expected based on the species distribution 
models.

Habitat suitability models for Atlantic mackerel larvae can be expanded upon. These results are influenced by the spatial interpolation of abundances where covariates were unavailable for predictions. Prediction spatial resolution can also influence the trends and patterns; Jones et al. (2015) found that species envelope models using different prediction grid sizes can affect the magnitude of trends and changes over time. As zooplankton distribution models become available for the northwest Atlantic (Albouy-Boyer et al., 2016), oceanographic and zooplankton spatial predictions can be used to refine Atlantic mackerel habitat suitability. Identifying essential fish habitat is critical in understanding key life history aspects (such as growth, survival, reproduction) and population trends, forecasting future abundances, and informing management regulations and quotas. Changes in habitat suitability have significant implications for marine fish species distribution shifts (Perry et al., 2005), match-mismatches between spawning grounds and suitable early-life habitats (Cowen et al., 2007; Walsh et al., 2015), and changes in prey and predator fields (Mountain and Murawski 1992; Murawksi 1993). Distributional shifts specifically pose challenges for future fisheries management. As evidenced in the northeast Atlantic, growing Iceland and Greenland mackerel fisheries and shifts in other European countries' harvest in response to northwestward expansion of northeast Atlantic mackerel will alter available fish for participating countries' fishery quotas (Astthorsson et al., 2012; Hughes et al., 2015). Such changes will have direct effects on the revenue, employment opportunities, and food supply for local communities (Jansen et al., 2016). By identifying the relationships between fisheries 
and the environment, we can continue to anticipate how species distributions and abundance may shift in a changing marine environment and prepare for socioeconomic changes.

\section{ACKNOWLEDGEMENTS}

We thank all scientists and crew members that have helped in collecting highquality plankton and hydrographic data for over five decades as part of the EcoMon and MARMAP programs. The authors thank K. Marancik, M. Jones, and R. Morse for assistance with data compilation and quality assurance. K. Curti, J. Manderson, C. Oviatt, D. Secor, and two anonymous reviewers provided valuable comments on earlier drafts of the manuscript. MCM was funded by The Nature Conservancy Global Marine Initiative Student Research Award Program. The views expressed in this work are those of the authors and do not necessarily reflect the views of their agencies.

\section{LITERATURE CITED}

Akaike, H. (1973) Information theory as an extension of the maximum likelihood principle. In: Second International Symposium on Information Theory. B.N. Petrov \& F. Csaki (eds) Budapest: Akademiai Kiado, pp. 267.

Albouy-Boyer, S., Plourde, S., and Pepin, P. (2016) Habitat modelling of key copepod species in the Northwest Atlantic Ocean based on the Atlantic Zone Monitoring Program. Journal of Plankton Research 38(3): 589-603.

Anderson, E.D. (1982) Status of the northwest Atlantic mackerel stock - 1981. U.S. National Maine Fisheries Service Northeast Fisheries Center Woods Hole Lab Ref. Doc. 81-38: 38p.

Anderson, E.D., and Paciorkowski, A.L. (1980) A review of the northwest Atlantic mackerel fishery. Rapp. P.-V. Réun. Cons. Int. Explor. Mer 177: 175-211.

Anderson, J. J., Gurarie, E., Bracis, C., Burke, B. J., and Laidre, K. L. (2013) Modeling climate change impacts on phenology and population dynamics of migratory marine species. Ecological Modelling, 264: 83-97.

Astthorsson, O. S., Valdimarsson, H., Gudmundsdottir, A., and Oskarsson, G. J. 
(2012) Climate-related variations in the occurrence and distribution of mackerel (Scomber scombrus) in Icelandic waters. ICES Journal of Marine Science, 69: 1289-1297.

Beare, D. J., and Reid, D. G. (2002) Investigating spatio-temporal change in spawning activity by Atlantic mackerel between 1977 and 1998 using generalized additive models. ICES Journal of Marine Science: Journal du Conseil, 59: 711-724.

Belkin, I.M. (2009) Rapid warming of large marine ecosystems. Progress in Oceanography 81:207-213.

Berrien, P. (1982). Atlantic mackerel, Scomber scombrus. In M.D. Grosslein and T.R. Azarovitz eds. Fish distribution. p. 99-102. MESA New York Bight Atlas Monograph 15. N.Y. Sea Grant Institute, Albany, NY.

Berrien, P., and Sibunka, J. (1999) Distribution patterns of fish eggs in the U.S. northeast continental shelf ecosystem, 1977-1987. U.S. Dep. Commer., NOAA Tech. Rep. NMFS 145, 310 p.

Bruge, A., Alvarez, P., Fontán, A., Cotano, U., and Chust, G. (2016) Thermal niche tracking and future distribution of Atlantic mackerel spawning in response to ocean warming. Frontiers in Marine Science 3(86): 1-13.

Buckley, L. J., and Caldarone, E. M. (2004) Optimum temperature and food-limited growth of larval Atlantic cod (Gadus morhua) and haddock (Melanogrammus aeglefinus) on Georges Bank. Fisheries Oceanography 13(2): 134-140.

Carletta, J. (1996) Assessing agreement on classification tasks: the kappa statistic. Computational Linguistics 22(2): 1-6.

Castonguay, M., Plourde, S., Robert, D., Runge, J. A., and Fortier, L. (2008) Copepod production drives recruitment in a marine fish. Canadian Journal of Fisheries and Aquatic Sciences 65: 1528-1531.

Cowen, R. K., Gawarkiewicz, G. G., Pineda, J., Thorrold, S. R., and Werner, F. E. (2007) Population connectivity in marine systems: an overview. Oceanography 20(3): 14-21.

Deroba, J., Shepherd, G., Gregoire, F., Nieland, J., and Rago, P. (2010) Stock assessment of Atlantic mackerel in the Northwest Atlantic for 2010.

Transboundary Resources Assessment Committee, Reference Document 2010/01. $59 \mathrm{pp}$.

Department of Fisheries and Oceans DFO. (2014) Assessment of the Atlantic Mackerel stock for the Northwest Atlantic (Subareas 3 and 4) in 2013. DFO Can. Sci. Advis. Sec. Sci. Advis. Rep. 2014/030. 
Dormann, C.F., McPherson, J.M., Araújo, M.B., Bivand, R., Bolliger, J., Carl, G., Davies, R.G., et al. (2007) Methods to account for spatial autocorrelation in the analysis of species distributional data: a review. Ecography 30: 609-628.

Elith, J., and Leathwick, J. R. (2009) Species Distribution Models: Ecological Explanation and Prediction Across Space and Time. Annual Review of Ecology, Evolution and Systematics 40: 677-697.

Fortier, L., and Villeneuve, A. (1996) Cannibalism and predation on fish larvae by larvae of Atlantic mackerel, Scomber scombrus: trophodynamics and potential impact on recruitment. Fishery Bulletin 94: 268-281.

Friedland, K.D., and Hare, J.A. (2007) Long-term trends and regime shifts in sea surface temperature on the continental shelf of the northeast United States. Continental Shelf Research 27: 2313-2328.

Friedland, K. D., Kane, J., Hare, J. A., Lough, R. G., Fratantoni, P. S., Fogarty, M. J., and Nye, J. A. (2013) Thermal habitat constraints on zooplankton species associated with Atlantic cod (Gadus morhua) on the US Northeast Continental Shelf. Progress in Oceanography 116: 1-13. Elsevier Ltd. 13 pp.

Garrison, L.P., Michaels, W., Link, J.S., and Fogarty, M.J. (2000) Predation risk on larval gadids by pelagic fish in the Georges Bank ecosystem. I. Spatial overlap associated with hydrographic features. Canadian Journal of Fisheries and Aquatic Sciences 57: 2455-2469

Grüss, A., Drexler, M., and Ainsworth, C. H. (2014) Using delta generalized additive models to produce distribution maps for spatially explicit ecosystem models. Fisheries Research, 159: 11-24.

Hare, J. A., Morrison, W. E., Nelson, M. W., Stachura, M. M., Teeters, E. J., Griffis, R. B., Alexander, M. A., et al. (2016) A vulnerability assessment of fish and invertebrates to climate change on the northeast U.S. continental shelf. PLoS ONE, 11: e0146756.

Hastie, T., and Tibshirani, R. (1986) Generalized additive models. Statistical Science: 297-310.

Hughes, K. M., Dransfeld, L., and Johnson, M. P. (2015) Climate and stock influences on the spread and locations of catches in the northeast Atlantic mackerel fishery. Fisheries Oceanography, 24: 540-552.

Hutchinson, G. E. (1957) Concluding remarks. Cold Spring Harbor Symposium, 22: 415-427.

Jacobson, L., Seaver, A., and Tang, J. (2011) AstroCalc4R: software to calculate solar 
zenith angle; time at sunrise, local noon and sunset; and photosynthetically available radiation based on date, time, and location. Northeast Fisheries Science Center Reference Document 11-14: 1-10.

Jansen, T. (2016) First-year survival of North East Atlantic mackerel (Scomber scombrus) from 1998 to 2012 appears to be driven by availability of Calanus, a preferred copepod prey. Fisheries Oceanography, 25: 457-469.

Jansen, T., and Gislason, H. (2011) Temperature affects the timing of spawning and migration of North Sea mackerel. Continental Shelf Research 31:64-72.

Jansen, T., Kristensen, K., van der Kooij, J., Post, S., Campbell, A., Utne, K. R., Carrera, P., et al. (2014) Nursery areas and recruitment variation of Northeast Atlantic mackerel. (Scomber scombrus). ICES Journal of Marine Science. doi: 10.1093/icesjms/fsu186.

Jansen, T., Post, S., Kristiansen, T., Oskarsson, G. J., Boje, J., MacKenzie, B. R., Broberg, M., et al. (2016) Ocean warming expands habitat of a rich natural resource and benefits a national economy. Ecological Applications. doi: 10.1002/eap.1384.

Johnson, D. L., and Morse, W. W. (1994) Net extrusion of larval fish: correction factors for $0.333 \mathrm{~mm}$ versus $0.505 \mathrm{~mm}$ mesh bongo nets. NAFO Sci. Counc. Stud. 20: 85-92.

Jones, M.C., Dye, S.R., Pinnegar, J.K., Warren, R., and Cheung, W.W.L. (2015) Using scenarios to project the changing profitability of fisheries under climate change. Fish and Fisheries, 16: 603-622.

Kane, J. (1984) The feeding habits of co-occurring cod and haddock larvae from Georges Bank. Marine Ecology Progress Series 16: 9-20.

Kane, J. (2003) Spatial and temporal abundance patterns for late stage copepodites of Metridia lucens (Copepoda: Calanoida) in the US northeast continental shelf ecosystem. Journal of Plankton Research 25(2): 151-167.

Kane, J. (2008) A comparison of two zooplankton time series data collected in the Gulf of Maine. Journal of Plankton Research, 31: 249-259.

Kleisner, K. M., Fogarty, M. J., McGee, S., Barnett, A., Fratantoni, P., Greene, J., Hare, J. A., et al. (2016) The Effects of Sub-Regional Climate Velocity on the Distribution and Spatial Extent of Marine Species Assemblages. PLOS ONE, 11: e0149220.

Llopiz, J. K., Cowen, R. K., Hauff, M. J., Ji, R., and Munday, P. L. (2014) Early life history and fisheries oceanography: new questions in a changing world. 
Oceanography 27(4):26-41.

Lobo, J. M., Jiménez-Valverde, A., and Real, R. (2008) AUC: a misleading measure of the performance of predictive distribution models. Global Ecology and Biogeography, 17: 145-151.

Lynch, P. D., Nye, J. A., Hare, J. A., Stock, C. A., Alexander, M. A., Scott, J. D., Curti, K. L., et al. (2015) Projected ocean warming creates a conservation challenge for river herring populations. ICES Journal of Marine Science. 72 (2): 374-387.

Maunder, M. N., and Punt, A. E. (2004) Standardizing catch and effort data: a review of recent approaches. Fisheries Research, 70: 141-159.

Mid-Atlantic Fisheries Management Council (MAFMC). (2016). Mid-Atlantic Fishery Council - Species Stock Status (as of November 28, 2016).

https://static1.squarespace.com/static/511cdc7fe4b00307a2628ac6/t/587e36662e6 9cf391ab50619/1484666472391/2016-11-28_MAFMC_Stock_Status.pdf. (accessed 4 February 2017).

Morse, W.W. (1989) Catchability, growth, and mortality of larval fishes. Fishery Bulletin 87: 417-446.

Morse, R.E., Friedland, K.D., Tommasi, D., Stock, C., Nye, J. (2016) Distinct zooplankton regime shift patterns across ecoregions of the U.S. Northeast continental shelf Large Marine Ecosystem. Journal of Marine Systems. doi: 10.1016/j.jmarsys.2016.09.011.

Mountain, D. G., and Murawski, S. A. (1992) Variation in the distribu- tion of fish stocks on the northeast continental shelf in relation to their environment, 1980 1989. ICES Marine Science Symposia, 195: 424-432.

Murawski, S. A. (1993) Climate change and marine fish distributions: forecasting from historical analogy. Transactions of the American Fisheries Society, 122: 647-658.

Murtaugh, P. A. (1996) The statistical evaluation of ecological indicators. Ecological Applications 6(1): 132-139.

Nye, J.A., Link, J.S., Hare, J.A., and Overholtz, W.J. (2009) Changing spatial distribution of fish stocks in relation to climate and population size on the Northeast United States continental shelf. Marine Ecology Progress Series, 393: 111-129.

Overholtz, W.J. (1989) Density-dependent growth in the northwest Atlantic stock of Atlantic mackerel (Scomber scombrus). Journal of the Northwest Atlantic Fishery 
Science, 9:115-121.

Overholtz, W. J., Hare, J. A., and Keith, C. M. (2011) Impacts of interannual environmental forcing and climate change on the distribution of Atlantic mackerel on the US Northeast continental shelf. Marine and Coastal Fisheries: Dynamics, Management, and Ecosystem Science, 3: 219-232.

Paradis, V., Sirois, P., Castonguay, M., and Ploudre, S. (2012) Spatial variability in zooplankton and feeding of larval Atlantic mackerel (Scomber scombrus) in the southern Gulf of St. Lawrence. Journal of Plankton Research 34(12): 1064-1077.

Parker, K. (1985) Biomass model for the egg production method. US Department of Commerce, NOAA Technical Report, NMFS-36. 99 pp.

Peterson, W. T., and Ausubel, S. J. (1984) Diets and selective feeding by larvae of Atlantic mackerel Scomber scombrus on zooplankton. Marine Ecology Progress Series 17: 65-75.

Pinsky, M. L., and Fogarty, M. (2012) Lagged social-ecological responses to climate and range shifts in fisheries. Climatic Change, 115: 883-891.

Plourde, S., Grégoire, F., Lehoux, C., Galbraith, P. S., Castonguay, M., and Ringuette, M. (2015) Effect of environmental variability on body condition and recruitment success of Atlantic Mackerel (Scomber scombrus L.) in the Gulf of St. Lawrence. Fisheries Oceanography doi: 10.1111/fog.12113.

Poloczanska, E. S., Burrows, M. T., Brown, C. J., García Molinos, J., Halpern, B. S., Hoegh-Guldberg, O., Kappel, C. V., et al. (2016) Responses of marine organisms to climate change across oceans. Frontiers in Marine Science, 3(62): 1-21.

Radlinski, M. K., Sundermeyer, M. A., Bisagni, J. J., and Cadrin, S. X. (2013) Spatial and temporal distribution of Atlantic mackerel (Scomber scombrus) along the northeast coast of the United States, 1985-1999. ICES Journal of Marine Science, 70: 1151-1161.

Richardson, D. E., Hare, J. A., Overholtz, W. J., and Johnson, D. L. (2010) Development of long-term larval indices for Atlantic herring (Clupea harengus) on the northeast US continental shelf. ICES Journal of Marine Science: Journal $d u$ Conseil, 67: 617-627.

Ringuette, M., Castonguay, M., Runge, J. A., and Grégoire, F. (2002) Atlantic mackerel (Scomber scombrus) recruitment fluctuations in relation to copepod production and juvenile growth. Canadian Journal of Fisheries and Aquatic Sciences, 59: 646-656.

Robert, D., Castonguay, M., and Fortier, L. (2007) Early growth and recruitment in 
Atlantic mackerel Scomber scombrus: discriminating the effects of fast growth and selection for fast growth. Marine Ecology Progress Series, 337: 209-219.

Robert, D., Castonguay, M., and Fortier, L. (2008) Effects of intra- and inter-annual variability in prey field on the feeding selectivity of larval Atlantic mackerel (Scomber scombrus). Journal of Plankton Research, 30: 673-688.

Robert, D., Castonguay, M., and Fortier, L. (2009) Effects of preferred prey density and temperature on feeding success and recent growth in larval mackerel of the southern Gulf of St. Lawrence. Marine Ecology Progress Series 377: 227-237.

Robert, D., Pepin, P., Dower, J. F., and Fortier, L. (2014) Individual growth history of larval Atlantic mackerel is reflected in daily condition indices. ICES Journal of Marine Science 71(4): 1001-1009.

Runge, J.A., Castonguay, M., de Lafontaine, Y., Ringuette, M., and Beaulieu, J.-L. (1999) Covariation in climate, zooplankton biomass and mackerel recruitment in the southern Gulf of St. Lawrence. Fisheries Oceanography 8(2): 139-149.

Sette, O.E. (1943) Biology of the Atlantic mackerel (Scomber scombrus) of North America. Part I. Early Life history, including growth, drift, and mortality of egg and larval populations. U.S. Fish and Wildlife Service Fishery Bulletin 50: 149237.

Sette, O.E. (1950) Biology of the Atlantic mackerel (Scomber scombrus) of North America. Part II. Migrations and habitat. U.S. Fish and Wildlife Service Fishery Bulletin 51: 251-358.

Simpson, C.A., Wilburg, M.J., Bi, Hongsheng, Schueller, A.M., Nesslage, G.M., and Walsh, H.J. (2016) Trends in relative abundance and early life survival of Atlantic menhaden during 1977-2013 from long-term ichthyoplankton programs. Transactions of the American Fisheries Society, 145:1139-1151.

Skud, B. E. (1982) Dominance in fishes: the relation between environment and abundance. Science 216: 144-149.

Studholme, A. L., Packer, D. B., Berrien, P. L., and Johnson, D. L., Zetlin, C.A., and Morse, W.W. (1999) Essential fish habitat source document: Atlantic mackerel, Scomber scombrus, life history and habitat characteristics. NOAA Technical Memorandum NMFS-NE-141.

Takasuka, A., Aoki, I., and Mitani, I. (2003) Evidence of growth-selective predation on larval Japanese anchovy Engraulis japonicus in Sagami Bay. Marine Ecology Progress Series, 252: 223-238.

Townsend, D. W., Thomas, A. C., Mayer, L. M., Thomas, M. A., and Quinlan, J. A. 
(2006) Oceanography of the northwest Atlantic continental shelf $(1, \mathrm{~W})$. The sea: the global coastal ocean: interdisciplinary regional studies and syntheses, 14: 119168.

Trenkel, V. M., Huse, G., MacKenzie, B. R., and Alvarez, P. (2014) Comparative ecology of widely distributed pelagic fish species in the North Atlantic: implications for modelling climate and fisheries impacts. Progress in Oceanography 129(B): 219-243.

Venables, W. N., and Dichmont, C. M. (2004) GLMs, GAMs and GLMMs: an overview of theory for applications in fisheries research. Fisheries Research, 70: 319-337.

Walsh, H. J., Richardson, D. E., Marancik, K. E., and Hare, J. A. (2015) Long-Term Changes in the Distributions of Larval and Adult Fish in the Northeast U.S. Shelf Ecosystem. PLOS ONE, 10: e0137382.

Ware, D. M., and Lambert, T. C. (1985) Early life history of Atlantic mackerel (Scomber scombrus) in the southern Gulf of St. Lawrence. Canadian Journal of Fisheries and Aquatic Sciences, 42: 577-592.

Wiedenmann, J. (2016). Application of a data-poor harvest control rules to Atlantic mackerel. Southeast Data, Assessment, and Review, Report\# SEDAR46-RD-09. $53 \mathrm{pp}$.

Wood, S.N. (2006) Generalized Additive Models: An Introduction with R. Chapman and Hall/CRC Press. Boca Raton, FL. 
Table 1. Model results for the presence/absence and abundance GAMs. Covariates are described by their estimated degrees of freedom (EDF) and p-values. Covariates with p-values $<0.05$ are in bold. Model fitness is described using $\mathrm{R}^{2}$ and unbiased risk estimator (UBRE, presence/absence model) and generalized cross validation (GCV, abundance model) scores.

\begin{tabular}{|c|c|c|c|c|}
\hline \multirow{2}{*}{ Covariate } & \multicolumn{2}{|c|}{ Presence/Absence } & \multicolumn{2}{|c|}{ Abundance } \\
\hline & EDF & $\mathrm{p}$-value & EDF & p-value \\
\hline Surface Temperature & 3.31 & $<0.001$ & 3.27 & $<0.001$ \\
\hline Bottom Temperature & 3.65 & 0.006 & 1.00 & 0.709 \\
\hline Calanus finmarchicus & 3.82 & $<0.001$ & 2.69 & $<0.001$ \\
\hline Temora longicornis & 4.23 & $<0.001$ & 3.00 & 0.005 \\
\hline Depth & 2.44 & $<0.001$ & 1.14 & 0.752 \\
\hline Pseudocalanus spp. & 1.00 & 0.034 & 2.51 & $<0.001$ \\
\hline Oithona spp. & 2.61 & 0.009 & 1.87 & 0.031 \\
\hline Centropages typicus & 3.82 & $<0.001$ & 4.30 & 0.012 \\
\hline Mesh & 1.00 & $<0.001$ & 1.00 & $<0.001$ \\
\hline $\mathrm{R}^{2}$ & & & & \\
\hline UBRE or GCV & & & & \\
\hline
\end{tabular}


Table 2. Confusion matrix describing the presence/absence model validation results.

\begin{tabular}{lcc} 
& Observed Absence & Observed Presence \\
\cline { 2 - 3 } Predicted Absence & $75.5 \%$ & $1.7 \%$ \\
Predicted Presence & $12.1 \%$ & $10.7 \%$ \\
\hline
\end{tabular}


Table 3. Relative model quality scores (represented as $\Delta \mathrm{AIC}$ ) of the presence/absence and abundance models used for these analyses (Final), only including temperature covariates from the Final model (Temperature) and only including zooplankton covariates from the Final model (Zooplankton).

\begin{tabular}{lcc} 
Model & \multicolumn{2}{c}{$\Delta$ AIC } \\
Description & Presence/Absence & Abundance \\
\cline { 2 - 3 } Final & 0 & 0 \\
Temperature & 622 & 372 \\
Zooplankton & 416 & 351
\end{tabular}


Table 4. Linear slopes for habitat suitability index time series of each ecoregion. Asterisks indicate degree of significance. ${ }^{*} \mathrm{p}<0.10,{ }^{*} \mathrm{p}<<0.05$.

\begin{tabular}{lcc}
\hline \multicolumn{1}{c}{ Ecoregion } & HSIs & $\mathrm{HSI}_{\mathrm{E}}$ \\
\hline $\begin{array}{l}\text { eastern Gulf of } \\
\text { Maine }\end{array}$ & $-1.0 \mathrm{E}-4$ & $-2.2 \mathrm{E}-5$ \\
$\begin{array}{l}\text { western Gulf of } \\
\text { Maine }\end{array}$ & $2.2 \mathrm{E}-3$ & $-1.5 \mathrm{E}-5$ \\
Georges Bank & $3.3 \mathrm{E}-3$ & $0.5 \mathrm{E}-5$ \\
southern New & $2.2 \mathrm{E}-3$ & $-1.2 \mathrm{E}-4$ \\
England & & \\
$\begin{array}{l}\text { Mid-Atlantic } \\
\text { Bight }\end{array}$ & $-4.6 \mathrm{E}-3 *$ & $-2.1 \mathrm{E}-4 * *$ \\
$\begin{array}{l}\text { Northeast U.S. } \\
\text { Shelf }\end{array}$ & NA & $-3.9 \mathrm{E}-4$ \\
\end{tabular}




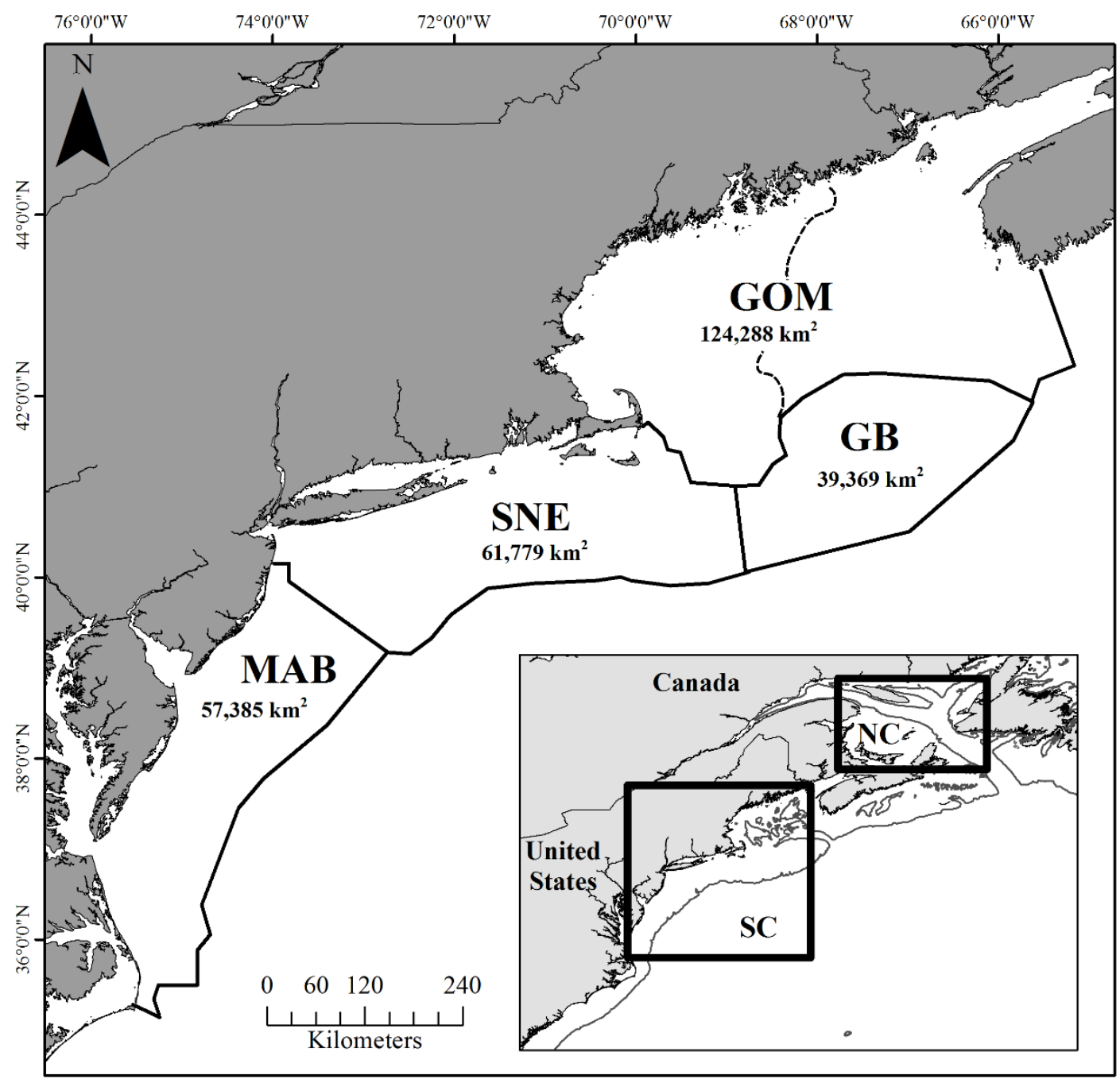

Figure 1. Regions of the Northeast U.S. Shelf examined for Atlantic mackerel larval habitat. Assessment was confined to the Mid-Atlantic Bight (MAB), southern New England (SNE), Georges Bank (GB), and the Gulf of Maine (GOM). The area $\left(\mathrm{km}^{2}\right)$ for each of these regions is provided. The dashed line through the Gulf of Maine delineates the western and eastern portions. Locus map illustrates the Northeast U.S. Shelf location within the northwest Atlantic, the southern (SC) and northern (NC) contingent spawning grounds, and the $200 \mathrm{~m}$ isobath (dark line). 

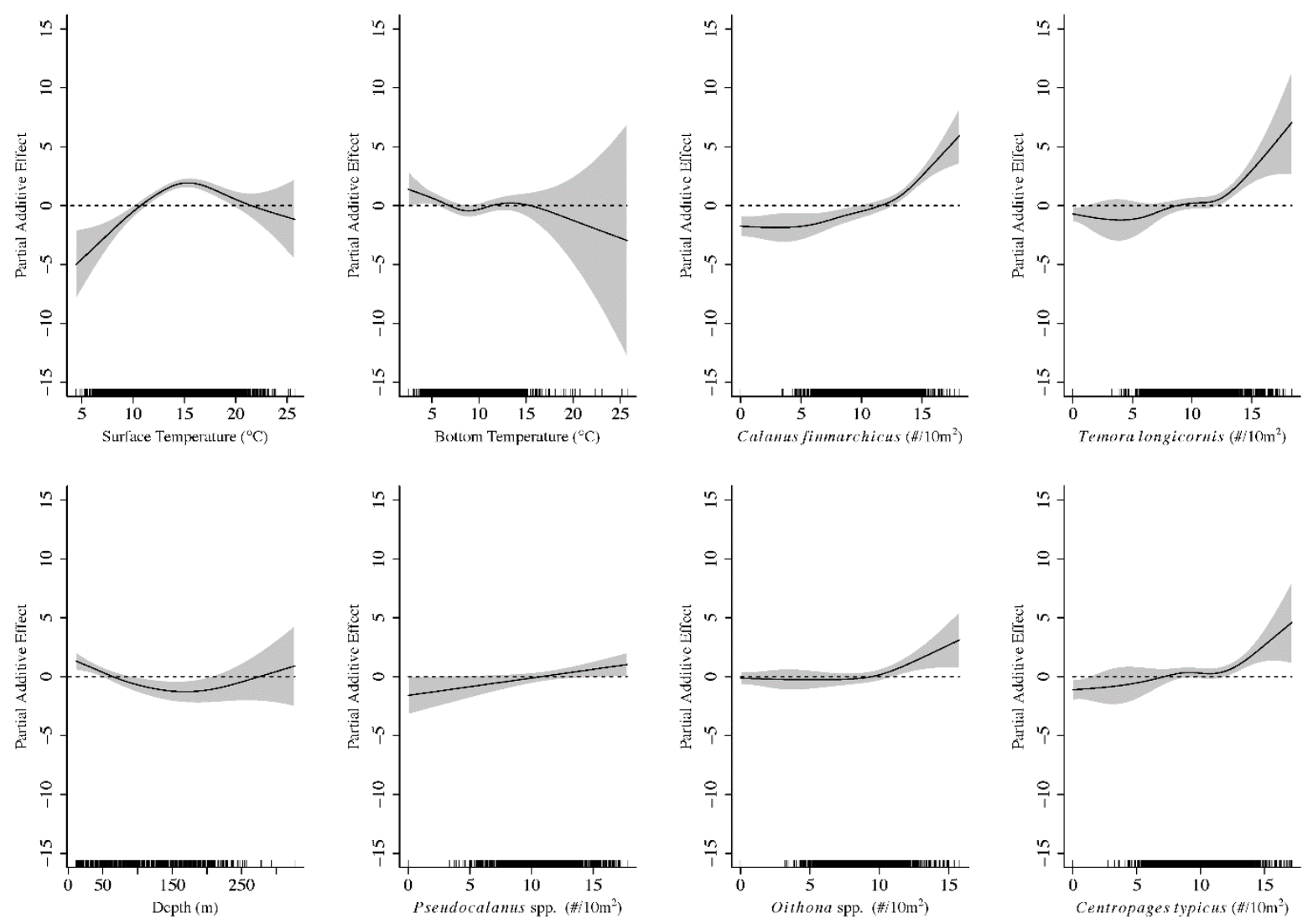

Figure 2. Partial additive effects for continuous variables used in the presence/absence GAM. Zooplankton abundances were transformed before modeling: $\ln ($ abundance+1). Dark lines indicate the mean fit for each relationship, with grey bounds indicating the 95\% confidence interval. The horizontal dashed lines represent a neutral effect on the presence/absence for the given covariate. Rug plots along $\mathrm{x}$-axes indicate the values of independent variable observations, with fewer tick marks indicating fewer samples of that quantity of the covariate observed. 

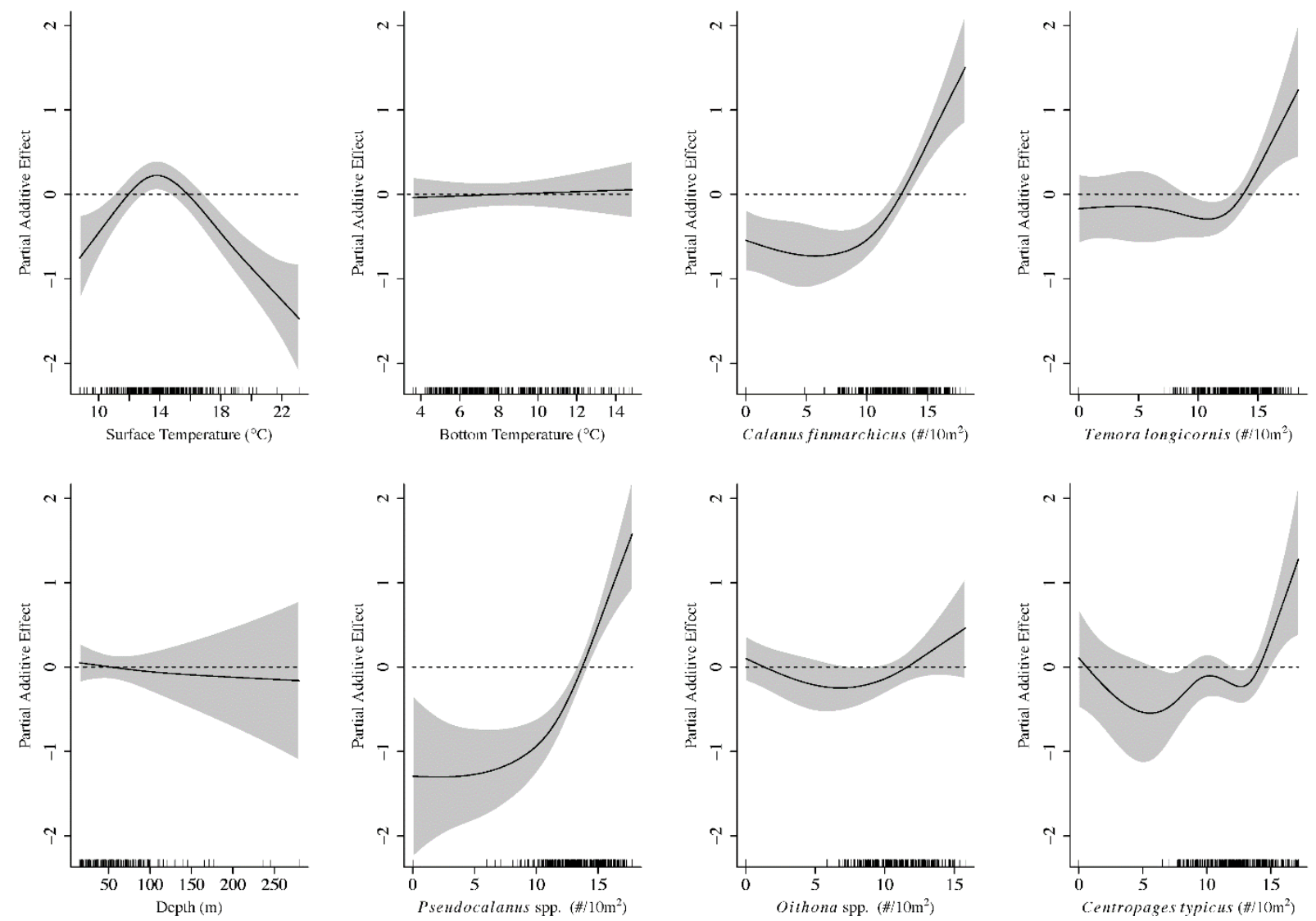

Figure 3. Partial additive effects for continuous variables used in the abundance GAM. Larval Atlantic mackerel and zooplankton abundances were transformed before modeling: $\ln ($ abundance+1). Dark lines indicate the mean fit for each relationship, with grey bounds indicating the $95 \%$ confidence interval. The horizontal dashed lines represent a neutral effect on the abundance for the given covariate. Rug plots along $x$-axes indicate the values of independent variable observations, with fewer tick marks indicating fewer samples of that quantity of the covariate observed. 

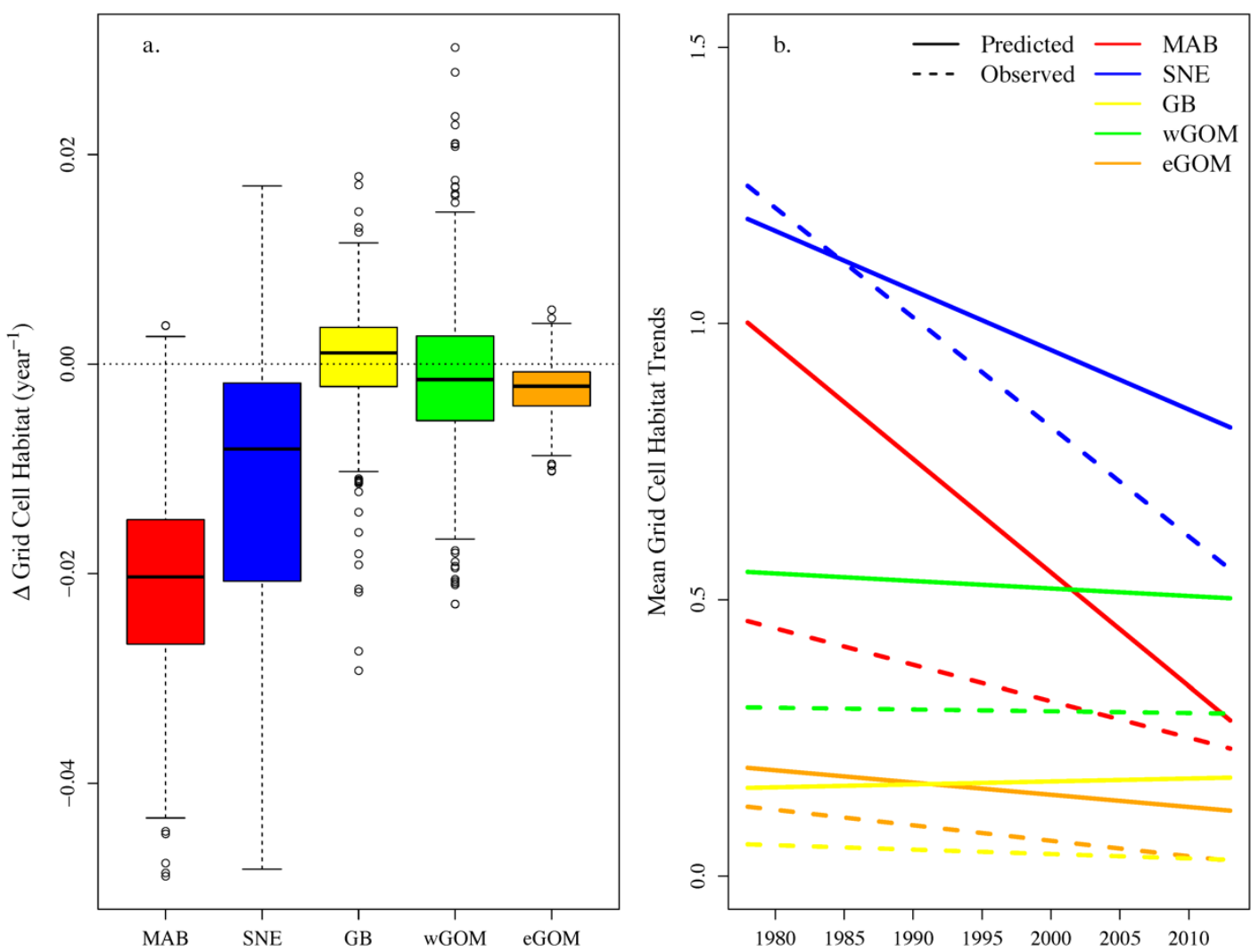

Figure 4. Grid cell trends in habitat for the five ecoregions: the Mid-Atlantic Bight (MAB, red), southern New England (SNE, blue), Georges Bank (GB, yellow), the western Gulf of Maine (wGOM, green), and the eastern Gulf of Maine (eGOM, orange) (a). Habitat grid cell linear trends (slopes) over time by ecoregion, with quartiles (lines) and outliers (points) presented. Horizontal dotted line represents no change in habitat. Mean grid cell trends (b) in interpolated abundance, representing habitat suitability (solid lines), and observed (dashed lines) abundance. 

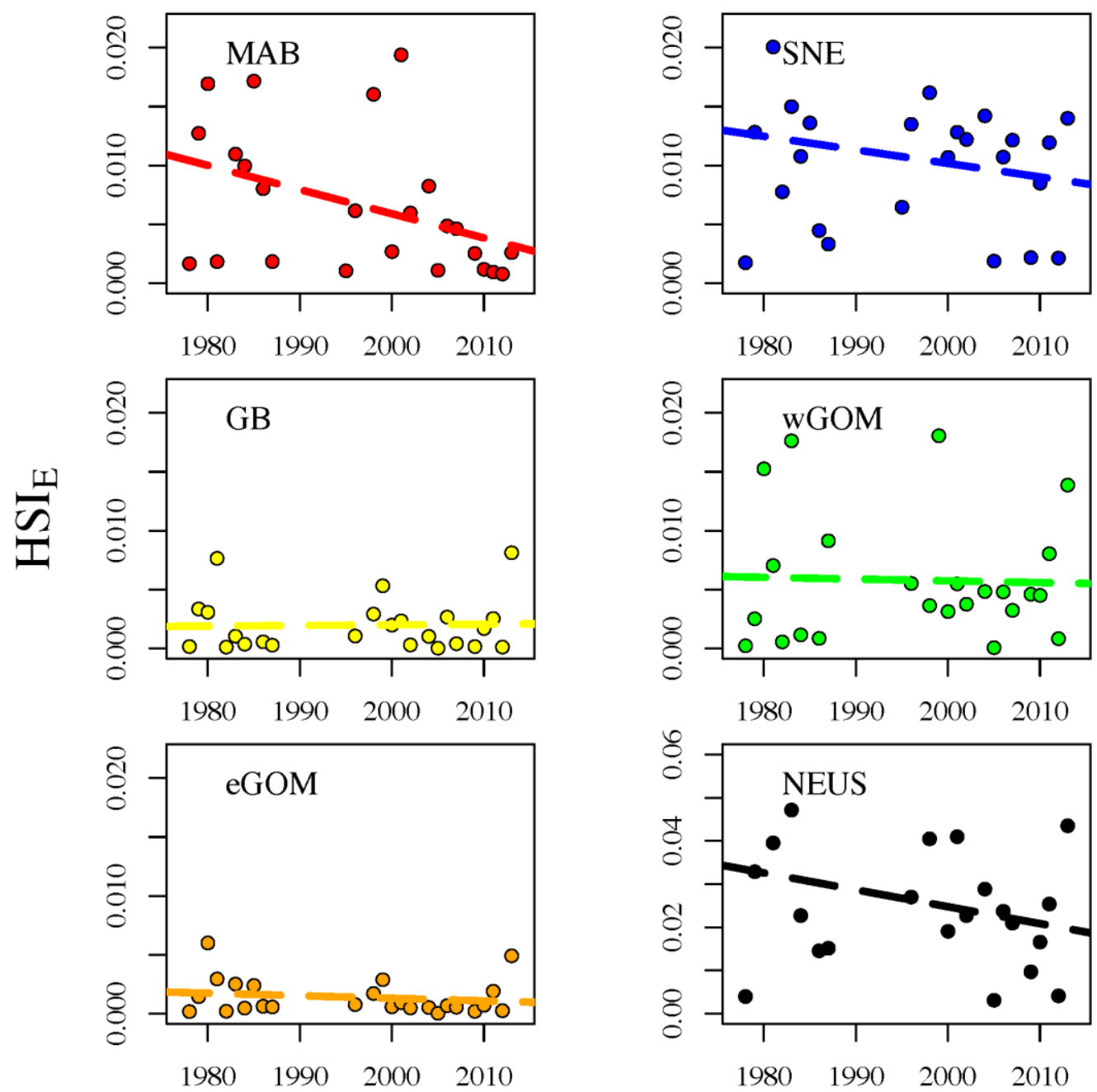

Figure 5. Habitat suitability indices within an ecoregion $\left(\mathrm{HSI}_{\mathrm{E}}\right)$ for the Mid-Atlantic Bight (MAB, red), southern New England (SNE, blue), Georges Bank (GB, yellow), the western Gulf of Maine (wGOM, green), the eastern Gulf of Maine (eGOM, orange), and the Northeast U.S. Shelf (NEUS, black). Dashed lines represent linear fits of the indices over time. Index values are in units of $\ln \left(\right.$ number $\left.+10.01 \mathrm{~m}^{-2}\right)$. 


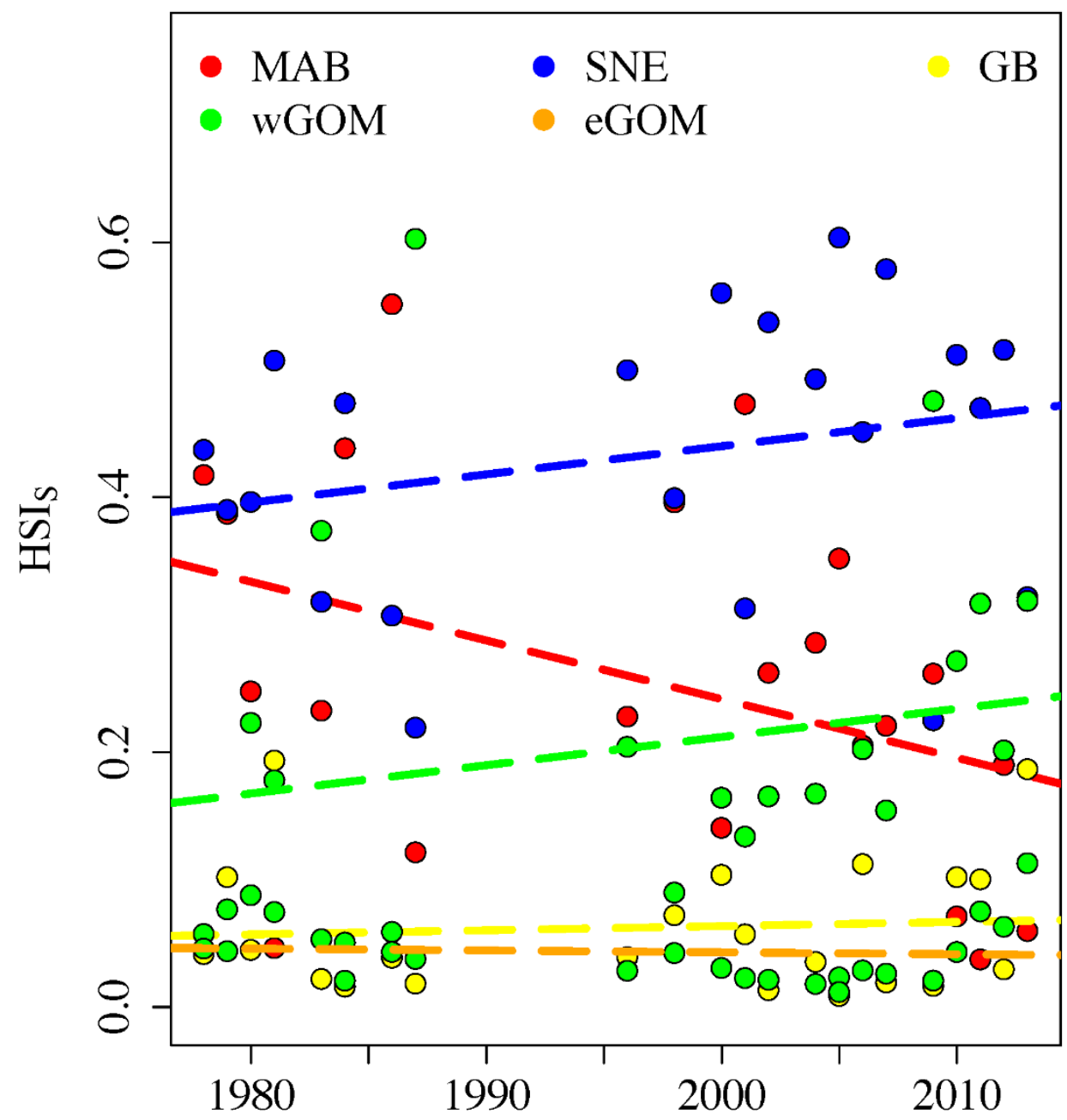

Figure 6. Habitat suitability indices within the Northeast U.S. Shelf (HSI $)$ for the Mid-Atlantic Bight (MAB, red), southern New England (SNE, blue), Georges Bank (GB, yellow), the western Gulf of Maine (wGOM, green), and the eastern Gulf of Maine (eGOM, orange). Dashed lines represent linear fits of the indices over time. 

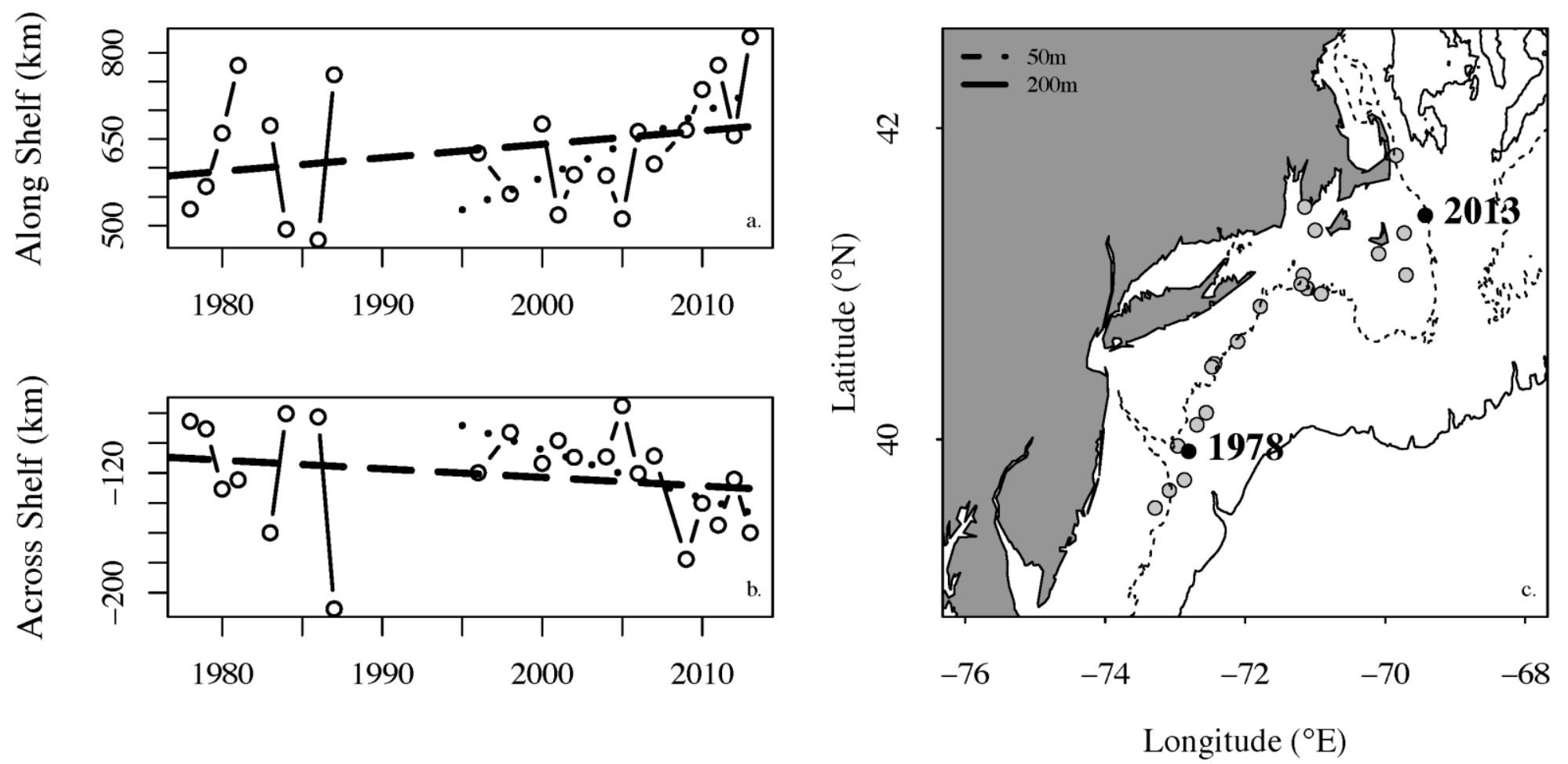

Figure 7. Along (a), across (b), and geographical (c) center positions of larval habitat over the Northeast U.S. Shelf. Along shelf distances $(\mathrm{km})$ are relative to the $200 \mathrm{~m}$ contour off Cape Hatteras, North Carolina, with increase in values indicating further movement north. Across shelf movements $(\mathrm{km})$ represent landward (negative) or seaward (positive) from the 200m contour. For further description on the along and across shelf distance calculations, see Nye et al. (2009). Geographical center positions are represented in grey circles, except for start and terminal years (1978 and 2013, black circles). Along and across shelf trends since the late 1970s (dashed lines) and 1995 (dotted lines) are presented. 


\section{SUPPLEMENTS}

Supplement 1. Tables providing the number of samples by year and ecoregion used in the presence/absence model (S1.A), abundance model (S1.B) and for predicting larval abundances used in the habitat suitability indices (S1.C).

Table S1.A. Number of samples used to construct the presence/absence GAM. Sample numbers are provided by year and ecoregion: Georges Bank (GB), Gulf of Maine (GOM), Mid Atlantic Bight (MAB) and southern New England (SNE).

\begin{tabular}{|ccccc|}
\hline Year & GB & GOM & MAB & SNE \\
\hline 1978 & 12 & 26 & 27 & 31 \\
1979 & 16 & 21 & 51 & 25 \\
1980 & 26 & 24 & 43 & 37 \\
1981 & 17 & 26 & 20 & 27 \\
1982 & 21 & 17 & 0 & 31 \\
1983 & 21 & 21 & 43 & 38 \\
1984 & 22 & 27 & 44 & 33 \\
1986 & 22 & 16 & 42 & 38 \\
1987 & 23 & 20 & 32 & 42 \\
2000 & 28 & 32 & 26 & 29 \\
2001 & 28 & 18 & 30 & 30 \\
2002 & 30 & 29 & 30 & 30 \\
2004 & 29 & 26 & 30 & 29 \\
2005 & 30 & 30 & 27 & 29 \\
2006 & 28 & 27 & 29 & 29 \\
2007 & 28 & 28 & 29 & 31 \\
2009 & 30 & 38 & 31 & 30 \\
2010 & 25 & 30 & 26 & 29 \\
2011 & 30 & 30 & 29 & 29 \\
2012 & 20 & 6 & 28 & 27 \\
2013 & 14 & 24 & 30 & 28 \\
\hline Total & 500 & 516 & 647 & 652 \\
\hline
\end{tabular}

Table S1.B. Number of samples used to construct the abundance GAM. Sample numbers are provided by year and ecoregion: Georges Bank (GB), Gulf of Maine (GOM), Mid Atlantic Bight (MAB) and Southern New England (SNE).

\begin{tabular}{|ccccc|}
\hline Year & GB & GOM & MAB & SNE \\
\hline 1978 & 0 & 0 & 1 & 1 \\
1979 & 0 & 1 & 3 & 9 \\
1980 & 1 & 3 & 13 & 27 \\
1981 & 0 & 0 & 0 & 13 \\
1982 & 0 & 0 & 0 & 10 \\
1983 & 0 & 3 & 7 & 17 \\
1984 & 0 & 1 & 0 & 0 \\
1986 & 0 & 0 & 0 & 10 \\
2000 & 0 & 2 & 4 & 10 \\
2001 & 0 & 2 & 13 & 15 \\
2002 & 4 & 3 & 6 & 18 \\
2004 & 0 & 0 & 15 & 18 \\
\hline
\end{tabular}




\begin{tabular}{|ccccc|}
\hline 2005 & 0 & 1 & 2 & 7 \\
2006 & 0 & 3 & 2 & 10 \\
2007 & 0 & 2 & 1 & 4 \\
2009 & 0 & 2 & 2 & 0 \\
2010 & 0 & 6 & 0 & 9 \\
2012 & 1 & 0 & 0 & 3 \\
2013 & 0 & 2 & 0 & 0 \\
\hline Total & 6 & 31 & 69 & 181 \\
\hline
\end{tabular}

Table S1.C. Number of samples used to predict habitat using the delta GAM. Sample numbers are provided by year and ecoregion: Georges Bank (GB), Gulf of Maine (GOM), Mid Atlantic Bight (MAB) and Southern New England (SNE).

\begin{tabular}{|c|c|c|c|c|}
\hline Year & GB & GOM & MAB & SNE \\
\hline 1978 & 12 & 26 & 27 & 31 \\
\hline 1979 & 16 & 21 & 51 & 25 \\
\hline 1980 & 26 & 24 & 43 & 37 \\
\hline 1981 & 17 & 26 & 20 & 27 \\
\hline 1982 & 21 & 17 & 0 & 31 \\
\hline 1983 & 21 & 21 & 43 & 38 \\
\hline 1984 & 22 & 27 & 44 & 33 \\
\hline 1985 & 23 & 4 & 47 & 37 \\
\hline 1986 & 22 & 16 & 42 & 38 \\
\hline 1987 & 23 & 20 & 32 & 42 \\
\hline 1995 & 0 & 0 & 9 & 18 \\
\hline 1996 & 9 & 28 & 23 & 17 \\
\hline 1998 & 29 & 22 & 30 & 29 \\
\hline 1999 & 29 & 25 & 0 & 0 \\
\hline 2000 & 28 & 32 & 26 & 29 \\
\hline 2001 & 28 & 18 & 30 & 30 \\
\hline 2002 & 30 & 29 & 30 & 30 \\
\hline 2003 & 29 & 0 & 0 & 0 \\
\hline 2004 & 29 & 26 & 30 & 29 \\
\hline 2005 & 30 & 30 & 28 & 29 \\
\hline 2006 & 28 & 28 & 29 & 29 \\
\hline 2007 & 28 & 28 & 29 & 31 \\
\hline 2008 & 0 & 3 & 0 & 1 \\
\hline 2009 & 30 & 38 & 31 & 30 \\
\hline 2010 & 25 & 30 & 26 & 29 \\
\hline 2011 & 30 & 55 & 29 & 66 \\
\hline 2012 & 20 & 6 & 28 & 27 \\
\hline 2013 & 14 & 25 & 30 & 28 \\
\hline Total & 619 & 625 & 757 & 791 \\
\hline
\end{tabular}


Supplement 2. Tables describing degree of collinearity and correlation between covariates: correlation coefficients for the continuous predictor variables in the presence/absence (S2.A) and abundance (S2.B) models, as well as these variables' generalized variance inflation factors for the two models (S1.C).

Table S2.A. Correlation matrix (pearson values) for continuous covariates used in the presence-absence model.

\begin{tabular}{|c|c|c|c|c|c|c|c|c|}
\hline & $\begin{array}{l}\text { surface } \\
\text { temp. }\end{array}$ & $\begin{array}{l}\text { bottom } \\
\text { temp. }\end{array}$ & depth & $\begin{array}{c}\text { Calanus } \\
\text { finmarchicus }\end{array}$ & $\begin{array}{c}\text { Temora } \\
\text { longicornis }\end{array}$ & $\begin{array}{c}\text { Centropages } \\
\text { typicus }\end{array}$ & $\begin{array}{c}\text { Pseudocalanus } \\
\text { spp. }\end{array}$ & $\begin{array}{l}\text { Oithona } \\
\text { spp. }\end{array}$ \\
\hline surface temp. & 1 & - & - & - & - & - & - & - \\
\hline bottom temp. & 0.54 & 1 & - & - & - & - & - & - \\
\hline depth & -0.34 & -0.27 & 1 & - & - & - & - & - \\
\hline $\begin{array}{l}\text { Calanus } \\
\text { finmarchicus }\end{array}$ & -0.43 & -0.47 & 0.50 & 1 & - & - & - & - \\
\hline $\begin{array}{l}\text { Temora } \\
\text { longicornis }\end{array}$ & 0.27 & 0.12 & -0.55 & -0.24 & 1 & - & - & - \\
\hline $\begin{array}{l}\text { Centropages } \\
\text { typicus }\end{array}$ & 0.44 & 0.26 & -0.41 & -0.19 & 0.44 & 1 & - & - \\
\hline $\begin{array}{l}\text { Pseudocalanus } \\
\text { spp. }\end{array}$ & -0.27 & -0.40 & -0.03 & 0.41 & 0.29 & 0.22 & 1 & - \\
\hline Oithona spp. & 0.21 & 0.08 & 0.04 & 0.15 & 0.14 & 0.27 & 0.17 & 1 \\
\hline
\end{tabular}


Table S2.B. Correlation matrix (pearson values) for continuous covariates used in the abundance model.

\begin{tabular}{|c|c|c|c|c|c|c|c|c|}
\hline & $\begin{array}{l}\text { surface } \\
\text { temp. }\end{array}$ & $\begin{array}{l}\text { bottom } \\
\text { temp. }\end{array}$ & depth & $\begin{array}{c}\text { Calanus } \\
\text { finmarchicus }\end{array}$ & $\begin{array}{c}\text { Temora } \\
\text { longicornis }\end{array}$ & $\begin{array}{c}\text { Centropages } \\
\text { typicus }\end{array}$ & $\begin{array}{l}\text { Pseudocalanus } \\
\text { spp. }\end{array}$ & $\begin{array}{l}\text { Oithona } \\
\text { spp. }\end{array}$ \\
\hline surface temp. & 1 & - & - & - & - & - & - & - \\
\hline bottom temp. & 0.04 & 1 & - & - & - & - & - & - \\
\hline depth & -0.04 & 0.02 & 1 & - & - & - & - & - \\
\hline $\begin{array}{l}\text { Calanus } \\
\text { finmarchicus }\end{array}$ & -0.18 & -0.25 & 0.42 & 1 & - & - & - & - \\
\hline $\begin{array}{l}\text { Temora } \\
\text { longicornis }\end{array}$ & -0.07 & -0.20 & -0.50 & -0.19 & 1 & - & - & - \\
\hline $\begin{array}{l}\text { Centropages } \\
\text { typicus }\end{array}$ & 0.07 & 0.05 & -0.05 & -0.07 & 0.16 & 1 & - & - \\
\hline $\begin{array}{l}\text { Pseudocalanus } \\
\text { spp. }\end{array}$ & -0.18 & -0.25 & -0.10 & 0.22 & 0.37 & 0.34 & 1 & - \\
\hline Oithona spp. & -0.06 & -0.03 & 0.03 & 0.03 & 0.16 & 0.15 & 0.22 & 1 \\
\hline
\end{tabular}


Table S2.C. Generalized variation inflation factor (GVIF) values for the continuous covariates used in presence-absence and abundance models.

\begin{tabular}{l|cc}
\multicolumn{1}{c}{ Covariate } & $\begin{array}{c}\text { Presence- } \\
\text { Absence }\end{array}$ & Abundance \\
\hline surface temperature & 1.08 & 1.88 \\
bottom temperature & 1.18 & 1.71 \\
depth & 1.60 & 1.90 \\
Calanus & 1.48 & 1.96 \\
finmarchicus & & \\
Temora longicornis & 1.64 & 1.75 \\
Centropages typicus & 1.21 & 1.71 \\
Pseudocalanus spp. & 1.55 & 1.84 \\
Oithona spp. & 1.08 & 1.22
\end{tabular}


Supplement 3. Annual predicted abundances (left) representing habitat suitability, and observed abundances (right). Abundances are presented by year and calculated using inverse distance weighting. Crosses (+) represent sampling locations and the dark line (-) represents the $200 \mathrm{~m}$ bathymetry contour.
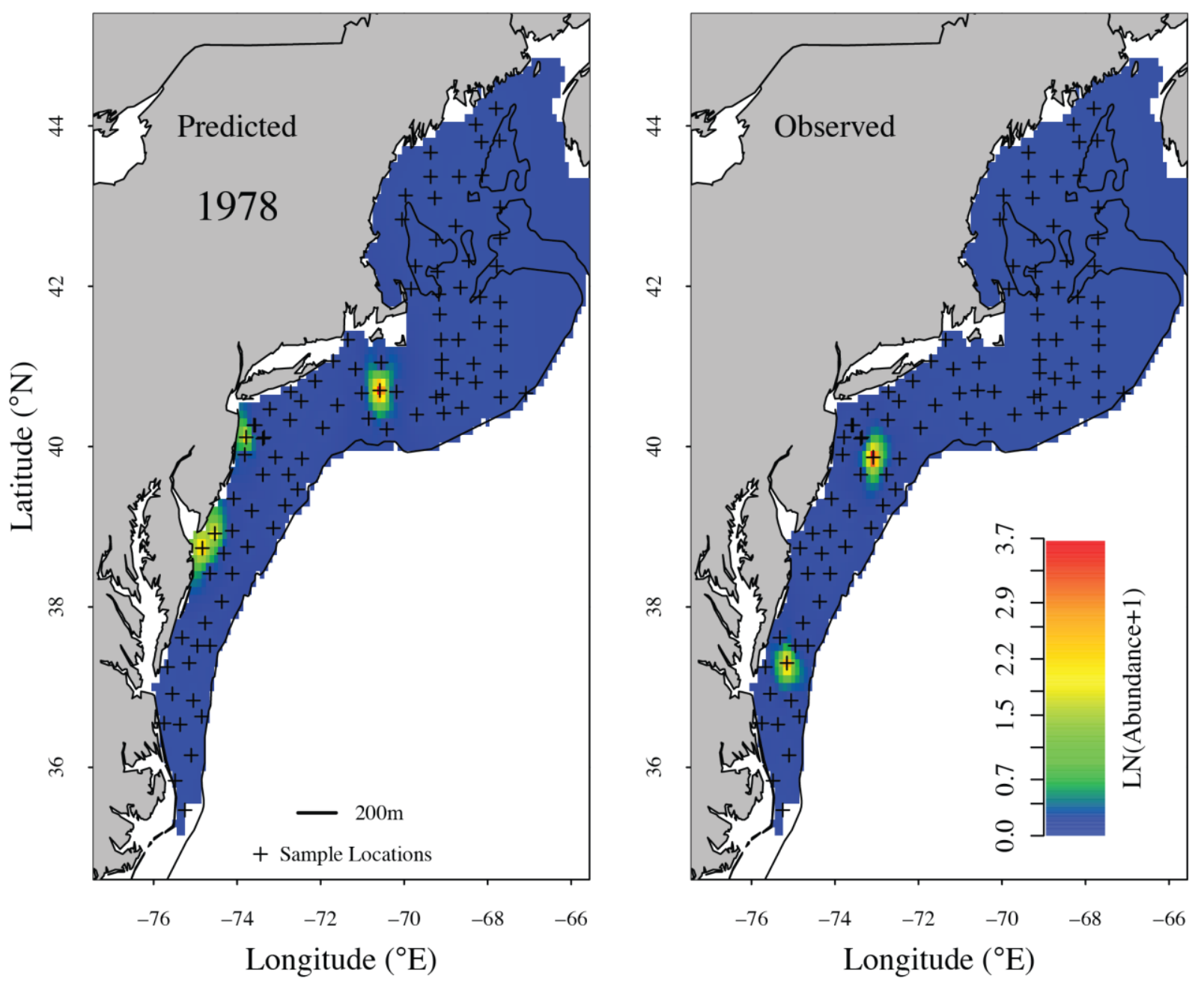

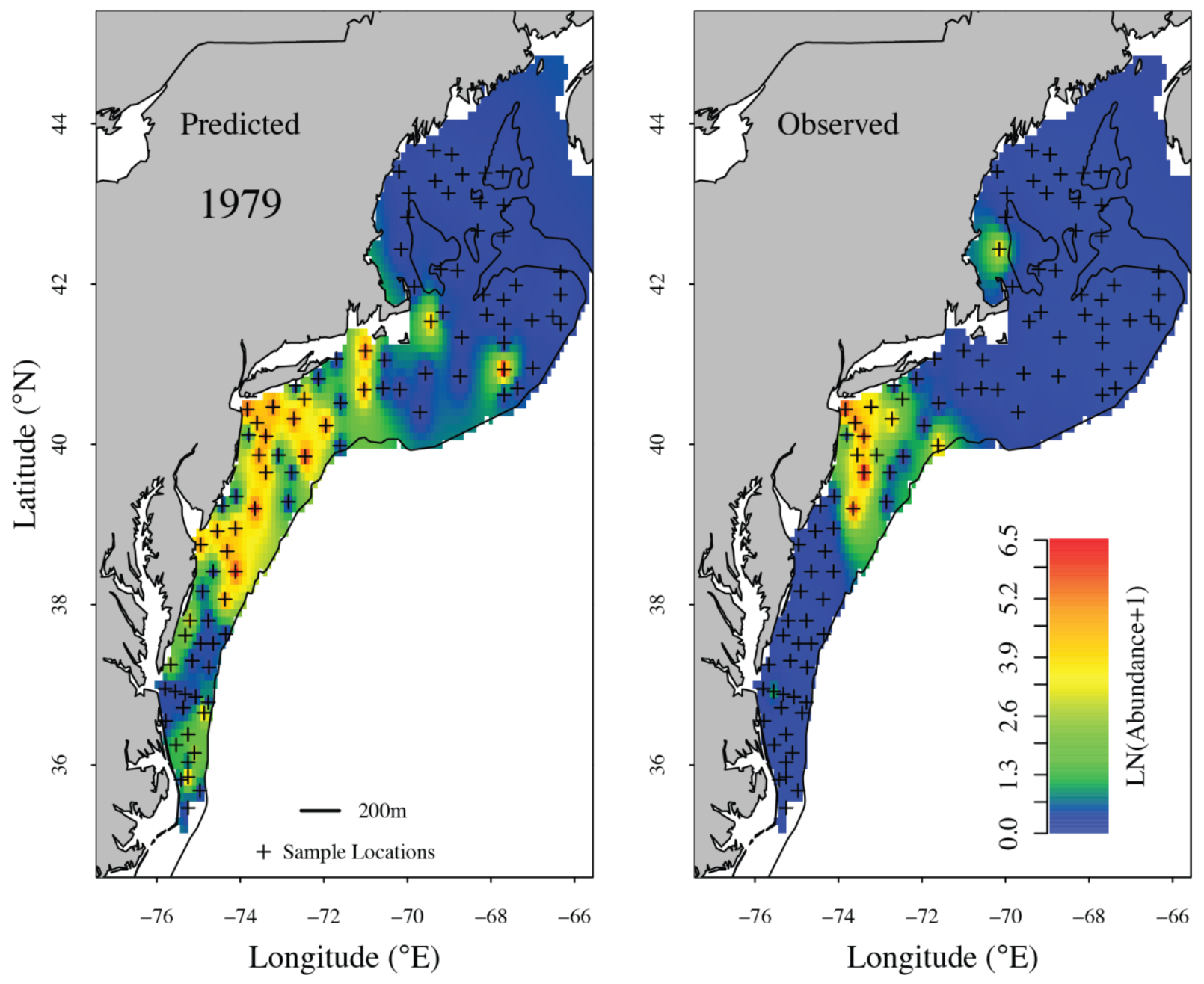

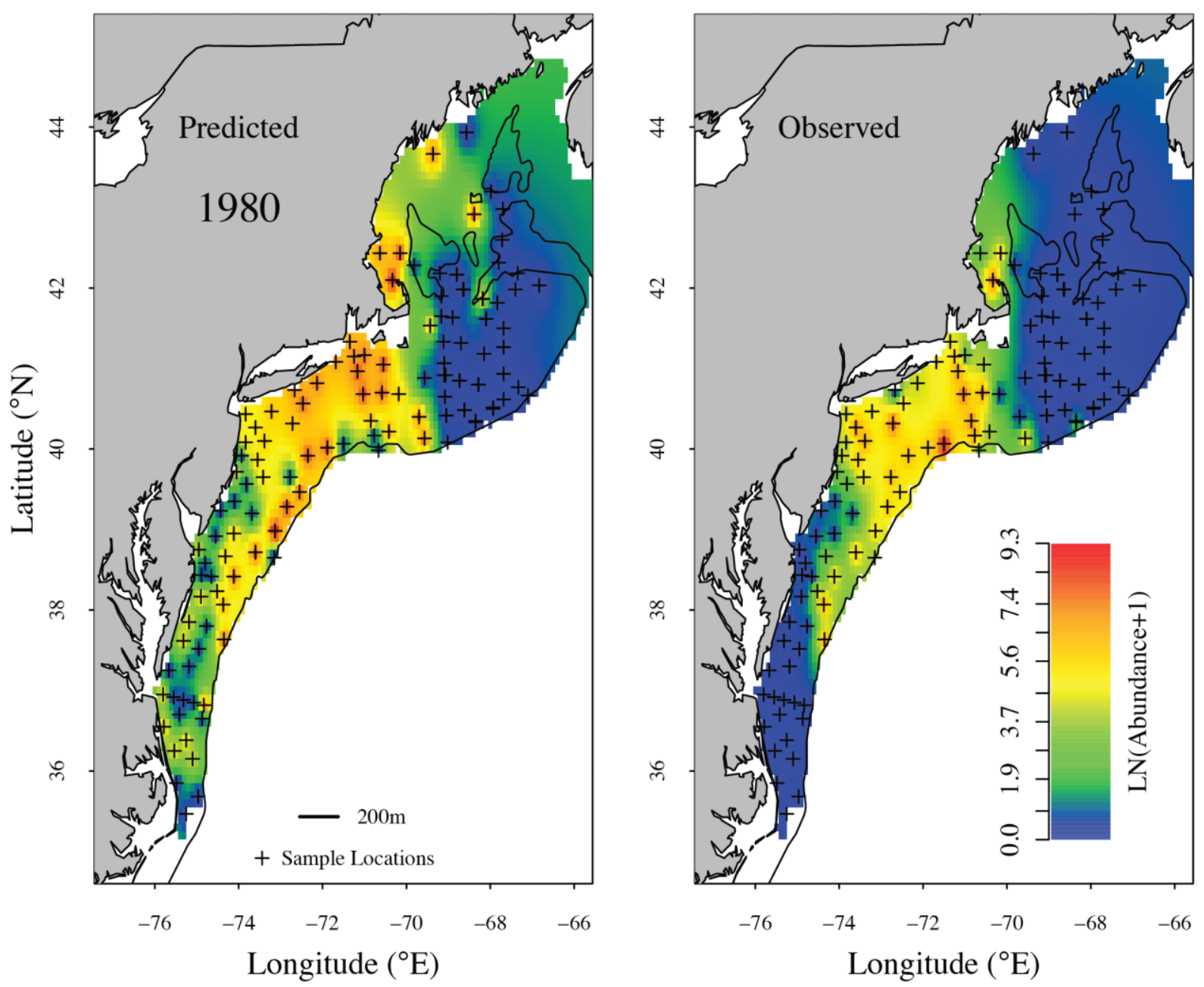

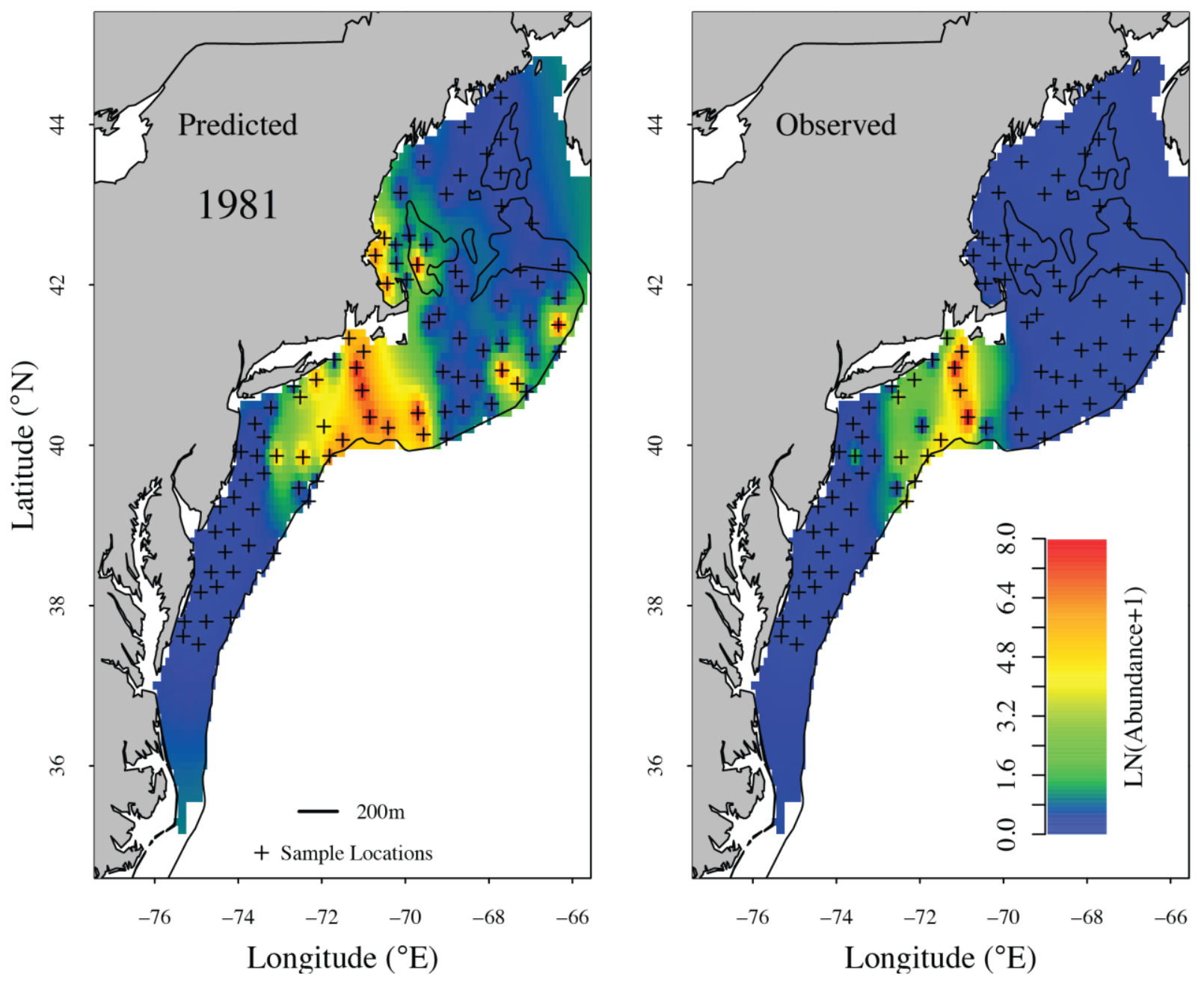

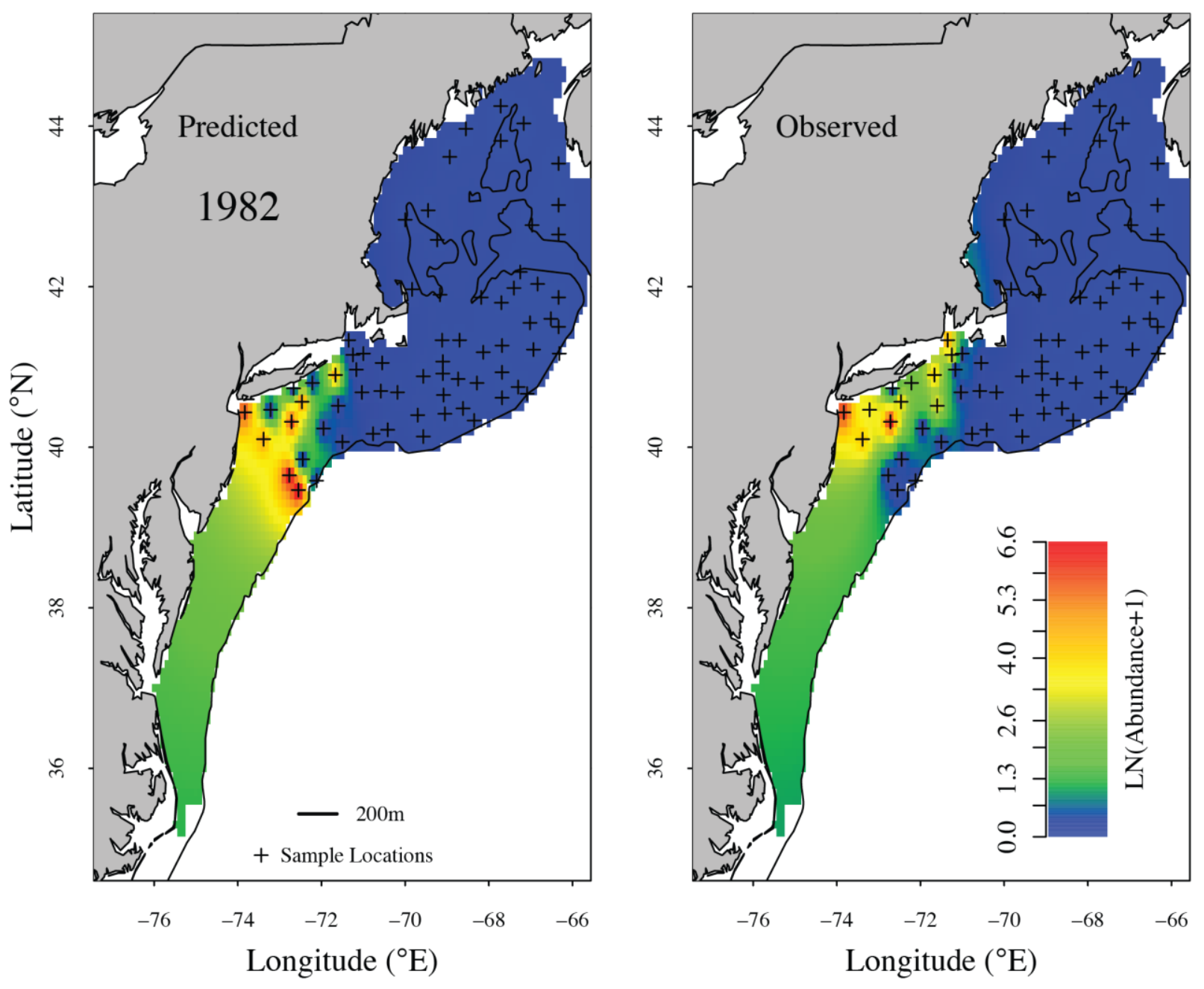

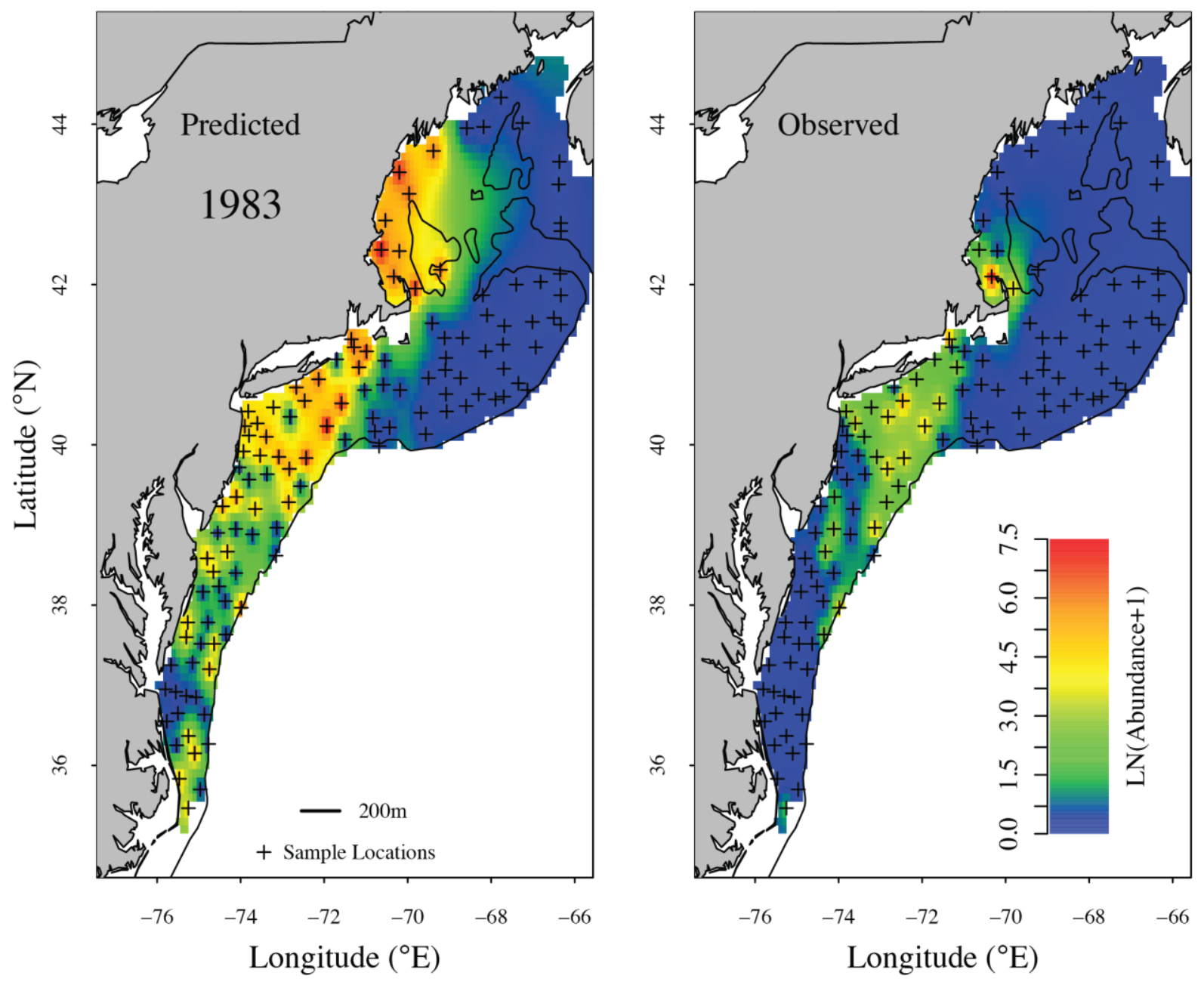

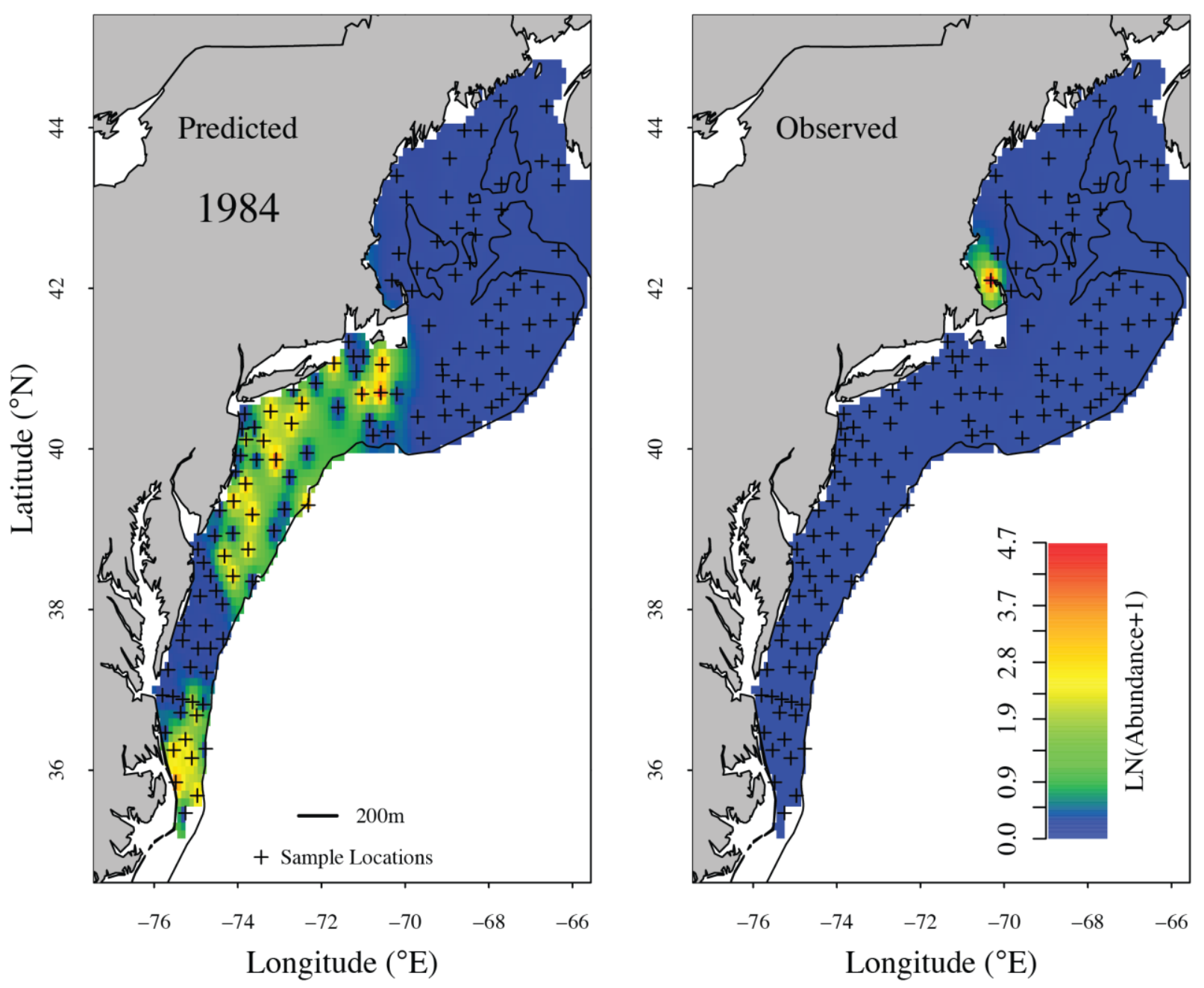

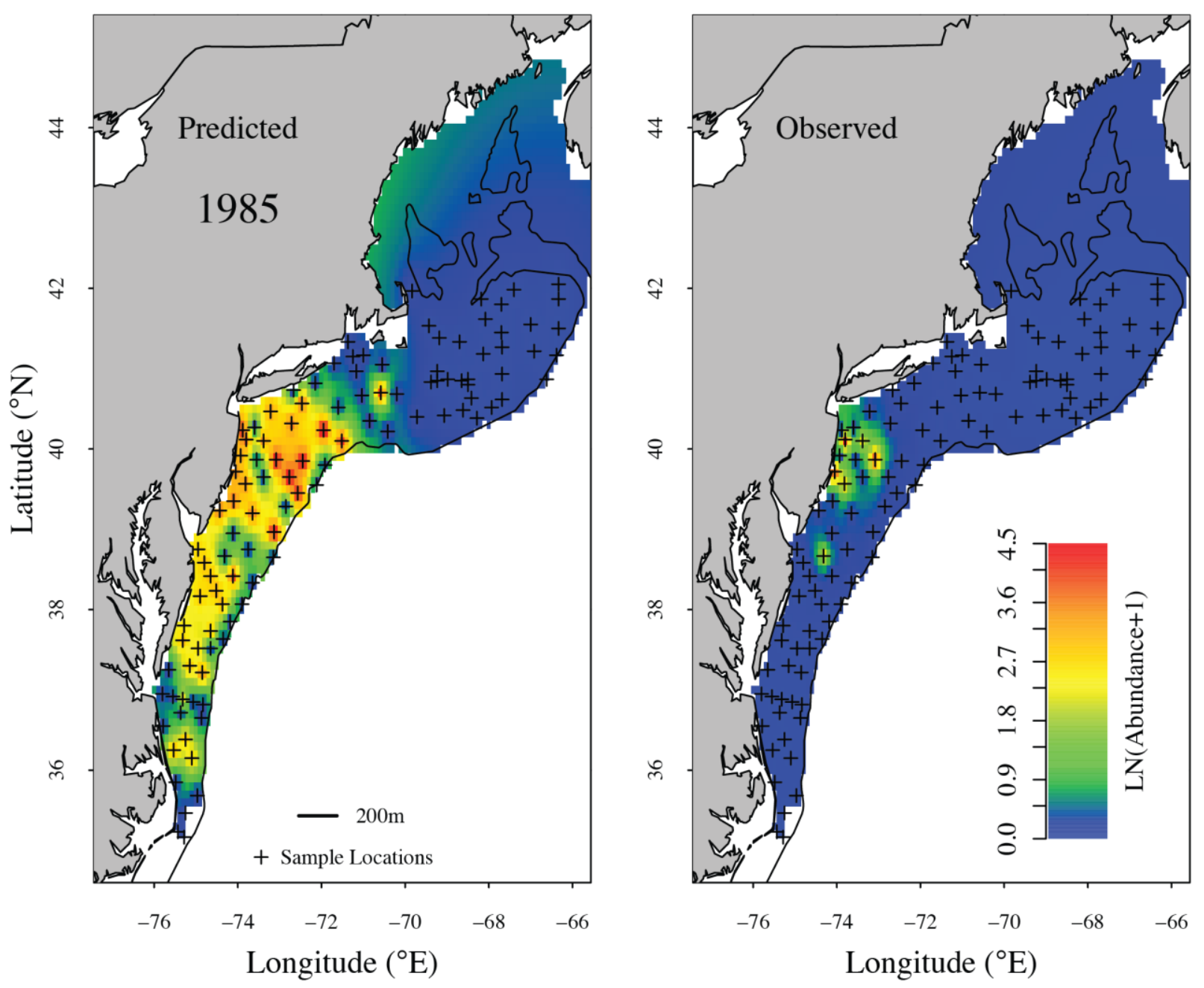

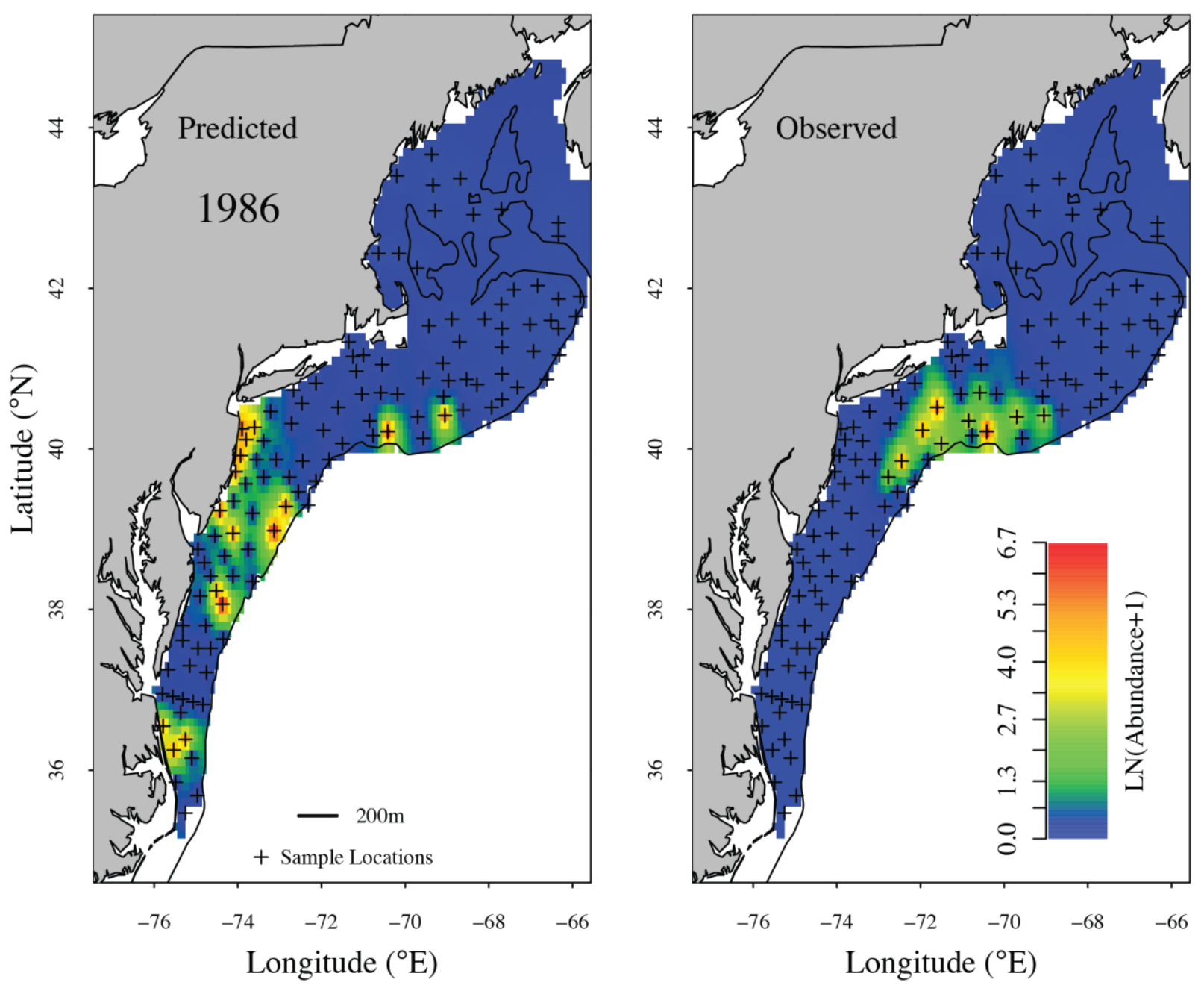

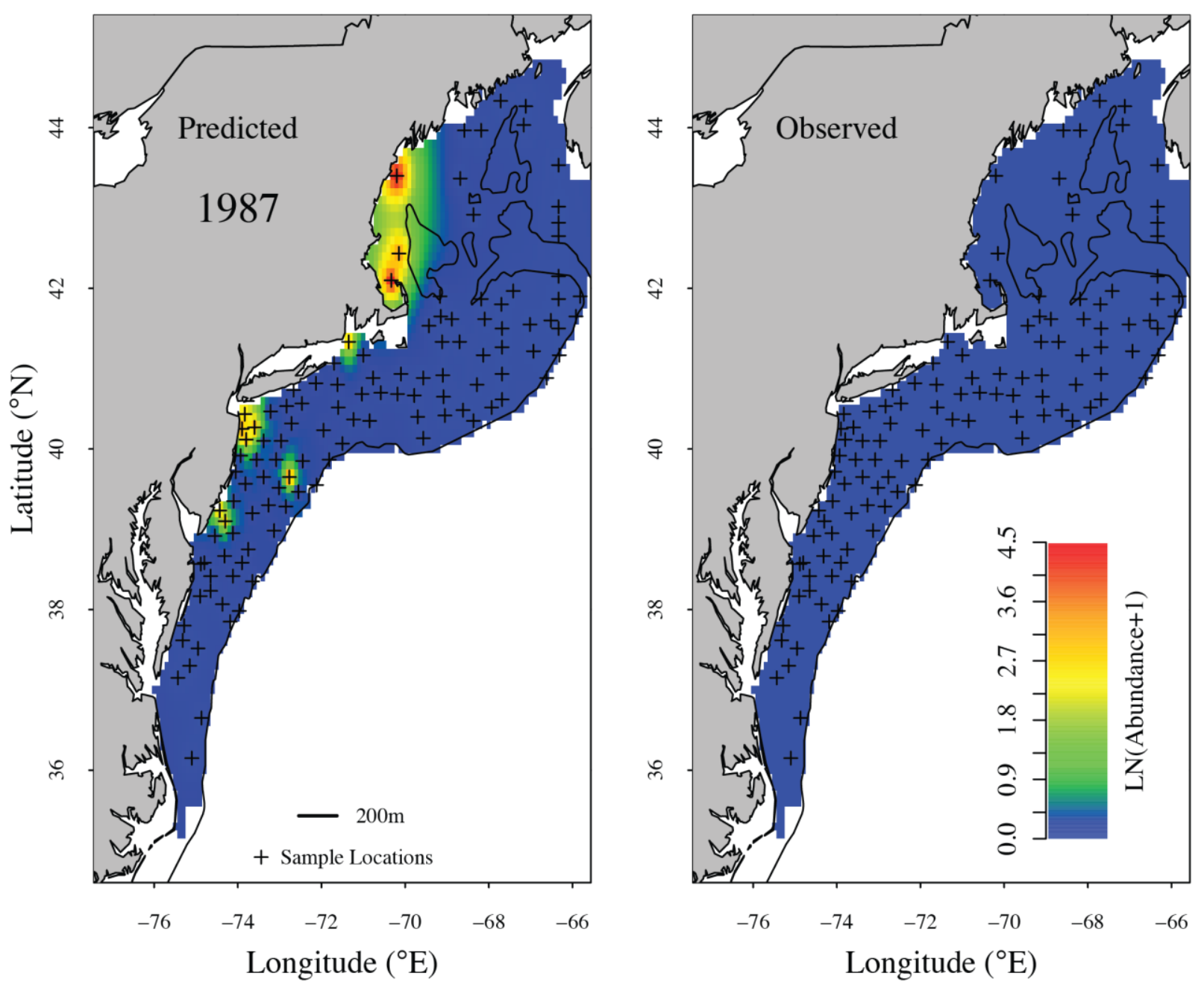

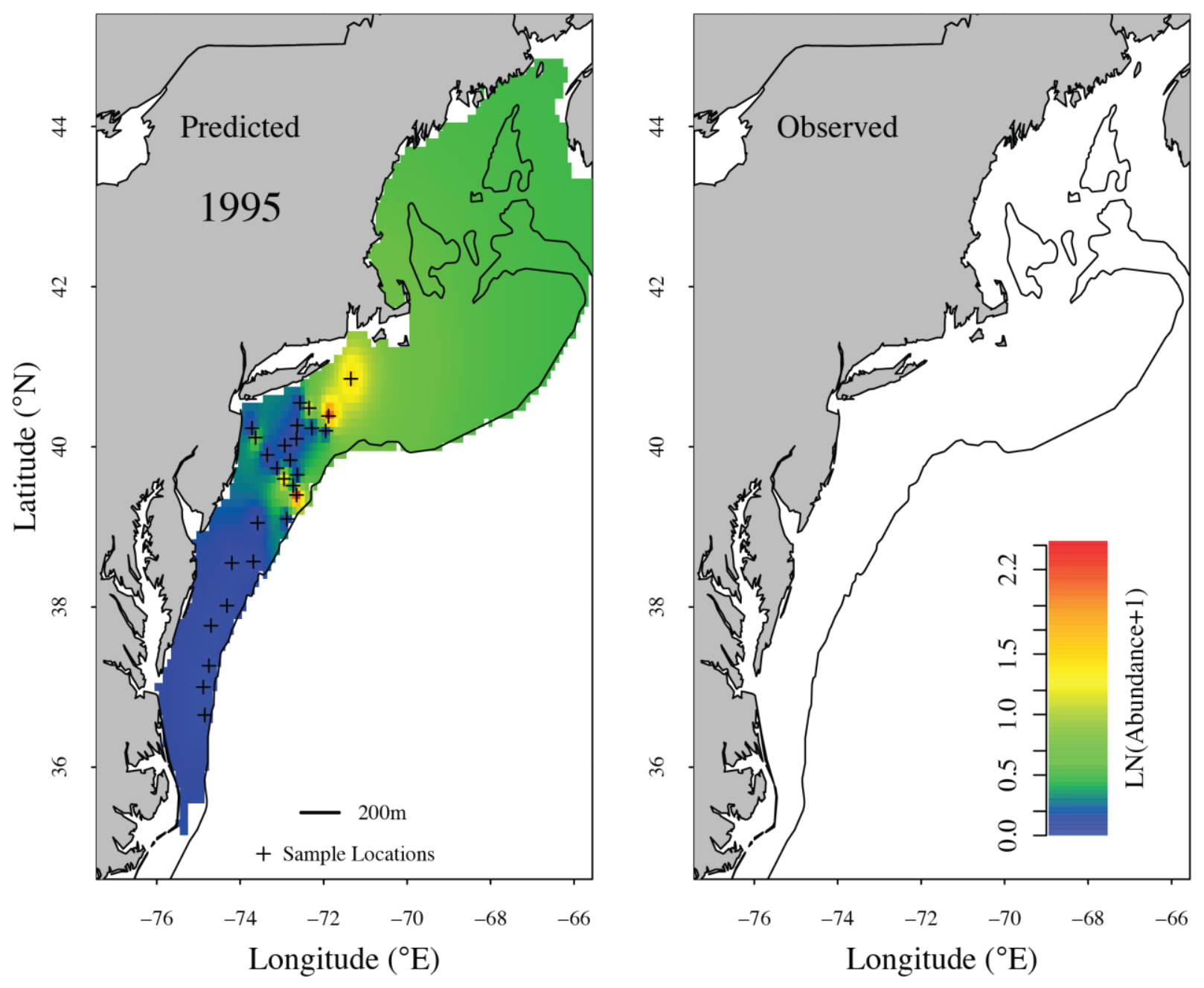

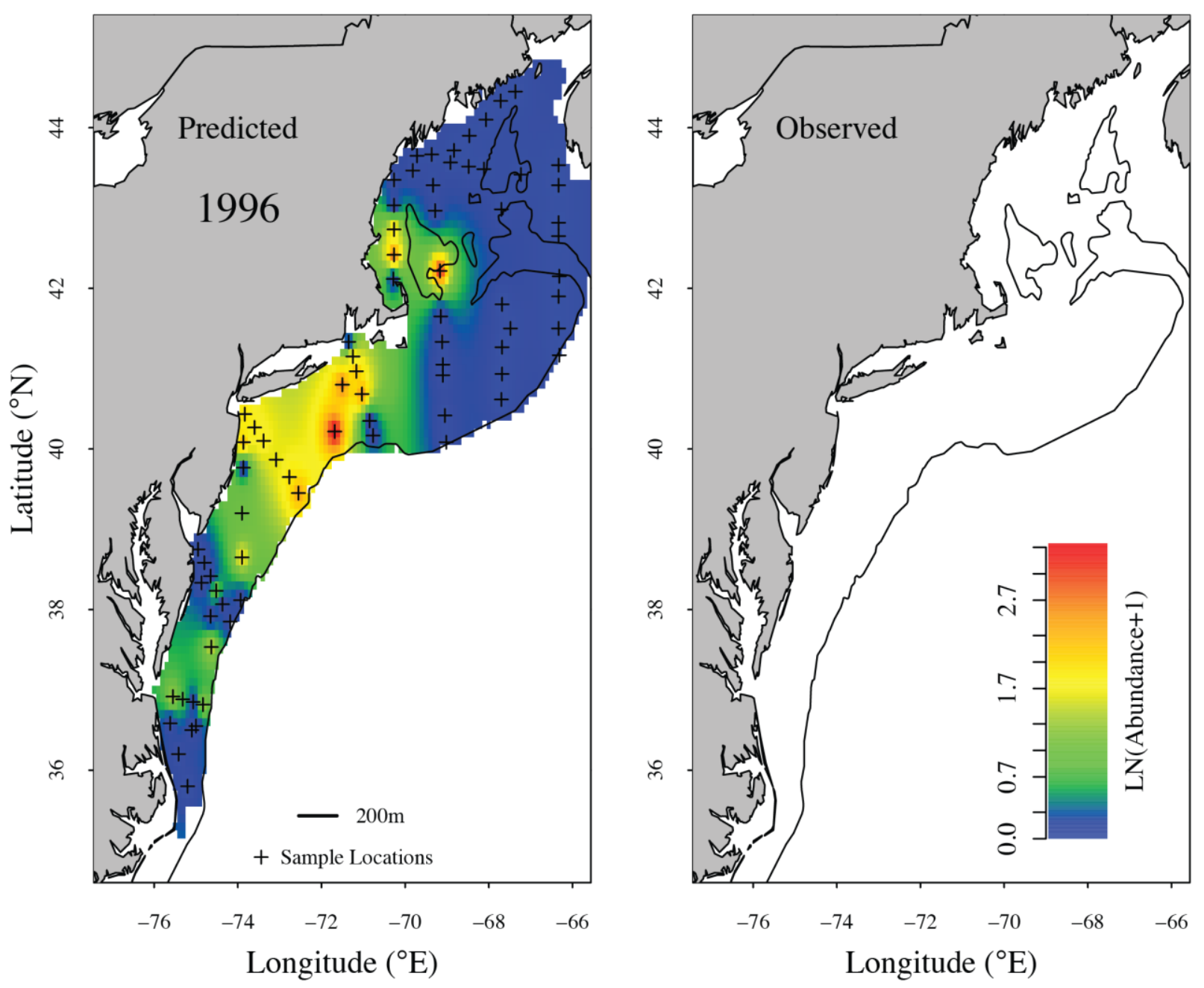

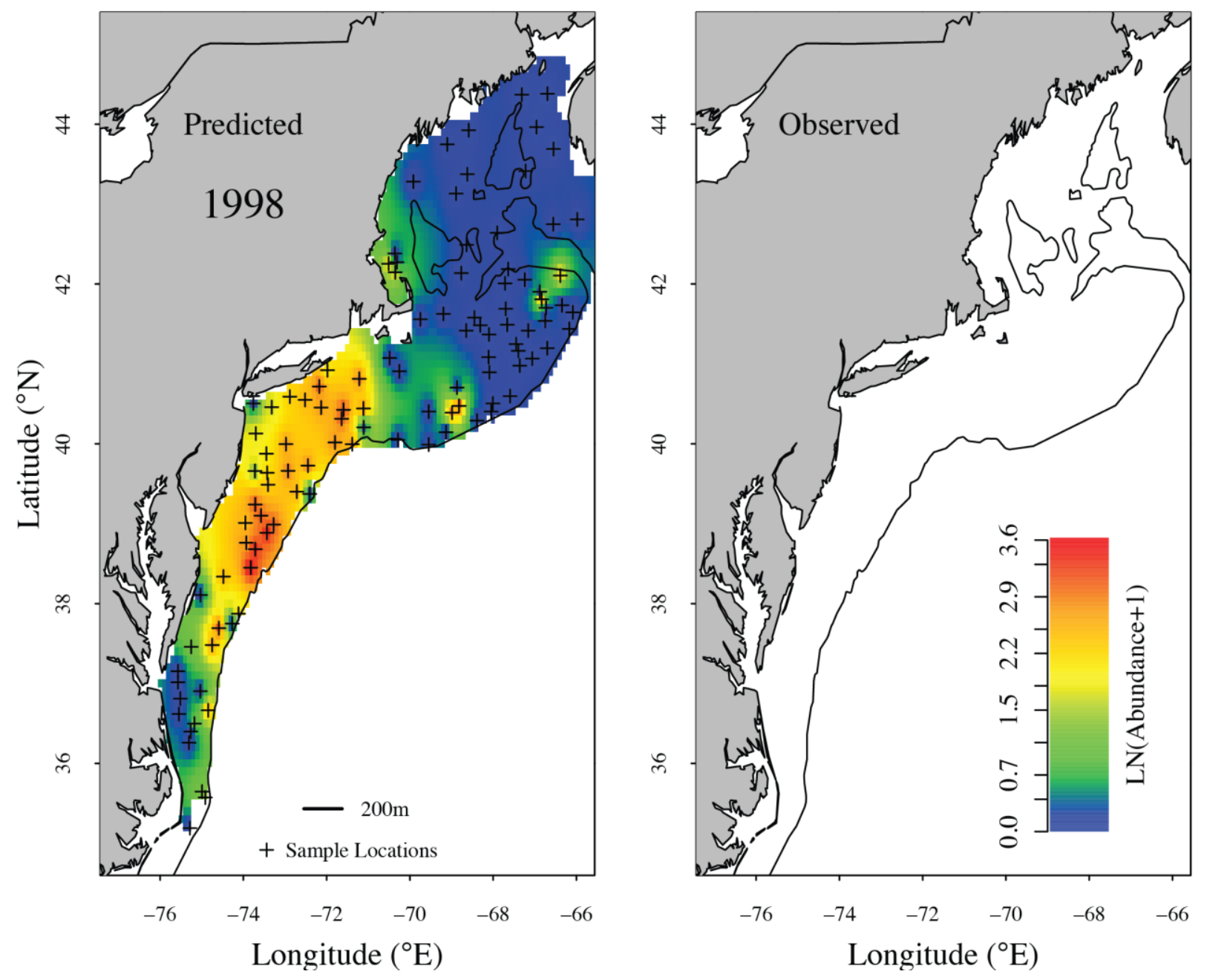

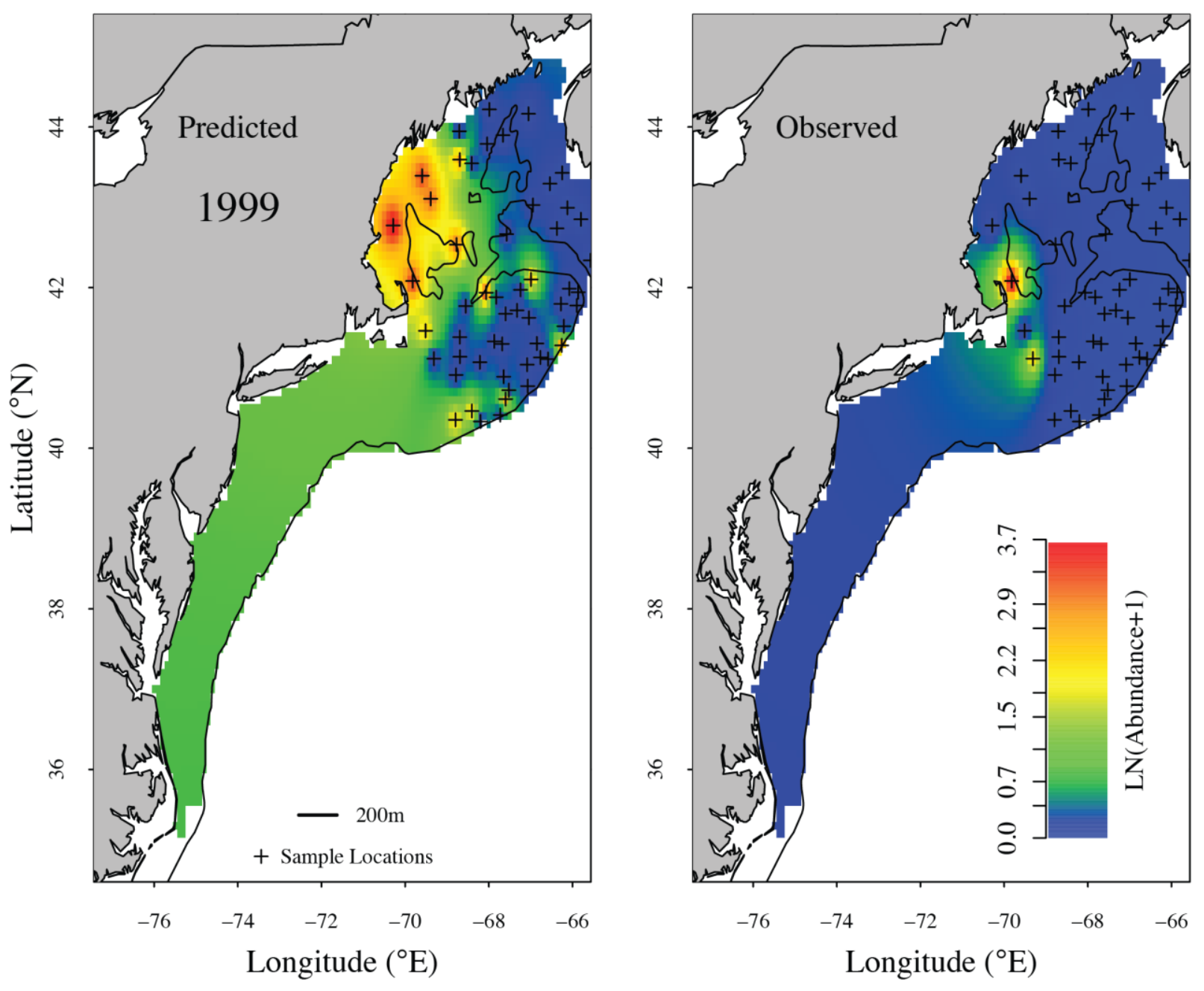

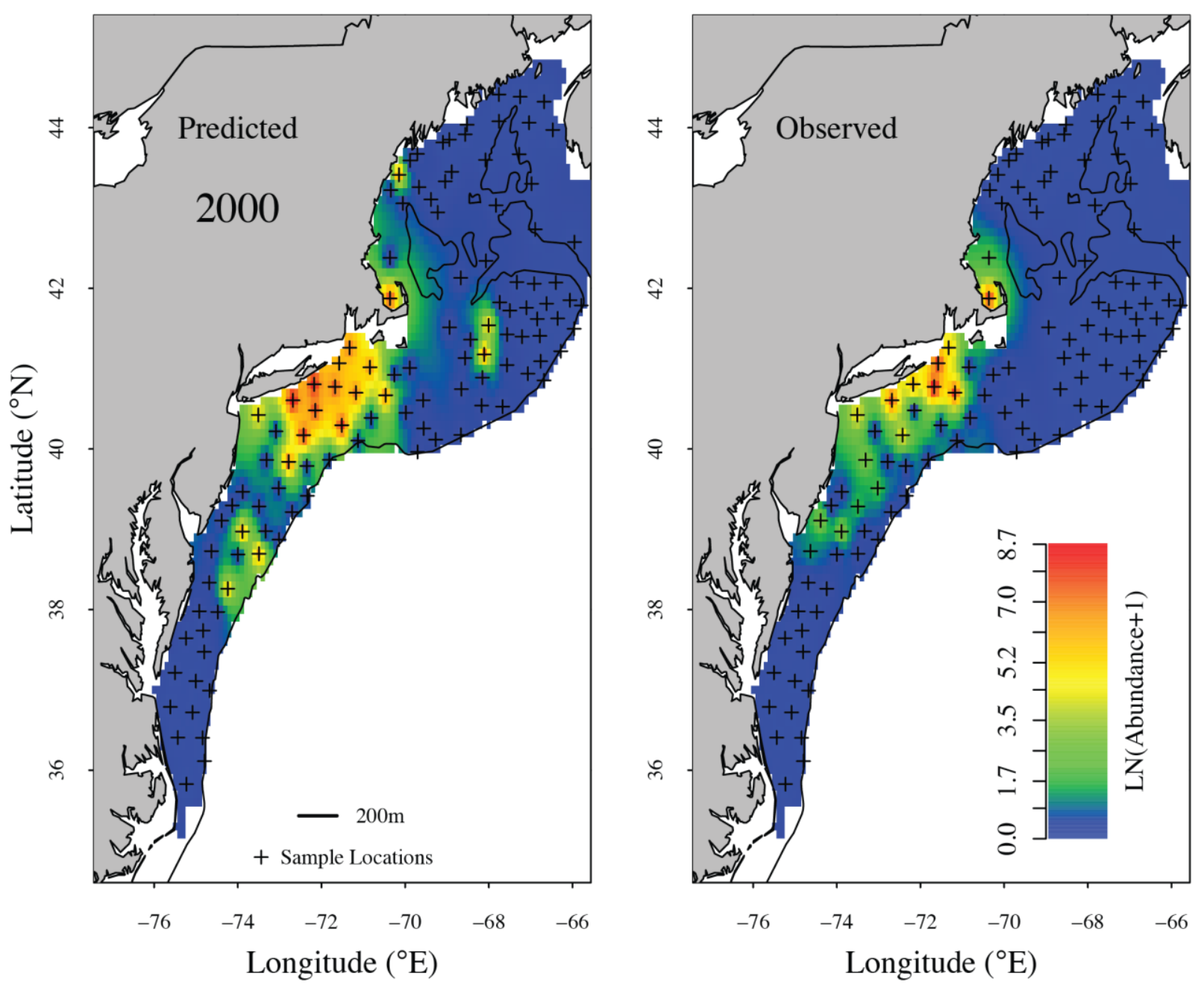

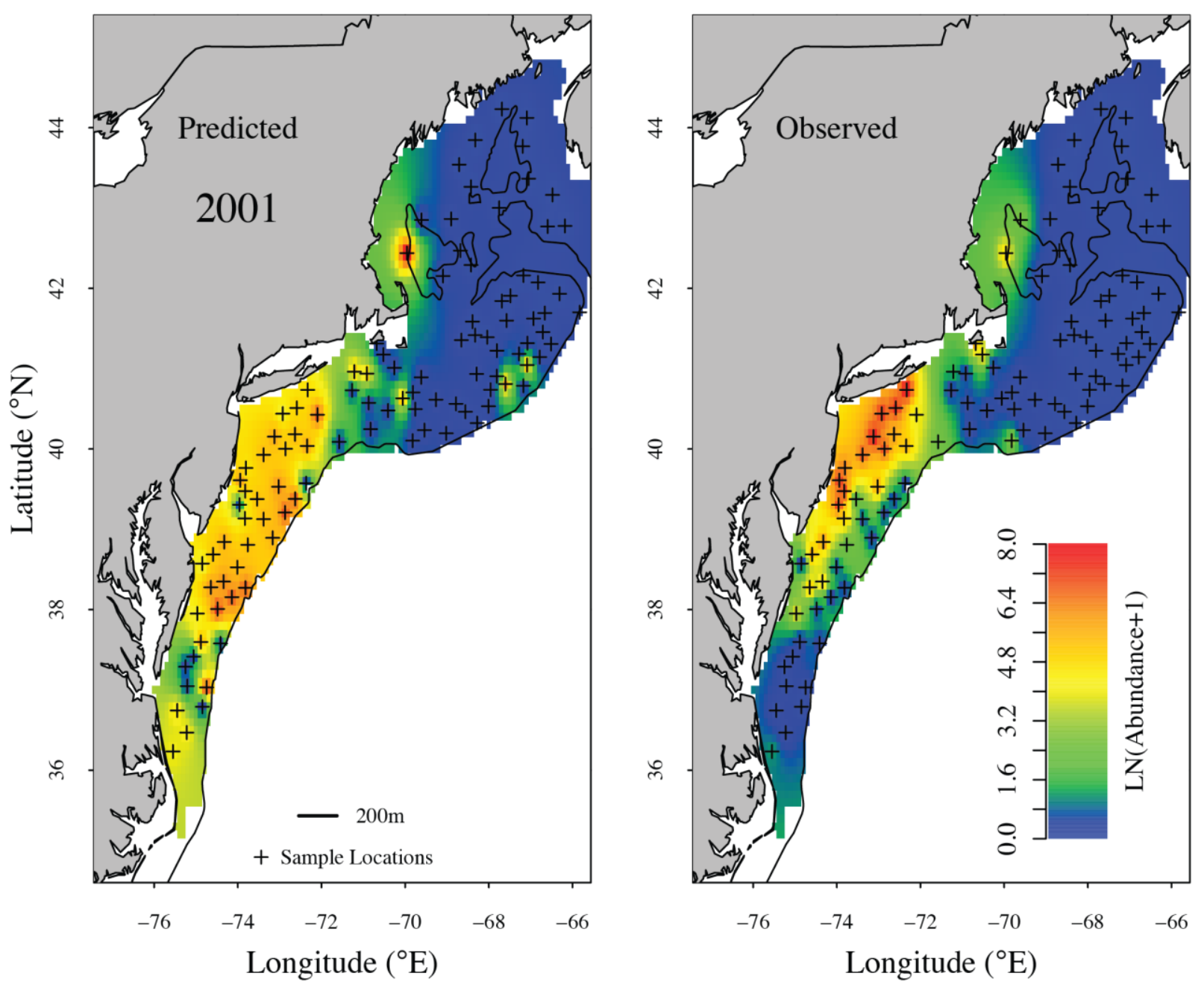

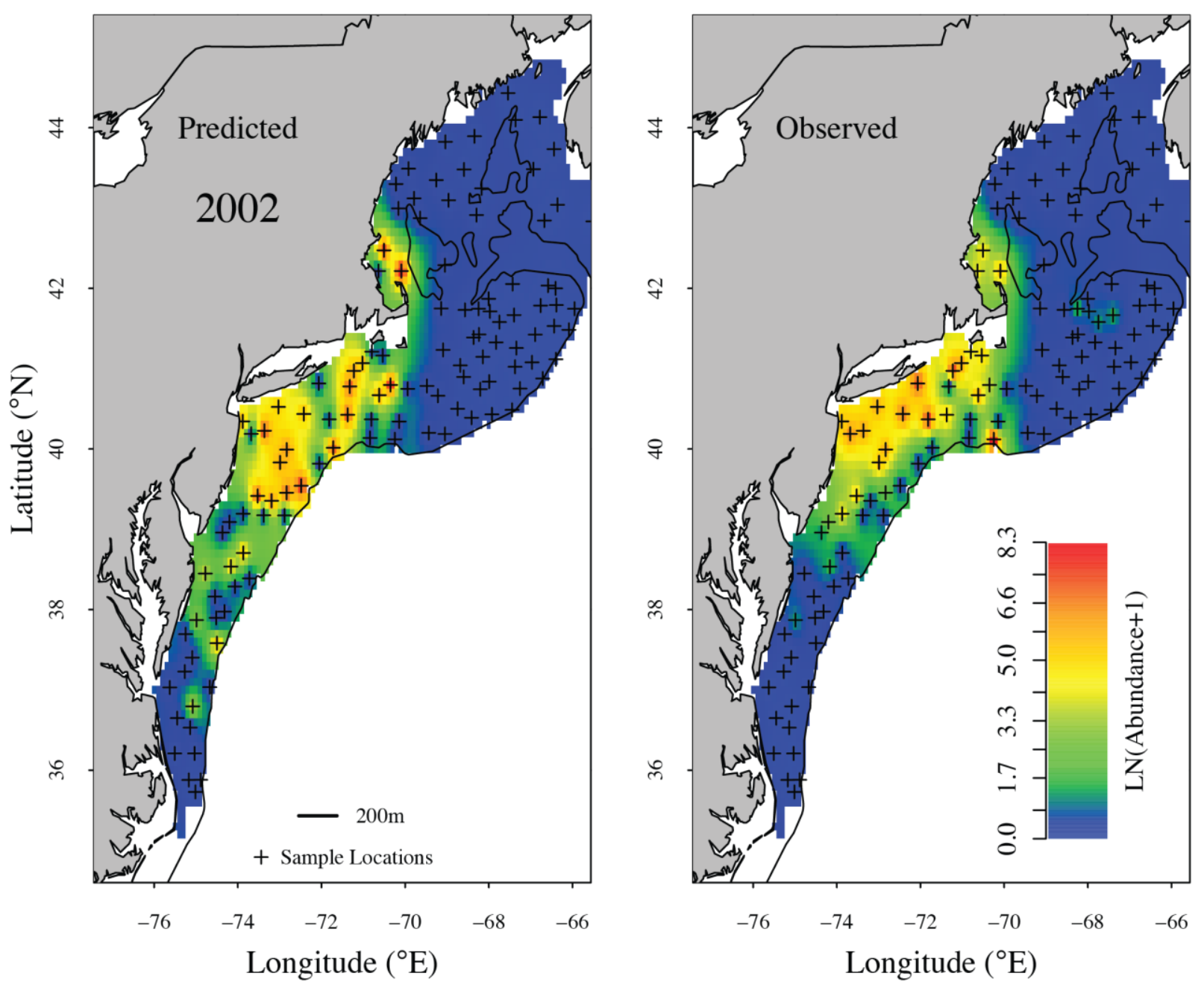

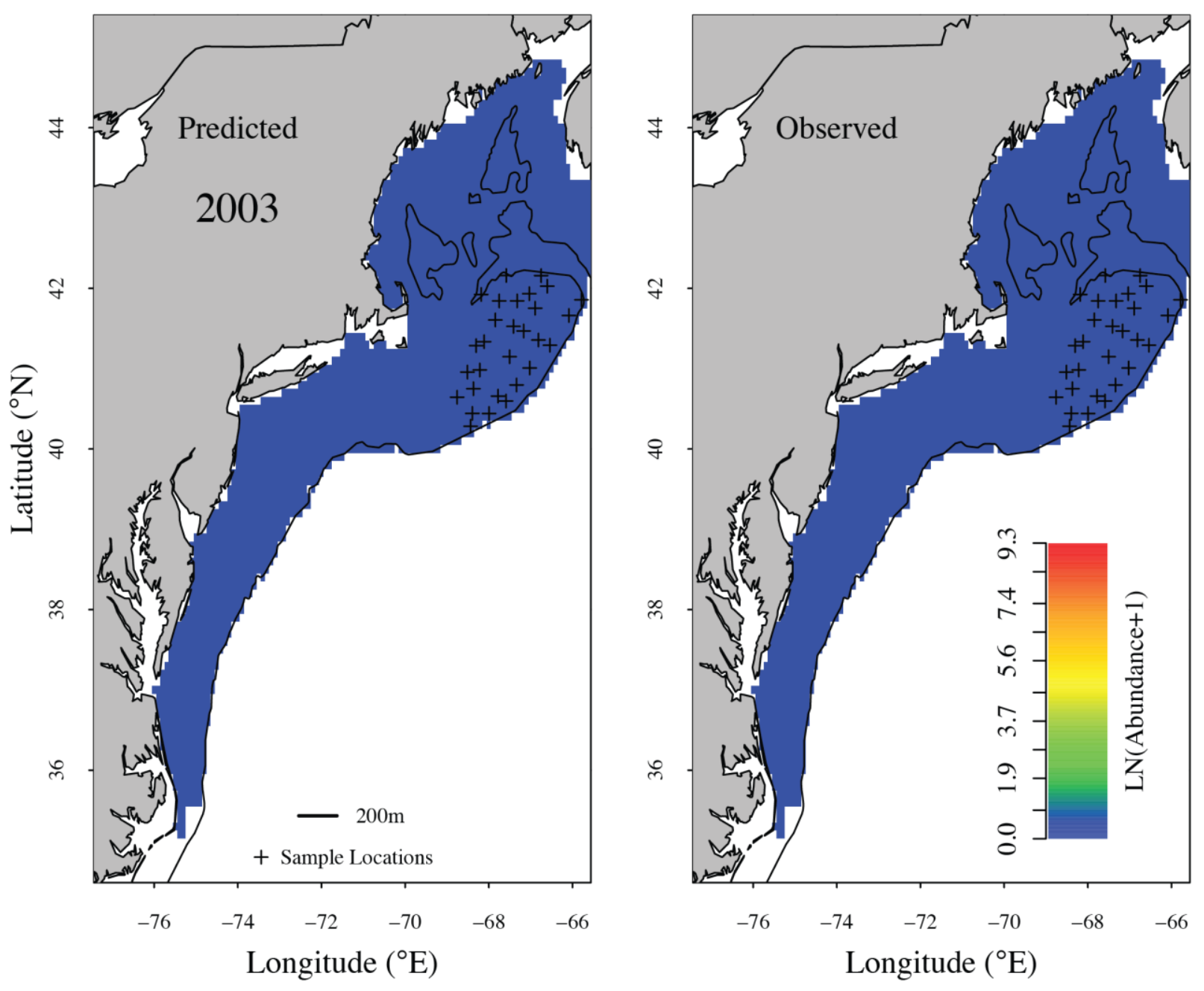

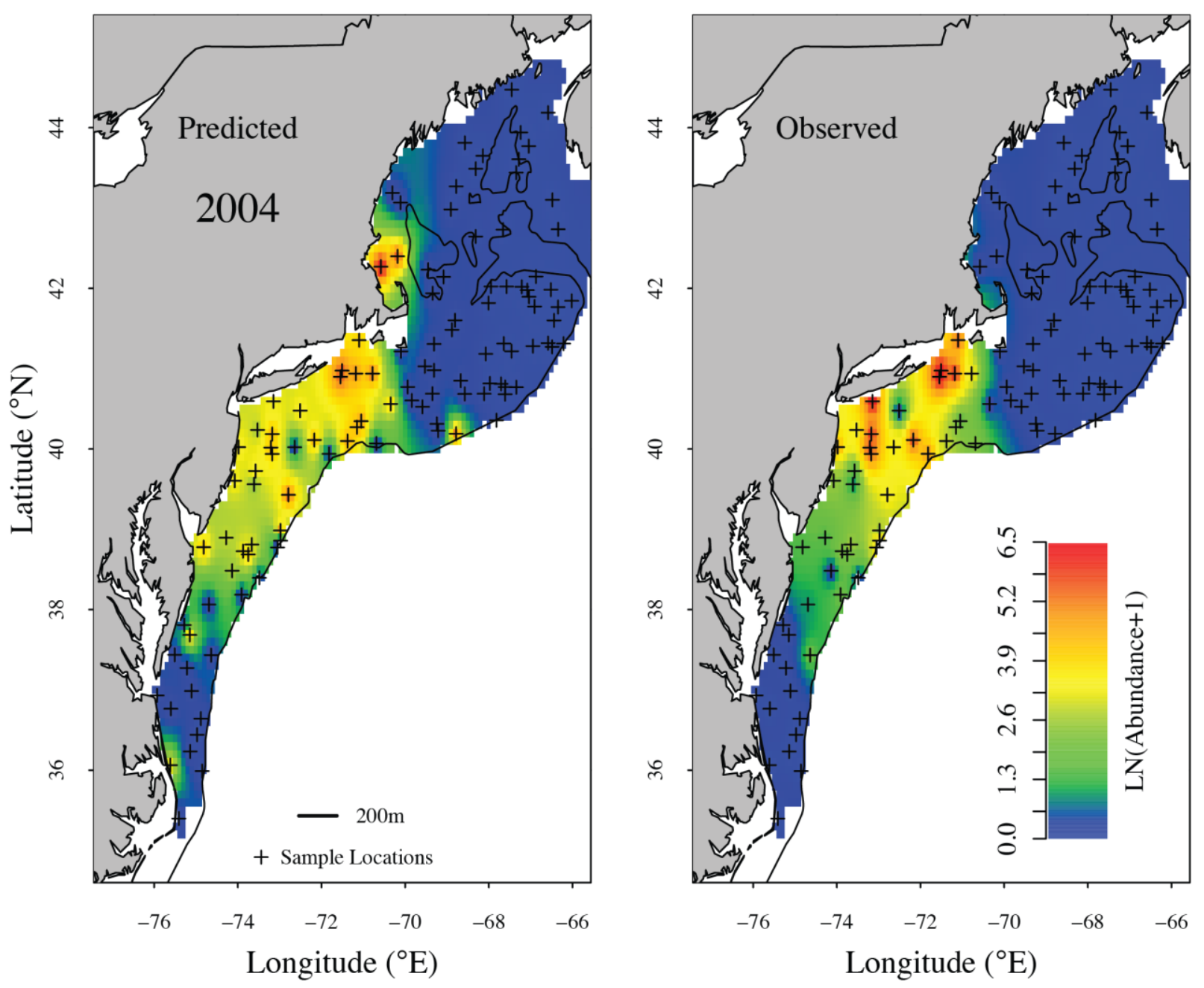

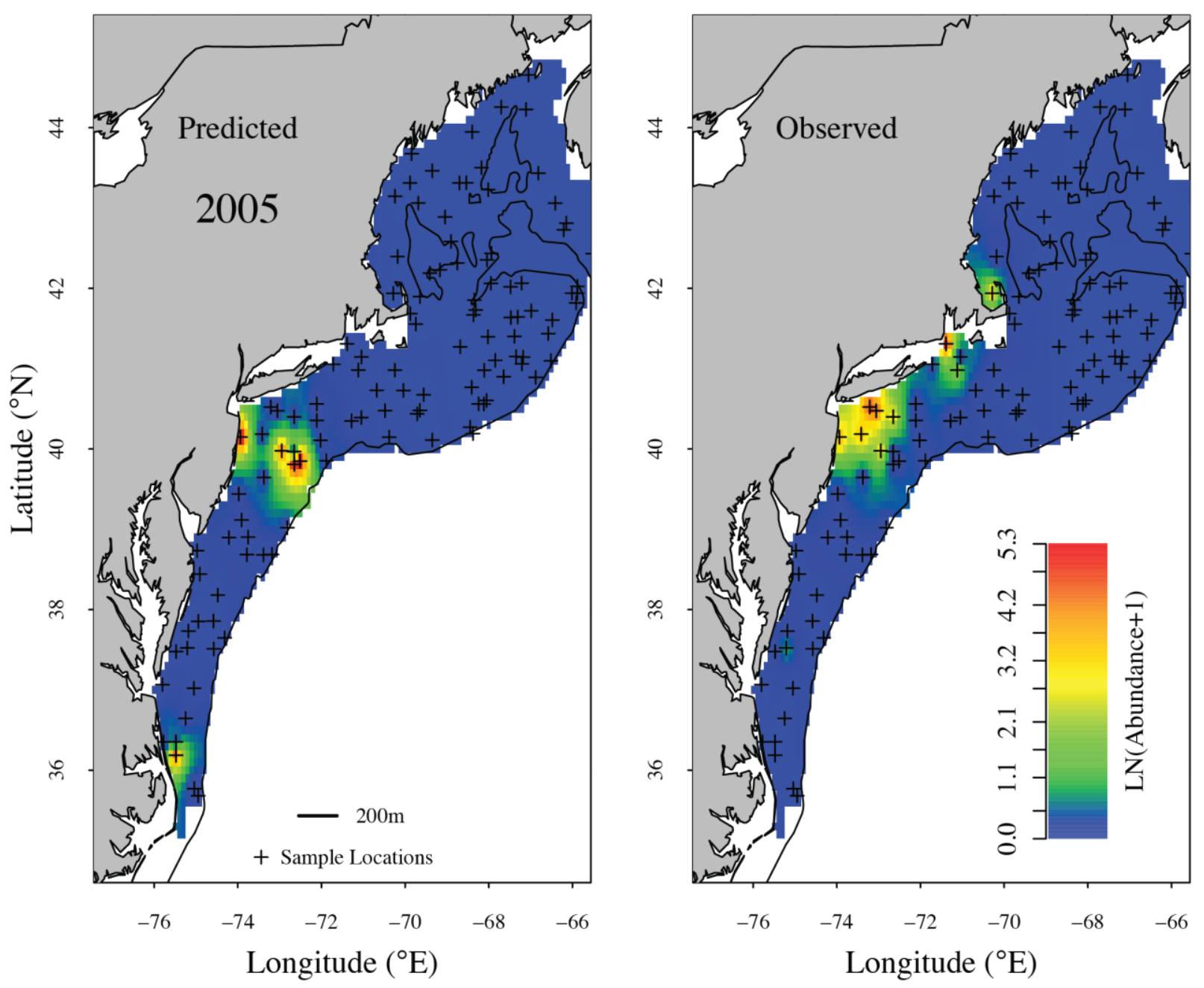

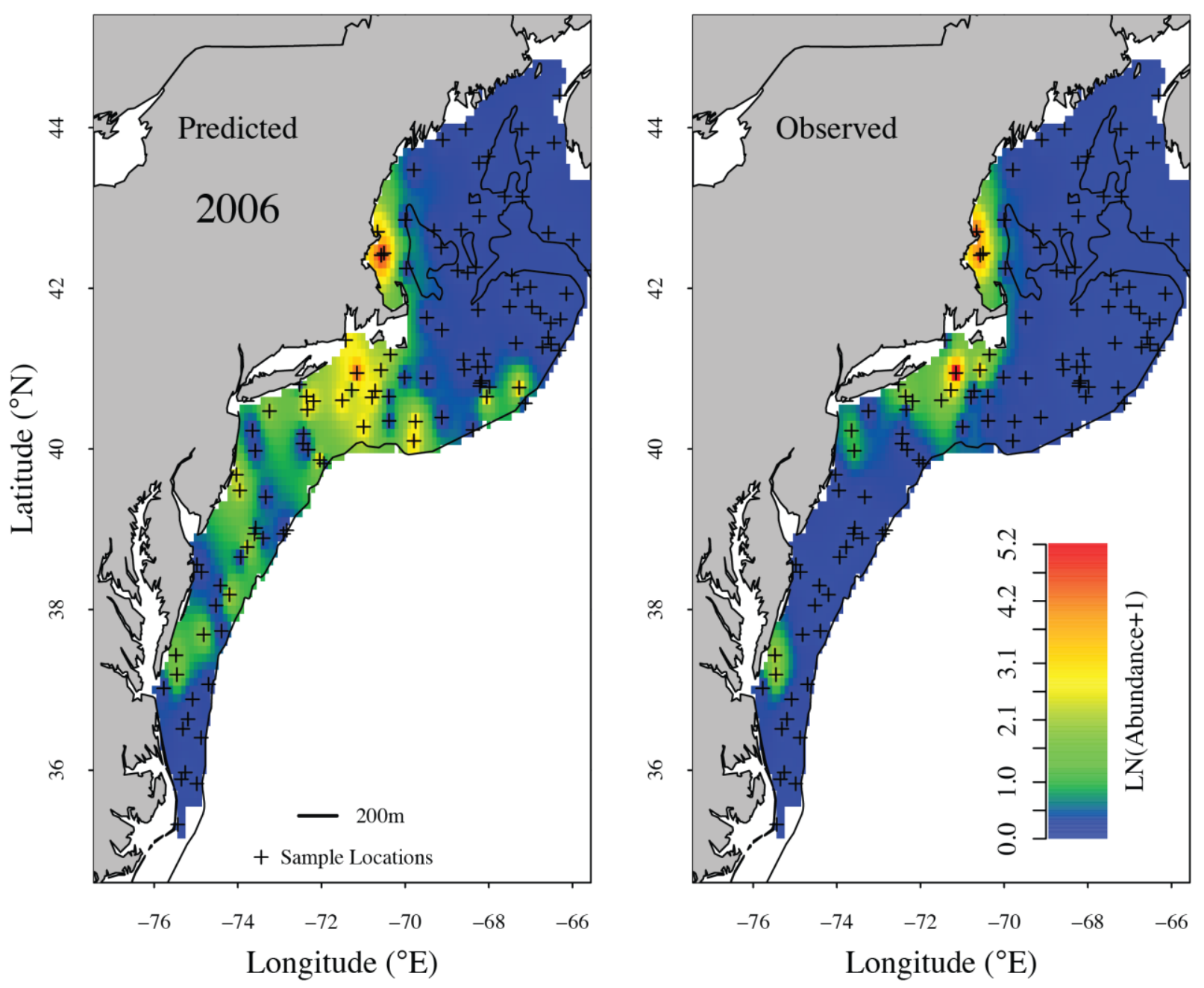

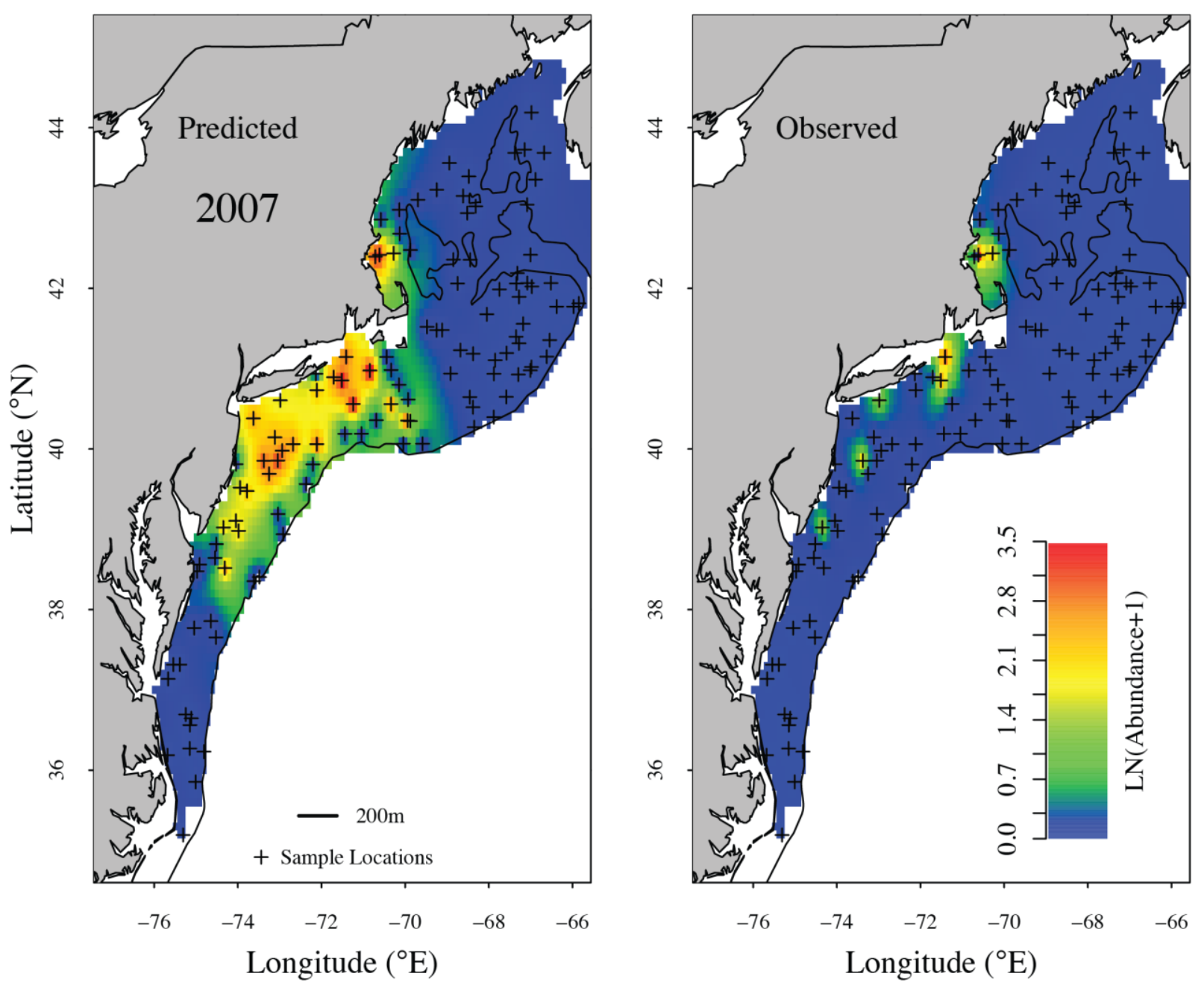

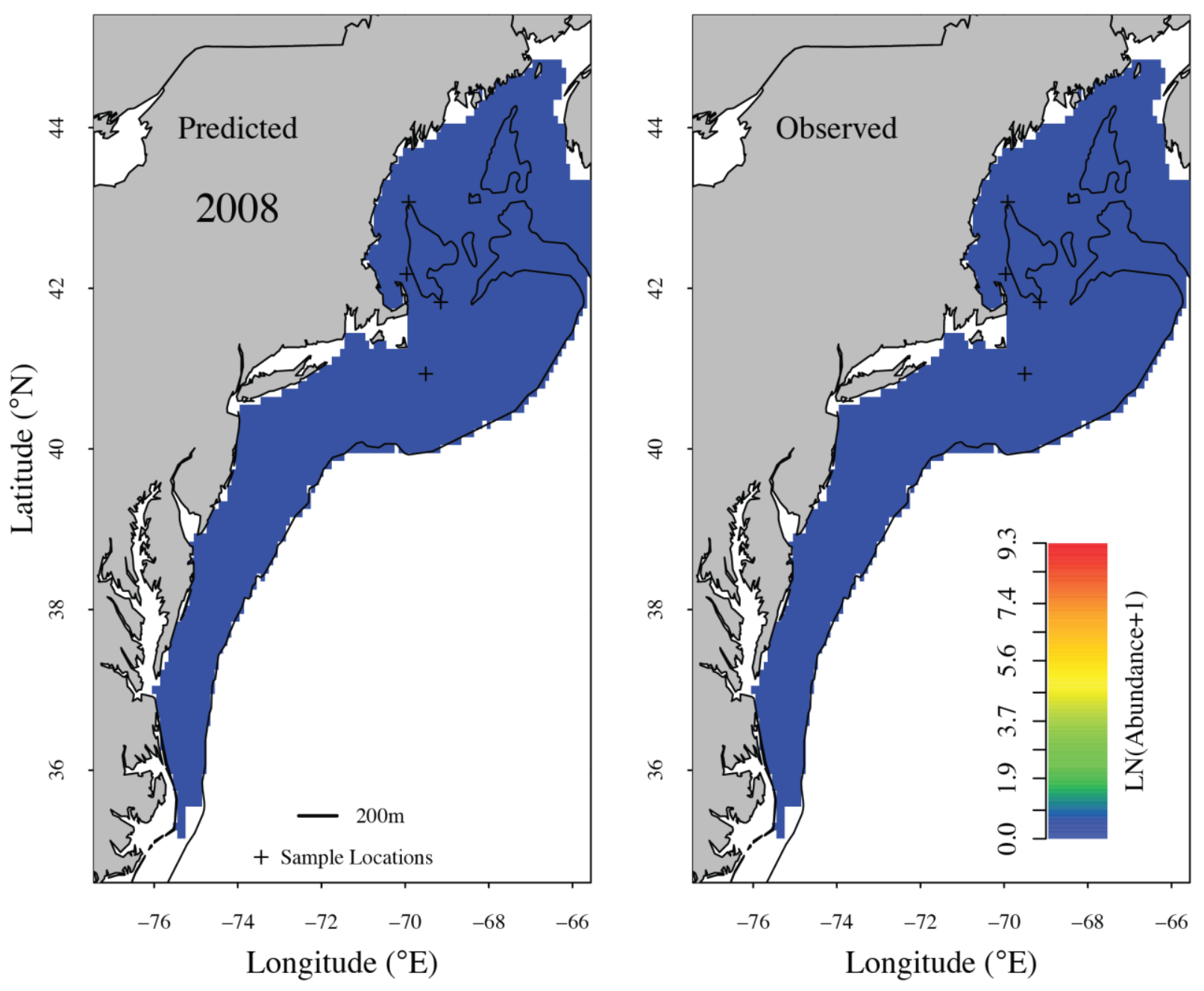

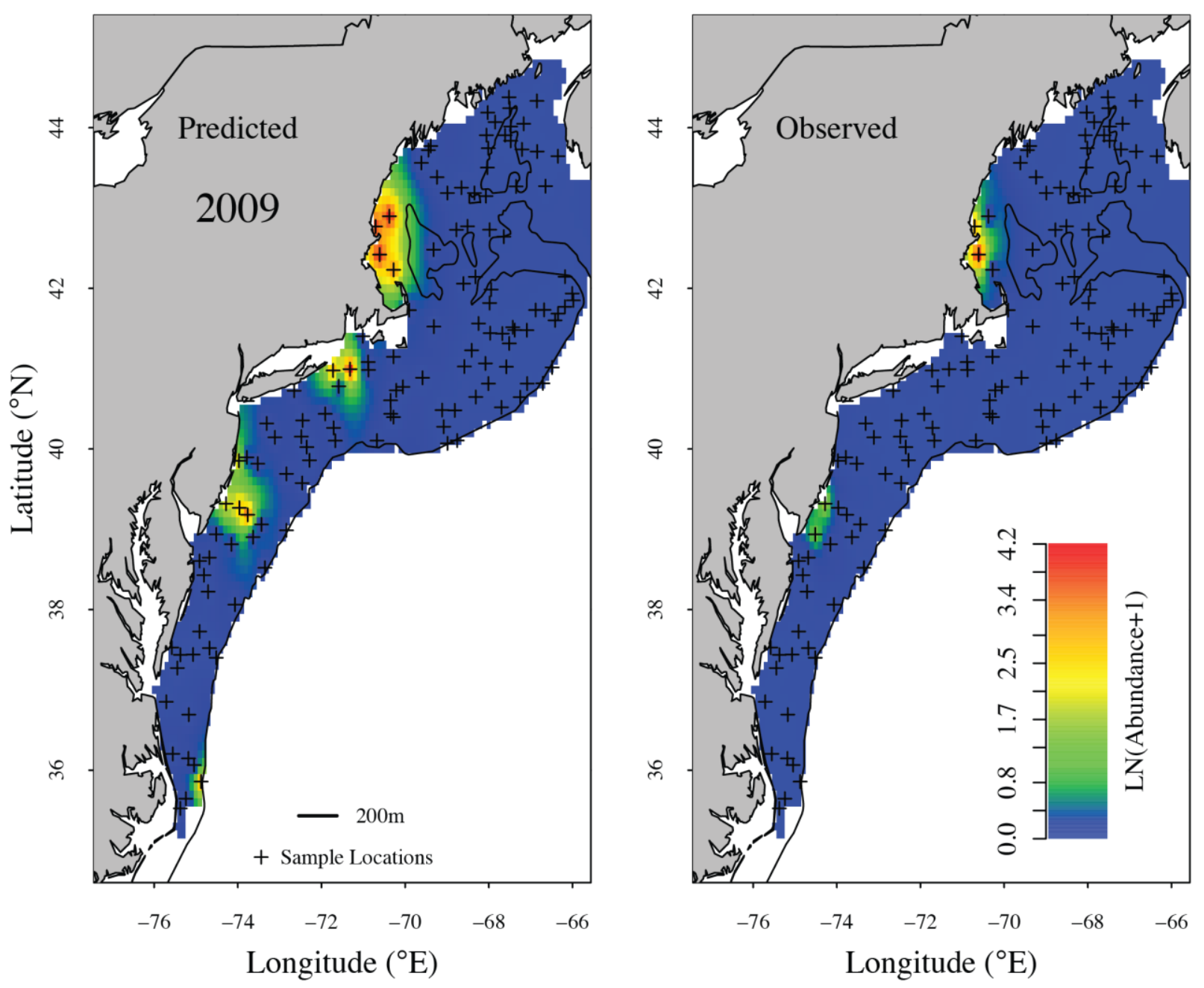

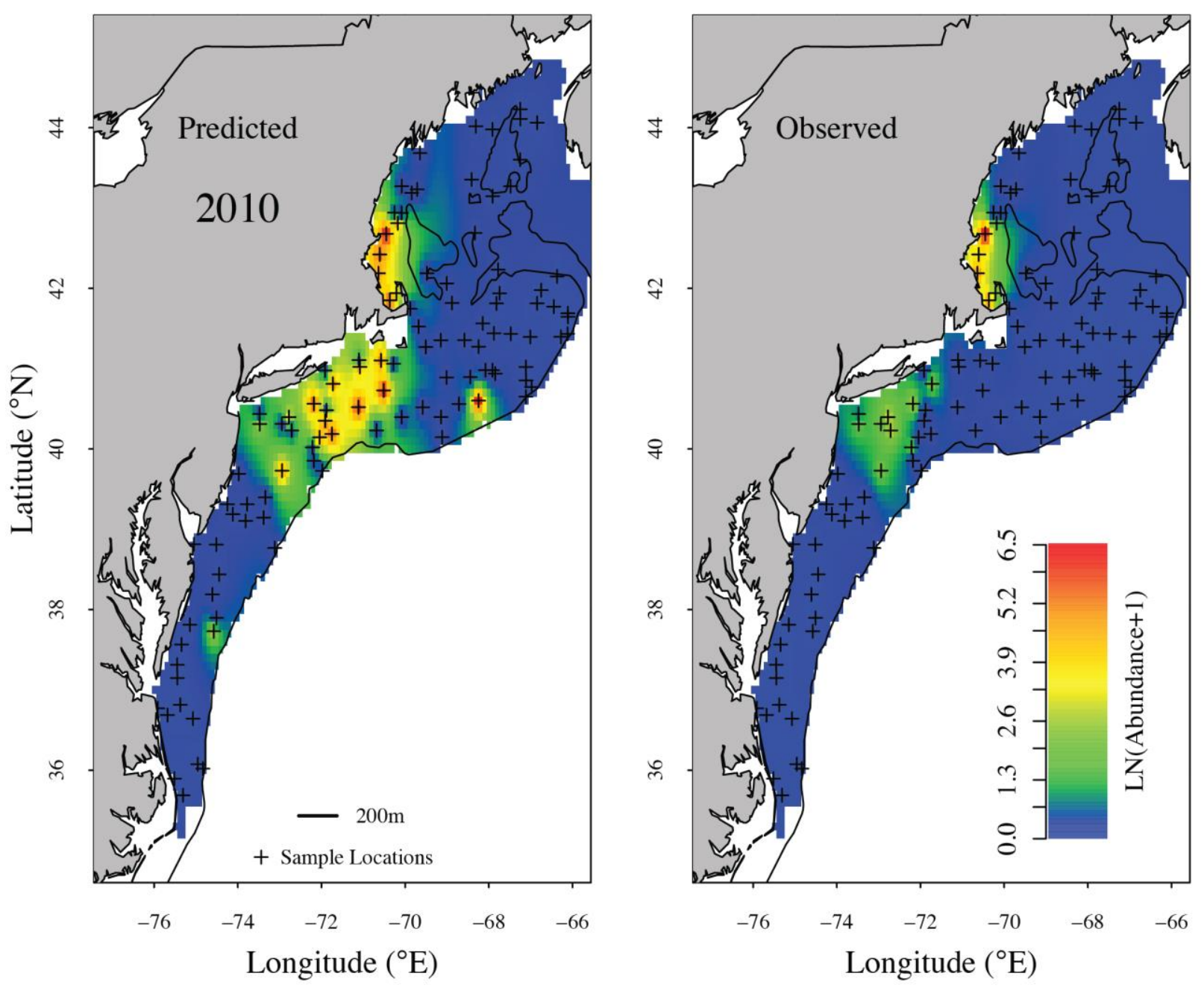

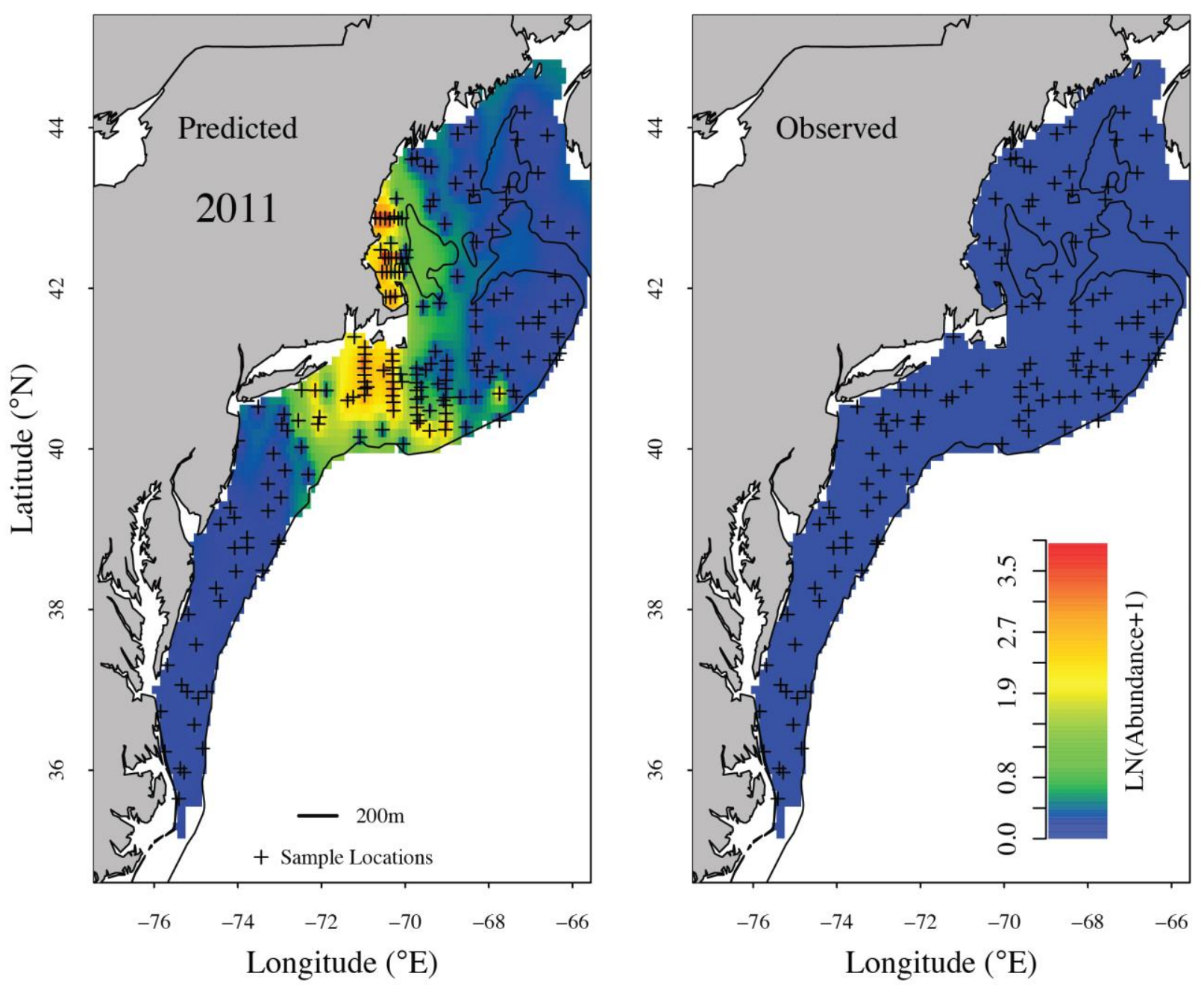

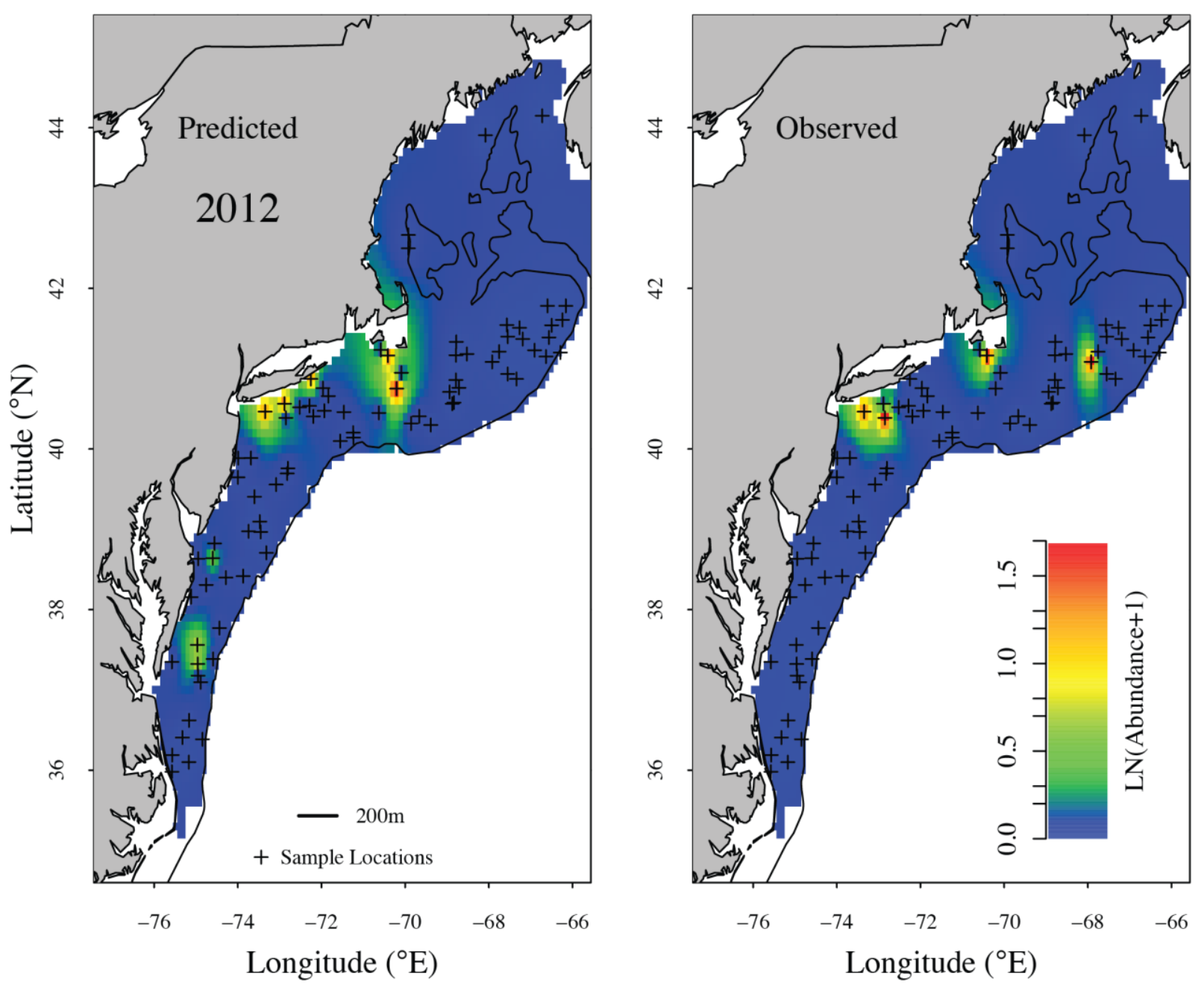

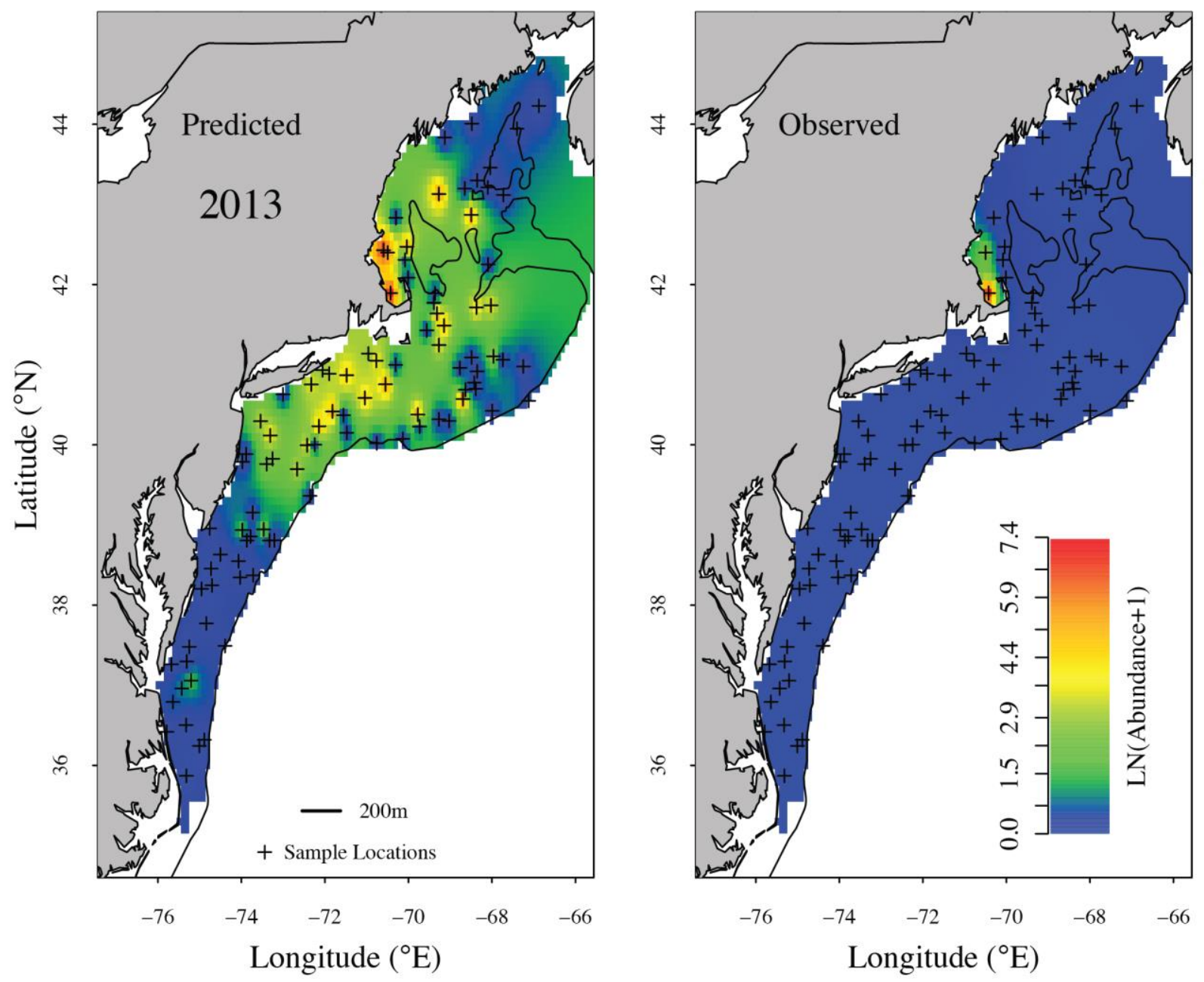
Supplement 4. Description of zooplankton taxa collected in MARMAP and EcoMon samples with stage specific information used in the species distribution models (Temora longicornis, Pseudocalanus spp., Centropages typicus, and Calanus finmarchicus): percent compositions of stages for each taxa over all available samples (S4.A.) and broken out by year (S4.B.), as well as correlations between copepods' total abundances and older stage abundances (S4.C.).
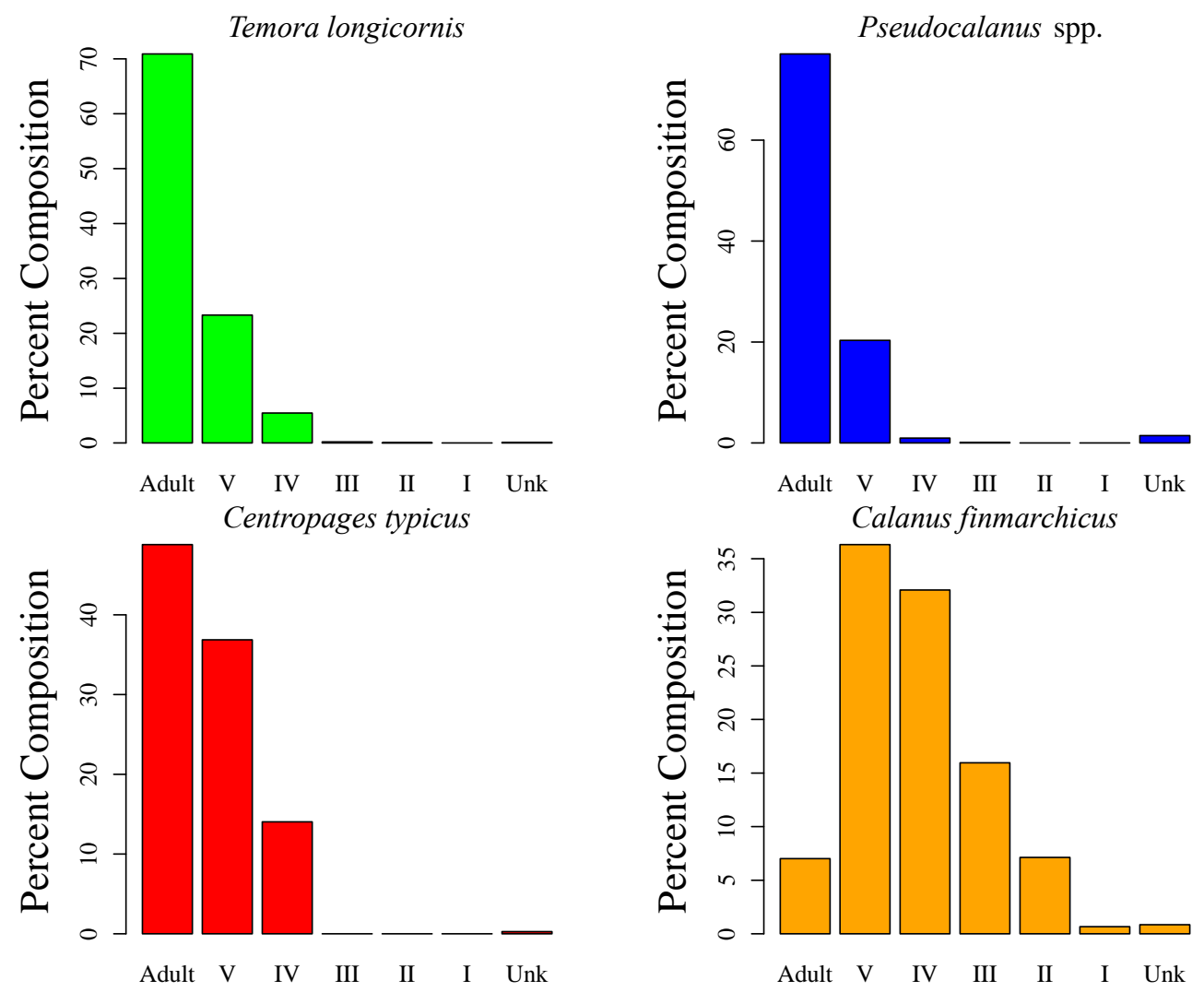

Figure S4.A. Percent composition for zooplankton taxa abundances from May and June by stage across MARMAP and EcoMon samples. Abundance (\# 10 $\left.\mathrm{m}^{2}\right)$ calculations only used samples when a given the taxa was present. 

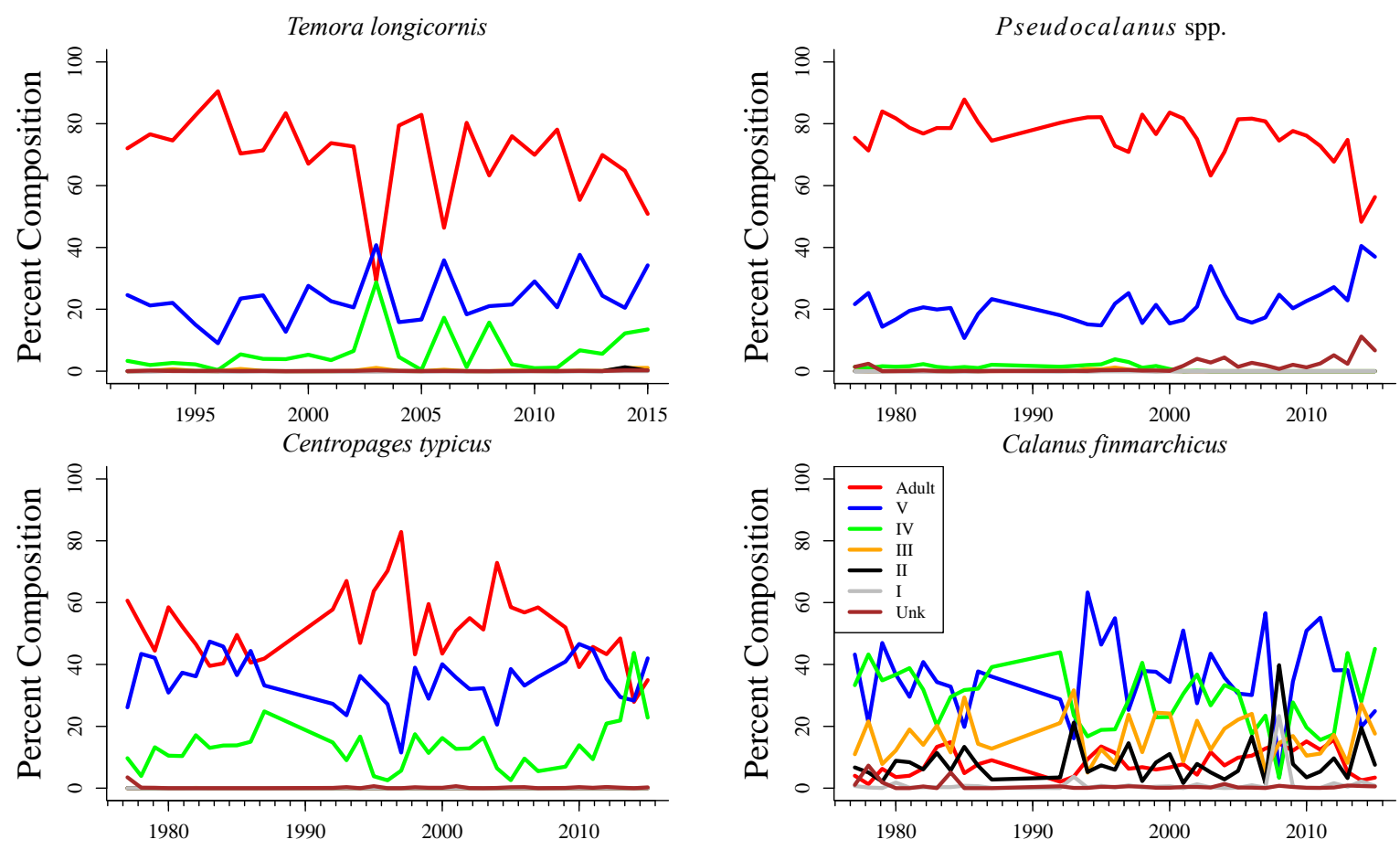

Figure S4.B. Percent composition for zooplankton taxa abundances from May and June by stage across MARMAP and EcoMon samples over time. Abundance $\left(\# 10 \mathrm{~m}^{2}\right)$ calculations only used samples when a given the taxa was present. 

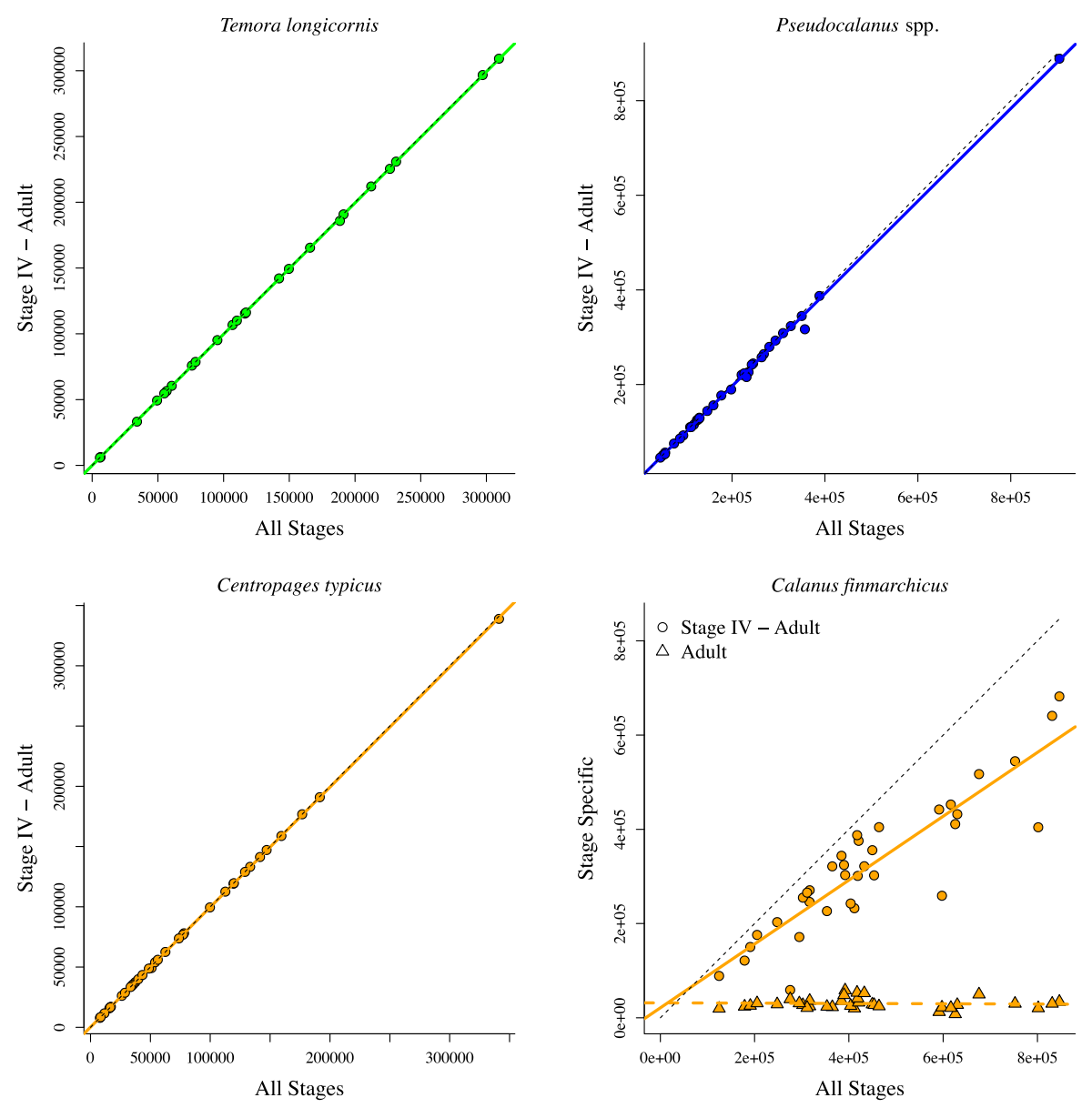

Figure S4.C. Annual mean abundances from May and June for all stages plotted

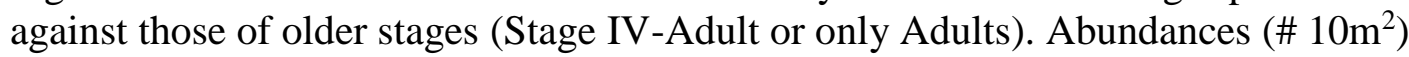
calculations only used samples when a given the taxa was present. Black dashed lines represent 1:1 lines. Correlation fits are represented by colored lines. Stage IV-Adult (circle, solid line) and Adult (triangles, dashed line) data and model fits are both presented for Calanus finmarchicus. Correlations for Temora longicornis, Pseudocalanus spp., Centropages typicus had $\mathrm{R}^{2}=1$. Correlations for Calanus finmarchicus for Stage IV-Adult and Adults only were $\mathrm{R}^{2}=0.81$ and $\mathrm{R}^{2}=0.003$, respectively. Both Adult and Stage IV-Adult correlations are presented given the unique life cycle and overwintering strategy of stage V Calanus finmarchicus (Miller and Tande, 1993; Hind et al., 2000).

\section{Literature Cited}

Hind, A., Gurney, W.S.C., Heath, M., and Bryant, A.D. (2000) Overwintering strategies in Calanus finmarchicus. Marine Ecology Progress Series 193: 95-107.

Miller, C.B., and Tande, K.S. (1993) Stage duration estimation for Calanus finmarchicus populations, a modelling study. Marine Ecology Progress Series 102: $15-34$. 


\section{MANUSCRIPT 3}

Estimating historic northwest Atlantic mackerel (Scomber scombrus) stock size with stochastic stock reduction analysis

M. Conor McManus ${ }^{1,2, *}$, Jeremy S. Collie ${ }^{1}$, Kiersten L. Curti ${ }^{3}$, and Matthew G. McKenzie ${ }^{4}$

${ }^{1}$ Graduate School of Oceanography, University of Rhode Island, Narragansett, RI, 02882

${ }^{2}$ Rhode Island Department of Environmental Management, Division of Marine Fisheries, Jamestown, RI, 02835

${ }^{3}$ National Oceanic and Atmospheric Administration, National Marine Fisheries Service, Northeast Fisheries Science Center, Woods Hole, MA, 02543

${ }^{4}$ University of Connecticut, Department of History, Groton, CT, 06340

*corresponding author: phone: (401) 423-1941, fax: (401) 423-1925; email:

cmcmanus@gso.uri.edu

Key words: Atlantic mackerel, landings, population trends, recruitment, stochastic, stock reduction analysis

Publication status: in preparation for the Canadian Journal of Fisheries and Aquatic Sciences 


\section{ABSTRACT}

Data-limited approaches are emerging as common options for understanding population changes through time and setting reference points. Such techniques are appealing for the northwest Atlantic mackerel (Somber scombrus) stock, as available data and information appear to present conflicting understandings on the stock. We present the application of one data-limited approach, stochastic stock reduction analysis (SSRA), for northwest Atlantic mackerel. Contemporary and historical information were combined to estimate population trajectories and fishing mortalities from 1804 to 2016. Stochastic simulations varied the unfished recruitment $\left(\mathrm{R}_{0}\right)$ and the stock-recruitment model's slope (K) to provide parameters that can be used to infer population changes through time. Model sensitivity to certain assumptions (natural mortality, unreported landings, and environmentally-influenced recruitment) are also presented. The influence of periods with significant harvest were reflected in stock size, with the 2016 population estimated to be approximately $53 \%$ of the 1804 , unfished stock size. When examining successful SSRA trajectories that best correlated to available abundance indices, these trends indicated 2016 stock size was $11 \%$ of the 1804, unfished population. The SSRA developed could benefit from additional model development, particularly more realistic and variable recruitment patterns through time. Despite these drawbacks, the SSRA for northwest Atlantic mackerel warrants inclusion for future stock assessments.

\section{INTRODUCTION}

Challenges remain for identifying status and establishing management plans for fish stocks without data required for formal age-structured stock assessments (data-poor), or when the quality of stocks' data available are considered inaccurate and assessments 
using such data produce unreliable management reference points (information-poor). For information-poor stocks, complexities with fisheries-independent surveys (e.g. gear catchability, spatial-temporal mismatch with sampling and species presence, the multipurpose nature of surveys unfavorable for a given species) can either disqualify data rich information from being included in conventional stock assessment models, or prevent benchmark assessments from passing peer-review. While these scenarios leave fisheries scientists and managers with poor inferences of stock statuses and management targets, catch limits and management action are often still required for species with fisheries management plans.

Stock reduction analysis (SRA) is one data-limited technique that has been used to understand population trajectories and parameters. SRA uses historical catch to estimate what population levels would have been required to sustain reported removals (Kimura and Tagart 1982, Kimura et al. 1984). Such methods can incorporate rich histories of catch data that the often preferred, more rigorous assessment models may not utilize. Evaluating historical landings and fisheries information through SRA can improve both historical and present understanding of stock trends and status (Rose 2004, Rosenberg et al. 2005). To understand the influence of assumed model parameters, stochastic SRAs (SSRAs) use Monte Carlo simulations to iteratively generate population parameters and estimate population trends through time (Walters et al. 2006, Dick and MacCall 2011). As such, the SSRA population parameter combinations that estimate abundances greater than catch represent plausible scenarios for stock abundance and lifehistory characteristics. These simulation runs provide a range of values for population 
abundance and parameters, from which variability and uncertainty in estimates can be evaluated.

Data-limited methods are appealing for the northwest Atlantic mackerel (Scomber scombrus) stock. Atlantic mackerel is a schooling, pelagic, planktivorous fish ranging from Newfoundland to North Carolina (Sette, 1950). The northwest Atlantic stock has northern and southern contingents spawning in the Gulf of St. Lawrence and MidAtlantic Bight through the Gulf of Maine, respectively (Morse 1980, Anderson 1982, Berrien 1982). It is widely believed that the northwest Atlantic mackerel population is near historic low levels. Recent Canadian (northern contingent) assessments indicate that reduced catches and abundances are attributed to overharvesting and recruitment overfishing (DFO 2014, Ploudre et al. 2015). U.S. (southern contingent) landings are also near their lowest in the last 40 years (Wiedenmann 2016). However, U.S. data provide conflicting information on stock trends; fishery-independent trawl survey abundance indices and landings indicate opposite trends, with landings declining and bottom-trawl survey abundance indices variable and occasionally higher in recent years. These contradicting data have produced large uncertainty and significant retrospective patterns in the most recent stock assessment (Deroba et al. 2010). A formal stock assessment was conducted in 2017 (awaiting peer-review), but currently the U.S. declares the northwest Atlantic mackerel stock status as unknown (MAFMC, 2016); it has recently been considered an "information-poor" stock (Wiedenmann 2016).

We present a stochastic, stock-reduction analysis for the northwest Atlantic mackerel stock using over two centuries of landings data. Our objective was to apply the SSRA approach for Atlantic mackerel and provide a complimentary tool for future 
Atlantic mackerel assessments. By incorporating rich catch history data and information from historical fishery reports, this work aims to quantify mackerel abundance trends over two hundred years, and provide a historical context for more recent assessment periods (late 1960s-present). Further, information on possible population characteristics, including population trajectories, unfished recruitment sizes, and recruitment rates, may be valuable for future management decisions when trying to evaluate the current status of the stock.

\section{Evolution of the Northwest Atlantic Mackerel Fishery}

Landings and details on the commercial fishery have been documented for over two centuries. In the 1600s and 1700s, mackerel were most commonly caught with hand lines and beach seines (Hoy and Clark 1967, McKenzie 2010a). The hook and line fishery often operated from boats, with fishing occurring while the boat was moving. Records of commercial landings date back to the early 1800s (Goode et al. 1883, Anderson and Paciorkowski 1980). From 1800 through 1815, mackerel were typically caught through the hook and line fishery, confined to shore using simple iron hooks (Sette and Needler 1934, McKenzie 2010a). The hook and line practice advanced during this period, increasing efficiency and catch. In 1812, fishermen used herring, mackerel and menhaden to chum the waters while fishing and attract mackerel (Sette and Needler 1934, Hoy and Clark 1967). In 1816, initiation of the jig and using tougher bait also increased efficiency. The jigging method used a sinker fastened to the shank of the hook, which allowed for a more durable hook and more effective tool when hauling mackerel into the boat (Hoy and Clark 1967, McKenzie 2010a). These advancements allowed for 
the salt mackerel fishery to expand offshore from 1815-1830 (Sette and Needler 1934, Anderson and Paciorkowski 1980).

From 1830-1869, the hook and line fishery was supplemented with the advent of pound nets, traps and weirs within inshore waters (McKenzie et al. 2010b). One of the most significant technological advances in the northwest Atlantic mackerel fishery was the introduction of the purse seine. Purse seining was first introduced in 1850, and by 1870-1880, this gear had fully replaced the hook and line practice (Sette and Needler 1934, Hoy and Clark 1967, Anderson and Paciorkowski 1980). With the advent of the purse seine, mackerel fishing in the Gulf of St. Lawrence declined, shifting the total landings to be primarily from U.S. fleets, and more specifically, southern New England (Sette and Needler 1934, Hoy and Clark 1967). Overall, the purse seine remained the dominant gear used through the early 1960s (Hoy and Clark 1967). Roughly 50-90\% of mackerel harvested in New England were from purse seines in the offshore fishery, with New England representing 95-100\% of all U.S. landings (Setter and Needler 1934). Other fractions of the fishery, such as the Canadian mackerel fishery, used gill nets and traps instead of purse seines and hook and line (Anderson and Paciorkowski 1980).

The decrease in landings in 1884 through 1920 under consistent fishing methods and pressure suggested that the declines were the result of a stock failure following periods of intensive fishing (Anderson and Paciorkowski 1980). However, this scarcity of mackerel was confined to U.S. waters and not necessarily applicable to Canada, suggesting that this was not a stock-wide failure. The reduced mackerel catches during this period caused mackerel prices to increase (Sette and Needler 1934). While the low catches appeared tied to low abundances and not to be gear related, the reduction in 
abundance resulted in gillnetting becoming a method increasingly used when purse seining under-performed (Sette and Needler 1934). During this same period (1880s1920s), vessels had gradually switched from sail boats to power boats, allowing for the conversion from a salt-mackerel fishery to a fresh-mackerel fishery (Sette and Needler 1934, Hoy and Clark 1967, Anderson and Paciorkowski 1980). From 1925-1926, the fishery responded to a strong mackerel year class in 1923, highlighting the stronger influence of abundances on landings than gear or effort during this time frame (Sette and Needler 1934, Anderson and Paciorkowski 1980). Reports from the 1930s through the 1960s indicated that mackerel fisheries also used various gears, including traps, gill nets, fish pots, and weirs (Sette and Needler 1934, Hoy and Clark 1967).

Modern trawling techniques began after WWII when technologies developed during the war were commercialized (Sette and Needler 1934, Anderson and Paciorkowski 1980). The time-series peaks in landings during the 1970s and 1980s are attributed to the introduction of distant water fleets, primarily from the USSR and Europe (Anderson and Paciorkowski 1980). These distant-water fleets harvested mackerel primarily in the stock's southern contingent using bottom and midwater trawls. By the mid-1970s, most U.S. mackerel fisheries used otter trawls, which were reported to have the same catch efficiencies as the midwater trawlers (Anderson and Paciorkowski 1980). While foreign catches subsided in the late 1970s with the implementation of the 200nautical-mile exclusive economic zone (DFO 2014), an agreement between the USSR and U.S. resulted in increased foreign catches in the 1980s, until the agreement was disbanded in 1992. Like the 1920s, increased landings in the early 1980s and mid 2000s resulted from industry responding to strong year classes. High recruitment during this 
period was believed to be supported by high densities of copepod prey (including Calanus finmarchicus) (Ringuette et al. 2002, Castonguay et al. 2008).

\section{METHODS}

\section{Data}

\section{Landings Records}

Landings data were obtained from 1804 through 2016 (Figure 1a). Landings information prior to 1960 was obtained from Anderson and Paciorkowski (1980), based on the earlier efforts of Goode et al. (1883) and Sette and Needler (1934). Landings from 1960-2016 were obtained from records maintained by the National Marine Fisheries Service, Northeast Fisheries Science Center (NEFSC) (K. Curti, personal communication). These landings are used to represent total landings (commercial, recreational, and discards, Figure 1a); however, reporting has changed over the time series. Prior to 1876, landings data were unavailable for Canadian fleets, thus landings during this period are solely from the U.S fishery (Anderson and Paciorkowski 1980). The Canadian fishery is believed to have become substantial by the 1850s (Sette and Needler 1934). Recreational landings for the U.S. were unavailable prior to 1981, and Canadian recreational and bait fisheries are not required to report landings (Van Beveren et al. 2017a). U.S. discards were available since 1989, and were included with the assumption of $100 \%$ discard mortality. When available, landings represented summed commercial and recreational harvests and discards from U.S. and Canadian fleets.

In more recent years (1968-2016), landings by age class were available for both U.S. and Canadian commercial fleets (K. Curti, personal communication). Catch-at-age by year were summed for U.S. and Canadian fleets, and calculated in units of proportion 
of the catch-at-age. These proportions were applied to the total catch to derive stock-wide catch-at-age. Catch-at-age information was only available through an age 10+ group. When age 10+ landings occurred, the landings from this age class were proportioned evenly between ages 10 through 14, the oldest age group modeled. While previous reports have indicated that Atlantic mackerel can live up to 20 years old (Studholme et al. 1999), available fisheries independent and dependent data suggest that $99 \%$ of mackerel are 14 years old or younger (K. Curti, personal communication). Weight-at-Age

Atlantic mackerel average weights-at-age were available from fishery-dependent sampling in the U.S. and Canada from 1968-2016 (K. Curti, personal communication). Weight-at-age $(\mathrm{kg})$ was available for ages one through ten. Weight-at-age for 11 to 14 year-old mackerel were assigned the 10-year-old mackerel weights of the same year, reflecting the asymptotic growth at these older ages (Collette and Klein-MacPhee 2002). While weight-at-age slightly increased from 1968-2016 for age-one mackerel, older age classes showed no significant changes in weight over the same period. As such, the mean weights-at-age from 1968-2016 were used for earlier years when weight-at-age information was not available.

\section{Natural Mortality}

Instantaneous natural mortality rates-at-age $\left(\mathrm{M}_{\mathrm{a}}\right)$ vary considerably for northwest Atlantic mackerel. Previous Atlantic mackerel assessments have used a rate of 0.2 constant over years and ages (Deroba et al. 2010, Van Beveren et al. 2017b). Using Atlantic mackerel life history parameters, Grégoire and McQuinn (2014) estimated agevarying northern contingent natural mortality through time, with results indicating that 
age-specific mortality could be more than eight times higher than the assumed 0.2. Similar mortality estimates have been reported for the southern contingent when estimating both residual and predation mortality for mackerel (Tyrell et al. 2008, Moustahfid et al. 2009), whereas others have found predation mortality to be low (Tsou and Collie 2001). To derive rates specific to the population being modeled, natural mortality was estimated with weight-at-age data using the meta-analysis described by Lorenzen (1996). Mortality rates with this approach were lower than Grégoire and McQuinn (2014): as high as 0.29 and low as 0.13 for age one and 14 fish, respectively. As a compromise to these varying rates, natural mortality was set at 0.4 for age one fish, and older age classes at 0.2 .

\section{Fishery Selectivity-at-Age}

In reviewing the history of the northwest Atlantic mackerel fishery, the dominant gears used over the time series were defined as three periods: 1804-1850 (hook and line), 1851-1950 (purse seine), and 1951 to present (otter and midwater trawls). As mentioned, other gear types were used within these time periods, and are not reflected by these timeseries demarcations in gear type. Thus, it is assumed that variability in gear types used within periods do not necessarily correspond to different selectivity-at-age between gears (e.g. purse seine and fish traps).

Selectivity-at-age $\left(\mathrm{v}_{\mathrm{a}}\right)$ from 1804 through 1850 was estimated based on research describing mackerel caught using hooks off Nova Scotia (Heighton and Grégoire 2006). The study used 10, 2/0, and 4/0 sized hooks, catching over 1117 fish with mean size of $30.19 \mathrm{~cm}$; we assume these hooks' selectivity are comparable to those used in the first half of the $19^{\text {th }}$ century. Length-frequency distributions for the three-hook types were 
combined, and lengths were transformed to ages using age-length keys (K. Curti, personal communication). The age-frequency distribution represented a dome-shape selectivity curve for the hook-and-line methodology, which was used to represent selectivity-at-age from 1804-1850 (Figure 1b). Selectivity-at-age from 1851 through 1950 was derived from catch-at-age distributions from trawl and seine comparison surveys of mackerel in the North Sea (Slotte et al. 2007). Seine data were collected in September and October from 1999 to 2006. Age-frequency information was averaged for the two months of presented data. In this study, seining is assumed to have asymptotic selectivity, with the modal age class sampled and older being fully selected to the gear. As such, the seining period of 1851-1950 was applied as flat-top selectivity (Figure 1b). The trawling period (1951-present) selectivity-at-age was derived from the previous TRAC assessment (Deroba et al. 2010). Selectivity-at-ages for U.S. and Canadian fisheries were averaged and represented the vulnerability of fish to both domestic and foreign otter and midwater fleets from 1951 through present (Figure 1b). In years for which catch-at-age data were available (1968-present), selectivity-at-age was not used in calculations.

\section{Stock Reduction Analysis Model}

Abundances estimated through the stock reduction analysis (SRA) represented the starting population of the given year. Based on descriptions of the fishery (McKenzie 2010a), the starting population on January 1, 1804 represented an unfished population at equilibrium. Thus, natural mortality constituted the total mortality-at-age for January 1, 1804 abundances:

$$
N_{a, 1804}= \begin{cases}R_{0} & \text { if } a=1 \\ N_{a-1} e^{-M_{a}} & \text { if } a>1\end{cases}
$$


Natural mortality-at-age $\left(\mathrm{M}_{\mathrm{a}}\right)$ was the same as used through the rest of the time series, and recruitment in an unfished population $\left(\mathrm{R}_{0}\right)$ was assigned at the beginning of the modeling. Recruitment for the stock reduction analysis was represented as the abundance of age one mackerel.

Fishing Mortality Estimation

Annual fishing mortality $\left(\mathrm{F}_{\mathrm{t}}\right)$ was solved for using Baranov's catch equation.

$$
\mathrm{C}_{\mathrm{t}}=\sum_{\mathrm{a}=1}^{\mathrm{a}=14} \mathrm{~N}_{\mathrm{a}, \mathrm{t}} \mathrm{w}_{\mathrm{a}, \mathrm{t}} \frac{\mathrm{F}_{\mathrm{t}} \mathrm{v}_{\mathrm{a}, \mathrm{t}}}{\mathrm{F}_{\mathrm{t}} \mathrm{v}_{\mathrm{a}, \mathrm{t}}+\mathrm{M}_{\mathrm{a}}}\left(1-\mathrm{e}^{-\left(\mathrm{F}_{\mathrm{t}} \mathrm{v}_{\mathrm{a}, \mathrm{t}}+\mathrm{M}_{\mathrm{a}}\right)}\right)
$$

Catch $\left(\mathrm{C}_{\mathrm{t}}\right)$ represented the total mackerel removals in each year (Figure 1a). Abundancesat-age $\left(\mathrm{N}_{\mathrm{a}, \mathrm{t}}\right)$ were those that survived to January 1 of the given year. Selectivity-at-age $\left(\mathrm{V}_{\mathrm{a}, \mathrm{t}}\right)$ was assigned based on the prevalent gear types used in each year. Annual weightsat-age $\left(\mathrm{w}_{\mathrm{a}, \mathrm{t}}\right)$ represented mackerel from U.S. and Canadian waters on January 1 of the given year. Fishing mortality $\left(\mathrm{F}_{\mathrm{t}}\right)$ was solved for using a root finder, calculating the solution of $F_{t}$ that set both sides of the Baranov catch equation equal. In years where proportions of catch-at-age were available for estimating annual catch-at-age $\left(\mathrm{C}_{\mathrm{a}, \mathrm{t}}, 1968\right.$ 2016), fishing mortality-at-age was directly estimated, and ignored selectivity-at-age:

$$
\mathrm{C}_{\mathrm{a}, \mathrm{t}}=\mathrm{N}_{\mathrm{a}, \mathrm{t}} \mathrm{W}_{\mathrm{a}, \mathrm{t}} \frac{\mathrm{F}_{\mathrm{a}, \mathrm{t}}}{\mathrm{F}_{\mathrm{a}, \mathrm{t}}+\mathrm{M}_{\mathrm{a}}}\left(1-\mathrm{e}^{-\left(\mathrm{F}_{\mathrm{a}, \mathrm{t}}+\mathrm{M}_{\mathrm{a}}\right)}\right)
$$

Population abundances in subsequent years prior to the availability of catch-at-age information incorporated both fishing mortality of the previous year and changes in egg production. Abundances older than recruits (age-one fish) were calculated as:

$$
\mathrm{N}_{\mathrm{a}, \mathrm{t}}=\mathrm{N}_{\mathrm{a}-1, \mathrm{t}-1} \mathrm{e}^{-\left(\mathrm{F}_{\mathrm{t}-1} \mathrm{v}_{\mathrm{a}-1, \mathrm{t}-1}+\mathrm{M}_{\mathrm{a}, \mathrm{t}-1}\right)}
$$


With catch-at-age information available, gear selectivity is not used and fishing mortality-at-age is solved for directly. Abundances for the recruitment population in years other than $1804\left(\mathrm{~N}_{1, \mathrm{t}}\right)$ were calculated using the Beverton and Holt (1957) stockrecruitment model:

$$
\mathrm{N}_{1, \mathrm{t}}=\frac{(\mathrm{K} / \phi) \mathrm{E}_{\mathrm{t}}}{1+\left[\frac{\mathrm{K}-1}{\left(\mathrm{R}_{0} / \phi\right)}\right] \mathrm{E}_{\mathrm{t}-1}}
$$

Average annual egg production $\left(\mathrm{E}_{\mathrm{t}}\right)$ was estimated based on abundance, maturity, and fecundity at age for the population:

$$
E_{t}=\sum_{a=1}^{a=14} N_{a, t-1} m_{a, t-1} f_{a} 0.5
$$

Abundances-at-age of the previous year $\left(\mathrm{N}_{\mathrm{a}, \mathrm{t}-1}\right)$ were multiplied by the proportion of the age group mature $\left(\mathrm{m}_{\mathrm{a}, \mathrm{t}-1}\right)$ and the estimated fecundity at age $\left(\mathrm{f}_{\mathrm{a}}\right)$. Proportion of mackerel mature at given annual ages $\left(\mathrm{m}_{\mathrm{a}}\right)$ were available from U.S. and Canadian regions. Maturity-at-age for U.S. caught fish were obtained from samples collected as part of the NEFSC Spring Bottom Trawl Survey since 1982. Canadian mackerel maturity-at-age was obtained from DFO records, as used in Van Beveren et al. (2017b), with data extending back to 1968. Canadian data from 1968 through 1981 were used to represent maturity-atage for the stock, with 1982-2016 maturity schedules representing the annual averages at age for the two countries' data. Maturity-at-age for years prior to 1968 were the averages by age for the whole stock from 1968-2016. Thus, maturity was implemented as static from 1804-1967. Fecundity-at-age was evaluated in mackerel collected during spring of 1977 from the southern contingent (Morse 1980). Mean fecundity at age from Morse (1980) was implemented statically across all years. A factor of 0.5 was applied to 
represent the fraction of the population contributing to egg production (i.e. females), as previously utilized (Berrien, 1988).

In the stock-recruitment relationship, phi $(\phi)$ represented the egg production for an unfished population (calculated using 1804 abundances-at-age, maturity schedule and the fecundity-age relationship). The Goodyear recruitment compensation ratio, $\mathrm{K}$, represented the steepness of the stock-recruitment curve, or the rate of survival from egg to age-one fish at low population sizes (Walters and Martell 2004, Walters et al. 2006). As described previously, $\mathrm{R}_{0}$ represented the recruitment size of an unfished population at equilibrium.

\section{Stochasticity}

The unknown and non-assigned life-history elements for the stochastic stockreduction analysis (SSRA) were the Goodyear coefficient, K, and initial recruitment size, $\mathrm{R}_{0}$. Myers et al. (1999) reviewed the literature for various species' recruitment compensation ratios from around the world, with the average across populations approximately 5 (Walters et al. 2006). Northwest Atlantic mackerel recruitment sizes have been estimated in several studies for more contemporary periods (Tyrell et al. 2008, Moustahfid et al. 2009, Van Beveren et al. 2017b), all indicating that recruitment in fished populations (since the late 1960s) may have been as high as over a billion. For the SSRA, calculations were run over 1000 iterations using varying $\mathrm{K}$ and $\mathrm{R}_{0}$ value combinations. By varying these parameters, resulting population trajectories provided inference as to which scenarios were unlikely (i.e. caused population crashes) and which were plausible given a population remaining in 2016. In each iteration, $\mathrm{K}$ was drawn randomly from a gamma distribution, and $\mathrm{R}_{0}$ was drawn from a uniform distribution: 


$$
\begin{gathered}
\mathrm{K}=\sim \operatorname{Gamma}(\text { shape }=5 \text {, rate }=1.5) \\
\mathrm{R}_{0}=\sim \text { Uniform }\left(\text { lower }=10^{6}, \text { upper }=10^{9}\right)
\end{gathered}
$$

Sensitivity Runs

Three sensitivity runs were conducted for the SSRA modeling to assess how specific uncertainties influenced the results of aforementioned SSRA model (i.e. the base case scenario) to see how select assumptions influence population size and fishing mortality estimates. The first variant assessed the impact on the assumed natural mortality rates. Given previous literature suggesting that natural mortality rates may be higher than 0.4 (age-one) and 0.2 (ages greater than 1), the SSRA model was also run using elevated mortality rates: $\mathrm{M}_{\mathrm{a}=1}=0.6, \mathrm{M}_{\mathrm{a}>1}=0.3$.

The second sensitivity run evaluated the influence of uncertainty in removals and landings reported. While considerable effort has gone into quantifying historical landings, many of the landings in the early and mid-1800s were estimated based on barrels of fish harvested (Goode et al. 1883, Taylor et al. 1957), causing reason to believe there is some error and uncertainty in this fisheries-dependent information. Further, Canadian landings were not recorded until 1876 (Anderson and Paciorkowski 1980) and considerable fractions of the mackerel fishery, including recreational and bait fisheries, are not required to be reported (Van Beveren et al. 2017a). Simulations were run with landings added each year to those reported $\left(\mathrm{C} \mathrm{p}_{\mathrm{t}}\right)$. Landings in each year were supplemented with between ten and fifty percent of their annual total, randomly chosen using a uniform distribution:

$$
\mathrm{Cp}_{\mathrm{t}}=\mathrm{C}_{\mathrm{t}}+\sim \text { Uniform }\left(\text { lower }=\mathrm{C}_{\mathrm{t}} * 0.1 \text {, upper }=\mathrm{C}_{\mathrm{t}} * 0.5\right)
$$


The third sensitivity run was designed to increase variability in recruitment through time. Within a given set of $\mathrm{K}$ and $\mathrm{R}_{0}$ value combinations, recruitment was estimated based on the mean stock-recruitment function over the time series. However, in addition to spawning stock biomass and egg production, the number of individuals surviving through the first year of life often varies with the surrounding conditions of the ecosystem, including temperature, prey availability, ocean currents, and predator abundance (Llopiz et al. 2014). Although incorporation of these elements influencing recruitment may result in better estimates of abundance, it's often difficult to incorporate these life-history components into traditional stock assessments or SSRAs. In an attempt to construct more realistic recruitment patterns, annual northwest Atlantic temperature trends were included in the stock-recruitment relationship. Temperature has correlated to changes in mackerel landings and abundances over multiple centuries (Taylor et al. 1957, Skud 1982). While portions of the landings time series have positively correlated with temperature, other portions of time have negatively correlated with temperature, in part due to other factors, such as competition with other small pelagic fish (Skud 1982). Annual mean temperatures were derived from the NOAA Extended Reconstructed Sea Surface Temperature (ERSST) dataset (Huang et al. 2017). An annual temperature index from 1854-2016 covering the northwest Atlantic shelf and Gulf of St. Lawrence was calculated as annual mean temperatures divided by the time series mean (Supplement 1). The reciprocal of these temperature anomalies $(1 / \mathrm{T})$ were included in the stockrecruitment function as a multiplier:

$$
\mathrm{N}_{1, \mathrm{t}}=\frac{(\mathrm{K} / \phi) \mathrm{E}_{\mathrm{t}}}{1+\left[\frac{\mathrm{K}-1}{\left(\mathrm{R}_{0} / \phi\right)}\right] \mathrm{E}_{\mathrm{t}}} * \frac{1}{\mathrm{~T}}
$$


As such, warmer years resulted in reduced recruits per eggs, and colder years a greater recruit per egg rate. Years of landings data without temperature information (1804-1853) were assigned values of one, effectively resulting in a non-environmentally explicit stock-recruit function.

\section{RESULTS}

\section{Population and Harvest Trends}

Stochastic inputs of $\mathrm{R}_{0}$ (1804 recruitment size) and $\mathrm{K}$ (Goodyear coefficient) influenced whether the population would crash prior to 2016. Successful simulations used $\mathrm{K}$ values between 2.8 and 9.3, with a mean of 4.6 (Figure 2 ). When $\mathrm{R}_{0}$ was on the smaller end of the prior distribution range, the stock was not able to survive over the two centuries. Based on the simulation runs, a minimum number of 545 million recruits were required for the population to not crash by 2016 (Figure 2). Of successful simulation runs, 1804 recruitment was approximately $824.9 \pm 112$ million. Plausible $\mathrm{K}$ and $\mathrm{R}_{0}$ were weakly negatively correlated, but indicated that low $\mathrm{K}$ and $\mathrm{R}_{0}$ combinations were unsuccessful (Figure 2).

Estimated population sizes varied considerably over the time series. Of the successful runs, considerable reductions in the stock occurred through the mid to late 1800 s, and in the 1970s onward (Figure 3). Average population size by 1837 had been reduced to $58 \%$ of the 1804 stock size, with population sizes from the 1840 s through 1880s approximately 62-76\% of the unfished stock (Figure 3). However, from the 1880s through the mid-1960s, the stock rebounded to $95 \%$ of the original stock size. The foreign fleet harvests in the 1970s reduced abundance by $84 \%$ relative to the 1804 
population size. Average population estimates increased variably thereafter, with the 2016 population approximately $53 \%$ of the 1804 population size (Figure 3 ).

Population reductions through time did not necessarily correspond to age truncations. Reductions from the 1830s through the 1880s resulted in proportional changes in abundance across age classes (Figure 4). Stable, proportional age structures were also evident as the stock rebuilt from late $19^{\text {th }}$ century through the 1950 s. However, with the inclusion of removals-at-age from 1968 onwards, population estimates indicated age truncations (Figure 5). During the 1970s, with extensive foreign fleets harvesting northwest Atlantic mackerel, significant removals targeted 3 through 5-year-old fish, in some years fishing cohorts to extinction (Figure 5). Through these years of intense fishing, low recruitment was supported by the older age classes, with little or no contribution from intermediate age classes. Comparing abundances-at-age between 2016 and 1960 indicated disproportionate abundances-at-age reductions, thus an age truncation in the population. By 2016, 11 to 14-year-old abundances were between zero and $27.1 \%$ of their 1960 population, whereas recruitment abundance only decreased $67.0 \%$.

Estimated fully-recruited fishing mortality (F) through time corresponded to the major reductions in the population; however, mean F rates were greater in the 1800s than the second half of the $20^{\text {th }}$ century. From the 1830 s through the 1880 s, median F peaked at $0.44(0.32-0.8795 \% \mathrm{CI})$, whereas the median peak of $\mathrm{F}$ since 1960 was $0.19(0.07-0.8$ CI). Of successful simulation runs, estimated fishing mortality rates were greatest and more variable between 1970 and 2000 (Figure 6). The lower F rates in more contemporary times corresponded to the lower population levels (Figures 3, 4, 5), with an 
apparent phase shift in population with F during the late 1960s and early 1970s (Figure 7).

\section{Comparison to Available Indices}

Population trends were compared to external abundance trend information to understand which successful SSRA runs may be most probable. Catch per unit effort (CPUE, pounds per vessel) were available for the stock unit from 1879 to 1917 (Sette and Needler 1934), providing a metric to corroborate abundances from historical periods. Contemporary spawning stock biomass (SSB) estimates were compared to those calculated based on annual egg production derived from the northern and southern spawning contingents combined (Grégoire et al. 2013, Carter and Richardson 2017). Linear correlations between each SSRA abundance trend and the comparison indices (historical CPUE and egg production) were computed. SSRA scenarios with the strongest correlation $\left(\mathrm{R}^{2}\right)$ to each of the two comparison indices represented the best-fit SSRA trajectories.

Correlation with the best-fit SSRA population time series and historical CPUE was weak $\left(\mathrm{R}^{2}=0.13\right.$, $\mathrm{p}$-value=0.02). Correlation between the best fitting SSRA SSB and those estimated from annual egg production was much stronger $\left(\mathrm{R}^{2}=0.61, \mathrm{p}\right.$ value $<0.001$ ), yet magnitudes were different and indicated SSRA SSB may be underestimated (Figure 8). The two best-fitting population trends from correlations averaged together were comparable with all SSRA runs population trends prior to the 1960s (Figures 3 and 8). The SSRA trajectories that best compared to the external abundance indices indicated that 2016 population size was $11 \%$ of the 1804 stock (Figures 3 and 8). Fishing mortality from the average of corroborating SRRA runs 
indicated more comparable harvest pressures in the $1830 \mathrm{~s}$ and latter half of the $20^{\text {th }}$ century (Figure 8).

\section{Sensitivity Runs}

Increasing natural mortality resulted in lower abundances and increased fishing mortality estimated compared to the base run, and population size differences between low and high natural morality rate runs varied through time (Figure 9). Under elevated natural mortality, the average 1804 population size was $76 \%$ of the base-line, lowmortality scenario. Base scenario population sizes were most similar to those of the unreported landings scenario, with abundances comparable throughout the time series (Figure 9). Differences between these scenarios are likely proportional to the differences between the original and elevated landings time series, with the 1804 population estimates incorporating assumed unreported catch $3 \%$ greater than that of the base scenario. The temperature-induced and base scenario population trends were similar; in the temperature-induced scenario was at most $12 \%$ greater than the base scenario, but by 2016 the population was $69 \%$ of the base-scenario.

Higher natural mortality rates corresponded with higher fully-recruited fishing mortality rates compared to the base scenario. Medan fishing mortality rates were on average 2.1 times greater than in the base case scenario, and as great as seven times greater (Figure 10). Median fishing mortality estimates derived from the unreported scenario ranged from $0.15-2.6$ times those of the base scenario, with a mean of 1.39 (Figure 10). Median fishing mortality estimates from the temperature-induced over time were on average $22 \%$ greater than the base scenario (Figure 10). 


\section{DISCUSSION}

\section{SSRA Population Trends}

Corroboration between abundances estimated using SSRA and those from historical accounts and fishery-independent surveys varies through time. The decrease in landings from 1884 through 1920 under consistent fishing methods are speculated to be from a stock failure following periods of intensive fishing (Anderson and Paciorkowski 1980); the SSRA tracked population decreases in the early 1880s, but the stock rebuilt through the early 1900s (Figure 3). SSRA indications of the significant population decrease since the 1970s match with reported removals (Anderson and Paciorkowski 1980) and speculated relative stock size compared to years prior to foreign fleet removals (Deroba et al. 2010). Size truncations through the 2000s are evident in the SSRA, and corroborated by fisheries-independent data (Derboa et al. 2010, Weidenmann 2016); however, other reports note a stronger truncation than estimated here, which may be due to under-sampling older age classes as abundances decrease compared to the SSRA, which reflects all fish in the population.

Weak correlation between historical catch-per-unit-effort data and estimated abundances are not necessarily surprising, as variability in landings and effort may be driven by economic and societal influences and not be biologically related (Sette and Needler 1934). Spawning stock biomass estimated from egg production appears to be a favorable tool in excluding certain SSRA trajectories (Figure 8). Further, this abundance index is one of the few that represents abundance patterns across the entire stock's range (i.e. both northern and southern contingents). As future, peer-reviewed assessments become available, additional assessment time-series products (e.g. spawning stock 
biomass, recruitment, fishing mortality) and terminal years' data can be used to refine SSRA results and improve our understanding of the stock's history.

While population-crash scenarios are a useful metrics in excluding results, defining these as "true population crashes" may unrealistic. Given the static nature of the population over the model domain (northwest Atlantic) spatial differences in removals and biology are not included. For example, removals of mackerel have varied spatially between northern and southern contingents (Sette and Needler 1934, Anderson and Paciorkowski 1980) and may reflect population declines in one area but not the other, suggesting population distribution and size reduction to levels not detected by fisheries, as opposed to true crashes.

\section{Future SSRA Considerations}

Long-term perspectives on the northwest Atlantic mackerel stock forces one to take a fundamental outlook on the stock's life history and abundance changes through time. By using the SSRA through two centuries of landings information, multiple assumptions are required, particularly prior to 1968. For example, northeast Atlantic mackerel life history characteristics have varied through time, including growth rates and maturity schedules (Martins 2007, Olafsdottir et al. 2016). Prospective interannual variations in these life history attributes prior to 1968 are not accounted for. Further, the maximum age allowed in SSRAs can influence total egg production and future recruitment. Atlantic mackerel have been reported to reach 20 years old (Studholme et al. 1999), but seldom, and aging of fish ten years or older is difficult and has greater uncertainty (Collete and Klein-MacPhee 2002). Incorporating catch-at-age for the SSRA allowed for more accurate population dynamics. Implementation of other catch-at-age 
information from earlier time periods would benefit the modeling; however, changes in life-history through time may introduce new inaccuracies. For example, catch-at-length information for the northern and southern contingents are available from 1926-1935 (Sette 1950); however, converting these data to catch-at-age would require assuming growth rates between then and more contemporary periods (1968-on) are the same, which may not be true.

The influence of assumptions regarding natural mortality on abundances (Figure 9) and fishing mortality (Figure 10) estimates are presented. Interannual variability in natural mortality-at-age due to prey availability, thermal tolerances, predator abundances and other external pressures are not traditionally accounted for in both data-limited and sophisticated stock assessments, but should be. Higher natural mortality rates estimated for the stock than used here (Grégoire and McQuinn 2014) may warrant more time variant mortality rates to improve future modeling efforts. Methods estimating natural mortality as a function of growth rate, temperature, or population size also warrant further exploration (Gislason et al. 2010, Pope 2014) . Further, as a long-lived species, incorporating senescence for the stock should be considered through altered natural mortality rates.

Assumed vulnerabilities of the species to the fishery ultimately influence estimated fishing mortalities (Walters et al. 2006). Selectivity schedules could be improved by accounting for multiple gear types in each year, as well as incorporating other technological advances that may not be reflected in landings data (e.g. chumming waters in the hook-and-line fishery, increased efficiencies when switching from sail to power boat in the early 1900s). Additional information on various fishing gears used to 
catch mackerel through time are available for constructing more realistic vulnerabilitiesat-age for the fishery (Sette and Needler 1934, McKenzie 2010a). However, incorporating additional gears' selectivity's without a more rigorous statistical model to estimate them relies on additional literature describing the selectivity-at-age for mackerel. Changes in mackerel selectivity unrelated to gear, including species and/or fishery distributional shifts, are more challenging to incorporate. Climate has been shown to influence mackerel distribution across ages and life stages (Overholtz et al. 2011, Radlinksi et al. 2013, Walsh et al. 2015) and their habitat (McManus et al. 2017). Thus, it's reasonable to assume that mackerel availability has changed irrespective of the gear types used.

\section{The Recruitment Dilemma}

The largest drawback to using SSRA is that model performance depends on the accuracy of assumptions made (Wetzel and Punt 2011, Thorson and Cope 2015). Bayesian theory can be used to define prior distributions for selecting stock-recruitment parameters, $\mathrm{R}_{0}$ and $\mathrm{K}$, by setting bounds based on prior knowledge, yet successful $\mathrm{K}$ and $\mathrm{R}_{0}$ combinations are still largely driven by the range of the priors. While larger alternative combinations could be plausible, it can be concluded that the ranges of $\mathrm{K}$ and $\mathrm{R}_{0}$ presented for northwest Atlantic mackerel are conceivable scenarios. A Bayesian approach may advance these modeling efforts by iteratively solving towards $\mathrm{K}-\mathrm{R}_{0}$ combinations that provide the most realistic scenarios in relation to other abundance indices. This method would require multiple fisheries-independent abundance indices that are believed to be accurate to allow for excluding scenarios that do not cause population 
crashes or unrealistic trends. Unfortunately for northwest Atlantic mackerel, such sound indices are largely unavailable (Deroba et al. 2010).

Allowing for more realistically variable, non-autocorrelated recruitment is an important consideration for SSRA (Walters et al. 2006), particularly for small schooling pelagic fish that may have highly variable, episodic recruitment events. Previous efforts have incorporated an additional variability component on annual recruitment by applying a randomly selected deviation each year (Walters et al. 2006). An alternative to construct more annually variable recruitment dynamics is presented here, by incorporating environmental influence on stock-recruitment dynamics. Incorporating environmental components into stock-recruitment dynamics has long been challenging, given multiple factors influencing fish recruitment, and the degree of which each factor contributes to recruitment size can widely vary year-to-year (Jacobson and MacCall 1994, Hare et al. 2015). In the case of northwest Atlantic mackerel, prey densities (i.e. copepods such as Calanus finmarchicus) have been the most documented driver for mackerel recruitment on both sides of the North Atlantic (Ringuette et al. 2002, Castonguay et al. 2008, Jansen 2016). Oceanographic and environmental conditions, including temperature, salinity, and freshwater discharge, are believed to also influence mackerel recruitment and copepod production (Runge et al. 1999, Ploudre et al. 2015). Decadal temperature changes have corresponded to fluctuations in zooplankton community composition (Morse et al. 2016), and warmer ocean temperatures are negatively correlated to $C$. finmarchicus densities, with future projections suggesting reduced copepod abundance (Grieve et al. 2017). Temperature has also independently been documented to influence mortality and distribution of mackerel over multiple life stages (Ware and Lambert 1985, Overholtz et 
al. 2011). Sette (1943) noted the influence of wind patterns in larval dispersal, with implications for local recruitment for the northwest Atlantic stock. Assuming a negative relationship between temperature and mackerel recruitment seems suitable given previous relations between landings and temperature, influence of temperature on mackerel larval mortality, and the negative influence of warmer waters on prey $C$. finmarchicus. Absence of more variable recruitment is likely contributing to lower recruitment levels estimated in the SSRA than those reported during "strong recruitment" years (e.g. 1923, early 1980s, 1999) (Figures 4, 5). Given that data for environmental drivers in recruitment over two centuries are unavailable, adequately incorporating critical environmental drivers in stock-recruitment patterns for Atlantic mackerel in this SSRA may remain a challenge. However, future information better describing the functional relationship between recruitment and temperature could be implemented in the SSRA.

\section{CONCLUSIONS}

SSRAs are unique from other data-limited approaches in that they provide the uncommon metric of relative population sizes through time to the natural, unfished stock size (Walters et al. 2006). While challenging for a species that has undergone overfishing, climate-induced changes, and population depensation, the SSRA has overall proven to be a functional tool to serve as a complimentary model during future stock assessments. As demonstrated here, the addition of more detailed information from both primary research and historical accounts can advance data limited approaches (Cope 2013, Martell and Froese 2013, Thorson and Cope 2015), particularly over other reduction analyses, such as depletion-based stock reduction analysis (DB-SRA, Dick and MacCall 2011). Caution 
must be used when evaluating $\mathrm{K}$ and $\mathrm{R}_{0}$ values in the context of contemporary systems, as changes in ecosystem may not allow for rebuilding to historical levels, with historically based targets may not be realistic goals. Yet, this SSRA provides population estimates describing the northwest Atlantic mackerel population's progression, and should be considered for incorporation in future assessments as part of a larger modeling ensemble approach.

\section{ACKNOWLEDGEMENTS}

This work could not have been performed without the efforts and data collection of countless scientists from both historical (George Browne Goode, Oscar Sette, A. W. H. Needler) and more contemporary (NEFSC staff) periods. The authors thank Adrien Tableau for assisting in aggregating ERSST data. The manuscript was improved by

comments from Jon Hare. MCM was funded by The Nature Conservancy Global Marine Initiative Student Research Award Program. Views expressed in this publication are those of the authors and do not necessarily reflect those of their agencies.

\section{LITERATURE CITED}

Anderson, E.D. 1982. Status of the northwest Atlantic mackerel stock - 1981. U.S. Natl. Mar. Fish. Serv. Northeast Fish. Cent. Woods Hole Lab Ref. Doc. 81-38: 38p.

Anderson, E.D., and Paciorkowski, A.J. 1980. A review of the Northwest Atlantic mackerel fishery. Rapports et Proce`s-Verbaux des Re' unions du Conseil International pour l'Exploration de la Mer, 177: 175-211.

Berrien, P. 1982. Atlantic mackerel, Scomber scombrus. In M.D. Grosslein and T.R. Azarovitz eds. Fish distribution. p. 99-102. MESA New York Bight Atlas Monograph 15. N.Y. Sea Grant Institute, Albany, NY.

Berrien, P. 1988. Atlantic mackerel, Scomber scombrus, total annual egg production and spawner biomass estimates for the Gulf of St. Lawrence and northeastern United States waters, 1987. National Marine Fisheries Service, Northeast Fisheries Science Center, Sandy Hook Lab. Rep. No. 88-02. 17 pp. 
Beverton, R.J.H., and Holt, S.J. 1957. On the dynamics of exploited fish populations. Fish. Invest. Lond. Series 2.

Carter, L., and D. Richardson. 2017. Development of an egg index for Atlantic mackerel (Scomber scombrus) on the northeast U.S. continental shelf. SARC 64 Atlantic Mackerel Data Meeting Working Paper. 13 pp.

Castonguay, M., Plourde, S., Robert, D., Runge, J.A., and Fortier, L. 2008. Copepod production drives recruitment in a marine fish. Canadian Journal of Fisheries and Aquatic Sciences 65: 1528-1531.

Collette, B.B., and Klein-MacPhee, G. 2002. Bigelow and Schroeder's Fishes of the Gulf of Maine, $3^{\text {rd }}$ Edition. Caldwell, N.J.: Blackburn Press, 577 p.

Cope, J.M. 2013. Implementing a statistical catch-at-age model (stock synthesis) as a tool for deriving overfishing limits in data-limited situations. Fisheries Research 142: 3-14.

Deroba, J., Shepherd, G., Gregoire, F., Nieland, J., and Rago, P. (2010) Stock assessment of Atlantic mackerel in the Northwest Atlantic for 2010. Transboundary Resources Assessment Committee, Reference Document 2010/01. 59 pp.

DFO. 2014. Assessment of the Atlantic Mackerel stock in the Northwest Atlantic (Subareas 3 and 4). DFO Can. Sci. Advis. Sec. Sci. Advis. Rep. 2014/030.

Gislason, H., Daan, N., Rice, J.C., and Pope, J.G. 2010. Size, growth, temperature, and the natural mortality of marine fish. Fish and Fisheries 11(2): 149-158.

Goode, G.B., Collins, J.W., Earll, R.E., and Clark, A. H. (1883) Materials for a history of the mackerel fishery. In App. B, The Fisheries, pp. 92-531, Report, U.S. Commissioner of Fisheries, 1881 (1884). Washington.

Grégoire, F., Gendron, M.-F., Beaulieu, J.-L. and Lévesque, I. 2013. Results of the Atlantic mackerel (Scomber scombrus L.) egg surveys conducted in the southern Gulf of St. Lawrence from 2008 to 2011. DFO Can. Sci. Advis. Sec. Res. Doc. 2013/035. v + 57 p.

Grégoire, F. et McQuinn, I. 2014. Estimation empirique du taux instantané de mortalité naturelle (M) du maquereau bleu (Scomber scombrus L.) des sous-régions 3 et 4 de 1'OPANO. Secr. can. de consult. sci. du MPO. Doc. de rech. 2014/078. v + $25 \mathrm{p}$.

Grieve, B.D., Hare, J.A., and Saba, V.S. 2017. Projecting the effects of climate change on Calanus finmarchicus distribution within the U.S. Northeast Continental Shelf. Scientific Reports 7(6262): 1-12. 
Hare, J.A., Brooks, E.N., Palmer, M.C., and Churchill, J.H. 2015. Re-evaluating the effect of wind on recruitment in Gulf of Maine Atlantic cod (Gadus morhua) using an environmentally-explicit stock recruitment model. Fisheries Oceanography 24(1): 90-105.

Heighton, R., and Grégoire, F. 2006. A hook selectivity study for Atlantic mackerel (Scomber scombrus L.) caught in St. Geogres Bay, Nova Scotia, in October 2005. Can. Ind. Rep. Fish. Aqaut. Sci. 278: vii + 50 p.

Hoy, D.L., and Clark, G.M. 1967. Atlantic mackerel fishery, 1804-1965. US Department of Interior Bureau of Commercial Fisheries, Fishery Leaflet 603. 9pp.

Huang, B., Thorne, P.W., Banzon, V.F., Boyer, T., Chepurin, G., Lawrimore, J.H., Menne, M.J., Smith, T.M., Vose, R.S., Zhang, H.-M. 2017. NOAA Extended Reconstructed Sea Surface Temperature (ERSST), Version 5. NOAA National Centers for Environmental Information. doi:10.7289/V5T72FNM [15 April 2017].

Jacobson, L.D., and MacCall, A.D. 1994. Stock-recruitment models for Pacific sardine (Sardinops sagax). Canadian Journal of Fisheries and Aquatic Sciences 52: 566577.

Jansen, T. 2016. First-year survival of North East Atlantic mackerel (Scomber scombrus) from 1998 to 2012 appears to be riven by availability of Calanus, a preferred copepod prey. Fisheries Oceanography 25(4): 457-469.

Kimura, D.K., Balsiger, J.W., and Ito, D.H. (1984) Generalized stock reduction analysis. Canadian Journal of Fisheries and Aquatic Sciences 41:1325-133.

Kimura, D.K., and Tagart, J.V. 1982. Stock reduction analysis, another solution to the catch equations. Canadian Journal of Fisheries and Aquatic Sciences 39: 14671472 .

Llopiz, J. K., Cowen, R. K., Hauff, M. J., Ji, R., Munday, P. L., Muhling, B.A., Peck, M.A., Richardson, D.E., Sogard, S., and Sponaugle, S. 2014. Early life history and fisheries oceanography: new questions in a changing world. Oceanography 27(4): 26-41.

Lorenzen, K. 1996. The relationship between body weight and natural mortality in juvenile and adult fish: a comparison of natural ecosystems and aquaculture. Journal of Fish Biology 49: 627-647.

Martell, S., and Froese, R. 2013. A simple method for estimating MSY from catch and resilience. Fisheries Research 14: 504-514. 
Martins, M. M. 2007. Growth variability in Atlantic mackerel (Scomber scombrus) and Spanish mackerel (Scomber japonicus) off Portugal. - ICES Journal of Marine Science, 64: 1785-1790.

McKenzie, M.G. 2010a. Chapter 3: Workspace. In: Cleaning the Coastline: The Nineteenth-Century Ecological and Cultural Transformation of Cape Cod. University Press of New England. Leabanon, NH. 35pp.

McKenzie, M.G. 2010b Chapter 4: Prosperity. In: Cleaning the Coastline: The Nineteenth-Century Ecological and Cultural Transformation of Cape Cod. University Press of New England. Leabanon, NH. 35pp.

McManus, M.C., Hare, J.A., Richardson, D.E. and Collie, J.S. 2017. Tracking shifts in Atlantic mackerel (Scomber scombrus) larval habitat suitability on the Northeast U.S. Continental Shelf. Fisheries Oceanography, 00:1-14. doi: 10.1111/fog.1233.

Morse, W.W. 1980. Spawning and fecundity of Atlantic mackerel, Scomber scombrus, in the Middle Atlantic Bight. Fishery Bulletin 78(1): 103-108.

Morse, R.E., Friedland, K.D., Tommasi, D., Stock, C., and Nye, J. 2017. Distinct zooplankton regime shift patterns across ecoregions of the U.S. Northeast continental shelf Large Marine Ecosystem 165:77-91.

Moustahfid, H., Link, J. S., Overholtz, W. J., and Tyrrell, M. C. 2009. The advantage of explicitly incorporating predation mortality into age structured stock assessment models: an application for Atlantic mackerel. ICES Journal of Marine Science, 66: 445-454.

Myers, R.A., Bowen, K.G., and Barrowman, N.J. 1999. Maximum reproductive rate of fish at low population sizes. Canadian Journal of Fisheries and Aquatic Sciences 56: 2404-2419.

Olafsdottir, A. H., Slotte, A., Jacobsen, J. A., Oskarsson, G. J., Utne, K. R., and Nøttestad, L. 2016. Changes in weight-at-length and size-at-age of mature Northeast Atlantic mackerel (Scomber scombrus) from 1984 to 2013: effects of mackerel stock size and herring (Clupea harengus) stock size. ICES Journal of Marine Science, 73(4): 1255-1265.

Overholtz, W. J., Hare, J. A., and Keith, C. M. 2011. Impacts of interannual environmental forcing and climate change on the distribution of Atlantic mackerel on the US Northeast continental shelf. Marine and Coastal Fisheries: Dynamics, Management, and Ecosystem Science, 3: 219-232.

Pope, J.E. 2014. Age-specific natural mortality rates in stock assessments: size-based vs. density-dependent. ICES Journal of Marine Science 71(7): 1629-1637.

Radlinski, M. K., Sundermeyer, M. A., Bisagni, J. J., and Cadrin, S. X. (2013) Spatial 
and temporal distribution of Atlantic mackerel (Scomber scombrus) along the northeast coast of the United States, 1985-1999. ICES Journal of Marine Science, 70: 1151-1161.

Ringuette, M., Castonguay, M., Runge, J.A., and Grégoire, F. 2002. Atlantic mackerel (Scomber scombrus) recruitment fluctuations in relation to copepod production and juvenile growth. Canadian Journal of Fisheries and Aquatic Sciences 59: 646656.

Rose, G.A. 2004. Reconciling overfishing and climate change with stock dynamics of Atlantic cod (Gadus morhua) over 500 years. Canadian Journal or Fisheries and Aquatic Sciences 61: 1553-1557.

Rosenberg, A.A., Bolster, W.J., Alexander, K.E., Leavenworth, W.B., Cooper, A.B., and McKenzie, M.G. 2005. The history of ocean resources: modeling cod biomass using historical records. Frontiers in Ecology and the Environment 3(2): 78-84.

Runge, J.A., Castonguay, M., de Lafontaine, Y., Ringuette, M., and Beaulieu, J.-L. 1999. Covariation in climate, zooplankton biomass and mackerel recruitment in the southern Gulf of St. Lawrence. Fisheries Oceanography 8: 139-149.

Sette, O.E. 1943. Biology of the Atlantic mackerel (Scomber scombrus) of North America. Part I. Early Life history, including growth, drift, and mortality of egg and larval populations. U.S. Fish and Wildlife Service Fishery Bulletin 50: 149237.

Sette, O.E. 1950. Biology of the Atlantic mackerel (Scomber scombrus) of North America. Part II. Migrations and habitat. U.S. Fish and Wildlife Service Fishery Bulletin 51: 251-358.

Sette, O. E., and Needler, A. W. H. 1934. Statistics of the mackerel fishery off the coast of North America. Invest. Rep., US Dept. Commer., 19, 48 p.

Slotte, A., Skagen, D., and Iversen, S. A. 2007. Size of mackerel in research vessel trawls and commercial purse-seine catches: implications for acoustic estimation of biomass. ICES Journal of Marine Science, 64: 989-994.

Studholme, A.L., Packer, D.B., Berrien, P.L., Johnson, D.L., Zetlin, C.A., and Morse, W.W. 1999. Essential Fish Habitat Source Document: Atlantic Mackerel, Scomber scombrus, Life History and Habitat Characteristics. NOAA technical Memorandum NMFS-NE-141. 44 pp.

Tsou, T.-S., and Collie, J.S. 2001. Estimating predation mortality in the Georges Bank fish community. Canadian Journal of Fisheries and Aquatic Sciences 58: 908-922. 
Thorson, J.T., and Cope, J.M. 2015. Catch curve stock-reduction analysis: An alternative solution to the catch equations. Fisheries Research 171: 33-41.

Tyrrell, M. C., Link, J. S., Moustahfid, H., and Overholtz, W. J. 2008. Evaluating the effect of predation mortality on forage species population dynamics in the Northeast US continental shelf ecosystem using multispecies virtual population analysis. ICES Journal of Marine Science, 65: 1689-1700.

Van Beveren, E., Castonguay, M., Doniol-Valcroze, T., and Duplisea, D. 2017a. Results of an informal survey of Canadian Atlantic mackerel commercial, recreational and bait fishers. DFO Can. Sci. Advis. Sec. Res. Doc. 2017/029. v + 26 p.

Van Beveren, E., Duplisea, D., Castonguay, M., Doniol-Valcroze, T., Ploudre, S., and Cadigan, N. 2017b. How catch underreporting can bias stock assessment and advice for northwest Atlantic mackerel and a possible resolution using censored catch. Fisheries Research, 194: 146-154.

Walters, C.J., and Martell, S.J.D. 2004. Fisheries ecology and management. Princeton University Press, Princeton, N.J.

Walters, C.J., Martell, S.J.D., and Korman, J. 2006. A stochastic approach to stock reduction analysis. Can J Fish Aquat. Sci 63:212-223.

Walsh, H. J., Richardson, D. E., Marancik, K. E., and Hare, J. A. 2015. Long-term changes in the distributions of larval and adult fish in the northeast U.S. shelf ecosystem. PLoS ONE, 10: e0137382.

Wetzel, C.R., and Punt, A.E. 2011. Model performance for the determination of appropriate harvest levels in the case of data-poor stocks. Fisheries Research, 110: 324-355.

Wiedenmann, J. 2016. Application of a data-poor harvest control rules to Atlantic mackerel. Southeast Data, Assessment, and Review, Report \#SEDAR46-RD-09. 53 pp. 


\section{FIGURES}
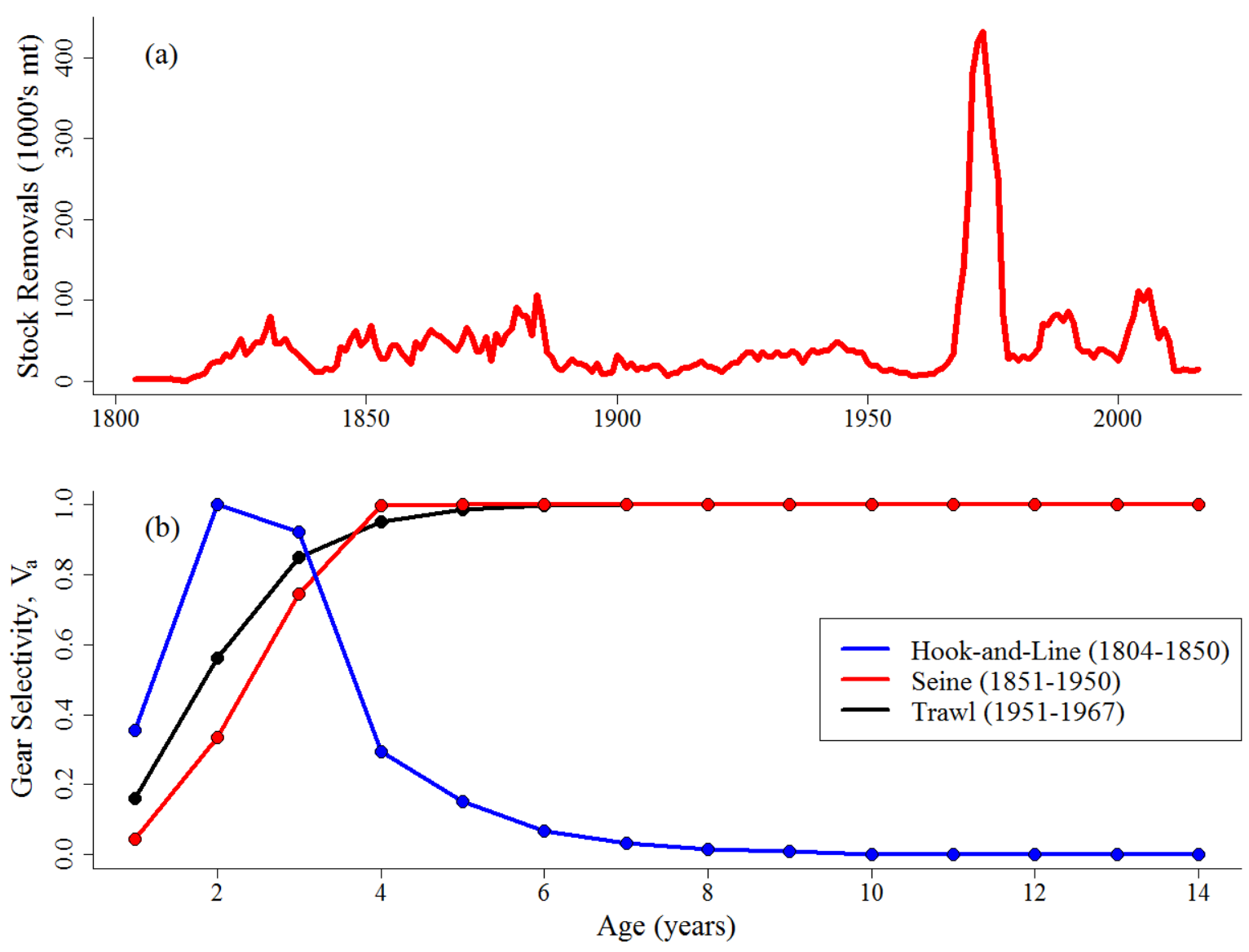

Figure 1. (a) Total removals (commercial and recreational landings, and discards) and (b) selectivity at ages used for the stock reduction analysis 

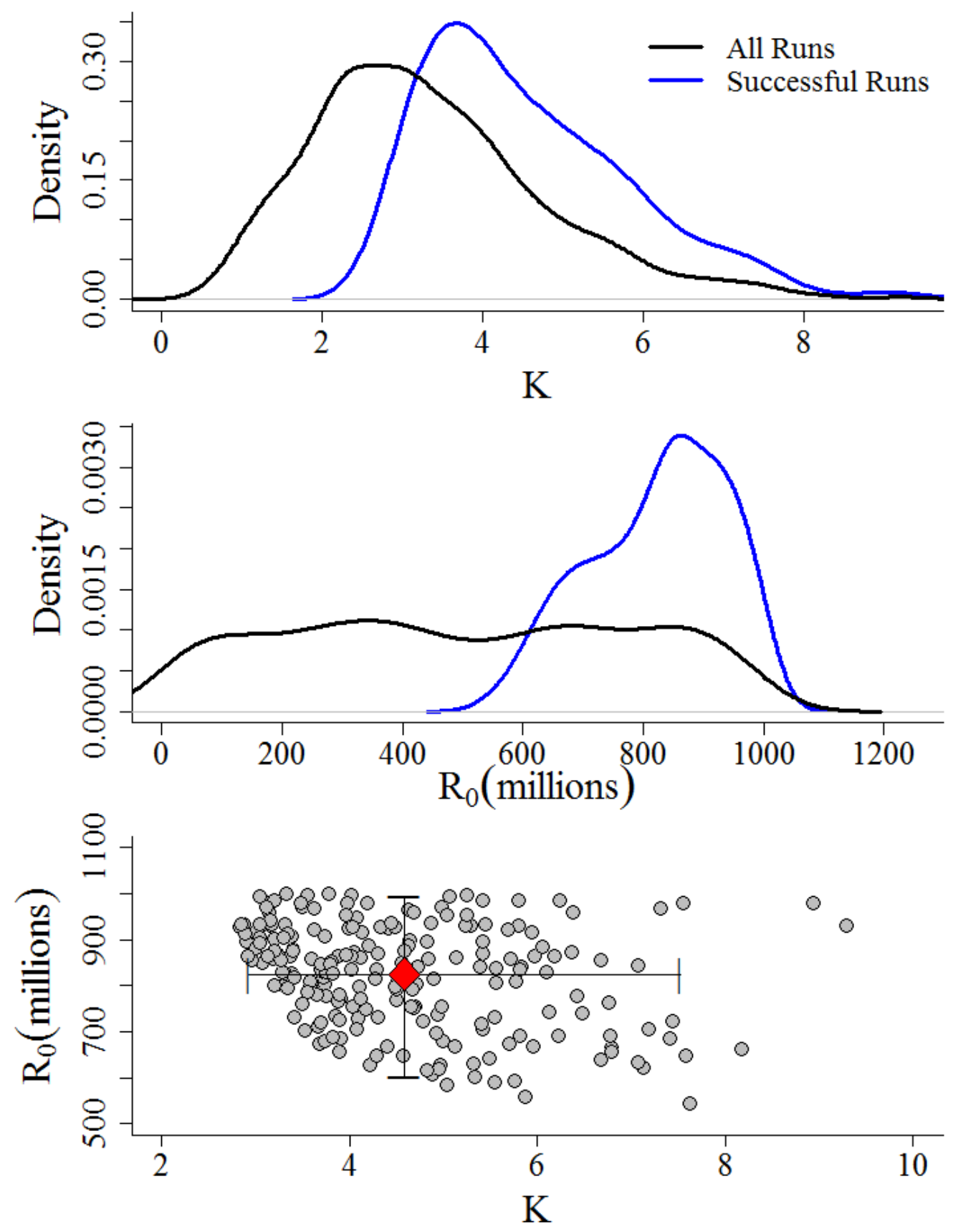

Figure 2. Density plots of Goodyear $(\mathrm{K})$ and 1804 recruitment population size $\left(\mathrm{R}_{0}\right)$ drawn from prior distributions for all SSRA runs (black) and those that did not result in population crashes (blue). $\mathrm{K}$ and $\mathrm{R}_{0}$ of successful runs were weakly, negatively correlated $\left(\mathrm{R}^{2}=0.08\right.$, $\mathrm{p}$-value $\left.<0.001\right)$. Mean $\mathrm{K}$ and $\mathrm{R}_{0}$ values (red diamond) and $95 \%$ ile ranges (black bars) are presented. 

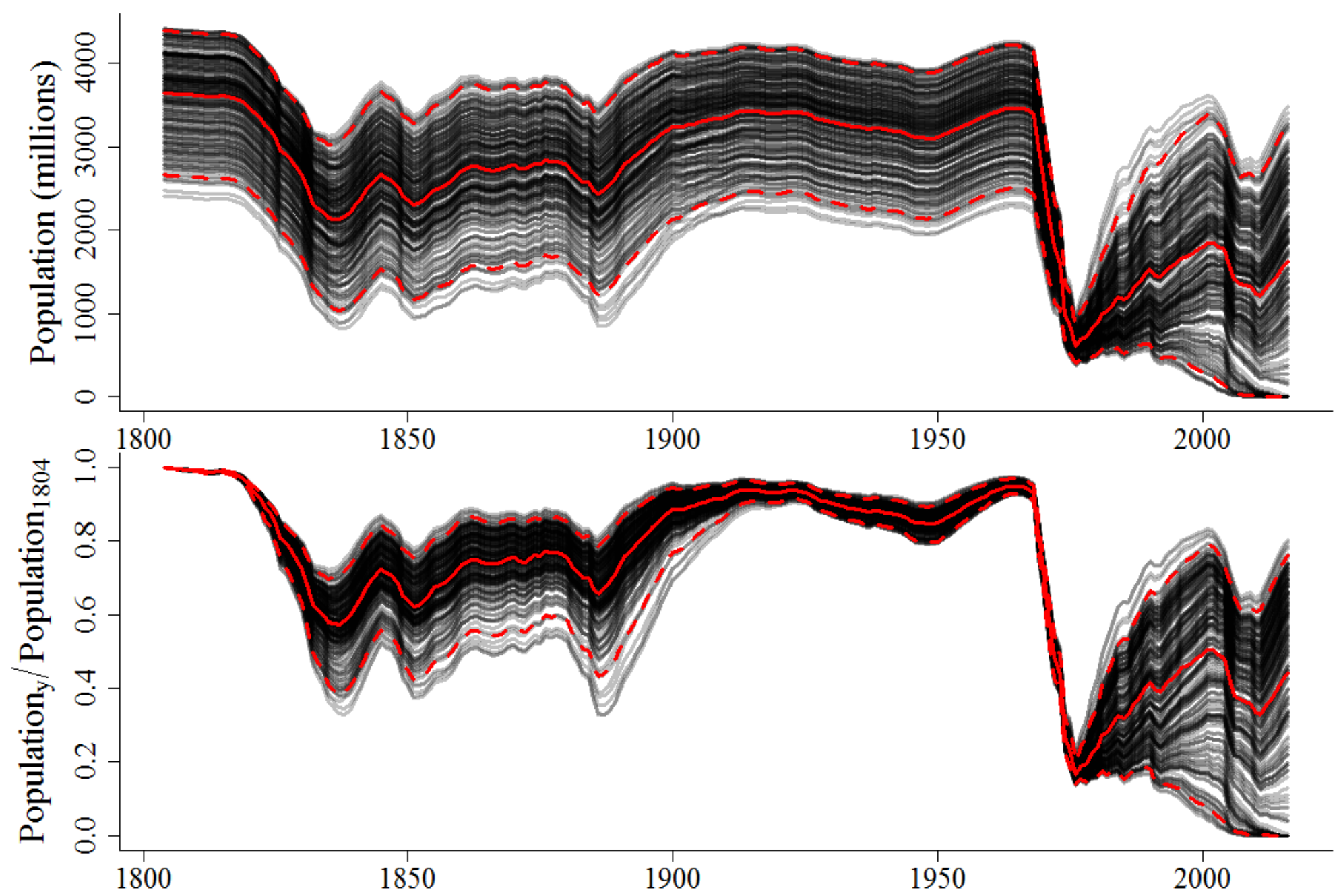

Figure 3. Population trajectories for successful simulation runs. Darker regions represent more probabilistic trajectories based on simulations. Total population numbers (top) and population expressed as proportion of the 1804 population size (bottom) are presented, with median (red, solid) and 95 percentile range (red, dashed) of the simulations indicated. 


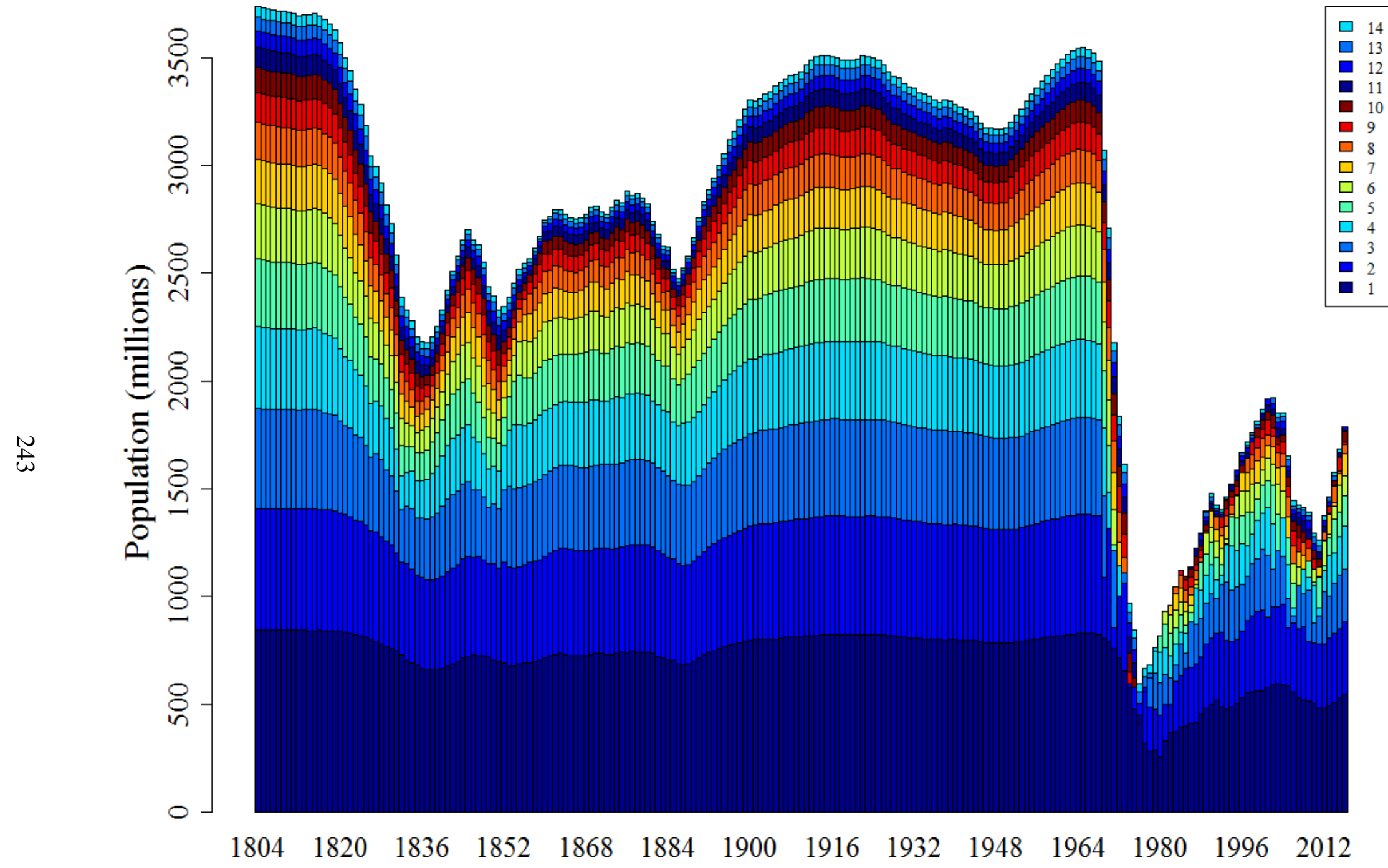

Figure 4. Median population sizes by age class since the inception of the northwest Atlantic mackerel fishery (1804). 


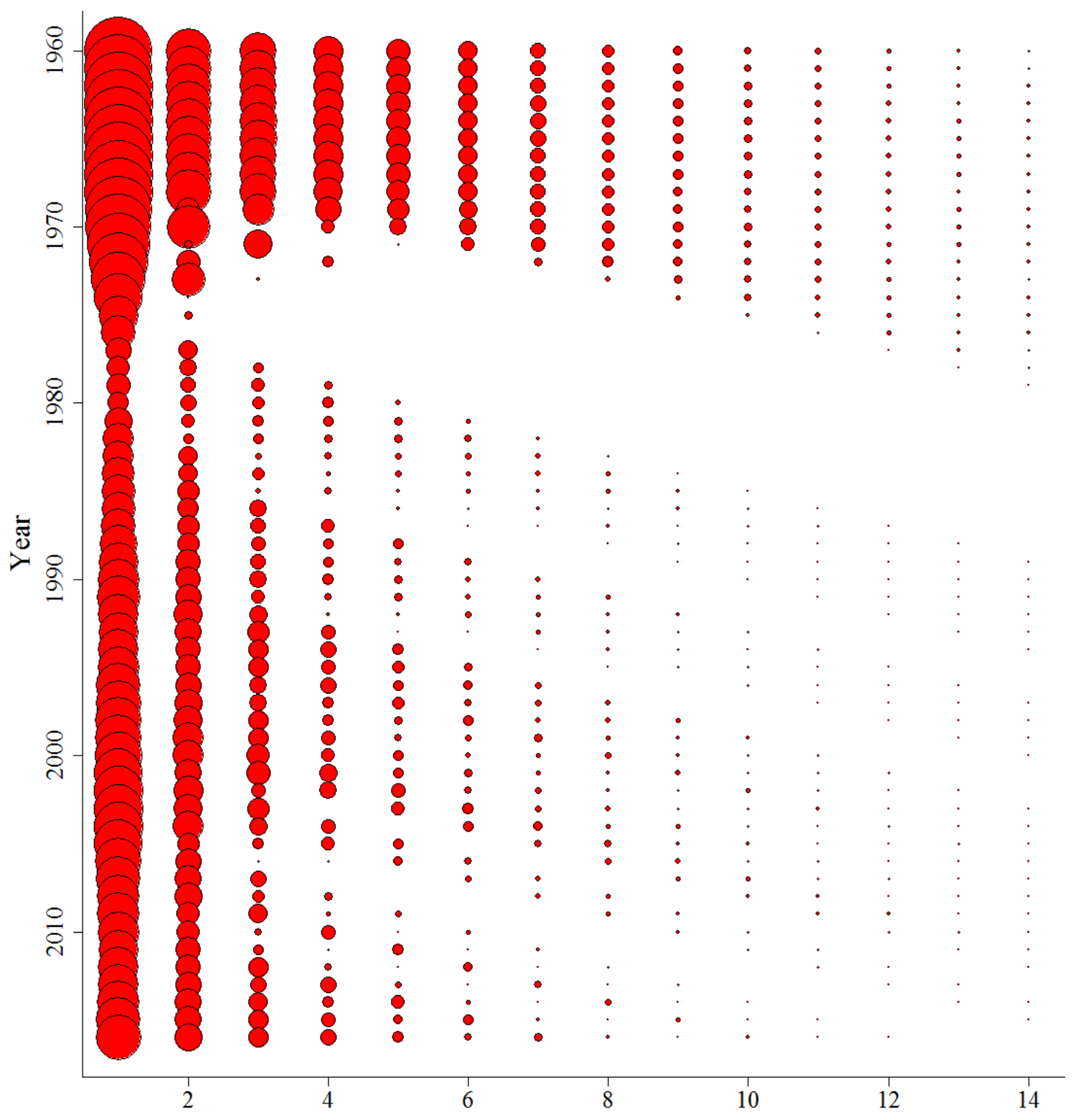

Figure 5. Median relative population sizes by age class for more contemporary periods covered in recent stock assessments (1960 onwards). Point sizes are proportional to population sizes represented in Figure 4. 


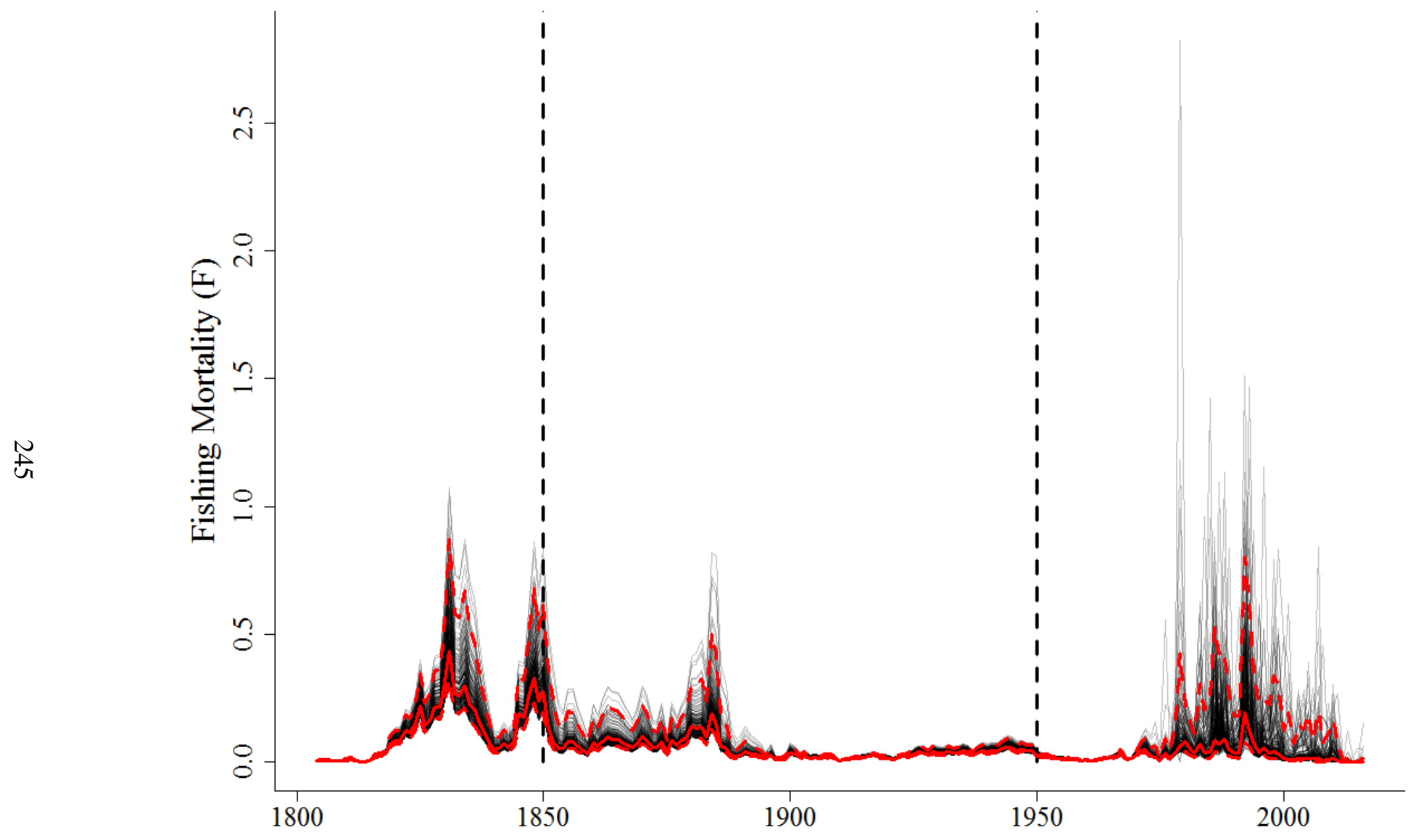

Figure 6. Fully recruited fishing mortality rates for successful simulation runs. Darker regions represent more probabilistic trajectories based on simulations. Median F values (red, solid) and the 95-percentile range (red, dashed) of the simulations are indicated. Horizontal dashed lines demarcate the selectivity periods: hook and line (1804-1850), seine (1851-1950), and trawl (1951-2016). 


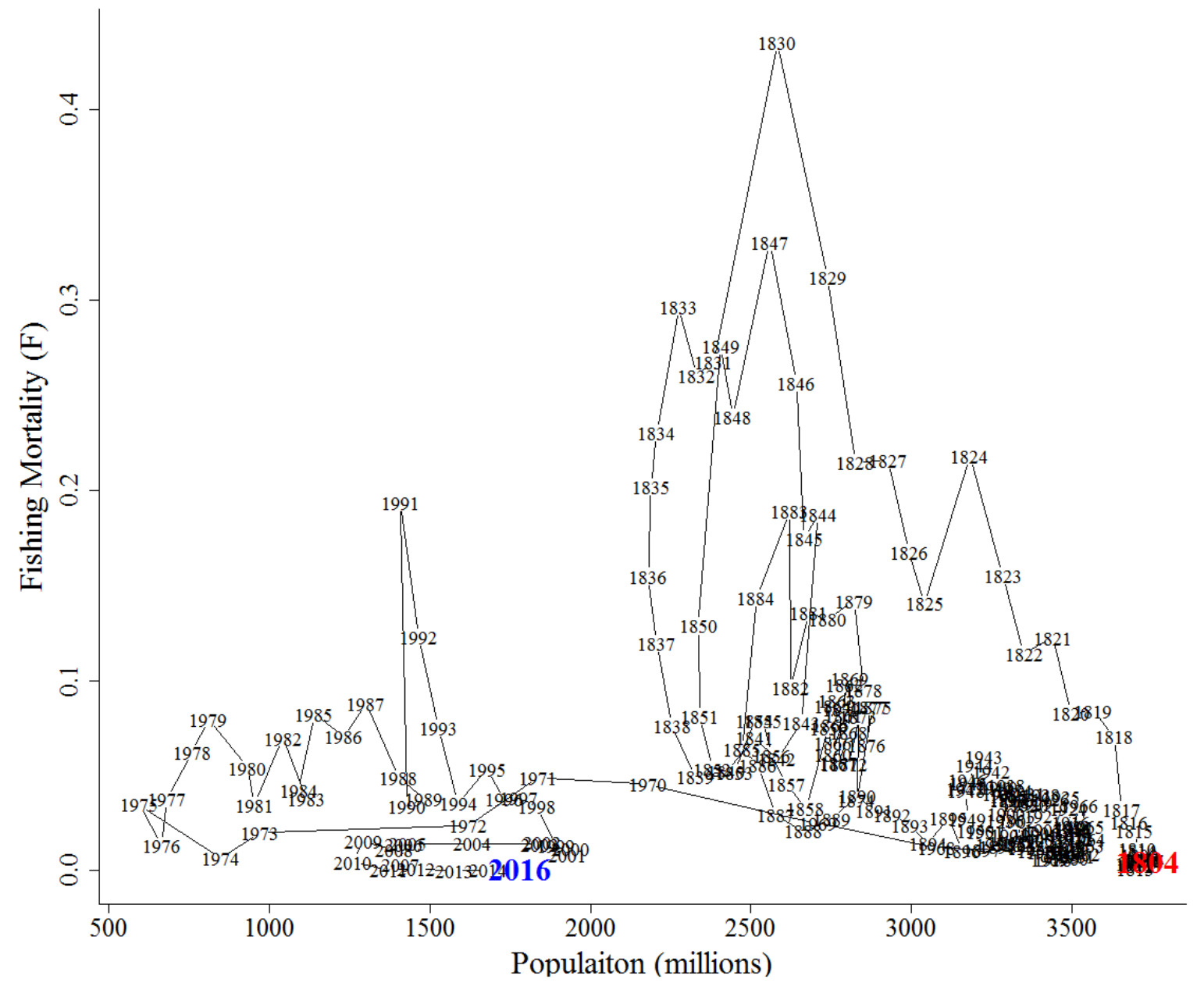

Figure 7. Phase plot of annual median population sizes by fishing mortalities. Initial (1804) and terminal (2016) years are represented in red and blue, respectively. 

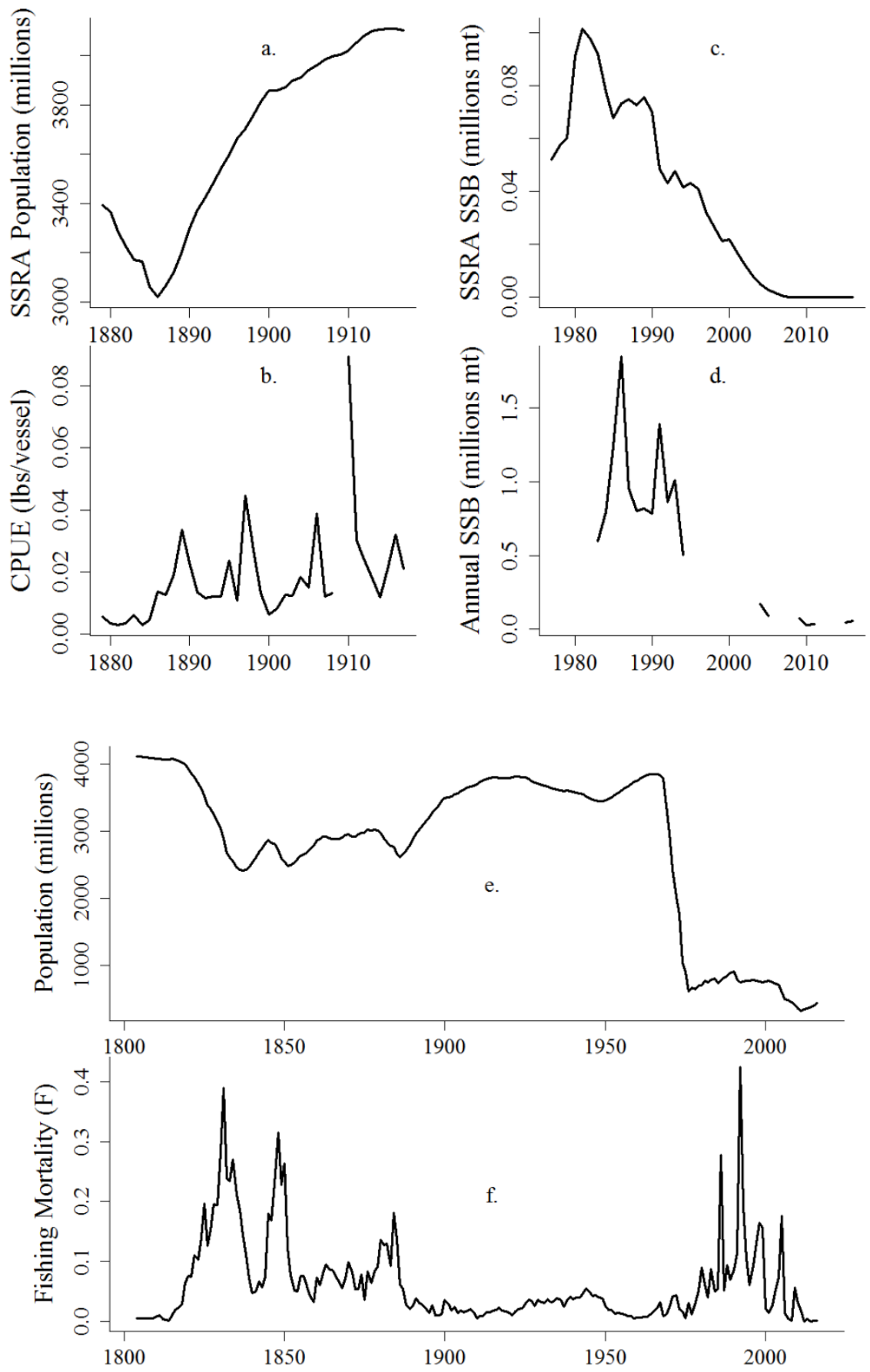

Figure 8. Comparison of SSRA runs that best corresponded to available indices data: (a) SSRA population size, (b) historical catch per unit effort reported by Sette and Needler (1934), (c) SSRA spawning tock biomass, and (d) northwest Atlantic spawning stock biomass estimated from annual egg production (Carter and Richardson, 2017). The average population (e) and fishing mortality estimates (f) from the two best-fit runs are presented. 


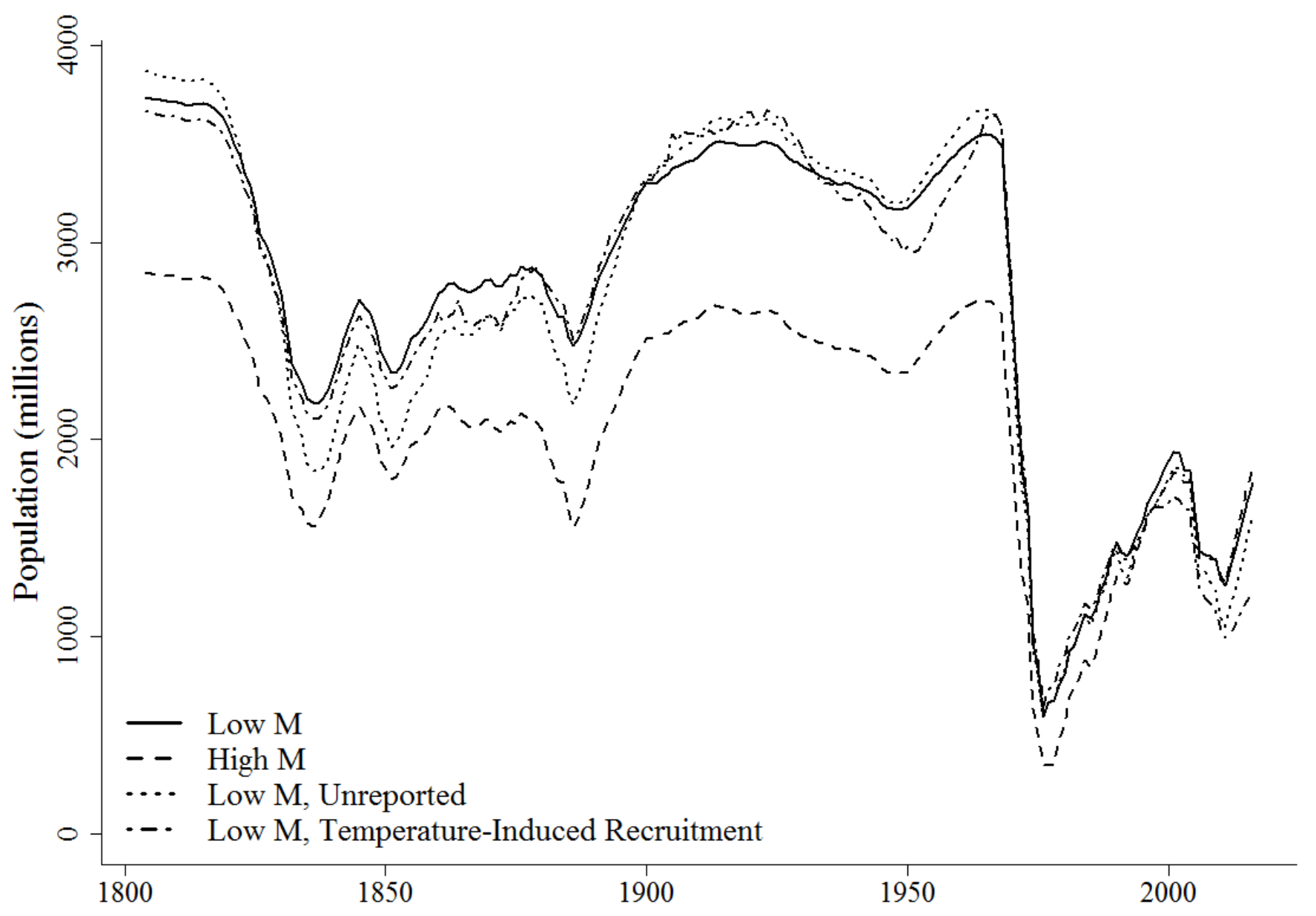

Figure 9. Median population trends for successful trajectories of the four different scenarios: base-case using lower natural mortality (solid line), elevated natural mortality (dashed line), incorporating unreported catch (dotted line), and time-varying recruitment from temperature (dash and dotted line). 


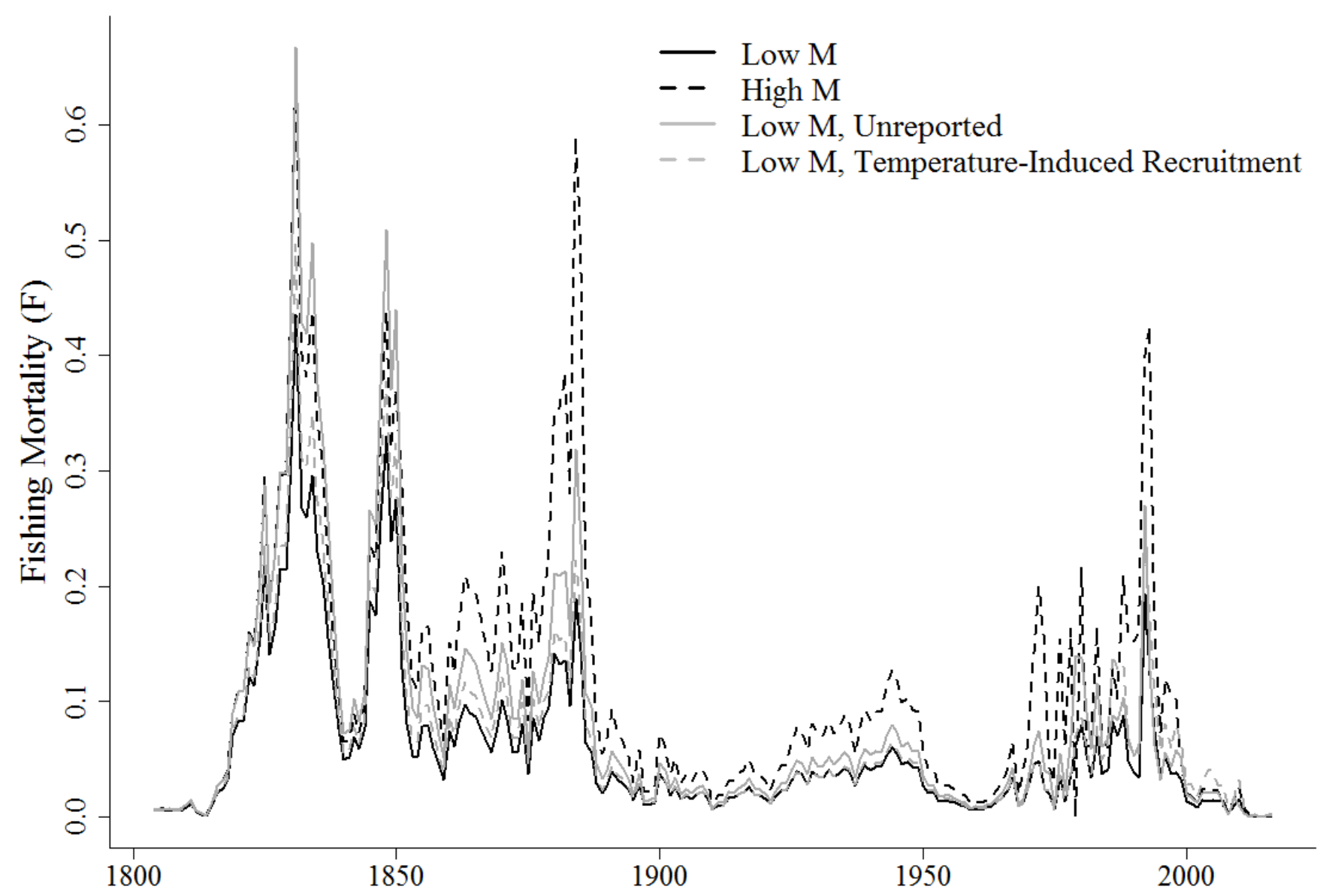

Figure 10. Median fully-recruited fishing mortality trajectories for successful runs from the four different scenarios: base-case using lower natural mortality (solid line), elevated natural mortality (dashed line), incorporating unreported catch (gray sold line), and timevarying recruitment from temperature (gray dashed line). 


\section{SUPPLEMENTS}

Supplement 1. Spatial extent and time series for the sea surface temperature (SST) derived from the ERSST database used in the SSRA.

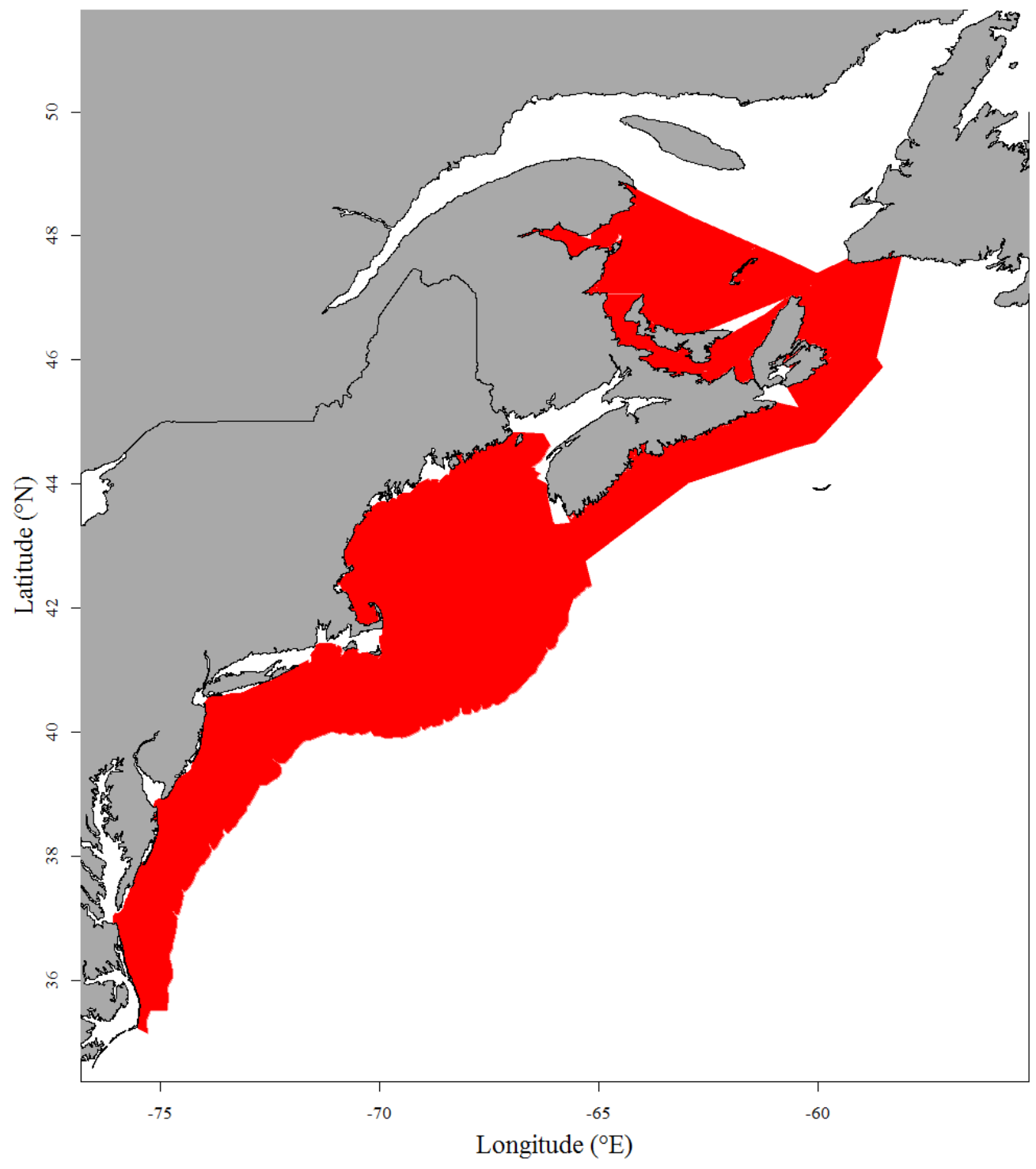

Figure S1A. Spatial domain (red) used to extract SST data and represent the temperature conditions that northwest Atlantic have been exposed to since 1804 . 


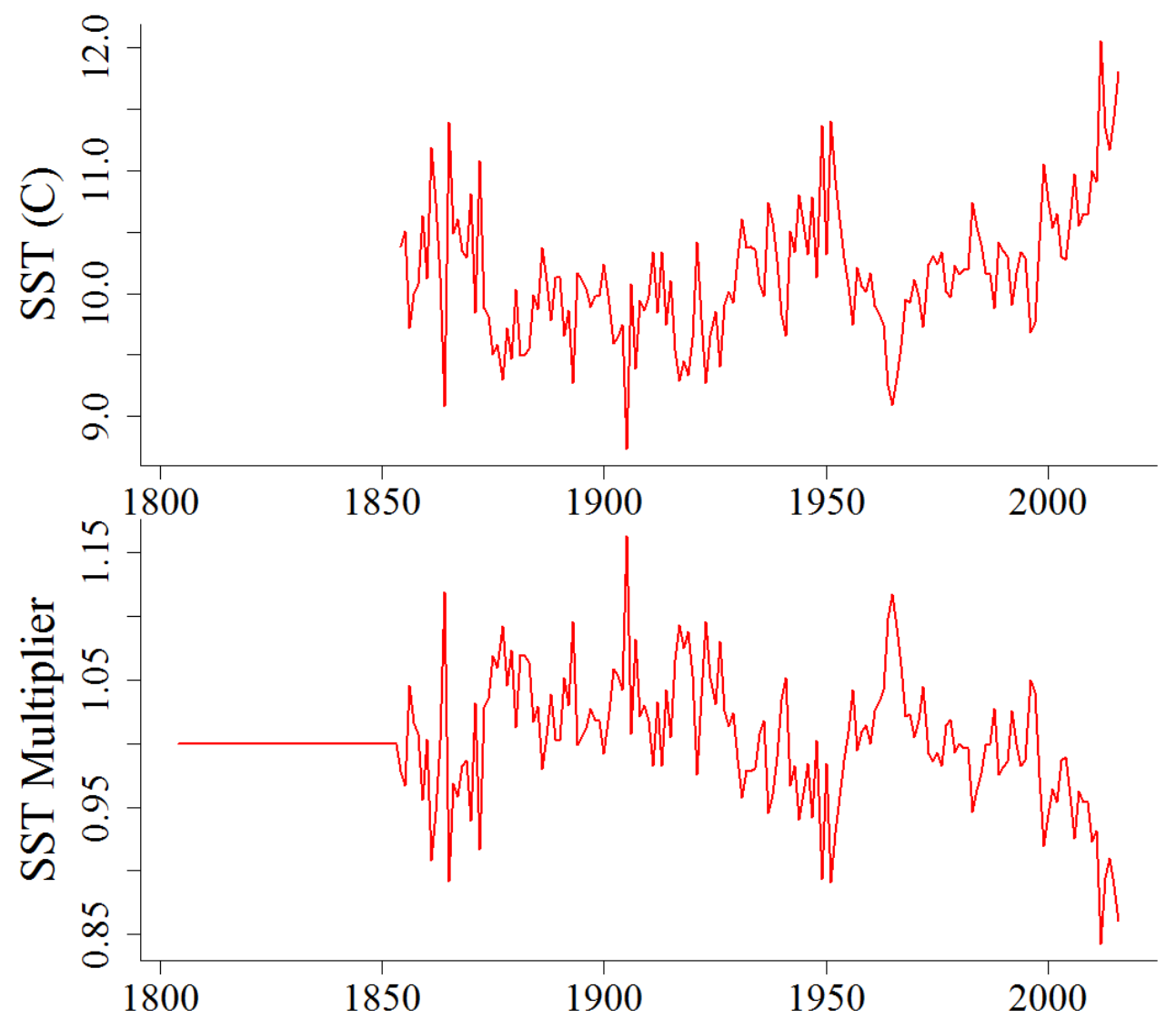

Figure S1B. Mean SST (top) for the spatial domain (Figure S1A), and the multiplier used in the stock-recruitment function in the SSRA. The multiplier represents the reciprocal of the temperature anomaly (annual average SST divided by the time series mean). Years prior to 1854 without temperature data have a value of 1 set. 


\section{CONCLUSIONS}

This dissertation provides both new and corroborating insights on the population and habitat trends for the northwest Atlantic mackerel stock, which are available for future northwest Atlantic mackerel benchmark assessments. Fisheries-independent ichthyoplankton data captured major peaks in larval abundance that have been reported in previous work, with corroboration to egg abundances. As noted, the larval index could benefit from future laboratory, field, and statistical work. When comparing the larval abundance index to the habitat suitability trends, conditions within southern New England $\left(\mathrm{R}^{2}=0.34, \mathrm{p}=0.002\right)$ the entire Northeast U.S. Shelf $\left(\mathrm{R}^{2}=0.36, \mathrm{p}=0.003\right)$ exhibited the strongest correlation to the larval index. These correlations suggest not only that habitat changes may explain a significant portion of the variability in the larval abundances through time, but also that the conditions with southern New England best match the changes to southern New England larval population dynamics. It is worth noting that such correlations do not incorporate changes in stock's spawning potential or production that may have changed from other environmental factors or fishing pressure.

The value of fisheries-independent abundance indices that capture natural interannual variability is highlighted in the SSRA work, both when data are directly incorporated in the models and when trying to calibrate or tune results. The larval index could be included as a tool for excluding certain SSRA runs; however, the catchability concerns remain with the larval index as is. If a catchability scalar $q$ is estimated in future benchmark assessments and appears to better handle catchability concerns, this would be a sounder index for use in the SSRA. Given the habitat 
suitability indices are somewhat derivative of abundance, these trends could also be considered for future SSRA calibrations.

Findings from this research suggest several actions or calls for additional work to improve management of Atlantic mackerel. All three chapters highlight the remaining need of better understanding trends and drivers in Atlantic mackerel recruitment. Much of our current knowledge on Atlantic mackerel recruitment dynamics is based on the Gulf of St. Lawrence spawning grounds, and the relation between copepod production and recruitment (Runge et al. 1999, Ringuette et al. 2002, Castonguay et al. 2008, Ploudre et al. 2015). Copepod production is driven by oceanographic process that support phytoplankton blooms, including temperature, water-column stratification, nutrient concentrations, and photosynthetically available radiation (McManus et al. 2014), yet these factors' ties to recruitment are not as well defined. While these conditions may be correlated to copepod production and thus larval mackerel abundances and recruitment, the processes describing these could be better analyzed: what combination of environmental drivers result in high mackerel recruitment indices (MARMEC)? Do the oceanographic variables provide direct ecological impacts on mackerel, or are their influences indirect (e.g. supporting zooplankton)? Are the drivers different across the stock (i.e. northern/Canada vs. southern/U.S.) and the North Atlantic?

The lack of information on recruitment lies partly in the inability to adequately sample the species. Bottom-trawl surveys have had considerable issues with estimating mackerel abundances through time, given their schooling nature, ability to evade nets, and distributional shifts through time. Further, industry members have 
reported that mackerel vertical distribution can vary based on schooling density, impacting catch and estimating abundances. Sonar survey estimates have also posed challenges, as it is hard to distinguish the species with no swim bladder from scattering layers. Such concerns are in large part why the larval index was explored with long-term ichthyoplankton monitory data, which also has sampling issues (e.g. extrusion, multipurpose nature of survey, changes in mackerel spawning location and season through time, variability in sampling through space in time). However, availability of a recruitment index would allow for testing whether larval abundances are better predictors of the same year's egg production or the subsequent year's recruitment (age-one) fish. Given the shorter period between egg and larval stages presented here ( $\sim 3-5$ days) than larval-recruitment stages ( $200-365$ days), it is intuitive to suspect that the planktonic stages would be more representative of each other than larval and recruitment indices. However, years of faster growth, reduced predation, and greater survival in the larval stage corresponding with larger recruitment indices suggesting that the larval period can strongly influence mackerel recruitment (Robert et al. 2007).

The habitat suitability modeling presented adds to the growing body of literature on distributional movements, habitat changes and species distribution modeling research for North Atlantic mackerel (Overholtz et al. 2011, Hughes et al. 2014, Walsh et al. 2015, Bruge et al. 2016, Brunel et al. 2017; Giannoulaki et al. 2017). Many of these studies highlight a distributional movement of mackerel north and inshore in northwest and northeast stocks, as seen with many species (Nye et al. 2009). However, unlike other studies, this work includes both the thermal and prey preferences of 
mackerel in the models. Habitat suitability work should be continued and expanded for all species to understand spatial changes in stock structure in relation to conventional stock boundaries. Additional northwest Atlantic mackerel habitat research is underway to assess other life stages, stock contingents, and seasonal habitats (Friedland et al. 2017, Mbaye et al. 2017), and will complement the efforts presented here. However, as modeling and projection efforts move forward, it is imperative to remember how the candidate variables ecologically influence Atlantic mackerel. One can test a plethora of spatial and oceanographic variables to predict species presence and abundance, so without a priori knowledge or hypotheses used to justify variables' inclusion in final models, these efforts quickly become predictive tools without explaining or representing essential fish habitat or ecological relations. As such, additional laboratory research testing influences on egg and larval ecology (e.g. temperature and prey studies) and perhaps bio-physical coupled transport modeling exercises are needed.

With increasing evidence of climate change's impact on marine fish stocks, the need to have traditional stock assessments incorporate environmental indices is emphasized in the case of Atlantic mackerel. Such habitat drivers should be incorporated into the functional relationships for the rates they influence (e.g. growth, mortality, recruitment). While the habitat modeling showcases the influence of the environment on mackerel, the SSRA work displays the challenges in incorporating such information, and again the importance of mechanistically understanding how the environment influences biology. Time series correlations between abundance indices and climate only allow to explore possible relationships. As shown with the larval 
index, these correlation analyses could prove null for multiple reasons, including true non-relations, time lags not considered, or mismatch in spatial coverages of data. Thus, movement toward environmentally-explicit stock assessments would also benefit from future laboratory experiments testing oceanographic influences on mackerel.

Lastly, the SSRA and larval index work provide examples of working toward incorporating as much information as is available for assessing fish stocks. The larval index attempted this by incorporating historical larval abundance estimates (Sette 1943). In the case of the SSRA, historical accounts on the fishery's evolution through time provided the basis for assigned fishery selectivity. Work combining fisheriesindependent data with fishermen's knowledge, historical records, and anecdotal information have primarily involved understanding essential fish habitat and fine-scale spatial patterns (Bergmann et al. 2004, Leopold et al. 2014, Decelles et al. 2017). Yet as shown with northwest Atlantic mackerel, similar practices can also be done for stock assessment modeling, particularly when a model ensemble approach is available. Data-limited techniques that rely on both historical accounts and scientific data are particularly interesting and insightful for biologically, economically, and culturally important northwest Atlantic species with rich time series of landings, such as Atlantic cod and mackerel (Goode et al. 1883, McKenzie 2010). It should be noted that for the northwest Atlantic mackerel stock, significant efforts toward a more inclusive modeling and data review process have been made through holding joint science and industry-based meetings on Atlantic mackerel population ecology prior to the formal stock assessment. Not only did these workshops bring all those interested and working 
toward sustainable mackerel management together, but the exercise also resulted in organized products from scientists and fishermen for the assessment (Axelson et al. 2017). The SSRA work presents another method towards this recognized effort that methodically and scientifically looks to understand northwest Atlantic mackerel population trends.

We hope that this work provides future scientists and managers with additional tools and information to further improve the management for one of the most historically renowned fisheries in the world.

\section{LITERATURE CITED}

Axelson, L., Bright, W.K., DiDomenico, G., Goodwin, G., Hoey, J., Kaelin, J., Knight, J., Lapp, M., Manderson, J., McCallig, G., Mtichell, B.P., Moore, P., Mullen, R., O’Neill, G., Quinn, P., Reichle, W., Rhule, J., and Sarro, C. 2017. Fishing industry perspectives on the socioecological factors driving catchability and landings of Atlantic Mackerel in US waters. SARC 64 Atlantic Mackerel Data Meeting Working Paper. 33 pp.

Bergmann, M., Hinz, H., Blyth, R. E., Kaiser, M. J., Rogers, S. I., and Armstrong, M. 2004. Using knowledge from fishers and fisheries scientists to identify possible groundfish ‘Essential Fish Habitats'. Fisheries Research, 66: 373-379.

Bruge, A., Alvarez, P., Fontán, A., Cotano, U., and Chust, G. 2016. Thermal niche tracking and future distribution of Atlantic mackerel spawning in response to ocean warming. Frontiers in Marine Science 3(86): 1-13.

Brunel, T., van Damme, C.J.G., Samson, M., and Dickey-Collas, M. 2017.

Quantifying the influence of geography and environment on the northeast Atlantic mackerel spawning distribution. Fisheries Oceanography 00:115. https://doi.org/10.1111/fog. 12242

Castonguay, M., Plourde, S., Robert, D., Runge, J.A., and Fortier, L. 2008. Copepod production drives recruitment in a marine fish. Canadian Journal of Fisheries and Aquatic Sciences 65: 1528-1531.

DeCelles, G. R., Martins, D., Zemeckis, D. R., and Cadrin, S. X. 2017. Using Fishermen's Ecological Knowledge to map Atlantic cod spawning grounds on Georges Bank. ICES Journal of Marine Science, doi:10.1093/icesjms/fsx031. 
Friedland, K., McManus, C., Morse, R., and Castonguay, M. 2017. Physical conditions and lower trophic level ecology in the spawning areas of mackerel in U.S. and Canadian Waters. SARC 64 Atlantic Mackerel Data Meeting Working Paper. 23 pp.

Giannoulaki M, Pyrounaki MM, Bourdeix J-H, Ben Abdallah L, Bonanno A, Basilone G, Iglesias M, Ventero A, De Felice A, Leonori I, Valavanis VD, Machias A and Saraux C. 2017. Habitat Suitability Modeling to Identify the Potential Nursery Grounds of the Atlantic Mackerel and Its Relation to Oceanographic Conditions in the Mediterranean Sea. Frontiers in Marine Science. 4:230. doi: 10.3389/fmars.2017.00230.

Goode, G.B., Collins, J.W., Earll, R.E., and Clark, A. H. (1883) Materials for a history of the mackerel fishery. In App. B, The Fisheries, pp. 92-531, Report, U.S. Commissioner of Fisheries, 1881 (1884). Washington.

Léopold M., Guillemot, N., Rocklin, D., and Chen, C. 2014. A framework for mapping small-scale coastal fisheries using fishers' knowledge. ICES Journal of Marine Science, 71: 1781-1792.

Mbaye, Doniol-Valcroze, T., Ploudre, S., Lehoux, C., Castonguay, M. 2017. Modeling and predicting the impact of environmental variability on mackerel potential spawning habitat distribution. ICES Annual Science Meeting Presentation: ICES CM 2017/A:177.

McManus, M. C., Oviatt, C. A., Giblin, A. E., Tucker, J., and Turner, J. T. 2014. The Western Maine Coastal Current reduces primary production rates, zooplankton abundance and benthic nutrient fluxes in Massachusetts Bay. ICES Journal of Marine Science 71(5):1158-1169.

McKenzie, M.G. 2010. Cleaning the Coastline: The Nineteenth-Century Ecological and Cultural Transformation of Cape Cod. University Press of New England. Leabanon, NH.

Plourde, S., Grégoire, F., Lehoux, C., Galbraith, P. S., Castonguay, M., and Ringuette, M. (2015) Effect of environmental variability on body condition and recruitment success of Atlantic Mackerel (Scomber scombrus L.) in the Gulf of St. Lawrence. Fisheries Oceanography doi: 10.1111/fog. 12113.

Ringuette, M., Castonguay, M., Runge, J.A., and Grégoire, F. 2002. Atlantic mackerel (Scomber scombrus) recruitment fluctuations in relation to copepod production and juvenile growth. Canadian Journal of Fisheries and Aquatic Sciences 59: 646-656. 
Robert, D., Castonguay, M., and Latour, R. 2007. Early growth and recruitment in Atlantic mackerel Scomber scombrus: discriminating the effects of fast growth and selection for fast growth. Marine Ecology Progress Series 337: 209-219.

Runge, J.A., Castonguay, M., de Lafontaine, Y., Ringuette, M., and Beaulieu, J.-L. 1999. Covariation in climate, zooplankton biomass and mackerel recruitment in the southern Gulf of St. Lawrence. Fisheries Oceanography 8: 139-149.

Sette, O.E. 1943. Biology of the Atlantic mackerel (Scomber scombrus) of North America. Part I. Early Life history, including growth, drift, and mortality of egg and larval populations. U.S. Fish and Wildlife Service Fishery Bulletin 50: 149-237. 


\section{BIBLIOGRAPHY}

Able, K.W., Sullivan, M.C., Hare, J.A., Bath-Martin, G., Taylor, J.C., and Hogan, R. (2011). Larval abundance of summer flounder (Paralichthys denatus) as a measure of recruitment and stock status. Fishery Bulletin 109: 68-78.

Akaike, H. (1973) Information theory as an extension of the maximum likelihood principle. In: Second International Symposium on Information Theory. B.N. Petrov \& F. Csaki (eds) Budapest: Akademiai Kiado, pp. 267.

Albouy-Boyer, S., Plourde, S., and Pepin, P. (2016) Habitat modelling of key copepod species in the Northwest Atlantic Ocean based on the Atlantic Zone Monitoring Program. Journal of Plankton Research, 38(3): 589-603.

Anderson, E.D. (1982) Status of the northwest Atlantic mackerel stock - 1981. U.S. Natl. Mar. Fish. Serv. Northeast Fish. Cent. Woods Hole Lab Ref. Doc. 81-38: $38 \mathrm{p}$.

Anderson, E.D., and Paciorkowski, A.J. (1980). A review of the Northwest Atlantic mackerel fishery. Rapports et Proce`s-Verbaux des Re' unions du Conseil International pour l'Exploration de la Mer, 177: 175-211.

Anderson, J. J., Gurarie, E., Bracis, C., Burke, B. J., and Laidre, K. L. (2013) Modeling climate change impacts on phenology and population dynamics of migratory marine species. Ecological Modelling, 264: 83-97.

Armstrong, M. (2001) An application of the annual egg production method to estimate the spawning biomass of cod (Gadus morhua L.), plaice (Pleuronectes platessa L.) and sole (Solea solea L.) in the Irish Sea. ICES Journal of Marine Science, 58:183-203.

Astthorsson, O. S., Valdimarsson, H., Gudmundsdottir, A., and Oskarsson, G. J. (2012) Climate-related variations in the occurrence and distribution of mackerel (Scomber scombrus) in Icelandic waters. ICES Journal of Marine Science, 69: 1289-1297.

Axelson, L., Bright, W.K., DiDomenico, G., Goodwin, G., Hoey, J., Kaelin, J., Knight, J., Lapp, M., Manderson, J., McCallig, G., Mtichell, B.P., Moore, P., Mullen, R., O’Neill, G., Quinn, P., Reichle, W., Rhule, J., and Sarro, C. (2017). Fishing industry perspectives on the socioecological factors driving catchability and landings of Atlantic Mackerel in US waters. SARC 64 Atlantic Mackerel Data Meeting Working Paper. 33 pp.

Bailey, K.M. (1982). The early life history of the Pacific hake, Merluccius productus. Fishery Bulletin, 80(3):589-598. 
Banzon, V., Smith, T. M., Chin, T. M., Liu, C., and Hankins, W. (2016). A long-term record of blended satellite and in situ sea-surface temperature for climate monitoring, modeling and environmental studies. Earth Systems Science Data, 8, 165-176.

Beare, D. J., and Reid, D. G. (2002) Investigating spatio-temporal change in spawning activity by Atlantic mackerel between 1977 and 1998 using generalized additive models. ICES Journal of Marine Science: Journal du Conseil, 59: 711-724.

Belkin, I.M. (2009) Rapid warming of large marine ecosystems. Progress in Oceanography 81:207-213.

Bergmann, M., Hinz, H., Blyth, R. E., Kaiser, M. J., Rogers, S. I., and Armstrong, M. (2004). Using knowledge from fishers and fisheries scientists to identify possible groundfish 'Essential Fish Habitats'. Fisheries Research, 66: 373-379.

Berrien, P. (1982). Atlantic mackerel, Scomber scombrus. In M.D. Grosslein and T.R. Azarovitz eds. Fish distribution. p. 99-102. MESA New York Bight Atlas Monograph 15. N.Y. Sea Grant Institute, Albany, NY.

Berrien, P. (1988). Atlantic mackerel, Scomber scombrus, total annual egg production and spawner biomass estimates for the Gulf of St. Lawrence and northeastern United States waters, 1987. NOAA Sandy Hook Laboratory Report, No. 88$02.18 \mathrm{pp}$.

Berrien, P., and Sibunka, J. (1999) Distribution patterns of fish eggs in the U.S. northeast continental shelf ecosystem, 1977-1987. U.S. Dep. Commer., NOAA Tech. Rep. NMFS 145, 310 p.

Beverton, R.J.H., and Holt, S.J. (1957) On the dynamics of exploited fish populations. Fish. Invest. Lond. Series 2.

Bolker, B.M. (2008) Ecological Models and Data in R. Princeton University Press. Woodshire, UK. 396 pp.

Bruge, A., Alvarez, P., Fontán, A., Cotano, U., and Chust, G. (2016) Thermal niche tracking and future distribution of Atlantic mackerel spawning in response to ocean warming. Frontiers in Marine Science 3(86): 1-13.

Brunel, T., van Damme, C.J.G., Samson, M., and Dickey-Collas, M. (2017).

Quantifying the influence of geography and environment on the northeast Atlantic mackerel spawning distribution. Fisheries Oceanography 00:115. https://doi.org/10.1111/fog.12242

Buckley, L. J., and Caldarone, E. M. (2004) Optimum temperature and food-limited 
growth of larval Atlantic cod (Gadus morhua) and haddock (Melanogrammus aeglefinus) on Georges Bank. Fisheries Oceanography 13(2): 134-140.

Carletta, J. (1996) Assessing agreement on classification tasks: the kappa statistic. Computational Linguistics 22(2): 1-6.

Carter, L., and D. Richardson. (2017). Development of an egg index for Atlantic mackerel (Scomber scombrus) on the northeast U.S. continental shelf. SARC 64 Atlantic Mackerel Data Meeting Working Paper. 13 pp.

Castonguay, M., Plourde, S., Robert, D., Runge, J. A., and Fortier, L. (2008) Copepod production drives recruitment in a marine fish. Canadian Journal of Fisheries and Aquatic Sciences 65: 1528-1531.

Collette, B.B., and Klein-MacPhee, G. (2002). Bigelow and Schroeder's Fishes of the Gulf of Maine, $3^{\text {rd }}$ Edition. Caldwell, N.J.: Blackburn Press, 577 p.

Cope, J.M. (2013). Implementing a statistical catch-at-age model (stock synthesis) as a tool for deriving overfishing limits in data-limited situations. Fisheries Research, 142: 3-14.

Cowen, R. K., Gawarkiewicz, G. G., Pineda, J., Thorrold, S. R., and Werner, F. E. (2007) Population connectivity in marine systems: an overview. Oceanography 20(3): 14-21.

DeCelles, G. R., Martins, D., Zemeckis, D. R., and Cadrin, S. X. (2017). Using Fishermen's Ecological Knowledge to map Atlantic cod spawning grounds on Georges Bank. ICES Journal of Marine Science, doi:10.1093/icesjms/fsx031.

Deroba, J., Shepherd, G., Gregoire, F., Nieland, J., and Rago, P. (2010) Stock assessment of Atlantic mackerel in the Northwest Atlantic for 2010. Transboundary Resources Assessment Committee, Reference Document 2010/01. 59 pp.

Department of Fisheries and Oceans DFO. (2014) Assessment of the Atlantic Mackerel stock for the Northwest Atlantic (Subareas 3 and 4) in 2013. DFO Can. Sci. Advis. Sec. Sci. Advis. Rep. 2014/030.

Dormann, C.F., McPherson, J.M., Araújo, M.B., Bivand, R., Bolliger, J., Carl, G., Davies, R.G., et al. (2007) Methods to account for spatial autocorrelation in the analysis of species distributional data: a review. Ecography 30: 609-628.

Drinkwater, K.F., Belgrano, A., Borja, A., Conversi, A. et al. (2003). The response of marine ecosystems to climate variability associated with the North Atlantic Oscillation. In: Hurrell JW, Kushnir Y, Ottersen G, Visbeck M (eds) The North Atlantic Oscillation. American Geophysical Union, Washington, DC, p 
$211-234$.

Elith, J., and Leathwick, J. R. (2009) Species Distribution Models: Ecological Explanation and Prediction Across Space and Time. Annual Review of Ecology, Evolution and Systematics 40: 677-697.

Enfield, D.B., A.M. Mestas-Nunez, and P.J. Trimble. (2001) The Atlantic Multidecadal Oscillation and its relationship to rainfall and river flows in the continental U.S., Geophysical Research Letters, 28: 2077-2080.

Fortier, L., and Villeneuve, A. (1996) Cannibalism and predation on fish larvae by larvae of Atlantic mackerel, Scomber scombrus: trophodynamics and potential impact on recruitment. Fishery Bulletin 94: 268-281.

Fournier, D.A., H.J Skaug, J. Ancheta et al. (2012) AD Model Builder: using automatic differentiation for statistical inference of highly parameterized complex nonlinear models. Optimization Methods and Software, 27:233-249.

Friedland, K.D., and Hare, J.A. (2007) Long-term trends and regime shifts in sea surface temperature on the continental shelf of the northeast United States. Continental Shelf Research 27: 2313-2328.

Friedland, K. D., Kane, J., Hare, J. A., Lough, R. G., Fratantoni, P. S., Fogarty, M. J., and Nye, J. A. (2013) Thermal habitat constraints on zooplankton species associated with Atlantic cod (Gadus morhua) on the US Northeast Continental Shelf. Progress in Oceanography 116: 1-13.

Friedland, K., McManus, C., Morse, R., and Castonguay, M. (2017) Physical conditions and lower trophic level ecology in the spawning areas of mackerel in U.S. and Canadian Waters. SARC 64 Atlantic Mackerel Data Meeting Working Paper. 23 pp.

Garrison, L.P., Michaels, W., Link, J.S., and Fogarty, M.J. (2000) Predation risk on larval gadids by pelagic fish in the Georges Bank ecosystem. I. Spatial overlap associated with hydrographic features. Canadian Journal of Fisheries and Aquatic Sciences 57: 2455-2469.

Giannoulaki M, Pyrounaki MM, Bourdeix J-H, Ben Abdallah L, Bonanno A, Basilone G, Iglesias M, Ventero A, De Felice A, Leonori I, Valavanis VD, Machias A and Saraux C. (2017) Habitat Suitability Modeling to Identify the Potential Nursery Grounds of the Atlantic Mackerel and Its Relation to Oceanographic Conditions in the Mediterranean Sea. Frontiers in Marine Science, 4:230. doi: 10.3389/fmars.2017.00230.

Gislason, H., Daan, N., Rice, J.C., and Pope, J.G. (2010). Size, growth, temperature, and the natural mortality of marine fish. Fish and Fisheries 11(2): 149-158. 
Glendhill, C.T. and Lyczkowski-Shultz, J. (2000) Indices of larval king mackerel (Scomberomorus cavalla) abundance in the Gulf of Mexico for use in population estimates. Fishery Bulletin, 98:684-691.

Goode, G.B., Collins, J.W., Earll, R.E., and Clark, A. H. (1883) Materials for a history of the mackerel fishery. In App. B, The Fisheries, pp. 92-531, Report, U.S. Commissioner of Fisheries, 1881 (1884). Washington.

Grégoire, F. et McQuinn, I. (2014) Estimation empirique du taux instantané de mortalité naturelle (M) du maquereau bleu (Scomber scombrus L.) des sousrégions 3 et 4 de l'OPANO. Secr. can. de consult. sci. du MPO. Doc. de rech. 2014/078. v + 25p.

Grieve, B.D., Hare, J.A., and Saba, V.S. (2017) Projecting the effects of climate change on Calanus finmarchicus distribution within the U.S. Northeast Continental Shelf. Scientific Reports, 7(6262): 1-12.

Grüss, A., Drexler, M., and Ainsworth, C. H. (2014) Using delta generalized additive models to produce distribution maps for spatially explicit ecosystem models. Fisheries Research, 159: 11-24.

Hanisko, D.S., A. Pollack, G. Zapfe, and Ingram Jr., G.W. (2017) King mackerel (Scomberomorus cavalla) larval indices of relative abundance from SEAMAP fall plankton surveys in the Gulf of Mexico, 1986 to 2014. SCRS/2017/095. $32 \mathrm{pp}$.

Hare, J.A., Brooks, E.N., Palmer, M.C., and Churchill, J.H. (2015) Re-evaluating the effect of wind on recruitment in Gulf of Maine Atlantic cod (Gadus morhua) using an environmentally-explicit stock recruitment model. Fisheries Oceanography 24(1): 90-105.

Hare, J. A., Morrison, W. E., Nelson, M. W., Stachura, M. M., Teeters, E. J., Griffis, R. B., Alexander, M. A., et al. (2016) A Vulnerability Assessment of Fish and Invertebrates to Climate Change on the Northeast U.S. Continental Shelf. PLoS ONE, 11: e0146756.

Hastie, T., and Tibshirani, R. (1986) Generalized additive models. Statistical Science: 297-310.

Heighton, R., and Grégoire, F. (2006) A hook selectivity study for Atlantic mackerel (Scomber scombrus L.) caught in St. Geogres Bay, Nova Scotia, in October 2005. Can. Ind. Rep. Fish. Aqaut. Sci. 278: vii + 50 p.

Hewit, R.P., G.H. Theilacker, and N.C.H. Lo. (1985) Causes of mortality in young jack mackerel. Marine Ecology Progress Series, 26:1-10. 
Hoy, D.L., and Clark, G.M. (1967) Atlantic mackerel fishery, 1804-1965. US Department of Interior Bureau of Commercial Fisheries, Fishery Leaflet 603. 9pp.

Huang, B., Thorne, P.W., Banzon, V.F., Boyer, T., Chepurin, G., Lawrimore, J.H., Menne, M.J., Smith, T.M., Vose, R.S., Zhang, H.-M. (2017) NOAA Extended Reconstructed Sea Surface Temperature (ERSST), Version 5. NOAA National Centers for Environmental Information. doi:10.7289/V5T72FNM [15 April 2017].

Hughes, K. M., Dransfeld, L., and Johnson, M. P. (2015) Climate and stock influences on the spread and locations of catches in the northeast Atlantic mackerel fishery. Fisheries Oceanography, 24: 540-552.

Hunter, J.R., and Kimbrell, C.A. 1979. Early life history of Pacific mackerel, Scomber japonicus. Fishery Bulletin 78(1): 89-101.

Hurrell, J., and National Center for Atmospheric Research Staff (Eds.) 2017. The Climate Data Guide: Hurrell North Atlantic Oscillation (NAO) Index (stationbased): https://climatedataguide.ucar.edu/climate-data/hurrell-north-atlanticoscillation-nao-index-station-based. Accessed 7 Jul 2017.

Hutchinson, G. E. (1957) Concluding remarks. Cold Spring Harbor Symposium, 22: $415-427$.

Jacobson, L.D., and MacCall, A.D. (1994) Stock-recruitment models for Pacific sardine (Sardinops sagax). Canadian Journal of Fisheries and Aquatic Sciences, 52: 566-577

Jacobson, L., Seaver, A., and Tang, J. (2011) AstroCalc4R: software to calculate solar zenith angle; time at sunrise, local noon and sunset; and photosynthetically available radiation based on date, time, and location. Northeast Fisheries Science Center Reference Document 11-14: 1-10.

Jansen, T. (2016) First-year survival of North East Atlantic mackerel (Scomber scombrus) from 1998 to 2012 appears to be driven by availability of Calanus, a preferred copepod prey. Fisheries Oceanography, 25: 457-469.

Jansen, T., and Gislason, H. (2011) Temperature affects the timing of spawning and migration of North Sea mackerel. Continental Shelf Research 31:64-72.

Jansen, T., Kristensen, K., van der Kooij, J., Post, S., Campbell, A., Utne, K. R., Carrera, P., et al. (2014) Nursery areas and recruitment variation of Northeast Atlantic mackerel. (Scomber scombrus). ICES Journal of Marine Science. doi: 10.1093/icesjms/fsu186. 
Jansen, T., Post, S., Kristiansen, T., Oskarsson, G. J., Boje, J., MacKenzie, B. R., Broberg, M., et al. (2016) Ocean warming expands habitat of a rich natural resource and benefits a national economy. Ecological Applications. doi: 10.1002/eap.1384.

Johnson, D. L., and Morse, W. W. (1994) Net extrusion of larval fish: correction factors for $0.333 \mathrm{~mm}$ versus $0.505 \mathrm{~mm}$ mesh bongo nets. NAFO Sci. Counc. Stud. 20: 85-92.

Jones, M.C., Dye, S.R., Pinnegar, J.K., Warren, R., and Cheung, W.W.L. (2015) Using scenarios to project the changing profitability of fisheries under climate change. Fish and Fisheries, 16: 603-622.

Kane, J. (1984) The feeding habits of co-occurring cod and haddock larvae from Georges Bank. Marine Ecology Progress Series 16: 9-20.

Kane, J. (2003) Spatial and temporal abundance patterns for late stage copepodites of Metridia lucens (Copepoda: Calanoida) in the US northeast continental shelf ecosystem. Journal of Plankton Research 25(2): 151-167.

Kane, J. (2008) A comparison of two zooplankton time series data collected in the Gulf of Maine. Journal of Plankton Research, 31: 249-259.

Kimura, D.K., Balsiger, J.W., and Ito, D.H. (1984) Generalized stock reduction analysis. Canadian Journal of Fisheries and Aquatic Sciences, 41:1325-133.

Kimura, D.K., and Tagart, J.V. (1982) Stock reduction analysis, another solution to the catch equations. Canadian Journal of Fisheries and Aquatic Sciences, 39: 1467-1472.

Kleisner, K. M., Fogarty, M. J., McGee, S., Barnett, A., Fratantoni, P., Greene, J., Hare, J. A., et al. (2016) The Effects of Sub-Regional Climate Velocity on the Distribution and Spatial Extent of Marine Species Assemblages. PLoS ONE, 11: e0149220.

Léopold M., Guillemot, N., Rocklin, D., and Chen, C. (2014) A framework for mapping small-scale coastal fisheries using fishers' knowledge. ICES Journal of Marine Science, 71: 1781-1792.

Llopiz, J. K., Cowen, R. K., Hauff, M. J., Ji, R., Munday, P. L., Muhling, B.A., Peck, M.A., Richardson, D.E., Sogard, S., and Sponaugle, S. (2014) Early life history and fisheries oceanography: new questions in a changing world. Oceanography, 27(4):26-41.

Lo, N.C.H. (2007) Daily larval production of Pacific hake (Merluccius productus) off 
California in 1951-2006. CalCOFI Rep. 48:147-164.

Lo, N.C.H., Y. Huang, and E. Dorval. (2009) Daily larval production of Pacific mackerel (Scomber japonicus) off California from 1951-2006. Appendix 3B in Pacific mackerel (Scomber japonicus) stock assessment for USA management in the 2009-10 fishing year (Crone, P. R., K. T. Hill, J. D. McDaniel, and N. C. H. Lo, eds.), p. 172-185. Pacific Fishery Management Council.

Lobo, J. M., Jiménez-Valverde, A., and Real, R. (2008) AUC: a misleading measure of the performance of predictive distribution models. Global Ecology and Biogeography, 17: 145-151.

Lynch, P. D., Nye, J. A., Hare, J. A., Stock, C. A., Alexander, M. A., Scott, J. D., Curti, K. L., et al. (2015) Projected ocean warming creates a conservation challenge for river herring populations. ICES Journal of Marine Science. 72 (2): 374-387.

Martell, S., and Froese, R. (2013) A simple method for estimating MSY from catch and resilience. Fisheries Research 14: 504-514.

Martins, M. M. (2007) Growth variability in Atlantic mackerel (Scomber scombrus) and Spanish mackerel (Scomber japonicus) off Portugal. ICES Journal of Marine Science, 64: 1785-1790.

Maunder, M. N., and Punt, A. E. (2004) Standardizing catch and effort data: a review of recent approaches. Fisheries Research, 70: 141-159.

Mbaye, Doniol-Valcroze, T., Ploudre, S., Lehoux, C., Castonguay, M. (2017) Modeling and predicting the impact of environmental variability on mackerel potential spawning habitat distribution. ICES Annual Science Meeting Presentation: ICES CM 2017/A:177.

McKenzie, M.G. (2010) Cleaning the Coastline: The Nineteenth-Century Ecological and Cultural Transformation of Cape Cod. University Press of New England. Leabanon, $\mathrm{NH}$.

McKenzie, M.G. (2010a) Chapter 3: Workspace. In: Cleaning the Coastline: The Nineteenth-Century Ecological and Cultural Transformation of Cape Cod. University Press of New England. Leabanon, NH. 35pp.

McKenzie, M.G. (2010b) Chapter 4: Prosperity. In: Cleaning the Coastline: The Nineteenth-Century Ecological and Cultural Transformation of Cape Cod. University Press of New England. Leabanon, NH. 35pp.

McManus, M.C., Hare, J.A., Richardson, D.E. and Collie, J.S. (2017) Tracking shifts in Atlantic mackerel (Scomber scombrus) larval habitat suitability on the 
Northeast U.S. Continental Shelf. Fisheries Oceanography, 00:1-14. doi: 10.1111/fog.1233

McManus, M. C., Oviatt, C. A., Giblin, A. E., Tucker, J., and Turner, J. T. (2014) The Western Maine Coastal Current reduces primary production rates, zooplankton abundance and benthic nutrient fluxes in Massachusetts Bay. ICES Journal of Marine Science 71(5):1158-1169.

McManus, M.C., P. Licandro, and S.H. Coombs. (2016) Is the Russell Cycle a true cycle? Multidecadal zooplankton and climate trends in the western English Channel. ICES Journal of Marine Science 73(2): 227-238.

Methot Jr., R.D., and Wetzel, C.R. (2013) Stock synthesis: A biological and statistical framework for fish stock assessment and fishery management. Fisheries Research 142: 86-99.

Mid-Atlantic Fisheries Management Council (MAFMC). (2016). Mid-Atlantic Fishery Council - Species Stock Status (as of November 28, 2016). https://static1.squarespace.com/static/511cdc7fe4b00307a2628ac6/t/587e3666 2e69cf391ab50619/1484666472391/2016-11-28_MAFMC_Stock_Status.pdf. (accessed 4 February 2017).

Morse, W.W. (1980) Spawning and fecundity of Atlantic mackerel, Scomber scombrus, in the Middle Atlantic Bight. Fishery Bulletin, 78(1): 103-108.

Morse, W.W. (1989) Catchability, growth, and mortality of larval fishes. Fishery Bulletin, 87: 417-446.

Morse, R.E., Friedland, K.D., Tommasi, D., Stock, C., and Nye, J. (2017) Distinct zooplankton regime shift patterns across ecoregions of the U.S. Northeast continental shelf Large Marine Ecosystem 165:77-91.

Mountain, D. G., and Murawski, S. A. (1992) Variation in the distribu- tion of fish stocks on the northeast continental shelf in relation to their environment, 19801989. ICES Marine Science Symposia, 195: 424-432.

Moustahfid, H., Link, J. S., Overholtz, W. J., and Tyrrell, M. C. (2009) The advantage of explicitly incorporating predation mortality into age structured stock assessment models: an application for Atlantic mackerel. ICES Journal of Marine Science, 66: 445-454.

Murawski, S. A. (1993) Climate change and marine fish distributions: forecasting from historical analogy. Transactions of the American Fisheries Society, 122: 647-658.

Murtaugh, P. A. (1996) The statistical evaluation of ecological indicators. Ecological 
Applications 6(1): 132-139.

Myers, R.A., Bowen, K.G., and Barrowman, N.J. (1999) Maximum reproductive rate of fish at low population sizes. Canadian Journal of Fisheries and Aquatic Sciences 56: 2404-2419.

Nye, J.A., Link, J.S., Hare, J.A., Overholtz, W.J. (2009) Changing spatial distribution of fish stocks in relation to climate and population size on the Northeast United States continental shelf. Marine Ecology Progress Series, 393, 111-129.

Nye, J.A., Baker, M.R., Bell, R., Kenny, A., Kilbourne, K.H., Friedland, K.D., Martino, E., Stachura, M.M., Van Houtan, K.S., and Wood, R. (2014) Ecosystem effects of the Atlantic Multidecadal Oscillation. Journal of Marine Systems, 133: 103-116.

Olafsdottir, A. H., Slotte, A., Jacobsen, J. A., Oskarsson, G. J., Utne, K. R., and Nøttestad, L. (2016) Changes in weight-at-length and size-at-age of mature Northeast Atlantic mackerel (Scomber scombrus) from 1984 to 2013: effects of mackerel stock size and herring (Clupea harengus) stock size. ICES Journal of Marine Science, 73(4): 1255-1265.

Overholtz, W.J. (1989) Density-dependent growth in the northwest Atlantic stock of Atlantic mackerel (Scomber scombrus). Journal of the Northwest Atlantic Fishery Science, 9:115-121.

Overholtz, W. J., Hare, J. A., and Keith, C. M. (2011) Impacts of interannual environmental forcing and climate change on the distribution of Atlantic mackerel on the US Northeast continental shelf. Marine and Coastal Fisheries: Dynamics, Management, and Ecosystem Science, 3: 219-232.

Paradis, V., Sirois, P., Castonguay, M., and Ploudre, S. (2012) Spatial variability in zooplankton and feeding of larval Atlantic mackerel (Scomber scombrus) in the southern Gulf of St. Lawrence. Journal of Plankton Research 34(12): 1064-1077.

Parker, K. (1985) Biomass model for the egg production method. US Department of Commerce, NOAA Technical Report, NMFS-36. 99 pp.

Payne, M.R., Hatfield, E.M., Dickey-Collas M., Falkenhaug T., Gallego A., Gröger J., Licandro P., Llope M., Munk P., and Röckmann, C. (2009) Recruitment in a changing environment: the 2000s North Sea herring recruitment failure. ICES Journal of Marine Science: Journal du Conseil 66:272-277.

Peterson, W. T., and Ausubel, S. J. (1984) Diets and selective feeding by larvae of Atlantic mackerel Scomber scombrus on zooplankton. Marine Ecology Progress Series 17: 65-75. 
Pinsky, M. L., and Fogarty, M. (2012) Lagged social-ecological responses to climate and range shifts in fisheries. Climatic Change, 115: 883-891.

Plourde, S., Grégoire, F., Lehoux, C., Galbraith, P. S., Castonguay, M., and Ringuette, M. (2015) Effect of environmental variability on body condition and recruitment success of Atlantic Mackerel (Scomber scombrus L.) in the Gulf of St. Lawrence. Fisheries Oceanography doi: 10.1111/fog.12113.

Poloczanska, E. S., Burrows, M. T., Brown, C. J., García Molinos, J., Halpern, B. S., Hoegh-Guldberg, O., Kappel, C. V., et al. (2016) Responses of marine organisms to climate change across oceans. Frontiers in Marine Science, 3(62): 1-21.

Pope, J.E. (2014). Age-specific natural mortality rates in stock assessments: size-based vs. density-dependent. ICES Journal of Marine Science 71(7): 1629-1637.

Radlinski, M. K., Sundermeyer, M. A., Bisagni, J. J., and Cadrin, S. X. (2013) Spatial and temporal distribution of Atlantic mackerel (Scomber scombrus) along the northeast coast of the United States, 1985-1999. ICES Journal of Marine Science, 70: 1151-1161.

Richardson, D. E., Hare, J. A., Overholtz, W. J., and Johnson, D. L. (2010) Development of long-term larval indices for Atlantic herring (Clupea harengus) on the northeast US continental shelf. ICES Journal of Marine Science: Journal du Conseil, 67: 617-627.

Richardson, D.E., K. Marancik, and H. Walsh. (2014) A larval index for Georges Bank yellowtail flounder with comparisons of relative larval production between yellowtail flounder stock areas. Transboundary Resource Assessment Committee 2014/19: 1-9.

Ringuette, M., Castonguay, M., Runge, J. A., and Grégoire, F. (2002) Atlantic mackerel (Scomber scombrus) recruitment fluctuations in relation to copepod production and juvenile growth. Canadian Journal of Fisheries and Aquatic Sciences, 59: 646-656.

Robert, D., Castonguay, M., and Fortier, L. (2007) Early growth and recruitment in Atlantic mackerel Scomber scombrus: discriminating the effects of fast growth and selection for fast growth. Marine Ecology Progress Series, 337: 209-219.

Robert, D., Castonguay, M., and Fortier, L. (2008) Effects of intra- and inter-annual variability in prey field on the feeding selectivity of larval Atlantic mackerel (Scomber scombrus). Journal of Plankton Research, 30: 673-688.

Robert, D., Castonguay, M., and Fortier, L. (2009) Effects of preferred prey density and temperature on feeding success and recent growth in larval mackerel of the 
southern Gulf of St. Lawrence. Marine Ecology Progress Series 377: 227-237.

Robert, D., Pepin, P., Dower, J. F., and Fortier, L. (2014) Individual growth history of larval Atlantic mackerel is reflected in daily condition indices. ICES Journal of Marine Science 71(4): 1001-1009.

Rose, G.A. (2004) Reconciling overfishing and climate change with stock dynamics of Atlantic cod (Gadus morhua) over 500 years. Canadian Journal or Fisheries and Aquatic Sciences 61: 1553-1557.

Rosenberg, A.A., Bolster, W.J., Alexander, K.E., Leavenworth, W.B., Cooper, A.B., and McKenzie, M.G. (2005) The history of ocean resources: modeling cod biomass using historical records. Frontiers in Ecology and the Environment 3(2): 78-84.

Runge, J.A., Castonguay, M., de Lafontaine, Y., Ringuette, M., and Beaulieu, J.-L. (1999) Covariation in climate, zooplankton biomass and mackerel recruitment in the southern Gulf of St. Lawrence. Fisheries Oceanography 8(2): 139-149.

Sette, O.E. (1943) Biology of the Atlantic mackerel (Scomber scombrus) of North America. Part I. Early Life history, including growth, drift, and mortality of egg and larval populations. U.S. Fish and Wildlife Service Fishery Bulletin 50: $149-237$.

Sette, O.E. (1950) Biology of the Atlantic mackerel (Scomber scombrus) of North America. Part II. Migrations and habitat. U.S. Fish and Wildlife Service Fishery Bulletin 51: 251-358.

Sette, O. E., and Needler, A. W. H. (1934) Statistics of the mackerel fishery off the coast of North America. Invest. Rep., US Dept. Commer., 19, 48 p.

Simard, P. M. Castonguay, D. D'Amours, and P. Magnan. (1992) Growth comparison between juvenile Atlantic mackerel (Scomber scombrus) for the two spawning groups in the Northwest Atlantic. Canadian Journal of Fisheries and Aquatic Sciences, 49:2242-2248.

Simpson, C.A., Wilburg, M.J., Bi, Hongsheng, Schueller, A.M., Nesslage, G.M., and Walsh, H.J. (2016) Trends in relative abundance and early life survival of Atlantic menhaden during 1977-2013 from long-term ichthyoplankton programs. Transactions of the American Fisheries Society, 145:1139-1151.

Spijkers, J., and Boonstra, W.J. (2017) Environmental change and social conflict: the northeast Atlantic mackerel dispute. Regional Environmental Change 17:18351851.

Skud, B. E. (1982) Dominance in fishes: the relation between environment and 
abundance. Science 216: 144-149.

Slotte, A., Skagen, D., and Iversen, S. A. (2007) Size of mackerel in research vessel trawls and commercial purse-seine catches: implications for acoustic estimation of biomass. ICES Journal of Marine Science, 64: 989-994.

Studholme, A. L., Packer, D. B., Berrien, P. L., and Johnson, D. L., Zetlin, C.A., and Morse, W.W. (1999) Essential fish habitat source document: Atlantic mackerel, Scomber scombrus, life history and habitat characteristics. NOAA Technical Memorandum NMFS-NE-141.

Takasuka, A., Aoki, I., and Mitani, I. (2003) Evidence of growth-selective predation on larval Japanese anchovy Engraulis japonicus in Sagami Bay. Marine Ecology Progress Series, 252: 223-238.

Taylor, C.C., Bigelow, H.B., and Graham, H.W. (1957) Climatic trends and the distribution of marine animals in New England. Fishery Bulletin 115(57): 293345.

Townsend, D. W., Thomas, A. C., Mayer, L. M., Thomas, M. A., and Quinlan, J. A. (2006) Oceanography of the northwest Atlantic continental shelf $(1, \mathrm{~W})$. The sea: the global coastal ocean: interdisciplinary regional studies and syntheses, 14: $119-168$.

Trenkel, V. M., Huse, G., MacKenzie, B. R., and Alvarez, P. (2014) Comparative ecology of widely distributed pelagic fish species in the North Atlantic: implications for modelling climate and fisheries impacts. Progress in Oceanography 129(B): 219-243.

Tsou, T.-S., and Collie, J.S. (2001) Estimating predation mortality in the Georges Bank fish community. Canadian Journal of Fisheries and Aquatic Sciences 58: 908-922.

Thorson, J.T., and Cope, J.M. (2015) Catch curve stock-reduction analysis: An alternative solution to the catch equations. Fisheries Research 171: 33-41.

Tyrrell, M. C., Link, J. S., Moustahfid, H., and Overholtz, W. J. (2008) Evaluating the effect of predation mortality on forage species population dynamics in the Northeast US continental shelf ecosystem using multispecies virtual population analysis. ICES Journal of Marine Science, 65: 1689-1700.

Van Beveren, E., Castonguay, M., Doniol-Valcroze, T., and Duplisea, D. (2017a) Results of an informal survey of Canadian Atlantic mackerel commercial, recreational and bait fishers. DFO Can. Sci. Advis. Sec. Res. Doc. 2017/029. v $+26 \mathrm{p}$. 
Van Beveren, E., Duplisea, D., Castonguay, M., Doniol-Valcroze, T., Ploudre, S., and Cadigan, N. (2017b) How catch underreporting can bias stock assessment and advice for northwest Atlantic mackerel and a possible resolution using censored catch. Fisheries Research, 194: 146-154.

Venables, W. N., and Dichmont, C. M. (2004) GLMs, GAMs and GLMMs: an overview of theory for applications in fisheries research. Fisheries Research, 70: 319-337.

Walsh, H. J., Richardson, D. E., Marancik, K. E., and Hare, J. A. (2015) Long-Term Changes in the Distributions of Larval and Adult Fish in the Northeast U.S. Shelf Ecosystem. PLoS ONE, 10: e0137382.

Ware, D. M., and Lambert, T. C. (1985) Early life history of Atlantic mackerel (Scomber scombrus) in the southern Gulf of St. Lawrence. Canadian Journal of Fisheries and Aquatic Sciences, 42: 577-592.

Walters, C.J., and Martell, S.J.D. (2004) Fisheries ecology and management. Princeton University Press, Princeton, N.J.

Walters, C.J., Martell, S.J.D., and Korman, J. (2006) A stochastic approach to stock reduction analysis. Canadian Journal of Fisheries and Aquatic Sciences $63: 212-223$.

Weber E.D., and McClatchie, S. (2012) Effect of environmental conditions on the distribution of Pacific mackerel (Scomber japonicus) larvae in the California Current system. Fishery Bulletin 110:85-97.

Wetzel, C.R., and Punt, A.E. (2011) Model performance for the determination of appropriate harvest levels in the case of data-poor stocks. Fisheries Research, 110: 324-355.

Wiedenmann, J. (2016). Application of a data-poor harvest control rules to Atlantic mackerel. Southeast Data, Assessment, and Review, Report\# SEDAR46-RD09. 53pp.

Wood, S.N. (2006) Generalized Additive Models: An Introduction with R. Chapman and Hall/CRC Press. Boca Raton, FL. 